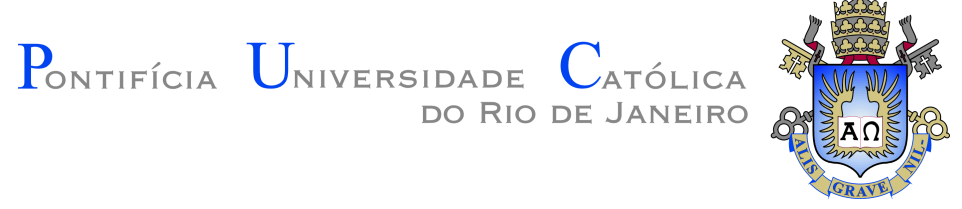

César Augusto de Oliveira Ferrante

Desenvolvimento de um sistema de piso misto
com viga em perfil alveolar assimétrico

Tese de Doutorado

Tese apresentada como requisito parcial para obtenção do grau de Doutor pelo Programa de Pós-graduação em Engenharia Civil da PUC-Rio.

Orientador : Prof. Ney Augusto Dumont Coorientador: Prof. Sebastião Arthur Lopes de Andrade 


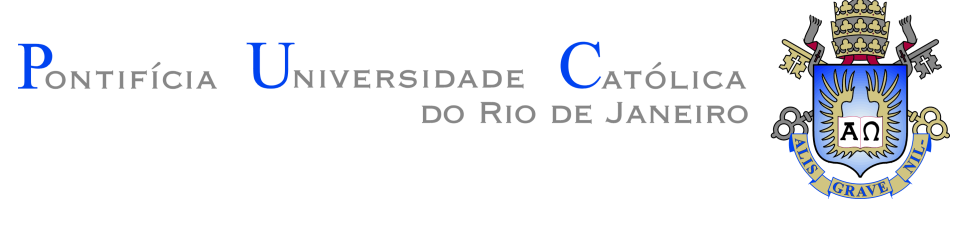

César Augusto de Oliveira Ferrante

\section{Desenvolvimento de um sistema de piso misto com viga em perfil alveolar assimétrico}

Tese apresentada como requisito parcial para obtenção do grau de Doutor pelo Programa de Pós-graduação em Engenharia Civil da PUC-Rio. Aprovada pela Comissão Examinadora abaixo.

Prof. Ney Augusto Dumont

Orientador

Departamento de Engenharia Civil e Ambiental - PUC-Rio

Prof. Sebastião Arthur Lopes de Andrade

Coorientador

Departamento de Engenharia Civil e Ambiental - PUC-Rio

Prof. Raul Rosas e Silva

Departamento de Engenharia Civil e Ambiental - PUC-Rio

Prof. Paulo Batista Gonçalves

Departamento de Engenharia Civil e Ambiental - PUC-Rio

Prof. Luciano Rodrigues Ornelas de Lima Universidade do Estado do Rio de Janeiro - UERJ

Prof. Pedro Colmar Gonçalves da Silva Vellasco Universidade do Estado do Rio de Janeiro - UERJ

Rio de Janeiro, 20 de Setembro de 2019 
Todos os direitos reservados. É proibida a reprodução total ou parcial do trabalho sem autorização da universidade, do autor e do orientador.

\section{César Augusto de Oliveira Ferrante}

Graduou-se em Engenharia Civil pela Universidade Federal do Pará (UFPA). Fez mestrado no Departamento de Engenharia Civil e Ambiental PUC-Rio, especializando-se na área de Estruturas, subárea estruturas de aço e mistas. Desenvolveu seu trabalho de pesquisa com ênfase em estudos experimentais com vigas mistas em escala real.

Ficha Catalográfica

Ferrante, César Augusto de Oliveira

Desenvolvimento de um sistema de piso misto com viga em perfil alveolar assimétrico / César Augusto de Oliveira Ferrante; orientador: Ney Augusto Dumont; coorientador: Sebastião Arthur Lopes de Andrade. - Rio de Janeiro: PUCRio, Departamento de Engenharia Civil e Ambiental, 2019.

v., 133 f: il. color. ; $30 \mathrm{~cm}$

Tese (doutorado) - Pontifícia Universidade Católica do Rio de Janeiro, Departamento de Engenharia Civil e Ambiental.

Inclui bibliografia

1. Engenharia Civil - Teses. 2. Estruturas mistas;. 3. vigas metálicas alveolares;. 4. análise experimental.. I. Dumont, Ney Augusto. II. Andrade, Sebastião Arthur Lopes de. III. Pontifícia Universidade Católica do Rio de Janeiro. Departamento de Engenharia Civil e Ambiental. IV. Título. 


\section{Agradecimentos}

Gostaria de expressar meu profundo e sincero agradecimento ao meu orientador principal Professor Sebastião Arthur Lopes de Andrade pela confiança depositada no desenvolvimento deste trabalho. Sua ajuda ilimitada, excelentes conselhos, orientação, profissionalismo e encorajamento tem sido inestimável em todas as fases do meu doutorado.

Aos professores que participaram da Comissão examinadora.

Aos meus colegas da PUC-Rio

Ao Laboratório de Estruturas e Materiais da PUC-Rio e seus funcionários pela colaboração e apoio técnico durante a fase experimental da pesquisa.

Eu também gostaria de agradecer ao CNPq e a PUC-Rio pelos auxílios concedidos para a realização desta pesquisa.

Finalmente, eu agradeço à minha mãe, minha irmã e aos outros membros da minha família por seu apoio e inspirações. 


\section{Resumo}

Ferrante, César Augusto de Oliveira; Dumont, Ney Augusto; Andrade, Sebastião Arthur Lopes de. Desenvolvimento de um sistema de piso misto com viga em perfil alveolar assimétrico. Rio de Janeiro, 2019. 133p. Tese de Doutorado Departamento de Engenharia Civil e Ambiental, Pontifícia Universidade Católica do Rio de Janeiro.

Sistemas de piso misto, quando comparados a lajes de concreto armado, são uma solução estrutural mais eficiente e econômica. O comportamento geral desses elementos mistos depende da conexão de cisalhamento entre o aço e a laje de concreto. O sistema de piso misto pré-moldado com aberturas de alma apresenta uma solução eficiente e útil que ajuda a reduzir a altura do piso. Este trabalho relata os resultados de ensaios em escala real de vigas mistas e os ensaios de cisalhamento direto da ligação aço-concreto. Além dos ensaios experimentais, uma análise nãolinear em Elementos Finitos foi conduzida com o objetivo de recalcular os resultados dos ensaios com precisão suficiente usando um conjunto de parâmetros consistente. O sistema de piso misto é composto por uma viga de aço assimétrica parcialmente embutida no concreto, e o mecanismo de transferência de cisalhamento foi estabelecido através de uma inovadora conexão de cisalhamento por aderência, atrito e efeito pino (por armaduras transversais passando através de furos na alma). Os resultados dos ensaios indicaram uma ligação rígida produzida pela aderência e atrito da mesa do perfil embutida no concreto, bem como a possibilidade da viga mista de desenvolver sua capacidade resistente ao momento fletor. O modelo analítico proposto fornece uma maneira eficiente de analisar e projetar vigas mistas com mesa de compressão embutida no concreto da laje.

\section{Palavras-chave}

Estruturas mistas; vigas metálicas alveolares; análise experimental. 


\section{Abstract}

Ferrante, César Augusto de Oliveira; Dumont, Ney Augusto (Advisor); Andrade, Sebastião Arthur Lopes de (Co-Advisor). Development of a composite floor system with asymmetric castellated steel beam. Rio de Janeiro, 2019. 133p. Tese de Doutorado - Departamento de Engenharia Civil e Ambiental, Pontifícia Universidade Católica do Rio de Janeiro.

Composite floor systems, when compared to reinforced concrete slabs, are a more cost-effective structural solution. The overall behaviour of these composite members depends on the shear connection between steel and the concrete encasement. The pre-cast composite flooring system with hollowcore section presents an efficient and useful solution that helps to reduce the flooring height. This thesis reports the results of full-scale tests in composite beams and the associated composite connection push-out tests. In addition to the tests, a nonlinear Finite Element analysis was conducted to recalculate the experimental results with sufficient precision using a consistent set of parameters. The system was composed of a partially encased asymmetric steel beam, and the shear transfer mechanism was established through an innovative shear connection by chemical bonding, friction, and dowel action (by transversal reinforcing bars passing through the web's holes). The tests results indicated that a rigid connection was produced by the chemical bonding and friction of the embedded flange profile in the concrete slab, as well as the composite beam's ability to develop its plastic bending moment capacity. The proposed analytical model provides an efficient way for analysing and designing a composite beam with encased compression flanges.

\section{Keywords}

Composite structures; composite beams; castellated steel beams; experimental analysis. 


\section{Sumário}

1 Introdução $\quad 21$

1.1 Objetivo 23

1.2 Justificativa 23

1.3 Metodologia de investigação 24

1.3.0.1 Avaliação numérica via método dos elementos finitos 24

1.3.1 Avaliação experimental 24

1.3.1.1 Ensaio à flexão simples 24

1.3.1.2 Ensaio de Cisalhamento Direto (Push-out) 24

1.3.2 Ensaios de cisalhamento direto segundo EUROCODE 4 [36] 25

1.3.2.1 Geometria dos protótipos 25

$\begin{array}{ll}\text { 1.3.2.2 Procedimento de ensaio } & 26\end{array}$

$\begin{array}{ll}\text { 1.3.2.3 Avaliação dos ensaios } & 26\end{array}$

$\begin{array}{lll}1.4 & \text { Estrutura da tese } & 27\end{array}$

2 Revisão Bibliográfica $\quad 29$

2.1 Sistemas de Vigamentos Mistos de Pequena Altura 29

2.1.1 Slimdek type systems 30

2.1.2 Composite Slim Floor Beam (CoSFB) 31

2.1.3 Deltabeam ${ }^{\circledR} \quad 32$

2.1.4 Slimline 34

2.1.5 iTECH composite beam 34

$\begin{array}{lll}2.1 .6 & \text { Ultra-Shallow Floor Beams (USFB) } & 36\end{array}$

2.2 Conectores de Cisalhamento 38

2.2.1 Conector Stud Bolt 38

2.2.2 Conector Perfobond 39

2.2.3 Conector linear por aderência 42

2.3 Trabalhos desenvolvidos na PUC-Rio 43

2.4 Resumo sistemas de piso misto de pequena altura 44

3 Comportamento de vigas mistas com mesa de compressão embutida $\quad 45$

3.1 Procedimentos de Projeto 46

3.1.1 Situação de projeto 48

3.2 Projeto estrutural 48

3.3 Resistência a flexão 48

3.3.1 Momento fletor resistente de cálculo 49

3.4 Resistência ao cisalhamento $\quad 51$

3.4.1 Resistência ao cisalhamento do perfil $\quad 51$

3.4.2 Resistência ao cisalhamento da laje de concreto 52

3.5 Abertura de alma 52

3.5.1 Interação cisalhamento - momento fletor 52

3.5.2 Verificação do tê inferior submetido à ação combinada da força axial e do momento fletor $\quad 52$

3.5.2.1 Momento fletor solicitante de Vierendeel $\left(M_{v s}\right)$

3.5.2.2 Força de tração solicitante $\left(T_{s}\right) \quad 53$ 
3.5.2.3 Resistência à força axial $\left(T_{n}\right)$ e ao momento fletor $\left(M_{n}\right)$ no tê inferior 54

3.6 Mecanismo da ligação entre aço e concreto 55

3.6.1 Aderência 55

3.6.2 Travamento mecânico 56

$\begin{array}{lll}3.6 .3 & \text { Atrito } & 56\end{array}$

3.6.4 Armadura transversal $\quad 58$

3.6.5 Ação mista 60

3.6.6 Modelo para determinação das propriedades mistas 60

3.6.7 Recomendações adicionais de projeto para interfaces sujeitas a carregamento cíclico $\quad 61$

3.6.8 Relação tensão-deslizamento na interface 62

4 Programa Experimental $\quad 63$

4.1 Pesquisa anterior 63

4.2 Ensaio de cisalhamento direto - Pushout 63

4.2.1 Confecção dos protótipos 66

4.2.2 Procedimento de ensaio e instrumentação 66

4.3 Ensaio em escala real das vigas mistas 69

4.3.1 Confecção dos protótipos 73

4.3.2 Procedimento de ensaio e instrumentação 75

5 Resultados Experimentais: análise e discussão $\quad 79$

5.1 Resultados dos ensaios de cisalhamento direto 79

$\begin{array}{lll}\text { 5.1.1 Comportamento carga - deslizamento } & 79\end{array}$

5.1.2 Ductilidade 81

5.1.3 Influência da armadura transversal na capacidade do conector 81

5.1.4 Influência da chapa de alma 82

5.2 Configuração das fissuras 83

5.3 Resultados dos ensaios de flexão das Vigas Mistas 86

5.3.1 Ensaio cíclico $\quad 86$

5.3.2 Ensaio Estático $\quad 88$

5.3.2.1 Comportamento momento fletor vs. deflexão 88

5.3.2.2 Deslizamento na interface aço-concreto 88

5.3.2.3 Deformação específica medida nos perfis 90

5.3.2.4 Deformação específica medida na laje de concreto 93

5.3.2.5 Deformação específica medida na armadura transversal 93

5.3.2.6 Configuração da fissuração e modo de ruptura 95

6 Modelagem em Elementos Finitos 100

6.1 Propriedades geométricas e condições de contorno do modelo 100

6.2 Elementos finitos adotados e malha 101

$\begin{array}{lll}6.3 & \text { Restrições e interações de contato } & 102\end{array}$

6.4 Relações constitutivas para os materiais 103

6.4.1 Modelo do material para o aço 103

6.4.2 Modelo do material para o concreto 104

$\begin{array}{lll}6.5 & \text { Procedimento de análise } & 106\end{array}$

6.6 Confiabilidade do modelo numérico 107

7 Comparação entre resultados previstos e experimentais 115 
8.1 Recomendações para trabalhos futuros 121

Referências bibliográficas 


\section{Lista de figuras}

Figura 1.1 Modelo de ensaio push-out (EUROCODE 4 [36]) 25

Figura 1.2 Curva força cisalhante vs deslizamento aço-concreto $\begin{array}{ll}\text { (EUROCODE } 4[36]) & 27\end{array}$

Figura 2.1 Hat Beam Lawson et al. [37] 29

Figura 2.2 Slimdek(B) type systems (a) Asymmetric Slimflor B Beam

(b) Rectangular Hollow Slimflor Beams 30

Figura 2.3 Composite Slim Floor Beam [11] 31

2.3(a) CoSFB 31

2.3(b) Seção transversal 31

Figura 2.4 Deltabeam(B) [48] 33

Figura 2.5 Slimline ${ }^{R}[5] \quad 34$

Figura 2.6 iTECH composite beam [6] 35

Figura 2.7 Shallow cellular floor beams [56] 36

2.7(a) USFB 36

2.7(b) Seção transversal 36

Figura 2.8 conector stud bolt [68] 38

Figura 2.9 Posicionamento do conector stud bolt nas vigas mistas [8] 39

Figura 2.10 Conector Perfobond [68] 40

Figura 2.11 (a) Conector Crestbond com armaduras transversais (b)

sistema de transmissão de forças pelo conector Crestbond [68] 41

Figura 2.12 Conector Concrete dowels [71] 41

Figura 2.13 Conector linear [82] 42

Figura 2.14 Viga mista com perfil alveolar [92] 43

Figura 3.1 Sistema de vigamentos mistos com perfil alveolar parcialmente embutido $\quad 45$

Figura 3.2 Detalhamento dos componentes da viga mista 46

$\begin{array}{lll}\text { Figura 3.3 Layout do sistema de piso misto } & 47\end{array}$

Figura 3.4 (a) viga mista simplesmente apoiada (b) continuidade na ligação entre vigas mistas 47

Figura 3.5 Distribuição das tensões plásticas na viga mista com a linha neutra posicionada na laje acima do perfil 49

Figura 3.6 Distribuição das tensões plásticas na viga mista com a linha neutra posicionada na mesa superior do perfil 50

Figura 3.7 Distribuição das tensões plásticas na viga mista com a linha neutra posicionada na abertura de alma 50

Figura 3.8 Terminologia utilizada para calcular forças axiais em vigas mistas 54

Figura 3.9 Comportamento cinemático na interface aço-concreto 56 3.9(a) Erosão pro fricção 56

3.9(b) Superfície de ruptura 56

Figura 3.10 Forças normais na interface aço-concreto 57

Figura 3.11 Comportamento mecânico da ligação 58 3.11(a) Deslizamento e deslocamentos perpendiculares a interface 58 
3.11(b) Deslocamento $u_{1}$ e restrições internas associadas $\quad 58$

3.11(c) Deslocamento $u_{2}$ e restrições internas associadas $\quad 58$

Figura 3.12 Fluxo de tensões em torno da interface aço-concreto $\quad 59$

3.12(a) Armadura transversal em 45 $\quad 59$

3.12(b) Armadura transversal reta $\quad 59$

Figura 3.13 Idealização do modo de falha sob cisalhamento longitudinal 59

3.13(a) Planos de cisalhamento $\quad 59$

3.13(b) Mecanismo de ruptura da laje $\quad 59$

Figura 3.14 Influência da armadura transversal na ligação 60

3.14(a) armadura reta 60

3.14(b) armadura em 45 $\quad 60$

Figura 3.15 Modelo para determinação das propriedades mistas. $\quad 61$

3.15(a) Perímetro de contato em torno da superfície do perfil 61

3.15(b) Transferência de cisalhamento ao longo da viga para um carregamento uniformemente distribuído 61

Figura 3.16 Relação tensão-deslizamento para ligação aço-concreto [107]

Figura 4.1 Protótipo da viga mista com abertura de alma estudada em [92] [mm]

4.1(a) Vista lateral 64

4.1(b) Seção transversal $\quad 64$

4.1(c) Perfil 64

Figura 4.2 Características geométricas dos protótipos de push-out [mm] 65

4.2(a) Protótipo P1 e P2 65

4.2(b) Protótipo P3 e P4 65

Figura 4.3 Confecção dos protótipos de push-out 67

4.3(a) Forma e Armadura $\quad 67$

4.3(b) Concreto $\quad 67$

4.3(c) Configuração final $\quad 67$

Figura 4.4 Configuração de ensaio de push-out 68

Figura 4.5 Configuração da instrumentação dos protótipos de push-

out $\quad 69$

Figura 4.6 Fabricação dos perfis alveolares assimétricos [mm $\quad 70$

$\begin{array}{ll}\text { 4.5(a) LVDT's } & 70\end{array}$

4.5(b) Extensômetros(P1-P2) 70

4.5(c) Extensômetros(P3-P4) 70

4.6(a) $2 \times \mathrm{W} 360 \times 32,9 \quad 70$

4.6(b) $2 \times \mathrm{V} 360-01 \quad 70$

4.6(c) 2 x V360-02 70

Figura 4.7 Detalhe dos perfis V360-01 e V360-02 [mm] 70

Figura 4.8 Ligação entre perfis alveolares utilizando perfil

$\begin{array}{ll}W 150 x 18,0 \text { soldado à alma }[\mathrm{mm}] & 71\end{array}$

4.7(a) Seção transversal $\quad 71$

4.7(b) Abertura de alma $\quad 71$

4.8(a) Seção transversal $\quad 71$

4.8(b) Vista superior $\quad 71$

Figura 4.9 Configuração do protótipo VMT [mm] 71 
Figura 4.10 Configuração do protótipo VMPI-1 [mm] 72

Figura 4.11 Configuração do protótipo VMPI-2 [mm] 73

Figura 4.12 Confecção do protótipo VMT $\quad 75$

Figura 4.13 Confecção dos protótipos VMPI-1 e VMPI-2 75

Figura 4.14 Configuração de ensaio do protótipo VMT [mm] 76

4.14(a) Elementos de ensaio $\quad 76$

4.14(b) Pontos de aplicação de carga 76

Figura 4.15 Configuração de ensaio dos protótipos VMPI-1 e VMPI-

$2[\mathrm{~mm}] \quad 77$

4.15(a) Elementos de ensaio (VMPI-1 e VMPI-2) 77

4.15(b) Pontos de aplicação de carga (VMPI-1) $\quad 77$

4.15(c) Pontos de aplicação de carga (VMPI-2) 77

Figura 4.16 Instrumentação das armaduras transversais e da laje [mm] 78

4.16(a) VMT 78

$\begin{array}{ll}\text { 4.16(b) VMPI-1 e VMPI2 } & 78\end{array}$

$\begin{array}{ll}\text { Figura } 4.17 \text { Instrumentação do perfil } & 78\end{array}$

$\begin{array}{lll}\text { Figura 5.1 Curva carga vs deslizamento } & 80\end{array}$

$\begin{array}{ll}4.17(\mathrm{a}) \mathrm{VMT} & 80\end{array}$

4.17(b) VMPI-1 80

$\begin{array}{ll}\text { 4.17(c) VMPI-2 } & 80\end{array}$

5.1(a) Protótipo P1 80

5.1(b) Protótipo P2 80

5.1(c) Protótipo P3 80

5.1(d) Protótipo P4 80

Figura 5.2 Curva carga vs deformação da armadura transversal $\quad 82$

5.2(a) Protótipo P1 82

5.2(b) Protótipo P2 82

5.2(c) Protótipo P3 82

5.2(d) Protótipo P4 82

Figura 5.3 Influência da chapa de alma na ligação aço-concreto 83

5.3(a) Protótipo P1, P3 e P4 83

5.3(b) Protótipo P2 83

Figura 5.4 Curva carga vs deformação da armadura transversal $\quad 84$

5.4(a) Protótipo P1 84

5.4(b) Protótipo P2 84

5.4(c) Protótipo P3 84

5.4(d) Protótipo P4 84

Figura 5.5 Configuração final do protótipo P1 84

Figura 5.6 Flexão da armadura transversal no protótipo P2 85

Figura 5.7 Configuração final do protótipo P3 85

Figura 5.8 Configuração final do protótipo P4 86

5.8(a) Laje-1 86

5.8(b) Laje-2 86

Figura 5.9 Resultado do ensaio cíclico - VMT 87

Figura 5.10 Resultado do ensaio cíclico - VMPI-1 88

Figura 5.11 Resultado do ensaio cíclico - VMPI-2 89

Figura 5.12 Comportamento momento fletor vs. deflexão 90

Figura 5.13 Deslizamento na interface aço-concreto 91 
5.13(a) VMT $\quad 91$

5.13(b) VMPI-1 91

5.13(c) VMPI-2 91

Figura 5.14 Deformação no perfil $\quad 92$

5.14(a) VMT $\quad 92$

5.14(b) VMPI-1 92

5.14(c) VMPI-2 92

Figura 5.15 Curvas força vs. deformação na face superior da laje de concreto 93

Figura 5.16 Deformação na armadura transversal do protótipo VMT 94

5.16(a) Armaduras extremidade esquerda 94

5.16(b) Armaduras extremidade direita 94

Figura 5.17 Deformação na armadura transversal do protótipo

$\begin{array}{ll}\text { VMPI-1 } & 94\end{array}$

5.17(a) Armaduras extremidade esquerda $\quad 94$

5.17(b) Armaduras extremidade direita 94

Figura 5.18 Deformação na armadura transversal do protótipo

VMPI-2 95

5.18(a) Armaduras extremidade esquerda $\quad 95$

5.18(b) Armaduras extremidade direita $\quad 95$

Figura 5.19 Configuração das fissuras na laje do protótipo VMT 96

Figura 5.20 Configuração das fissuras na laje do protótipo VMPI-1 96

Figura 5.21 Configuração das fissuras na laje do protótipo VMPI-2 97

Figura 5.22 Configuração das fissuras nas extremidades das vigas $\quad 97$

$\begin{array}{ll}5.22(\text { a) VMPI-1 } & 97\end{array}$

$\begin{array}{ll}5.22(\mathrm{~b}) \text { VMPI-2 } & 97\end{array}$

Figura 5.23 Configuração final do protótipo VMT 97

$\begin{array}{ll}\text { 5.23(a) Configuração deformada } & 97\end{array}$

5.23(b) Armadura transversal $\quad 97$

Figura 5.24 Configuração final do protótipo VMPI-1 98

5.24(a) Configuração deformada 98

5.24(b) Armadura transversal 98

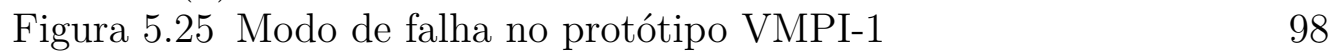

5.25(a) Desagregação do concreto 98

5.25(b) Deslizamento aço-concreto (D1) 98

5.25(c) Flambagem do perfil 98

Figura 5.26 Configuração final do protótipo VMPI-2 99

Figura 5.27 Modo de falha no protótipo VMPI-2 $\quad 99$

5.27(a) Desagregação do concreto 99

5.27(b) Fissuras na borda (D3) 99

5.27(c) Flambagem do perfil $\quad 99$

5.27(d) Armadura transversal $\quad 99$

Figura 6.1 Discretização da malha da viga mista em Elementos Finitos102

Figura 6.2 Detalhe da tela soldada no modelo em Elementos Finitos 102

Figura 6.3 Detalhe das armaduras transversais no modelo em Ele-

mentos Finitos 103

Figura 6.4 Modelo constitutivo do aço [114] 104 
Figura 6.5 Curva tensão-deformação para o concreto da laje e para o aço do perfil 106

6.5(a) Aço 106

6.5(b) Concreto 106

$\begin{array}{lll}\text { Figura } 6.6 & \text { Energia vs. tempo } & 108\end{array}$

Figura 6.7 Comparação entre resultados experimentais e modelo em EF - VMT 109

6.7(a) Momento fletor vs. deflexão 109

6.7(b) Momento fletor vs. deslizamento 109

6.7(c) Momento fletor vs. deformação no perfil 109

6.7(d) Momento fletor vs. deformação no concreto 109

Figura 6.8 Comparação entre resultados experimentais e modelo em EF - VMPI-1 110

6.8(a) Momento fletor vs. deflexão 110

6.8(b) Momento fletor vs. deslizamento 110

6.8(c) Momento fletor vs. deformação no perfil 110

6.8(d) Momento fletor vs. deformação no concreto 110

Figura 6.9 Comparação entre resultados experimentais e modelo em EF - VMPI-2 111

6.9(a) Momento fletor vs. deflexão 111

6.9(b) Momento fletor vs. deslizamento 111

6.9(c) Momento fletor vs. deformação no perfil 111

6.9(d) Momento fletor vs. deformação no concreto 111

Figura 6.10 Modelo em EF do protótipo VMT 112

Figura 6.11 Modelo em EF do protótipo VMPI-1 113

6.10(a) Distribuição das tensões no perfil W250X25,3 113

6.10(b) Dano do concreto por tração na face superior da laje 113

6.10(c) Dano do concreto por tração na face inferior da laje 113

6.11(a) Distribuição das tensões no perfil V360-01 113

6.11(b) Dano no concreto por tração na face superior da laje 113

6.11(c) Dano no concreto por tração na face inferior da laje 113

Figura 6.12 Modelo em EF do protótipo VMPI-2 114

6.12(a) Distribuição das tensões no perfil V360-02 114

6.12(b) Dano no concreto por tração na face superior da laje 114

6.12(c) Dano no concreto por tração na face inferior da laje 114

Figura 7.1 Momento fletor vs. deslocamento no meio do vão 115

$\begin{array}{lll}\text { Figura 7.2 Momento fletor vs. deslocamento } & 117\end{array}$

$\begin{array}{lll}\text { Figura 7.3 Momento fletor vs. deslizamento } & 118\end{array}$ 


\section{Lista de tabelas}

Tabela 2.1 Resumo sistemas de piso misto de pequena altura 44

Tabela 4.1 Caracteristicas dos protótipos de push-out 64

Tabela 4.2 Propriedade do aço e do concreto nos protótipos de pushout 66

$\begin{array}{lll}\text { Tabela 4.3 } & \text { Propriedade do concreto das vigas mistas } & 74\end{array}$

$\begin{array}{lll}\text { Tabela 4.4 Propriedade do aço dos perfis } & 74\end{array}$

Tabela 5.1 Resultados dos ensaios de cisalhamento direto $\quad 80$

$\begin{array}{lll}\text { Tabela 5.2 } & \text { Resultados medidos do ensaio cíclico } & 87\end{array}$

$\begin{array}{lll}\text { Tabela 5.3 } & \text { Resultados medidos do ensaio estático } & 89\end{array}$

Tabela 5.4 Resultado do deslizamento aço-concreto 91

Tabela 6.1 Quantidade de elementos finitos 101

$\begin{array}{lll}\text { Tabela } 6.2 & \text { Resultados da análise modal } & 107\end{array}$

Tabela 7.1 Momentos fletores obtidos para cada viga 116 


\section{Lista de Símbolos}

\section{Letras Romanas Maiúsculas}

$A_{b}$ - área de contato na interface aço-concreto

$A_{c}$ - área da seção transversal do pino de concreto

$A_{s 1}$ - área da seção transversal da armadura

$A_{s b}$ - área da seção transversal do tê inferior do perfil

$A_{w}$ - área da seção transversal da alma

$C_{r}^{\prime}$ - força fatorada de compressão no concreto acima do perfil

$C_{r}$ - resistência à compressão no aço e na região de concreto adjacente

$C_{R S}$ - força de compressão na mesa superior e na região de concreto adjacente

$C_{r}^{\prime \prime}$ - força de compressão na região de concreto abaixo da mesa de aço

$C_{s}$ - força axial no concreto

$E_{s}$ - módulo de elasticidade do aço

$E_{c}$ - módulo de elasticidade do concreto

$F_{s b}$ - resistência devido o contato aço-concreto

$F_{b b}$ - resistência devido o preenchimento das aberturas pelo concreto

$F_{b}$ - máxima força de cisalhamento por unidade de comprimento

$F_{n}$ - força total de compressão transferida na interface

$L$ - vão da viga

$M_{R d}-$ momento fletor resistente de cálculo

$M_{S d}-$ momento fletor solicitante de cálculo

$M_{n}$ - resistência nominal de flexão

$M_{m}$ - resistência máxima de momento fletor

$M_{v s}$ - momento fletor solicitante de Vierendeel

$M_{p}$ - momento de plastificação da viga mista

$N$ - força de tração na armadura transversal

$N_{S d}$ - força longitudinal na seção devida a protensão ou carregamento

$P_{R k}$ - resistência característica

$P_{u}$ - resistência última ao cisalhamento do conector

$S_{d}$ - desvio padrão

$T_{r}$ - força de tração resistente no tê inferior

$T_{s}$ - força de tração solicitante no tê inferior

$T_{n}$ - força de tração nominal no tê inferior

$V_{S d}$ - força cortante solicitante de cálculo 
$V_{R d}$ - força cortante resistente de cálculo

$V_{R d c}$ - resistência ao cisalhamento da laje de concreto

$V_{R d a}$ - resistências ao cisalhamento do perfil

$V_{p l}$ - força cortante correspondente à plastificação da alma

$V_{n}$ - resistência nominal de cisalhamento

$V_{m}$ - resistência máxima de cisalhamento

$V_{s t}$ - força de cisalhamento sobre o tê

$Y_{c}$ - espessura de concreto que resistirá ao momento global

$Z_{x-t e ̂}$ - módulo de resistência plástico da seção transversal do tê em relação ao eixo de flexão

\section{Letras Romanas Minúsculas}

$a$ - espessura do bloco de tensão no concreto

$a_{1}$ - largura da abertura de alma

$b_{c}$ - largura efetiva da laje de concreto

$b_{s}$ - largura da mesa superior de aço

$d$ - altura do perfil

$d_{e f}$ - altura efetiva da seção mista

$e$ - distância entre as forças $C_{r}$ e $T_{r}$

$e^{\prime}$ - distância entre as forças $C_{r}^{\prime}$ e $T_{r}$

$e^{\prime \prime}$ - distância entre as forças $C_{r}^{\prime \prime}$ e $T_{r}$

$f_{b b}$ - resistência devido o contato entre o concreto e a alma do perfil na região

de abertura

$f_{c k}$ - resistência característica à compressão do concreto

$f_{\text {ckest }}$ - valor medido da resistência característica à compressão do concreto

$f_{c u}$ - resistência à compressão do concreto

$f_{c m}$ - valor médio da resistência à compressão do concreto

$f_{c t m}$ - resistência a tração média do concreto

$f_{y}$ - tensão de escoamento do aço

$f_{u}$ - limite de resistência do aço

$h_{c}$ - espessura da laje de concreto

$l_{o}$ - comprimento da interface aço-concreto

$n$ - número de aberturas

$s$ - deslocamentos paralelos à interface de contato aço-concreto

$t_{c}$ - espessura da laje de concreto acima do perfil

$t_{s}$ - espessura da mesa superior do perfil

$t_{0}$ - espessura da laje de concreto abaixo da mesa superior do perfil

$u$ - deslocamentos perpendiculares à interface de contato aço-concreto

$y_{s b}$ - distância entre a face inferior do perfil e o centro de gravidade do tê 


\section{Letras Gregas}

$\gamma$ - coeficiente de p onderação da resistência

$\delta_{u}$ - capacidade de deslizamento

$\epsilon_{l n}^{p l}$ - deformação logarítmica

$\epsilon_{\text {nom }}$ - deformação nominal

$\epsilon_{c t m}$ - deformação correspondente a tensão de tração do concreto

$\lambda$ - índice de esbeltez

$\lambda_{p}$ - parâmetro de esbeltez limite para seções compactas

$\lambda_{r}$ - parâmetro de esbeltez limite para seções semicompactas

$\mu$ - coeficiente de atrito

$\sigma_{c}$ - tensão compressiva na interface aço-concreto

$\sigma_{\text {true }}$ - tensão verdadeira

$\sigma_{\text {nom }}$ - tensão nominal

$\tau_{b}$ - tensão de contato entre o perfil e a laje de concreto

$\tau_{R d}$ - tensão resistente de cálculo do concreto ao cisalhamento

$\tau_{\text {in }}$ - tensão de cisalhamento na interface aço-concreto

$\phi$ - coeficiente de ponderação do aço

$\phi_{c}$ - coeficiente de ponderação do concreto 


\section{Lista de Abreviaturas}

AISC - American Institute of Steel Construction

ASB - Asymmetric Slimflor B Beam

CDP - Concrete Damaged Plasticity

$\mathrm{CP}$ - Corpo de prova

CoSFB - Composite Slim Floor Beam

$\mathrm{EF}$ - Elementos finitos

FLM - Flambagem local da mesa

IFB - Integrated Floor Beam

iTECH - Innovative, Technical, Economical and Convenient Hybrid

LEM - Laboratório de Estruturas e Materiais

LNP - linha neutra plástica

LVDT - Linear Variable Differential Transformer

MTS - Material Testing Systems

PUC - Pontifícia Universidade Católica

RWSB - Rectangular Hollow Slimflor B Beams

SCI - Steel Construction Institute

SPMP - Sistema de piso misto pré-fabricado

USFB - Ultra-Shallow Floor Beam

VMT - Viga mista no formato "T"

VMPI - Viga mista no formato "Pi" 
Mission defines strategy, and strategy defines structure.

Peter F. Drucker, 


\section{Introdução}

Cada tipo de edifício exige diferentes soluções de construção. Os requisitos de projeto de um edifício variam dependendo do tipo de uso, sua localização, condições ambientais e outras demandas, mas há algumas questões mais sutis a serem analisadas. Muitas metrópoles limitam a altura dos edifícios de vários andares com base nas legislações vigentes, em questões econômicas e detalhes estéticos. A capacidade de atender a essas restrições é uma consideração importante na seleção de um sistema estrutural.

Quando comparados a estruturas de concreto armado, sistemas estruturais mistos mostram ser soluções estruturais melhores e de ótima viabilidade econômica. No termo "estrutura mista", fica implícito o uso do aço e do concreto para formar um único componente, assim como acontece na construção de concreto armado. O objetivo é atingir um nível de desempenho mais alto do que se obteria com os dois materiais trabalhando separadamente.

O primeiro uso de estruturas mistas data do ano de 1894 nos EUA, quando vigas metálicas foram utilizadas embutidas no concreto para a construção de uma ponte em Iowa e de um edifício em Pittsburgh [1]. Os primeiros ensaios com vigas mistas ocorreram no Canadá, no Dominion Bridge Works, em 1922. Os conectores de cisalhamento stud bolt foram ensaiados pela primeira vez na Universidade de Illinois, em 1954. Essa pesquisa possibilitou a publicação, em 1956, da fórmula para o cálculo da resistência da ligação açoconcreto utilizando conectores. Nesse mesmo ano, ocorreu também a primeira utilização dos conectores stud bolts em pontes e projetos de construção, ao passo que a teoria da interação parcial foi proposta em 1951 pela equipe de Illinois. As formas de metal para laje (steel decks) apareceram pela primeira vez na década de 1950, com o primeiro uso registrado de soldagem de conectores em decks no Tribunal Federal do Brooklyn, em 1960. No entanto, foi somente em 1978 que esse arranjo foi reconhecido pela especificação AISC (American Institute of Steel Construction).

Na Europa, pesquisas paralelas ocorriam nesse mesmo período. Em 1950, foi publicado um regulamento provisório para projeto de vigas em construção mista, com as primeiras aplicações de estruturas mistas em pontes e edifícios surgindo no final dos anos 50, no Reino Unido. 
No Brasil, a utilização do sistema misto se iniciou com a construção de pontes e edifícios nas décadas de 50 e 60, ficando parcialmente estagnada na década de 70 e início da década de 80. Nos últimos anos, a construção de edifícios utilizando estrutura mista aumentou, boa parte devido ao aumento na produção de aço estrutural no Brasil e à busca por novas opções arquitetônicas e estruturais.

Um dos principais objetivos dos sistemas de piso misto desenvolvidos recentemente é a redução da altura do pavimento. Alguns exemplos são as vigas Thor-beam e Delta-beam, desenvolvidas na Escandinávia [2], e o slimflor beam, desenvolvido pelo Instituto de Construção em Aço (Steel Construction Institute - SCI) [3]. Alguns desses sistemas utilizam steel decks ou lajes alveolares na construção do piso [2-4].

Mensinger et al. [5] estudaram um sistema de piso misto baseado em vigas celulares parcialmente embutidas na laje de concreto. A conexão entre o aço e o concreto foi obtida pela aderência entre o concreto e vergalhões soldados ao longo da alma do perfil. Ju et al. [6,7] apresentam um estudo experimental de vigas mistas utilizando perfis assimétricos com abertura na alma, com os perfis revestidos por concreto na lateral e em sua parte superior. A resistência ao cisalhamento longitudinal foi obtida por meio da aderência na interface aço-concreto e pelo travamento mecânico do concreto na região da abertura. Nardin et al. [8,9] sugeriram uma metodologia que pode determinar a localização ideal dos conectores de cisalhamento tipo stud bolt em vigas mistas, ao passo que Lawson et al. [10] propuseram um novo sistema de vigas mistas sem conectores de cisalhamento. Braun et al. [11], por sua vez, desenvolveram uma viga mista (CoSFB) que utiliza armaduras passando pela alma da seção da viga.

O comportamento geral desses elementos mistos depende da conexão de cisalhamento entre o aço e o concreto. Muitos estudos têm sido conduzidos nos últimos anos para investigar vários tipos de conectores de cisalhamento, como o conector stud bolt [12-15] e o conector perfobond e suas variações [16-24]. Além desses, outros tipos de conectores já foram estudados, como os post-installed ou retrofitted [25,26], inverted umbrella [27], demountable [28, 29], channel connectors [30], angles [31,32] e V-shaped connectors [33]. Outra alternativa para transferir o cisalhamento longitudinal da laje de concreto para o perfil é por meio das aberturas de alma na viga metálica, as quais permitem o preenchimento pelo concreto e melhoram, assim, a interação entre a laje de concreto e o perfil [34].

Dessa forma, o sistema de piso misto pré-fabricado (SPMP) com perfil alveolar - estudado anteriormente em [35] e apresentado nesta tese - é uma 
solução eficiente, econômica e construtiva que ajuda a diminuir a altura dos pavimentos. Esse sistema foi concebido como uma alternativa construtiva às lajes duplo T pré-fabricadas de concreto armado, com a intenção de combinar os dois sistemas - concreto pré-fabricado e estruturas mistas - e permitir maior rapidez na execução da construção e melhor qualidade na moldagem dos elementos estruturais. A abordagem da tese se concentra na ligação não convencional entre o perfil e a laje de concreto, substituindo os conectores de cisalhamento usuais apresentados anteriormente por uma conexão composta por três elementos principais: a aderência entre a mesa superior e a laje de concreto, o efeito pino na armadura transversal que transpassa o perfil e o travamento mecânico que ocorre entre a laje e o perfil devido às aberturas de alma.

Algumas normas abordam o tema da aderência aço-concreto. A hipótese básica presume uma perfeita interação entre os dois materiais e, para que isso seja confirmado, não deve haver deslizamento relativo excessivo entre os dois materiais. É por esse motivo que o EUROCODE 4 [36], por exemplo, estabelece a tensão máxima de cisalhamento que pode ocorrer na interface aço-concreto - denominada tensão limite de aderência - sem que seja necessário o emprego de conectores de cisalhamento.

\section{1 \\ Objetivo}

Este trabalho tem como objetivo estudar e desenvolver uma nova proposta de sistema de piso misto que seja uma solução eficiente, econômica e construtiva. Desta forma, busca-se compreender o comportamento estrutural deste sistema de piso identificando a influência de cada elemento que compõe a viga, e elucidar como a ligação aço-concreto influencia no comportamento da laje a flexão.

\section{2}

\section{Justificativa}

Embora existam diversos sistemas de pisos mistos semelhantes, a particularidade de cada um não permite que a previsão da capacidade resistente da ligação aço-concreto seja diretamente aplicada ao sistema proposto. Além disso, os fatores que podem influenciar o comportamento da ligação não convencional aço-concreto fazem com que a descrição analítica seja complexa, tornando mais fácil descrever o comportamento a partir de resultados experimentais. Dessa forma, justifica-se o desenvolvimento de mais pesquisas para 
melhor compreender o funcionamento estrutural do sistema de vigas mistas com perfil alveolar.

\section{3}

\section{Metodologia de investigação}

O estudo da viga mista passa por duas avaliações: primeiramente, é realizada uma análise teórica cujos resultados servirão de base para definir, na segunda parte, os modelos estudados experimentalmente.

\subsubsection{1}

\section{Avaliação numérica via método dos elementos finitos}

Devido ao complexo estado tridimensional tensão-deformação do concreto que preenche as aberturas de alma, torna-se difícil realizar uma análise por modelos matemáticos. Por isso, neste estudo, foram desenvolvidos modelos numéricos em elementos finitos (EF) para avaliar a resistência ao cisalhamento longitudinal da ligação aço-concreto e a resistência a flexão das vigas mistas.

\subsection{1}

\section{Avaliação experimental}

Para o estudo do comportamento mecânico das vigas mistas, foram desenvolvidos ensaios de laboratório cujos resultados foram usados para aferir os modelos matemático e numérico.

Foram realizados dois tipos de avaliação experimental: ensaio à flexão simples e ensaio de cisalhamento direto (push-out).

\subsubsection{1}

\section{Ensaio à flexão simples}

O ensaio de flexão simples consiste em apoiar o corpo de prova nas extremidades e aplicar o carregamento em pontos ao longo do vão.

Durante o ensaio, algumas grandezas podem ser medidas, tais como: deslocamentos verticais e horizontais, deslizamento na interface aço-concreto, deformações no concreto, na armadura e no perfil e valor do carregamento aplicado.

\subsubsection{2}

\section{Ensaio de Cisalhamento Direto (Push-out)}

O ensaio de cisalhamento direto consiste na aplicação de uma força de cisalhamento longitudinal diretamente sobre os conectores de cisalhamento. A 
capacidade resistente ao cisalhamento e o comportamento carga-deslizamento da conexão podem ser obtidos por meio desse ensaio.

\subsection{2}

\section{Ensaios de cisalhamento direto segundo EUROCODE 4 [36]}

Os ensaios de cisalhamento direto deste trabalho foram desenvolvidos com base nos padrões determinados pelo EUROCODE 4 [36]. Na medida do possível, levou-se em conta as recomendações feitas pela norma acerca da geometria e procedimento de ensaios, mas também foram realizadas modificações para atender ao modelo estudado. Uma descrição do ensaio é apresentada a seguir.

\subsubsection{1}

\section{Geometria dos protótipos}

O ensaio consiste em um perfil de aço "I", de pequeno comprimento, em posição vertical entre duas lajes de concreto solidarizadas ao perfil por meio dos conectores a ensaiar. O conjunto é submetido a uma carga vertical que produz a força de cisalhamento na interface entre o concreto e a mesa do perfil. As dimensões dos protótipos a serem ensaiados são dadas na Fig. 1.1.
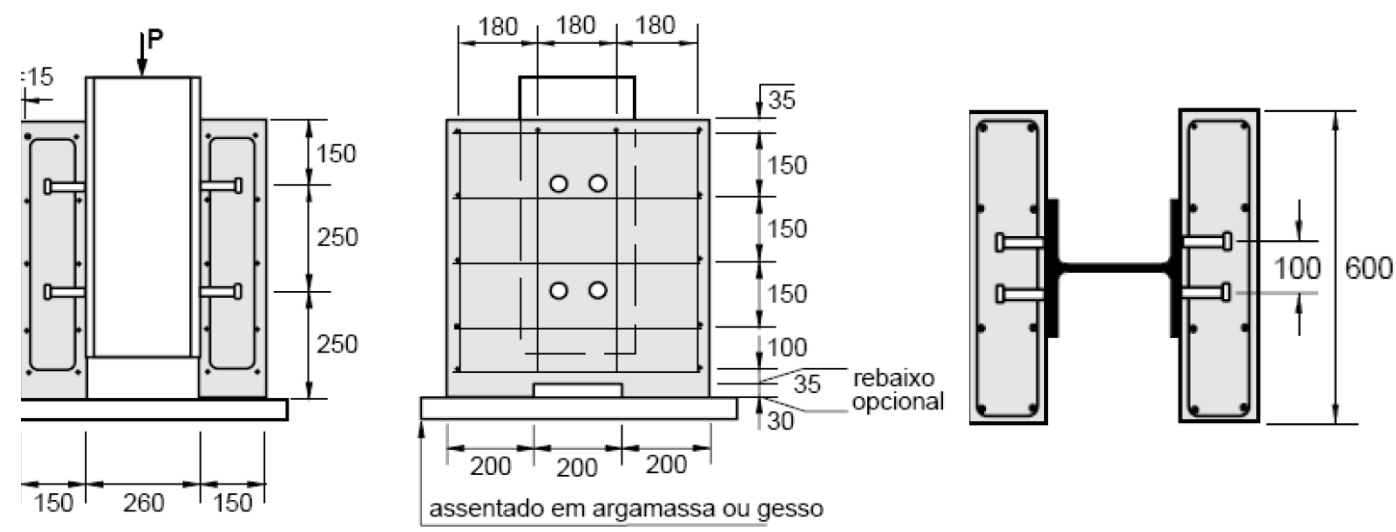

Figura 1.1: Modelo de ensaio push-out (EUROCODE 4 [36])

Os ensaios tipo push-out devem ser dimensionados de maneira adequada às vigas para as quais o teste foi projetado. Em particular:

$\triangleright \mathrm{O}$ comprimento, L, de cada laje deve ser relacionado ao espaçamento longitudinal dos conectores;

$\triangleright$ A largura, b, de cada laje não deve exceder a largura efetiva da laje da viga; 
$\triangleright$ A espessura, h, de cada laje não deve exceder a espessura mínima da laje da viga;

$\triangleright$ Os modelos de push-out devem ter a mesma armadura utilizada na laje da viga.

\subsubsection{2}

\section{Procedimento de ensaio}

Inicialmente, são aplicados incrementos de carga até se atingir $40 \%$ da carga máxima esperada. Então, são realizados 25 ciclos de carga/descarga entre $5 \%$ e $40 \%$ da carga de ruptura prevista. Os incrementos de carga após a fase cíclica devem ser aplicados de modo a não provocar ruptura antes de um período de 15 minutos.

O deslizamento relativo entre a laje de concreto e a viga de aço deve ser monitorado durante todo ensaio, sendo ele medido ao menos até que a carga aplicada decresça em $20 \%$ do valor máximo. Além disso, próximo aos conectores, deve-se medir a separação transversal entre a mesa e a laje.

\subsubsection{3}

\section{Avaliação dos ensaios}

Para a análise dos resultados dos ensaios de três modelos nominalmente idênticos, cujo desvio padrão entre o resultado individual de cada modelo e os resultados médios não exceda 10\%, usa-se a eq. (1-1) para determinar a resistência de cálculo do conector.

$$
q_{r d}=\frac{f_{u}}{f_{u t}} \cdot \frac{P_{R k}}{\gamma_{V}} \leqslant \frac{P_{R k}}{\gamma_{V}}
$$

$\mathrm{Na}$ equação, $f_{u}$ representa a resistência a ruptura especificada para o material do conector, $f_{u t}$ é a resistência a ruptura do conector obtida no ensaio experimental, $\gamma_{V}$ é o coeficiente de ponderação da resistência igual a 1,25 e $P_{R k}$ é a menor resistência encontrada nos três ensaios de modelos idênticos, reduzida em $10 \%$.

O valor da capacidade de deslizamento, $\delta_{u}$, deve ser tomado como o maior valor medido no nível de carga característica $\left(P_{R k}\right)$, assim como mostra a Fig. 1.2.

A carga característica é tomada como a menor carga de colapso, dividida pelo número de conectores e reduzida em 10\%. O deslizamento característico, $\delta_{u k}$, considerado é igual a $0,9 \delta_{u}$. 


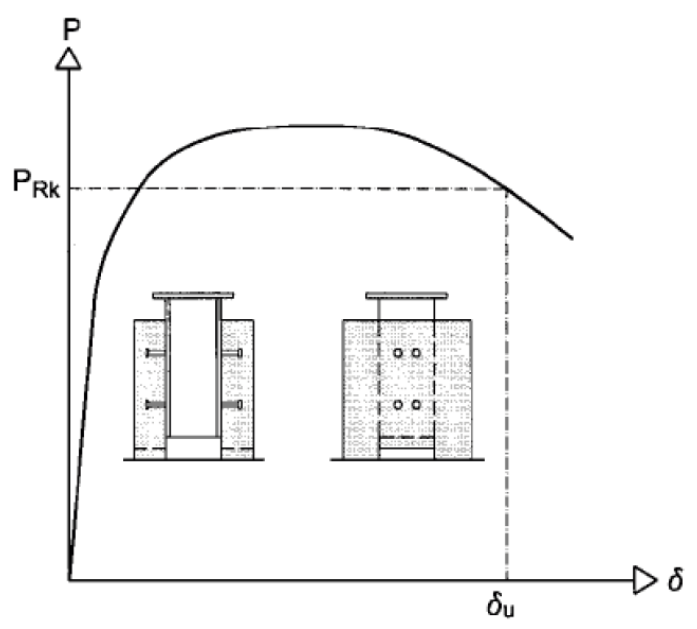

Figura 1.2: Curva força cisalhante vs deslizamento aço-concreto (EUROCODE $4[36])$

Dependendo do valor do deslizamento característico, os conectores podem ser classificados como rígidos ou flexíveis. Segundo o EUROCODE 4 [36], um conector de cisalhamento é classificado como dúctil quando ele apresenta deslizamento característico superior a $6 \mathrm{~mm}$.

Os conectores flexíveis, quando submetidos a um carregamento crescente, têm como característica o aumento da deformação mesmo após atingir a resistência máxima, sem que haja ruptura. Os conectores rígidos, por sua vez, apresentam dificuldade na redistribuição dos esforços, culminando em uma ruptura frágil.

\section{4}

\section{Estrutura da tese}

Esta tese foi organizada em oito capítulos, sendo este primeiro uma introdução do assunto abordado e uma apresentação da motivação e dos objetivos deste estudo.

No capítulo 2, é apresentada uma revisão bibliográfica de publicações sobre vigas mistas de pequena altura e conectores de cisalhamento, assim como investigações experimentais.

O capítulo 3 apresenta uma revisão teórica para avaliação do comportamento e resistência do sistema de piso misto estudado nesta tese. Os procedimentos de projeto foram determinados com base em normas que tratam de sistemas de pisos mistos semelhantes.

No capítulo 4, é apresentado o programa experimental dos ensaios de flexão de vigas mistas e de cisalhamento direto (Push-out). Os ensaios foram 
realizados no Laboratório de Estruturas e Materiais da Pontifícia Universidade Católica do Rio de Janeiro (LEM/PUC-Rio). Foram confeccionados três protótipos de vigas mistas em escala real e quatro protótipos de cisalhamento direto. O capítulo apresenta a configuração dos modelos, o modo de confecção dos protótipos e os procedimentos de ensaio e instrumentação.

Na sequência, o capítulo 5 expõe os resultados experimentais dos protótipos descritos no capítulo 4. Foram realizados ensaios de cisalhamento direto e de flexão. O objetivo principal era prover informações sobre o comportamento à flexão sob carga cíclica e estática, o mecanismo de ruptura, a resistência ao cisalhamento longitudinal, a influência das armaduras transversais e a contribuição da aderência na ligação mista.

O capítulo 6 descreve uma análise não-linear em Elementos Finitos (EF) utilizando o software de simulação ABAQUS. O objetivo dessas simulações numéricas era recalcular os resultados dos ensaios com precisão suficiente, utilizando um conjunto de parâmetros consistente.

No capítulo 7, é apresentada a comparação entre os resultados do modelo analítico do capítulo 3 e os valores experimentais do capítulo 5 .

O capítulo 8 expõe as considerações finais, as conclusões e as recomendações para trabalhos futuros. 


\section{2}

\section{Revisão Bibliográfica}

Esta seção apresenta uma revisão de publicações sobre vigas mistas de pequena altura, conectores de cisalhamento e investigações experimentais. São abordados os sistemas de piso misto utilizados comercialmente e trabalhos experimentais desenvolvidos recentemente sobre ensaios de flexão e cisalhamento direto.

\section{1}

\section{Sistemas de Vigamentos Mistos de Pequena Altura}

Ao contrário dos pisos mistos convencionais nos quais a altura total do piso é a soma das alturas do perfil e da laje, os pisos mistos de pequena altura, conhecidos como slim floor, apresentam a viga de aço embutida na laje de concreto. O sistema foi criado para eliminar o rebaixo da viga em relação ao nível da laje, reduzindo consideravelmente a altura do piso.

Esse sistema de piso misto surgiu em meados da década de 70, quando pesquisadores do Swedish Institute of Steel Construction desenvolveram um perfil de aço denominado Hat Beam ou viga-caixa. O segredo foi criar mesas inferiores mais largas que as superiores em uma configuração que possibilitou apoiar a laje diretamente na aba inferior do perfil (ver Fig. 2.1).

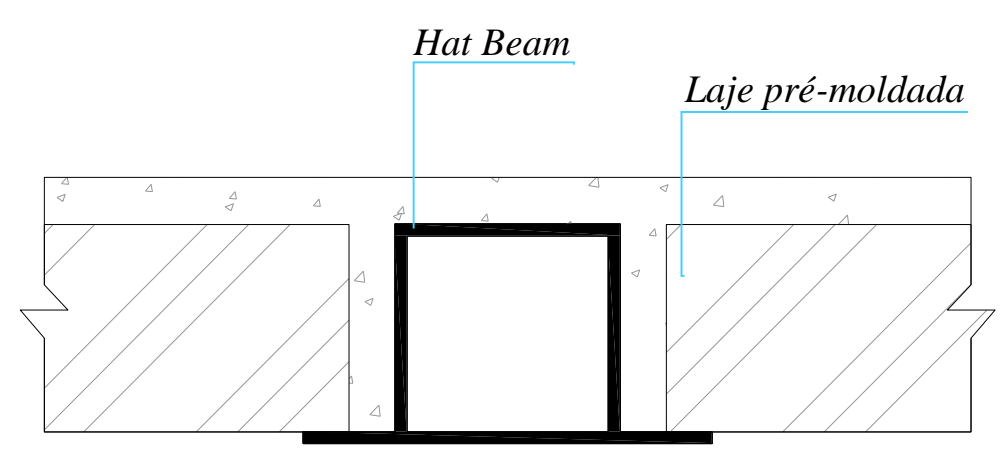

Figura 2.1: Hat Beam Lawson et al. [37] 


\subsection{1}

\section{Slimdek type systems}

O Slimdek® type systems (Fig. 2.2(a)) é um sistema de piso misto de pequena altura comercializado pela empresa britânica Tata Steel. Esse sistema utiliza um perfil laminado assimétrico denominado Asymmetric Slimflor ${ }^{\circledR}$ Beam (ASB). Sua principal característica é a mesa inferior mais larga e mais espessa, possibilitando o apoio da laje de concreto. O vão efetivo é de 5 m a 9 $\mathrm{m}$, com uma altura de 310 a $340 \mathrm{~mm}$.

O sistema Slimdek® utiliza somente a aderência entre o aço e o concreto para resistir aos esforços de cisalhamento horizontal. O perfil apresenta corrugações na mesa superior, aumentando o contato entre o aço e o concreto. O projeto de ASB com lajes alveolares pré-moldadas foi estudado, gerando as diretrizes de projeto que foram propostas para dois tipos de estruturas: com e sem a cobertura de concreto [38].

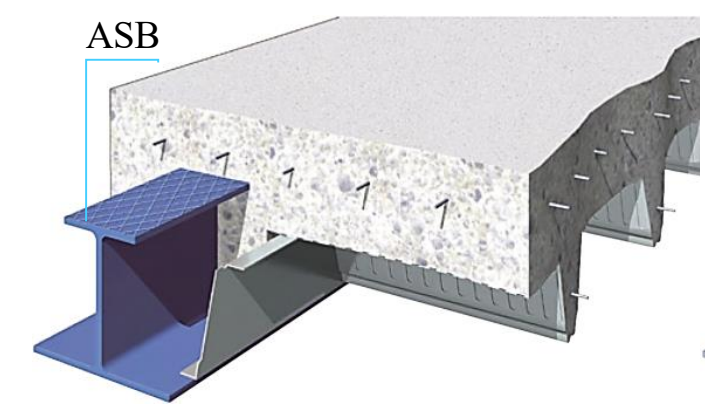

(a)

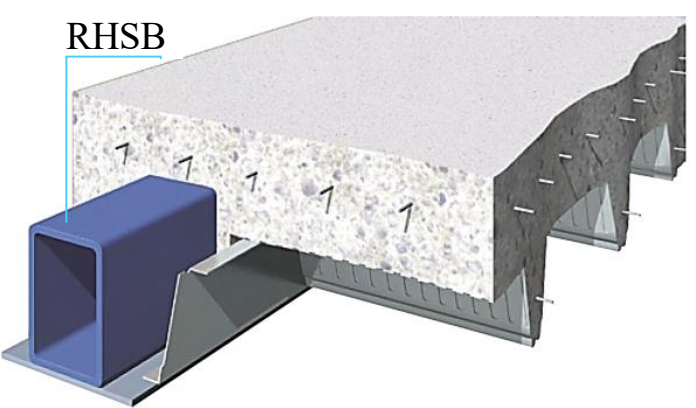

(b)

Figura 2.2: Slimdekß type systems (a) Asymmetric Slimflor B Beam (b) Rectangular Hollow Slimflor Beams

Há extensos estudos experimentais utilizando ASB de $280 \mathrm{~mm}$ e 300 mm de altura e vão de 7,5 m [39]. Mullett [40] realizou um ensaio em escala real do sistema de piso misto utilizando o perfil ASB, obtendo resultados de transferência do cisalhamento horizontal ocorrida por meio da aderência entre o aço e o concreto. O momento fletor máximo atingido foi de $925 \mathrm{kN} . \mathrm{m}$, sendo 1,68 vezes maior do que a resistência do perfil sozinho.

Wang et al. [41] realizaram uma investigação experimental do comportamento de duas vigas mistas de pequena altura submetidas a flexão. O vão dos dois protótipos foi de $6 \mathrm{~m}$ com altura de $290 \mathrm{~mm}$. A ligação por aderência entre o perfil e a laje de concreto foi suficiente para permitir que a viga mista atingisse a capacidade resistente a flexão. 


\subsection{2}

\section{Composite Slim Floor Beam (CoSFB)}

Assim como a empresa Tata Steel, o grupo ArcelorMittal lançou um sistema de piso misto denominado Composite Slim Floor Beam (CoSFB). O sistema é constituído por lajes mistas ou pré-fabricadas apoiadas sobre a mesa inferior do perfil de aço, chamado Integrated Floor Beam (IFB) (ver Fig. 2.3). Além da aderência, o sistema CoSFB utiliza armaduras transversais atravessadas na alma para resistir aos esforços de cisalhamento horizontal. O sistema permite alcançar vãos de até $12 \mathrm{~m}$.
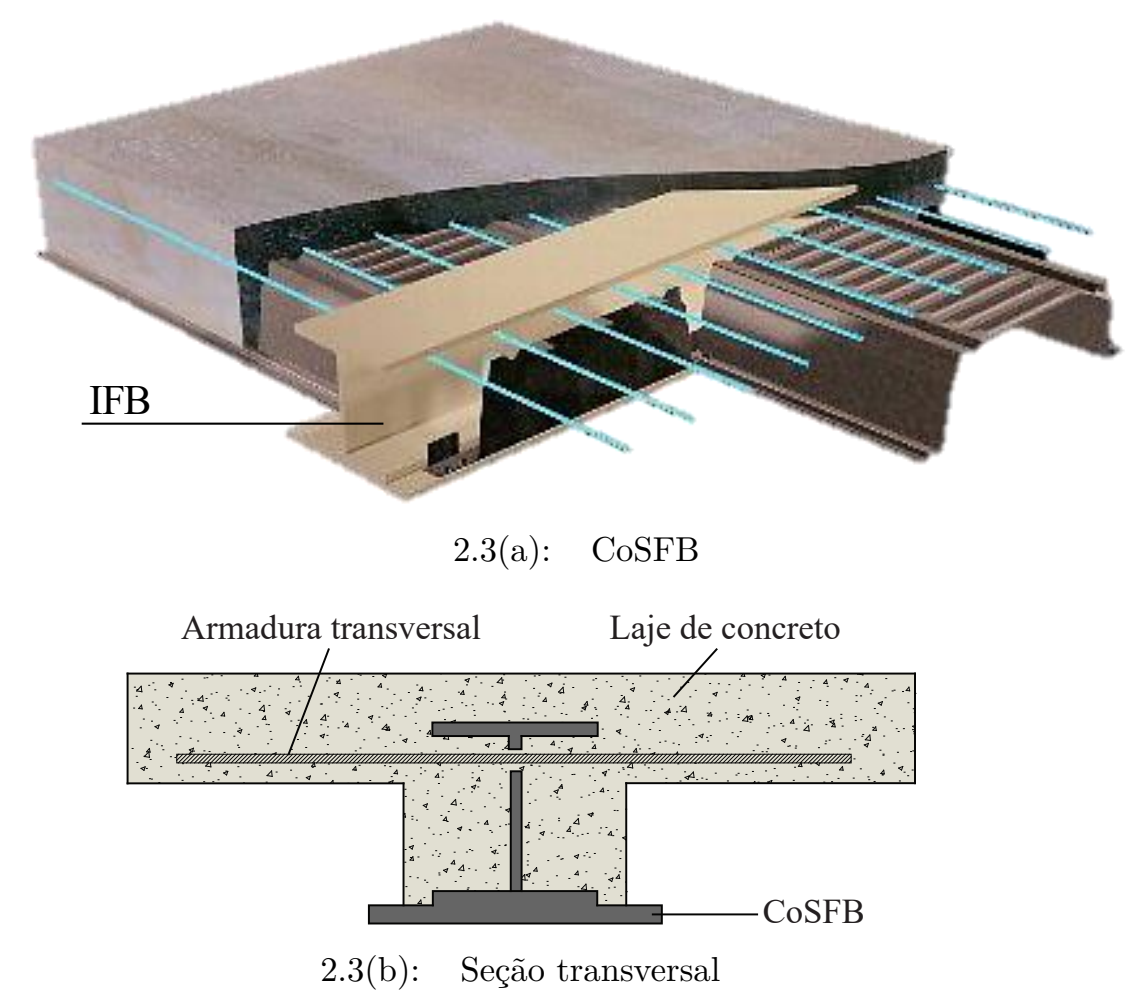

Figura 2.3: Composite Slim Floor Beam [11]

Um dos primeiros estudos sobre CoSFB abrangeu uma investigação empírica do comportamento global dessas vigas com interação total ou parcial (i.e. concreto passando por todas as aberturas ou apenas por algumas delas, respectivamente) [42]. Outro programa experimental foi realizado com a intenção de investigar a capacidade de carga das aberturas preenchidas por concreto [43]. Nesses ensaios, o foco foi dado ao efeito pino do concreto e sua resistência a compressão. Os resultados provaram que o uso do concreto nas aberturas aumenta consideravelmente a capacidade de carga da viga mista.

Para simular o comportamento da ligação aço-concreto nos CoSFBs, foi desenvolvido um estudo de análise em EF [44], cujo modelo validado provou que as aberturas preenchidas por concreto demonstram comportamento dúctil e alta rigidez sob cargas de serviço ao atingir a resistência de carga. $\mathrm{O}$ 
estado limite de serviço para esse tipo de viga mista também foi examinado, demonstrando um desempenho adequado em termos de vibrações.

Braun et al. [11] realizaram ensaios em escala real de 4 protótipos de CoSFB submetidos a flexão, além de 27 ensaios de cisalhamento direto (push$o u t$ ). Os principais parâmetros investigados foram o diâmetro da armadura, o diâmetro do furo e a resistência do concreto. Segundo os autores, os resultados apresentados mostram que o uso dessa conexão de cisalhamento aumenta significativamente a capacidade de carga da viga mista.

Klaiber e Wipf [45] estudaram o comportamento desse tipo de ligação alternativa para vigas mistas de pontes. Onze séries de ensaios de cisalhamentos diretos foram realizados, totalizando 36 protótipos, além do ensaio de cinco modelos de vigas mistas. As variáveis investigadas incluíam diâmetro do furo, espaçamento do furo, alinhamento do furo, adição de armadura através do furo e diâmetro da armadura. Os resultados mostraram que a resistência da ligação foi influenciada pela aderência entre o perfil e o concreto, pela área do furo, pela quantidade de armadura transversal, pelo número de furos e pela resistência a compressão do concreto. As lajes mistas, por sua vez, atingiram sua capacidade máxima sem nenhum problema na ligação.

He et al. [46] propuseram um modelo analítico para prever a capacidade resistente desse tipo de ligação, utilizando ensaios de cisalhamento direto para validar a equação desenvolvida. A equação era composta por três parcelas: a resistência devido à aderência na interface, o efeito pino do concreto no furo e a resistência da armadura transversal passando pelo furo. Os resultados apresentaram um coeficiente de correlação de Pearson de 0,99 entre os valores experimentais e analíticos.

$$
V_{u}=\tau_{b} A_{b}+1.06 A_{c} f_{c u}+2.09 A_{s 1} f_{y}
$$

$\mathrm{Na}$ equação acima, $\tau_{b}$ é a tensão de contato entre o perfil e a laje de concreto, $A_{b}$ é a área de contato na interface aço-concreto, $A_{c}$ é a área da seção transversal do pino de concreto, $f_{c u}$ é a resistência a compressão do concreto, $A_{s 1}$ é a área da seção transversal da armadura e $f_{y}$ é a tensão de escoamento do aço.

\subsection{3 \\ Deltabeam ${ }^{\circledR}$}

Outro tipo inovador de sistemas de piso misto de pequena altura são as vigas Deltabeam $(B$, registradas pelo grupo Peikko. O sistema é constituído por perfil formado a partir de placas de aço soldadas em formato "delta", com base alargada para apoio da laje (ver Fig. 2.4). A conexão de cisalhamento é 
criada pelo concreto que passa pelas aberturas de alma, as quais são espaçadas regularmente ao longo da viga.

O conjunto é finalizado com preenchimento de concreto in loco, resultando em vigas que podem ser utilizadas com diversos tipos de lajes, como lajes alveolares pré-moldadas, steel decks e outros tipos de lajes mistas. A viga Deltabeam® está disponível em uma variedade de alturas que variam de 200 $\mathrm{mm}$ a $500 \mathrm{~mm}$. De acordo com o fabricante, a viga pode atingir um vão de $13,5 \mathrm{~m}$ com uma altura de $500 \mathrm{~mm}$ [47].

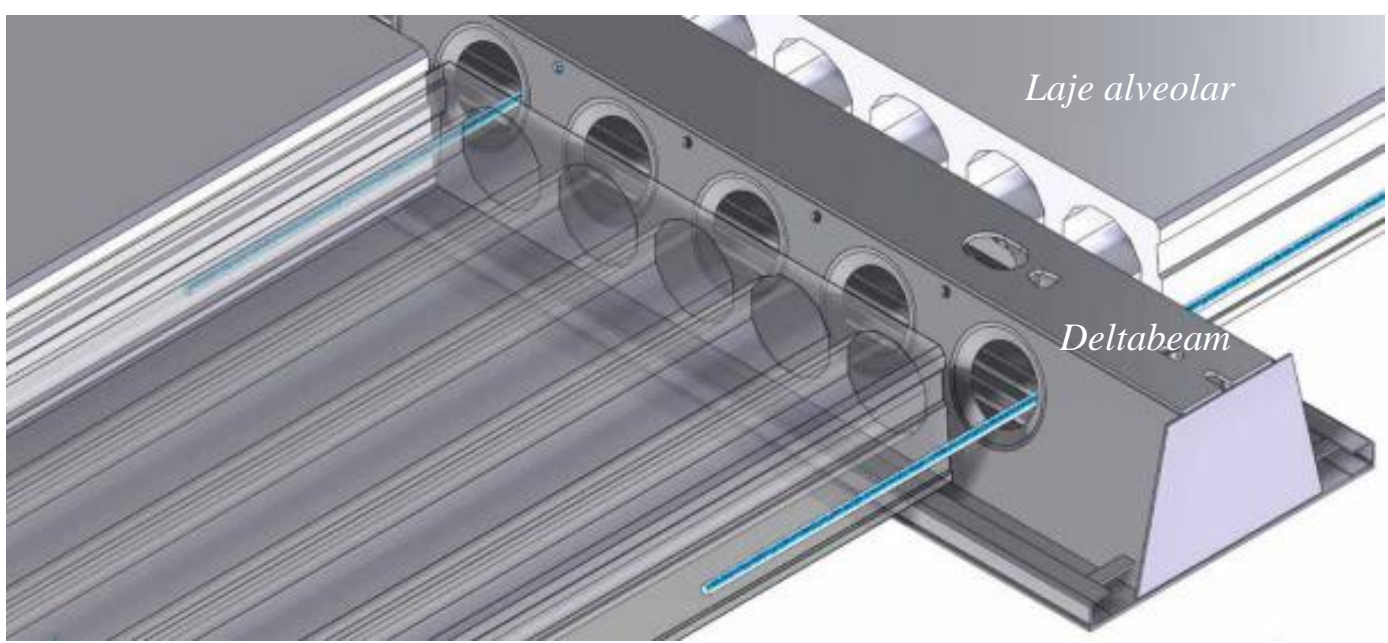

Figura 2.4: Deltabeam® $[48]$

As vigas Deltabeam(B têm sido utilizadas em construção de edifícios desde 1989. Peltonen e Leskela [48] realizaram uma avaliação dos resultados de 74 ensaios de cisalhamento direto utilizando vários perfis Deltabeam® com diferentes aberturas circulares. Os autores concluíram que a ligação atingiu elevada resistência mesmo com aberturas de pequeno diâmetro. Além disso, eles enfatizaram que a principal diferença entre esse tipo de conexão e o conector perfobond são os tamanhos das aberturas e, ao comparar os resultados, o perfobond apresentou maior rigidez efetiva. Uma modificação também foi

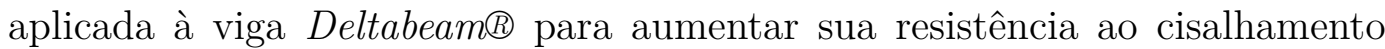
vertical usando conectores stud bolts, fazendo com que, assim, fosse aproveitada a resistência a tração do conector quando esse está embutido no concreto [49].

Posteriormente, estudos examinaram o comportamento à flexão das Deltabeams submetidas a carregamento de longa duração. Os resultados demonstraram uma resposta estrutural benéfica para as vigas devidamente reforçadas, a qual pode ser implementada pelos projetistas não apenas para condições construtivas normais, mas também para casos extremos, como colapso progressivo e cargas acidentais [50]. A resistência ao fogo e o desempenho em vibração da 
viga também foram analisados, apresentando resultados de $60 \mathrm{~min}$ e $>3 \mathrm{~Hz}$, respectivamente $[51,52]$.

\subsection{4}

\section{Slimline}

Slimline $B^{\circledR}$ é um produto criado pela empresa Slimline Buildings B.V. que consiste em um sistema misto pré-fabricado integrado às instalações prediais. O sistema é baseado em vigas alveolares feitas a partir de perfis laminados, parcialmente embutidos na laje de concreto. A conexão entre o aço e o concreto é realizada por vergalhões soldados ao longo da alma do perfil. Essas vigas são utilizadas invertidas, com o concreto na região inferior. O subpiso é formado por placas de borracha e aço apoiadas sobre a mesa das vigas metálicas (ver Fig. 2.5).

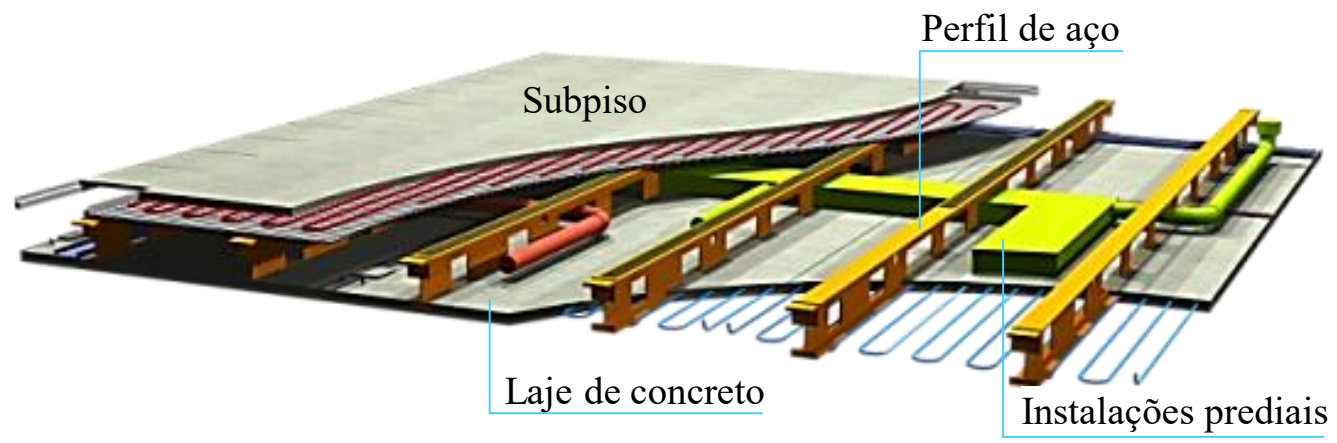

Figura 2.5: Slimline $[5]$

Mensinger et al. [5] realizaram o ensaio de dois protótipos de vigas mistas tipo slimline, sendo um ensaio feito com a laje de concreto para cima e o outro, com os lados invertidos. Para ambos os testes, a armadura soldada à viga de aço foi capaz de garantir interação total entre a viga de aço e a laje de concreto. Para a viga mista com a laje de concreto na parte inferior, observou-se um comportamento não linear devido à fissuração da laje de concreto.

\subsection{5}

\section{iTECH composite beam}

O sistema de piso misto iTECH (Innovative, Technical, Economical and Convenient Hybrid) foi desenvolvido por um grupo coreano em 2002. A viga mista é formada por um perfil I assimétrico com aberturas de alma e uma calha sem função estrutural fixada na mesa inferior para apoiar o steel deck durante a fase de construção (ver Fig. 2.6). Ambos os lados da alma e a laje são preenchidos com concreto in loco. A resistência ao cisalhamento ocorre 
pela aderência entre o perfil e a laje e pelo preenchimento das aberturas pelo concreto.

A contribuição de cada componente da ligação aço-concreto foi experimentalmente investigada, gerando uma proposta de metodologia para o cálculo da capacidade resistente [53].

$$
F_{n}=F_{s b}+F_{b b}=\tau_{b} l_{o} \frac{L}{2}+n f_{b b} A_{b}
$$

$\mathrm{Na}$ equação acima, $\tau_{b}$ é a tensão de contato entre o perfil e a laje de concreto $(0,6 \mathrm{MPa}), l_{o}$ é o comprimento da interface aço-concreto (perímetro da mesa superior + ambos os lados da alma), $L$ é o vão da viga, $n$ é o número de aberturas, $f_{b b}$ é a resistência devido ao contato entre o concreto e a alma do perfil na região de abertura $\left(2 x 0,85 f_{c k}\right)$ e $A_{b}$ é a área de contato entre o concreto e a alma do perfil na região de abertura.

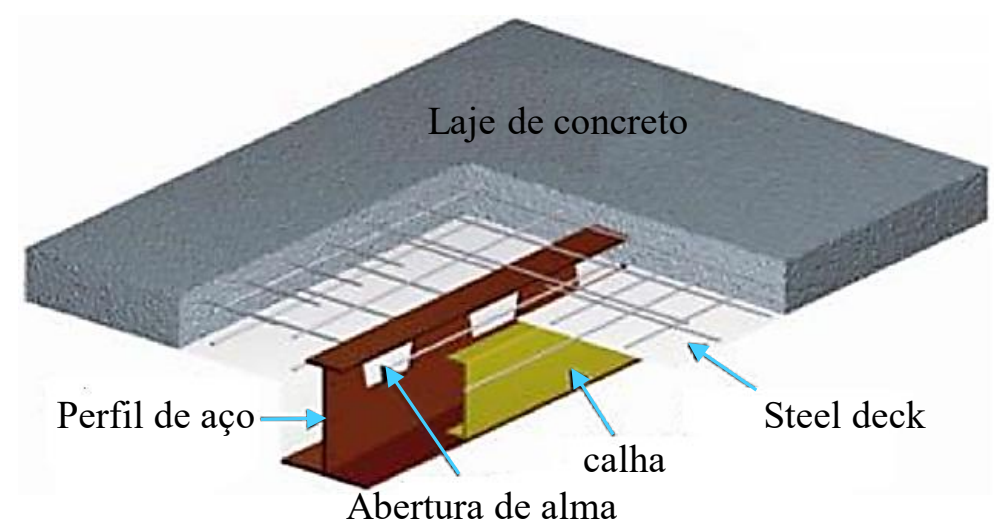

Figura 2.6: iTECH composite beam [6]

A viga mista pode atingir de $7,5 \mathrm{~m}$ a $15 \mathrm{~m}$ de vão, com altura de 300 mm incluindo as tubulações de serviço. Ju et al. [6] realizaram o ensaio de três protótipos submetidos a flexão, sendo eles o ensaio de uma viga mista iTECH utilizando protótipo em escala real, um ensaio com o sistema CoSFB para comparação e um ensaio do perfil de aço para avaliar a resistência sob cargas de construção. O comportamento do CoSFB foi semelhante ao do iTECH, e os resultados demonstraram que a resistência última a flexão do modelo experimental excedeu o valor teórico. O modelo apresentou interação total entre o aço e o concreto até o início do escoamento do perfil e, no ensaio do perfil, ocorreu flambagem da mesa superior na região de abertura.

Foram realizados, também, ensaios cíclicos da ligação viga-coluna utilizando o sistema iTECH [7], nos quais a ligação apresentou boa ductilidade e demonstrou capacidade de resistência ao momento fletor. Como a altura do sistema iTECH é menor do que os sistemas de piso misto de pequena altura já 
apresentados, suas características de vibração foram testadas em cada estágio de construção (estágio de montagem, concretagem e acabamento) [54].

\subsection{6}

\section{Ultra-Shallow Floor Beams (USFB)}

Outro tipo de sistema de piso misto de pequena altura é o UltraShallow Floor Beam (USFB), desenvolvido pela empresa britânica Westok. O piso consiste em um perfil assimétrico com aberturas de alma espaçadas regularmente, com a laje de concreto incorporada entre as mesas superior e inferior. O perfil é formado por duas seções "T"assimétricas soldadas à alma, cujas aberturas são preenchidas com concreto quando o piso é concretado.

A força de cisalhamento longitudinal é transferida pelo concreto que passa por algumas ou todas aberturas da alma, dependendo da configuração do deck de metal (baixo ou alto). A ligação é semelhante à conexão de cisalhamento usada nas vigas iTECH e Deltabeam (ver Fig. 2.7). Recomenda-se utilizar armaduras transversais dentro das aberturas para melhorar a continuidade das lajes de cada lado do perfil. Esse tipo de ligação aumenta a resistência ao cisalhamento longitudinal e vertical, bem como a resistência ao fogo [55].

A viga USFB recebeu propostas para os principais parâmetros de projeto e mecanismos de transferência de força [4]. A análise plástica foi adotada para avaliar a capacidade resistente a flexão, estando os procedimentos de projeto descritos de acordo com o Eurocode 4.

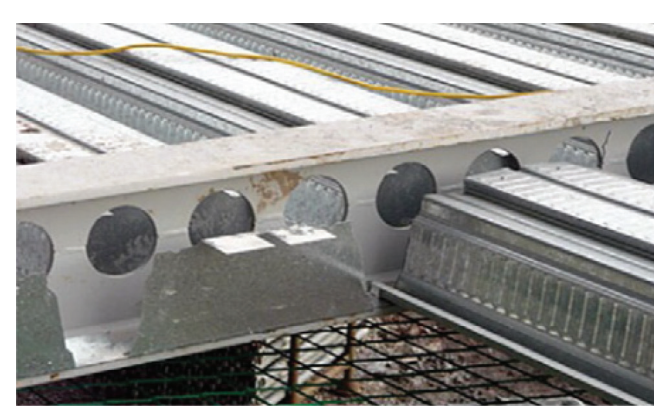

2.7(a): USFB

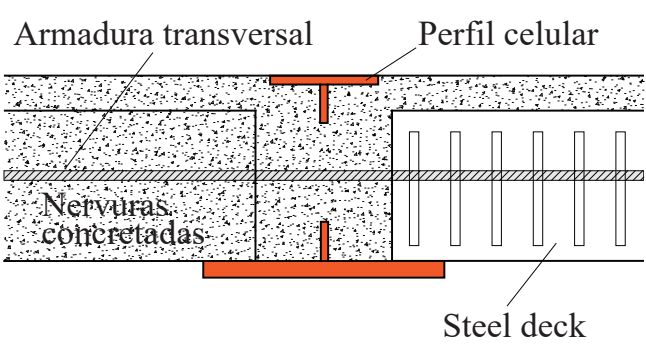

2.7(b): Seção transversal

Figura 2.7: Shallow cellular floor beams [56]

As vigas USFB têm vão acima de $10 \mathrm{~m}$ com altura de $300 \mathrm{~mm}$, de forma que alcançam vãos maiores com alturas menores se comparadas a outras vigas mistas (iTECH e Deltabeam). Ensaios demonstraram que os dutos podem substituir a armadura transversal sem perda de integridade estrutural, contanto que os dutos não estejam localizados próximos a áreas de altas forças de cisalhamento vertical [57]. A contribuição do concreto entre as mesas da seção de aço da USFB para resistir às forças de cisalhamento verticais 
foi amplamente investigada $[57,58]$. Os resultados revelaram um aumento significativo na resistência ao cisalhamento dos USFBs em comparação a vigas de aço sem concreto.

Outro aspecto interessante é o comportamento à flexão de USFBs parcialmente embutidas. Vários ensaios foram conduzidos para determinar a resistência a flexão da viga mista e a resistência longitudinal ao cisalhamento dos "plugues" não reforçados e reforçados, usando armaduras e concreto, dutos ou conectores stud bolt soldados transversalmente à alma [59].

Huo e D’Mello [60] ensaiaram 24 protótipos tipo push-out, com variáveis que incluíam o diâmetro das aberturas de alma, a resistência do concreto, o diâmetro da armadura e a presença de stud bolt. Os testes de cisalhamento direto mostraram que a resistência ao cisalhamento da conexão aumentou com o a elevação do diâmetro de abertura de alma e com a resistência do concreto. Os elementos adicionais, isto é, armaduras transversais ou conectores stud bolt, aumentaram significativamente a resistência ao cisalhamento, a capacidade de deslizamento e a ductilidade da ligação. Além disso, dois tipos de concreto (concreto normal e reforçado com fibras sintéticas) foram usados para as lajes de concreto.

Os ensaios de cisalhamento direto examinaram a relação entre a resistência do concreto e a conexão de cisalhamento [61]. Nesse ponto, o estudo poderia ser aprimorado com o aumento da resistência a tração do concreto normal, bem como do aspecto de sustentabilidade com o uso de fibras de aço, fibras plásticas e resíduos de fios de aço [62].

Posteriormente, foi realizado o ensaio de uma viga mista em escala real [56], formando as ligações com armaduras transversais e concreto preenchendo as aberturas. O ensaio de flexão mostrou que a ligação aço-concreto foi suficiente para resistir ao cisalhamento longitudinal. O ensaio não atingiu a ruptura, ocorrendo somente a plastificação da seção transversal.

Chen et al. [63] fizeram um estudo experimental do comportamento à flexão de 4 protótipos de USFB. A ligação entre o aço e o concreto ocorreu com preenchimento de concreto e adição de armaduras transversais na região da abertura. Três variáveis foram consideradas: forma da seção transversal do perfil, abertura de alma e espessura da laje de concreto acima da viga de aço. Os resultados demonstraram que os protótipos romperam por flexão com esmagamento do concreto, não ocorrendo ruptura na interação aço-concreto.

Um programa detalhado de análise em Elementos Finitos foi realizado para investigar o mecanismo de transferência de força, a capacidade de carga e o modo de ruptura das ligações simulando os ensaios de cisalhamento direto [64]. Foram confirmados os modos de falha da conexão de cisalhamento, 
assim como foi observado que, se projetado adequadamente, esse tipo de conexão é efetivamente capaz de fornecer a resistência ao cisalhamento e o comportamento dúctil desejados.

Com o objetivo de aumentar o vão do sistema USFB e torná-lo mais leve e menor, deve-se satisfazer o estado limite de serviço e, em particular, os critérios de vibração. Modelos experimentais e numéricos foram analisados com foco nas frequências fundamentais a fim de entender a probabilidade de ressonância dos USFBs [65-67], demostrando que o aumento da extensão da laje reduziu as frequências naturais. Observou-se também que a espessura da laje afetou significativamente as frequências naturais, o que foi consistente com todos os estudos computacionais, independentemente das condições de apoio, vãos e técnicas de modelagem [66].

\section{2}

\section{Conectores de Cisalhamento}

A ligação entre a laje de concreto e a viga de aço depende do fluxo de cisalhamento longitudinal que é gerado na interface entre os dois materiais. Em vigas mistas, o cisalhamento é transferido por meio de uma pequena quantidade de pontos representados pelos conectores de cisalhamento. Uma variedade de dispositivos e configurações tem sido utilizada como conectores de cisalhamento, e diversos aspectos econômicos e técnicos continuam a motivar o desenvolvimento de novos produtos.

\subsection{1}

\section{Conector Stud Bolt}

O stud bolt é o conector de cisalhamento mais difundido atualmente. Esse conector, tipo pino com cabeça, foi desenvolvido na década de 40 pela Nelson Stud Welding (Fig. 2.8).

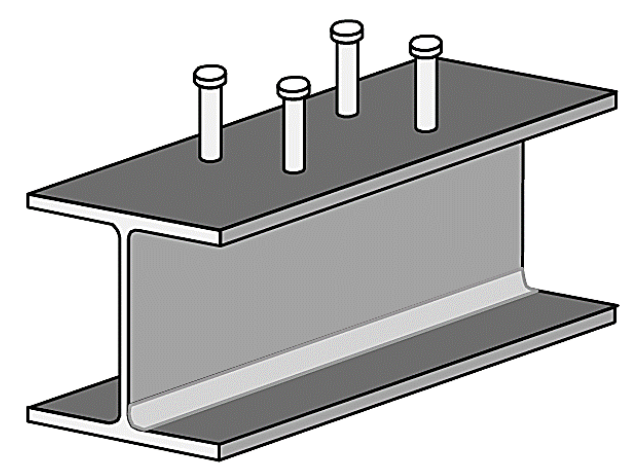

Figura 2.8: conector stud bolt [68] 
Utilizado principalmente em sistemas de piso de edifícios, ele proporciona alta produtividade e facilidade na aplicação. Em pisos mistos convencionais, o stud bolt é soldado na mesa superior do perfil (Fig. 2.9(a)), mas também pode ser utilizado em pisos mistos de pequena altura. Nesse caso, os conectores de cisalhamento são fixados nas mesas (Fig. 2.9(b) e (c)) ou na alma do perfil (Fig. 2.9(d)).

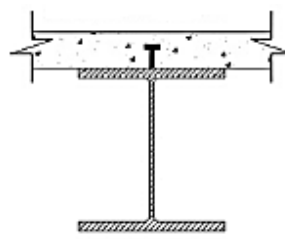

(a)

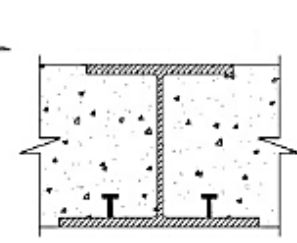

(b)

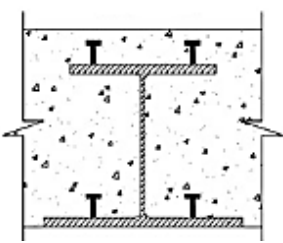

(c)

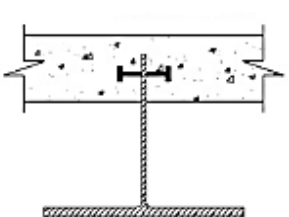

(d)

Figura 2.9: Posicionamento do conector stud bolt nas vigas mistas [8]

Nardil e El Debs [8,9] estudaram posições alternativas para os conectores stud bolt, realizando, para isso, o ensaio experimental de três protótipos de vigas mistas parcialmente revestidas. A resistência ao cisalhamento foi obtida por stud bolts soldados em duas posições: verticalmente na mesa inferior (Fig. 2.9(b)) e horizontalmente soldado nas faces da alma (Fig. 2.9(d)). O terceiro modelo, por sua vez, foi confeccionado sem conector. Os resultados experimentais mostraram que os conectores fornecem interação aço-concreto e aumentam a resistência a flexão. Em relação aos conectores soldados na mesa inferior, os resultados indicaram que essa é a configuração mais eficaz dos ensaios com conectores.

\subsection{2}

\section{Conector Perfobond}

O conector Perfobond foi inicialmente concebido como uma alternativa ao baixo desempenho que os studs bolts têm sob fadiga. Desenvolvido por Leonhardt et. al. [69] para aplicação em pontes, esse conector consiste basicamente em uma chapa de aço plana com furos circulares. O Perfobond é soldado à mesa superior do perfil metálico e depois é concretado juntamente com a laje (Fig. 2.10).

Esse conector é de tipo rígido e sofre apenas deformações elásticas em estado de serviço. O concreto que flui através dos furos forma pinos virtuais dentro da peça, com dois planos de corte. O desempenho estrutural da ligação pode ser melhorado com a adição de armadura transversal passando pelos furos. 


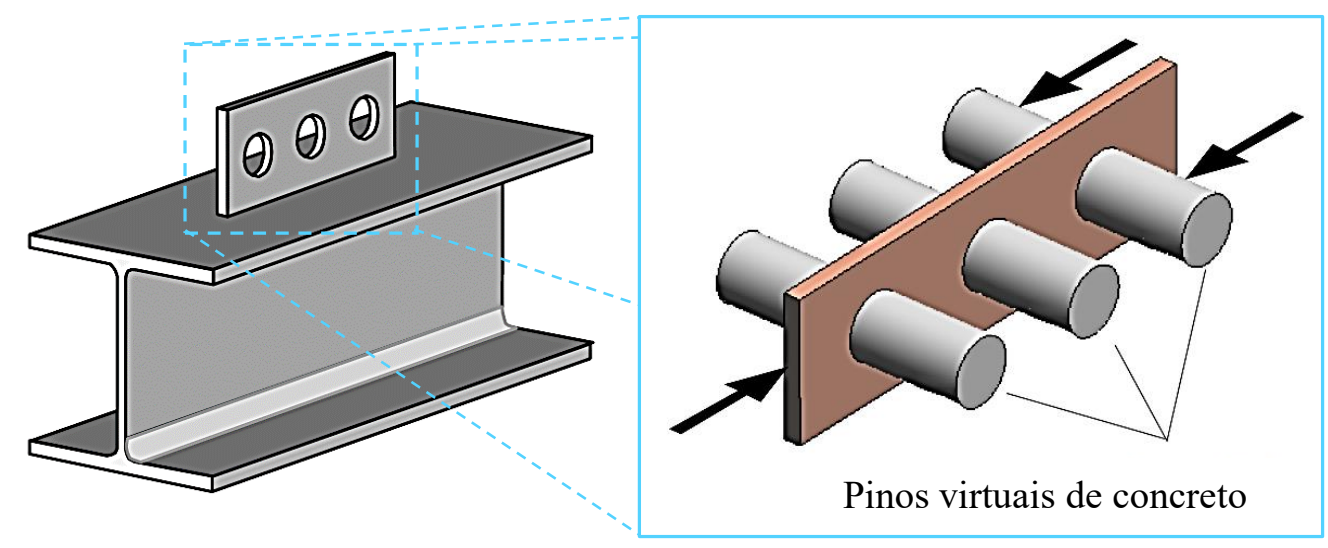

Figura 2.10: Conector Perfobond [68]

Como mostrado na Fig. 2.10, o comportamento mecânico do Perfobond é afetado pela resistência ao cisalhamento do concreto confinado dentro dos furos do conector (cisalhamento horizontal e vertical), pela resistência ao cisalhamento das barras transversais e pela resistência da região sob compressão do concreto em frente ao conector. Em virtude de sua pequena magnitude, a parcela da resistência produzida pela aderência química não é levada em consideração.

Viana et al. [21] realizaram o ensaio de cisalhamento direto com 16 protótipos, investigando os seguintes parâmetros: números de furos nos conectores, presença de armadura transversal nos furos dos conectores e espessura da laje. De acordo com os resultados, a laje de menor espessura obteve maior resistência e melhor capacidade de deslizamento em decorrência do acréscimo de furos e armaduras transversais. Por outro lado, para as lajes mais espessas, a variação no número de furos e a quantidade de armadura não resultaram em mudanças significativas no comportamento da ligação.Também foram realizados ensaios com conectores T-Perfobond [16], os resultados mostraram um aumento na capacidade resistente da ligação em comparação com o conector Perfobond, por outro lado os conectores apresentaram comportamento rígido.

Uma variação do conector Perfobond é o conector Crestbond [68]. Seu objetivo é proporcionar uma boa rigidez em situação de serviço e maior ductilidade em relação ao conector Perfobond.

Como apresentado na Fig. 2.11(b), a geometria do conector é no formato de uma chapa dentada, sendo os lados dos dentes inclinados para confinar o concreto no seu interior e impedir o uplift (1). Em função dessa geometria, a base do dente é menor (2), o que diminui a rigidez longitudinal do conector e contribui para a ductilidade da conexão. A região sob compressão do concreto 
em frente ao conector (3) também contribui para a resistência ao cisalhamento longitudinal.

Ensaios experimentais [68] mostraram que o conector Crestbond, em comparação ao Perfobond, tem a vantagem dos furos abertos (que facilitam a disposição das barras de armadura) e deslizamento característico médio superior a $6,0 \mathrm{~mm}$, podendo ser classificado como um conector dúctil de acordo com o EUROCODE 4 [36].

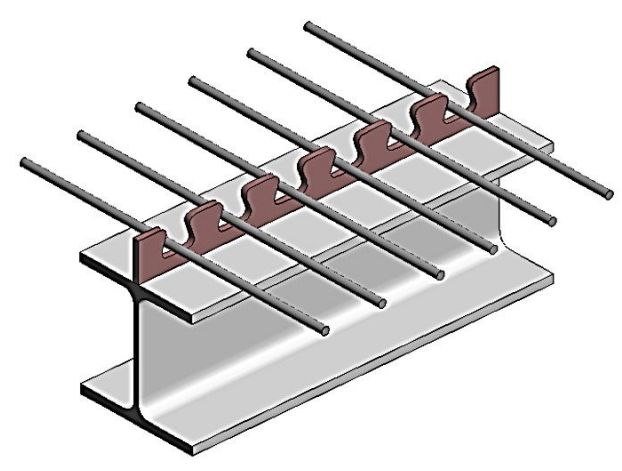

(a)

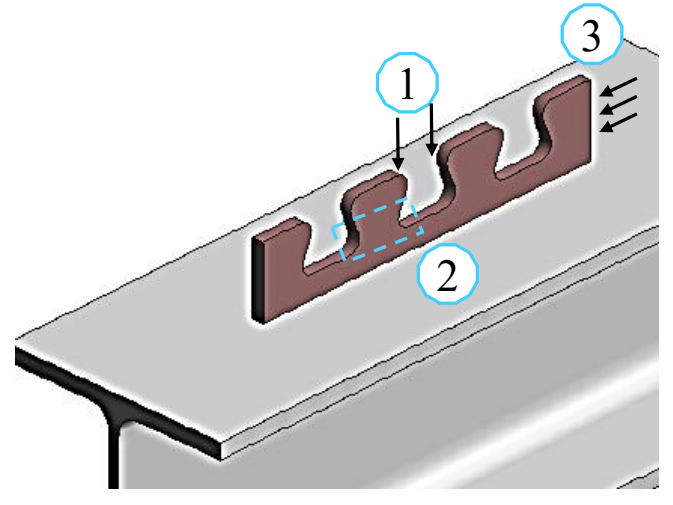

(b)

Figura 2.11: (a) Conector Crestbond com armaduras transversais (b) sistema de transmissão de forças pelo conector Crestbond [68]

Conectores semelhantes ao Crestbond são utilizados em vigas mistas de pequena altura. Os perfis são cortados na alma, criando a dentição (ver Fig. 2.12). Esses conectores são denominados concrete dowels [70], e foram objeto de vários estudos realizados para avaliar seu comportamento [71-79].

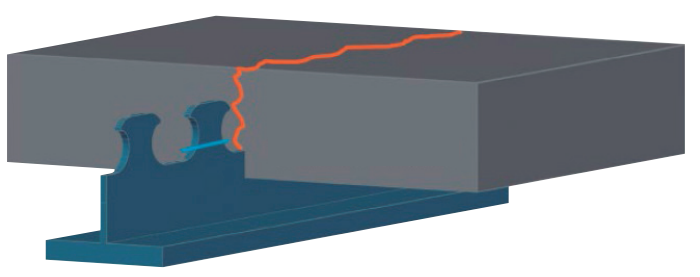

Figura 2.12: Conector Concrete dowels [71]

Jurkiewiez et al. [79] analisaram o comportamento estático de vigas mistas de aço-concreto com conectores de cisalhamento formados a partir da alma do perfil. A conexão entre o perfil e o concreto era feita por armaduras transversais que transpassavam a alma do perfil. Os resultados experimentais mostraram um comportamento similar a vigas mistas de aço-concreto com 
conectores clássicos: domínios elásticos e de escoamento, grande ductilidade, modo de ruptura por flexão (rótula plástica) e baixo deslizamento na interface aço-concreto.

Lorenc et al. [74] ensaiaram 19 protótipos tipo push-out utilizando o conector Concrete dowels. Realizou-se a análise da influência da espessura da alma, do tamanho do conector e do grau do aço. Os testes comprovaram a hipótese de que o tamanho dos conectores não tem influência na capacidade de carga da ligação. Além disso, descobriu-se que a ductilidade é uma função linear do inverso do tamanho dos conectores.

\subsection{3}

\section{Conector linear por aderência}

Os conectores lineares foram criados no final da década de 80 e receberam o nome de ligação por aderência aço-concreto, sendo esse termo uma referência a uma ligação por contato entre interfaces. A resistência desse conector é associada ao cisalhamento existente entre a laje pré-fabricada de concreto e a viga de aço. Esse tipo de ligação foi proposto inicialmente por Dauner [80] e posteriormente estudado por Thomann [81] e Papastergiou [82]. Um exemplo de ligação por aderência é ilustrado na Fig. 2.13.

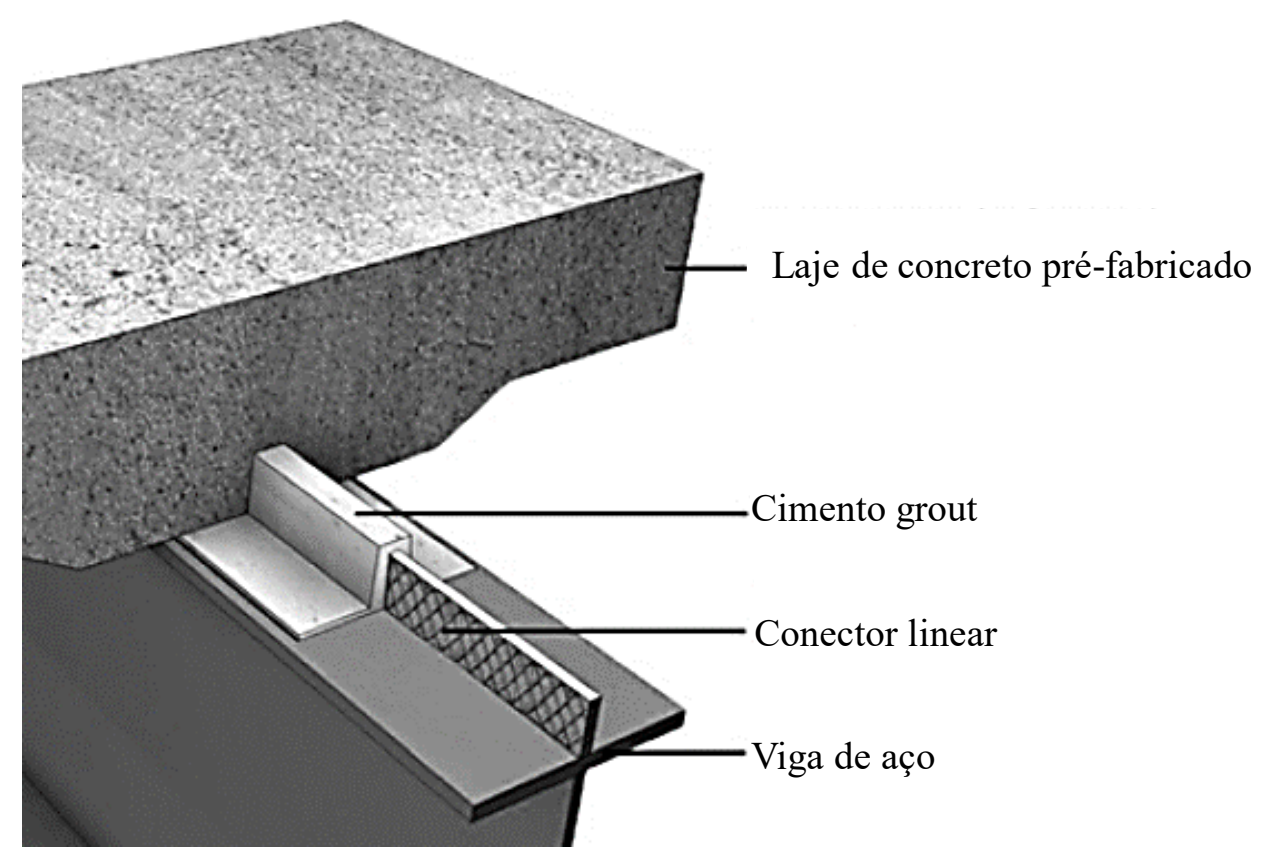

Figura 2.13: Conector linear [82]

A aderência ocorre entre a superfície da laje de concreto pré-fabricado em contato com o conector linear e com a mesa superior da viga metálica. A laje 
de concreto possui um sulco longitudinal (nervura) de encaixe sobre o conector linear de superfície rugosa. Sobre a mesa superior e conector, aplica-se uma camada adesiva para aumentar o coeficiente de atrito e, consequentemente, a resistência da ligação.

Segundo Thomann [81], tensões normais externas podem atuar nas interfaces do conector, aumentando a resistência ao cisalhamento da ligação. Essas ações externas podem estar associadas, por exemplo, à protensão ou à flexão transversal da laje. Ensaios experimentais mostraram que as ligações por aderência apresentam elevada resistência última, além de apontarem os conectores como rígidos e demonstrarem que eles levam a uma ruptura frágil $[81,83]$.

\section{3}

\section{Trabalhos desenvolvidos na PUC-Rio}

O grupo de pesquisa em estruturas mistas de aço-concreto da PUC-Rio vem desenvolvendo trabalhos na área desde 1990. Diversas pesquisas foram realizadas sobre sistemas de pisos mistos [84-92], conectores de cisalhamento [16, 21,93-95] - principalmente o conector perfobond - e ligações semirrígidas mistas [96-100].

Dentre esses trabalhos, os estudos com o sistema de pisos mistos préfabricado (SPMP) com perfil alveolar iniciaram-se em 2015 [92]. Na presente pesquisa, foi desenvolvida uma análise experimental de duas vigas mistas " $\mathrm{T}$ ", com protótipos compostos por perfil celular parcialmente embutido na laje de concreto. A laje de concreto tinha $1200 \mathrm{~mm}$ de largura efetiva, $80 \mathrm{~mm}$ de espessura e vão de $6 \mathrm{~m}$ (ver Fig. 2.14).

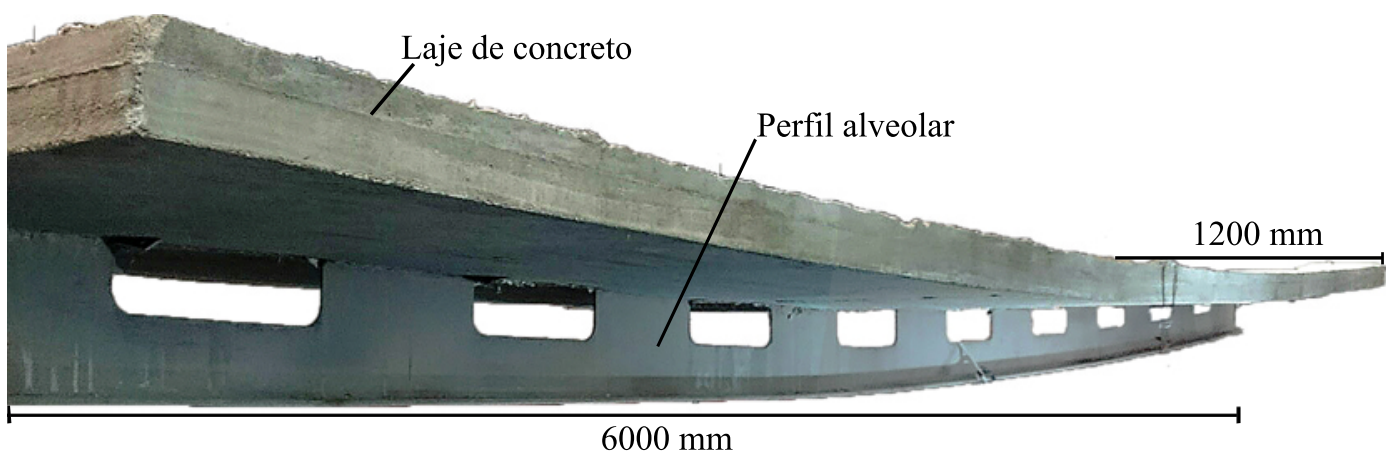

Figura 2.14: Viga mista com perfil alveolar [92]

Os ensaios das vigas mistas demonstraram satisfatoriamente um comportamento misto e resistência ao cisalhamento longitudinal. Os valores obtidos por meio do modelo teórico, considerando-se a resistência plástica da seção, 
mostraram-se satisfatórios para uma análise preliminar do comportamento geral do sistema misto. O ensaio da viga mista atingiu $97 \%$ do momento resistente esperado pelo modelo analítico, mas não foi identificado um modo de ruína global.

\section{4}

\section{Resumo sistemas de piso misto de pequena altura}

A Tabela 2.1 apresenta um resumo dos sistemas de pisos mistos de pequena altura com suas principais características.

Tabela 2.1: Resumo sistemas de piso misto de pequena altura

\begin{tabular}{llll}
\hline Sistema & Ligação mista & $\begin{array}{l}\text { Vão máximo } \\
(m)\end{array}$ & Referências \\
\hline Slimdeck & Aderência & 9,0 & {$[38-41]$} \\
CoSFB & Aderência + Armadura & 12,0 & {$[11,42-46]$} \\
Deltabeam & Aderência + Abertura + Armadura & 13,5 & {$[47-52]$} \\
Slimline & Aderência + Abertura + Armadura & 17,2 & {$[5]$} \\
iTECH & Aderência + Abertura + Armadura & 15,0 & {$[6,7,53,54]$} \\
USFB & Aderência + Abertura + Armadura & 12,0 & {$[4,55-67]$} \\
SPMP & Aderência + Abertura + Armadura & 10,0 & {$[92]$} \\
$\overleftarrow{\Xi}$ & & &
\end{tabular}




\section{3 \\ Comportamento de vigas mistas com mesa de compressão embutida}

O sistema de piso misto consiste em vigas mistas pré-fabricadas com formato duplo T. As vigas são produzidas em formas metálicas proporcionando rapidez na fabricação e um ótimo acabamento de superfície. Após a montagem, elas devem ser recobertas por um capeamento de concreto armado para solidarizar o conjunto, sem necessidade de escoramento para a concretagem. As nervuras longitudinais do duplo $\mathrm{T}$ são constituídas por vigas alveolares assimétricas, com mesa de compressão embutida na laje de concreto (ver Fig. 3.1).

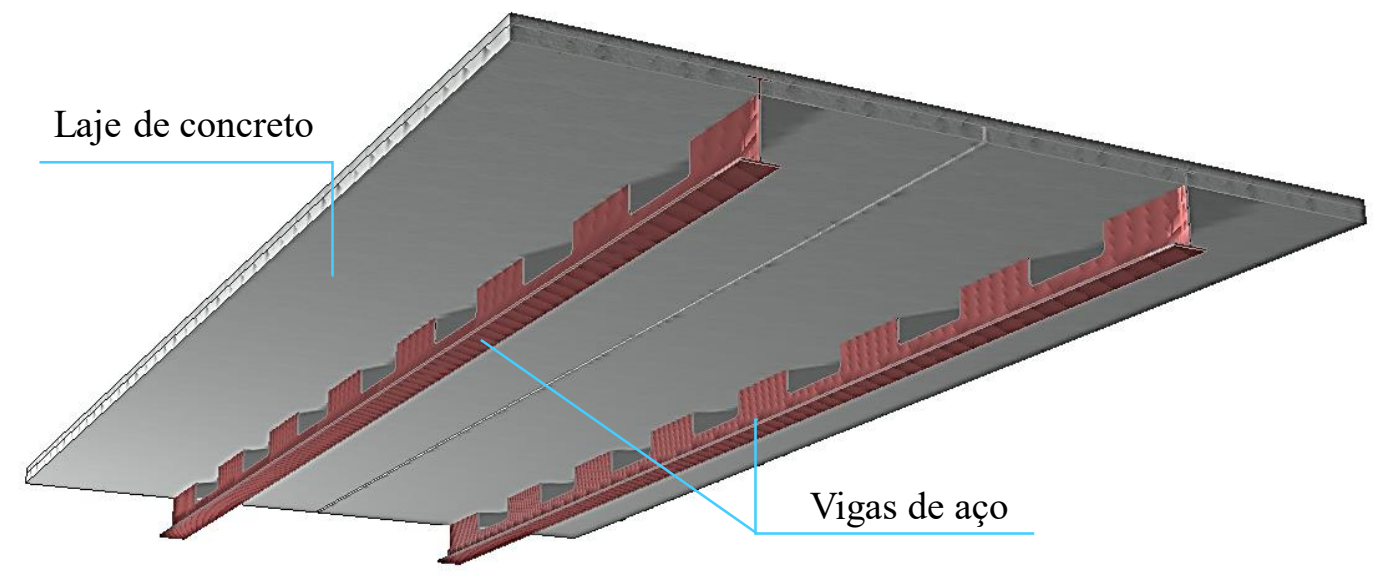

Figura 3.1: Sistema de vigamentos mistos com perfil alveolar parcialmente embutido

As vigas de aço são produzidas a partir de um perfil I laminado. Esse perfil é cortado longitudinalmente na alma, criando espaços regularmente intervalados. Para cada parte, é adicionada uma barra chata soldada no topo da alma.

Para a estrutura, considera-se que o concreto trabalha solidário ao aço por meios mecânicos, por atrito ou simples aderência, permitindo aproveitar o melhor das características de cada material. São utilizadas armaduras para controle da fissuração do concreto e armaduras transversais transpassando o perfil (Fig. 3.2). Aberturas na alma podem ser usadas para passar dutos 
Capítulo 3. Comportamento de vigas mistas com mesa de compressão embutida

e tubulações através de vigas e, assim, reduzir os custos operacionais e de manutenção, bem como os custos de construção. Por outro lado, as aberturas podem reduzir significativamente a capacidade de cisalhamento e flexão das vigas mistas.

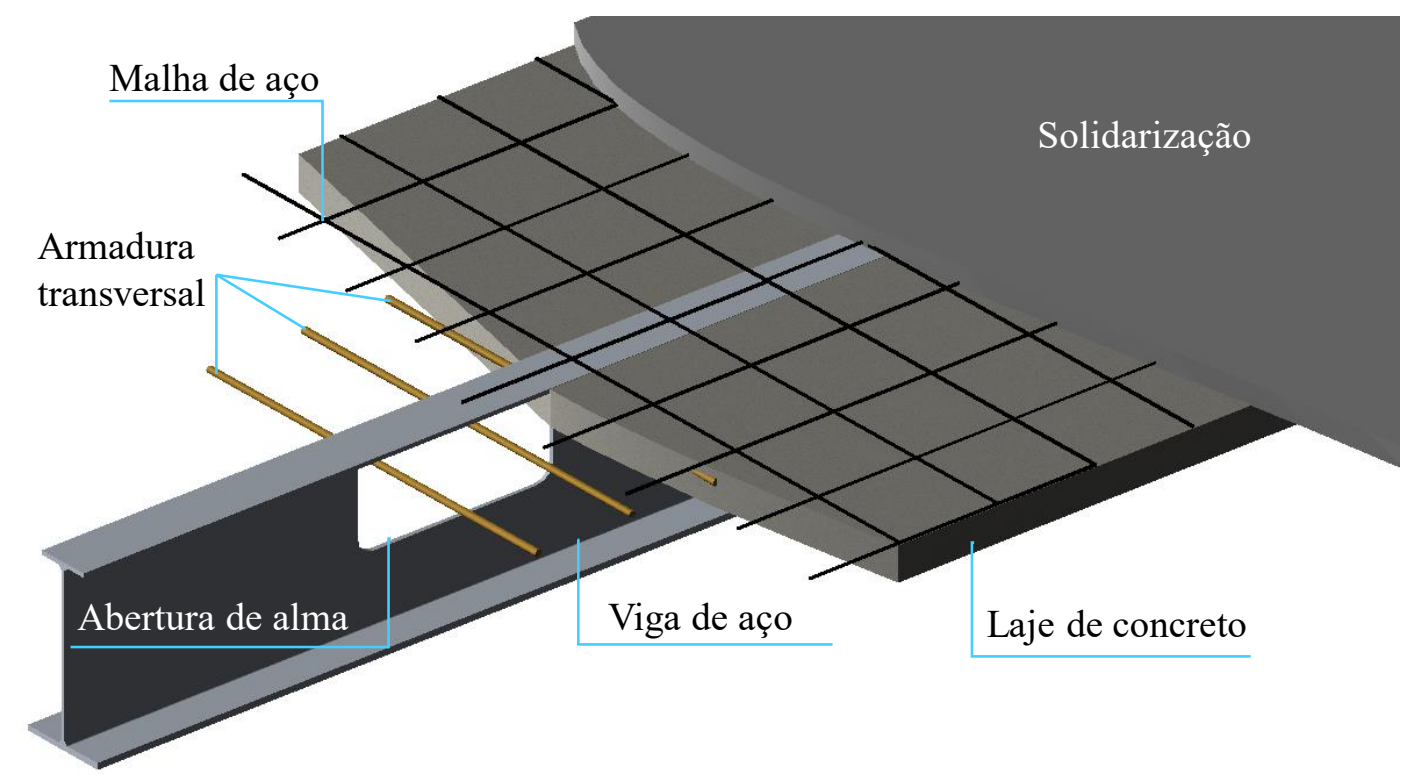

Figura 3.2: Detalhamento dos componentes da viga mista

O projeto de pré-fabricação exige, desde o início, conceitos como racionalização, modulação e repetição dos elementos construtivos e um alto grau de detalhamento. Apesar de cada produto ter uma finalidade bem específica, as peças podem assumir mais de uma função na edificação, desde que isso esteja previsto no projeto. Elas podem ser usadas como entrepisos, coberturas e fechamentos laterais em obras comerciais, industriais, depósitos etc.

\section{1}

\section{Procedimentos de Projeto}

Em projetos que utilizam o sistema de piso misto pré-fabricado, é possível empregar duas configurações de construção fundamentais: vigas secundárias ou vigas continuas (ver Fig. 3.3). Em ambos os casos, considera-se uma interação total entre a laje de concreto e a viga de aço.

Utilizando as vigas mistas como secundárias, esses elementos são simplesmente apoiados em vigas principais (ver Fig. 3.4(a)), sendo posicionadas lado a lado para formar o piso. O conjunto é solidarizado por meio de um capeamento de concreto armado em todo o piso, chamado de solidarização. Dê um modo geral, as vigas mistas são produzidas com largura máxima de 2400mm para facilidade de transporte e içamento. 
Capítulo 3. Comportamento de vigas mistas com mesa de compressão embutida

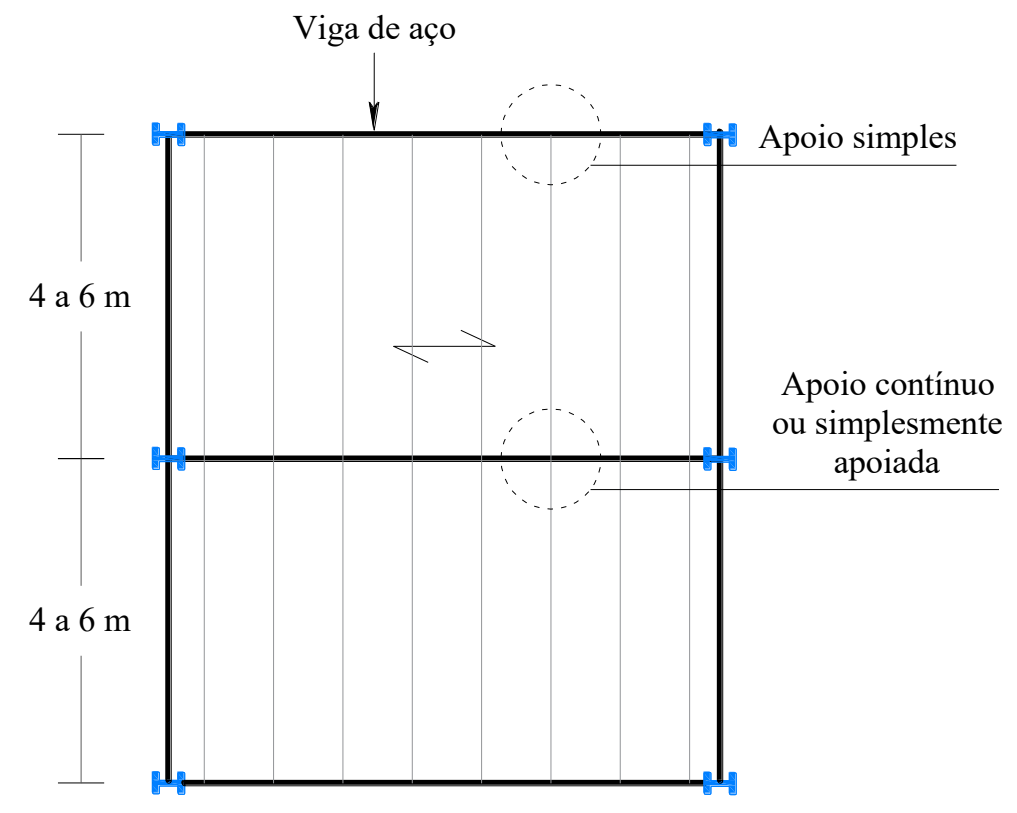

Figura 3.3: Layout do sistema de piso misto

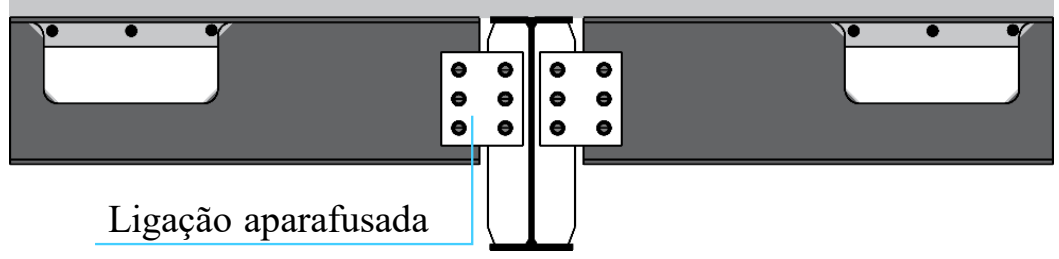

(a)

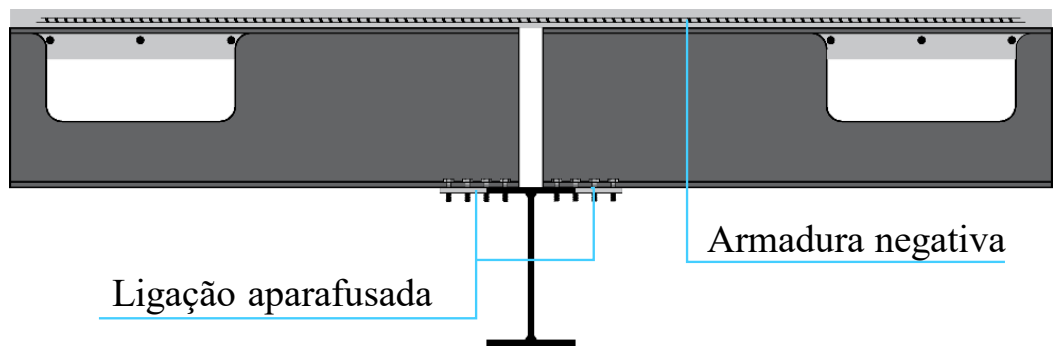

(b)

Figura 3.4: (a) viga mista simplesmente apoiada (b) continuidade na ligação entre vigas mistas

O segundo caso refere-se às vigas mistas com continuidade sob um apoio intermediário. A ligação é realizada com armaduras negativas na pré-laje de concreto e ligação aparafusada entre a mesa inferior da viga mista e a mesa superior da viga de aço (ver Fig. 3.4(b)). 


\subsection{1}

\section{Situação de projeto}

As vigas mistas podem ser submetidas a três situações de carregamento: a primeira diz respeito ao manuseio da viga, que é içada e transportada da fábrica ao local da construção; a segunda refere-se à fase de construção com as vigas posicionadas e devidamente aparafusadas, porém sem a capa de concreto ou sem continuidade sobre os apoios; por fim, a terceira é constituída pela situação normal, quando a laje está totalmente concretada e o piso é submetido não somente ao peso próprio, mas também às cargas impostas. Nos dois primeiros casos, sem capa de concreto, a viga mista deverá ser verificada para o estadolimite da flambagem local da mesa (FLM).

\section{2}

\section{Projeto estrutural}

Devido à presença de um significante número de aberturas de alma na viga mista, esses elementos não podem ser tratados como vigas de alma cheia. A presença da abertura de alma introduz outros modos de ruína não presentes em elementos de alma cheia [101]. Os seguintes estados limites devem ser verificados para as vigas mistas parcialmente embutidas com abertura de alma:

1. Resistência a flexão;

2. Resistência ao cisalhamento vertical;

3. Interação força axial - momento fletor no tê inferior;

4. Interação cisalhamento - momento fletor na abertura de alma;

5. Flambagem da alma entre aberturas;

6. Resistência ao cisalhamento horizontal.

\section{3}

\section{Resistência a flexão}

A capacidade última à flexão das vigas mistas é calculada em regime plástico. A resistência a flexão depende do nível de interação entre o aço e o concreto, da resistência a compressão da laje de concreto e do escoamento do perfil de aço. O modelo de cálculo foi baseado nas recomendações da norma CAN/CAS-S16-10 [102].

No dimensionamento da viga mista submetida ao momento fletor, a seguinte condição deve ser atendida: 


$$
M_{S d} \leq M_{R d}
$$

em que $M_{S d}$ é o momento fletor solicitante de cálculo e $M_{R d}$ é o momento fletor resistente de cálculo.

\subsection{1}

\section{Momento fletor resistente de cálculo}

O cálculo do momento fletor resistente de cálculo, $M_{R d}$, é realizado na seção com abertura no perfil, desprezando a resistência a tração do concreto. Três equações são apresentadas, sendo cada uma dependente da localização da linha neutra plástica (LNP) na seção mista. No primeiro caso (Fig. 3.5), a LNP encontrar-se-á no concreto acima do perfil caso satisfaça a condição:

$$
\phi A_{s b} f_{y}<0.85 \phi_{c} b_{c} t_{c} f_{c k}
$$

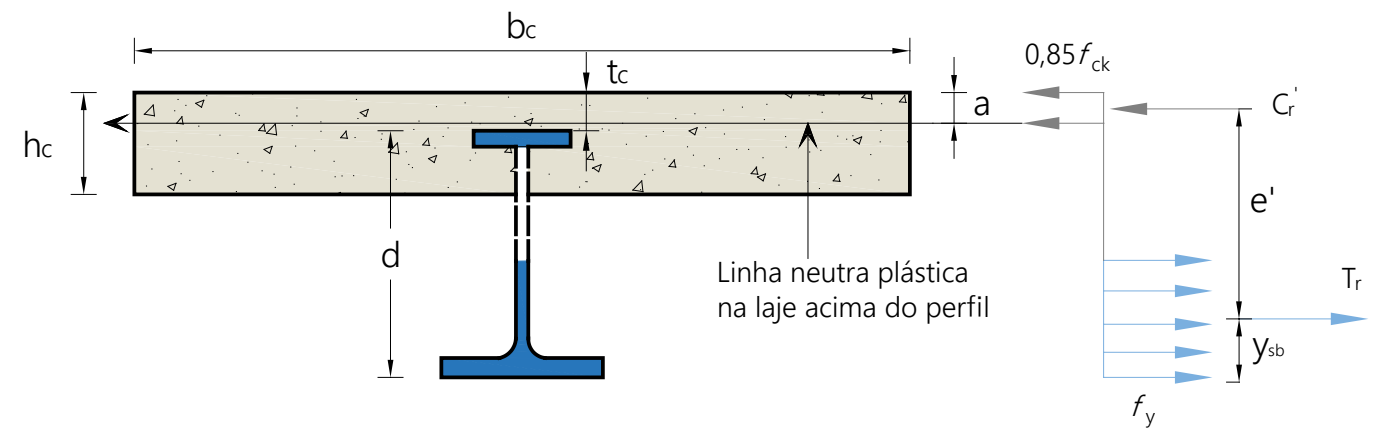

Figura 3.5: Distribuição das tensões plásticas na viga mista com a linha neutra posicionada na laje acima do perfil

A capacidade à flexão da viga mista pode ser estimada pela Eq.:

$$
M_{R d}=e^{\prime} \phi A_{s b} f_{y} .
$$

Quando a linha neutra se encontra sobre o perfil, surgem duas possibilidades: LNP na mesa e LNP na alma. Em ambos os casos, a área de concreto comprimida também aumenta, e a resistência da seção continua sendo governada pelo escoamento do aço em tração. A força fatorada de compressão no concreto acima do perfil é calculada de acordo com a Eq.:

$$
C_{r}^{\prime}=0.85 \phi_{c} b_{c} t_{c} f_{c k} .
$$

A resistência a compressão no aço e na região de concreto adjacente é dada pela Eq.:

$$
C_{r}=\frac{\phi A_{s b} f_{y}-C_{r}^{\prime}}{2}
$$


No segundo caso (Fig. 3.6), a LNP encontrar-se-á na mesa de aço caso satisfaça a condição:

$$
C_{r} \leq \phi b_{s} t_{s} f_{y}+0.85 \phi_{c}\left(b_{c}-b_{s}\right) f_{c k} t_{s}
$$

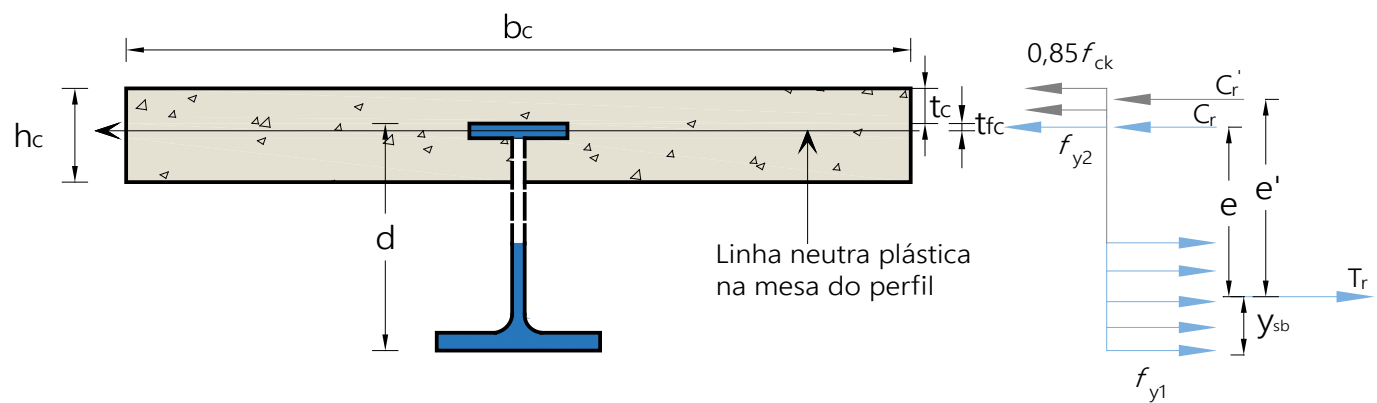

Figura 3.6: Distribuição das tensões plásticas na viga mista com a linha neutra posicionada na mesa superior do perfil

Para esse caso, a capacidade à flexão da viga mista pode ser estimada pela Eq.:

$$
M_{R d}=C_{r}^{\prime} e^{\prime}+C_{r} e .
$$

No terceiro caso (Fig. 3.7), a LNP encontrar-se-á no concreto abaixo da mesa de aço caso satisfaça a condição:

$$
C_{r} \geq \phi b_{s} t_{s} f_{y}+0.85 \phi_{c}\left(b_{c}-b_{s}\right) f_{c k} t_{s} .
$$

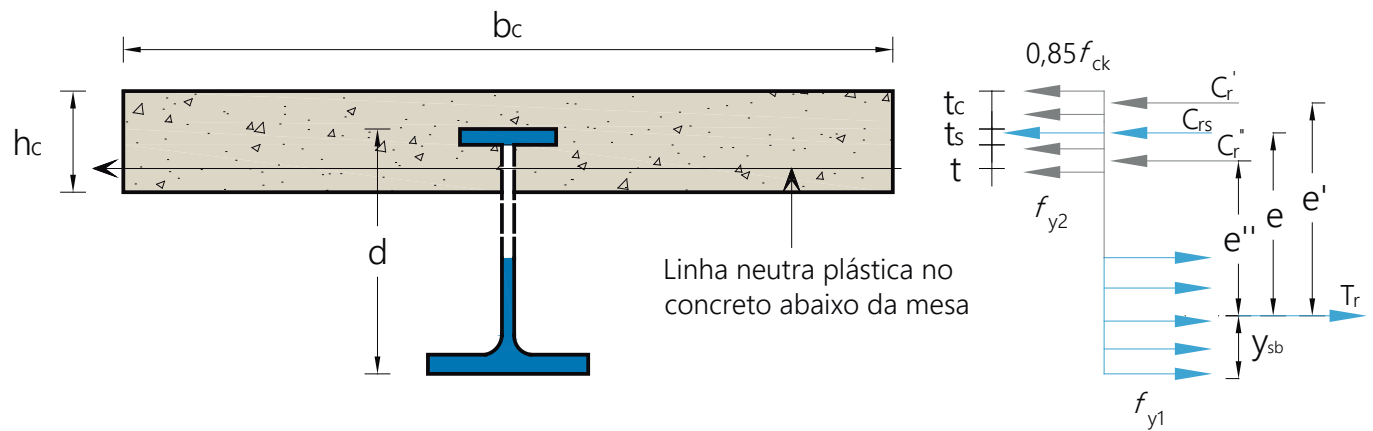

Figura 3.7: Distribuição das tensões plásticas na viga mista com a linha neutra posicionada na abertura de alma

A força de compressão na mesa superior e na região de concreto adjacente $\left(C_{r s}\right)$ é dada pela Eq. 3-9, ao passo que a força de compressão na região de concreto abaixo da mesa de aço $\left(C_{r}^{\prime \prime}\right)$ é dada pela Eq. 3-10: 
Capítulo 3. Comportamento de vigas mistas com mesa de compressão embutida

$$
\begin{gathered}
C_{r s}=\phi b_{s} t_{s} f_{y}+0.85 \phi_{c}\left(b_{c}-b_{s}\right) f_{c k} t_{s} . \\
C_{r}^{\prime \prime}=C_{r}-C_{r s} .
\end{gathered}
$$

A capacidade à flexão da viga mista no terceiro caso pode ser estimada por meio da Eq.:

$$
M_{R d}=C_{r}^{\prime} e^{\prime}+C_{r}^{\prime \prime} e^{\prime \prime}+C_{r s} e .
$$

\section{4}

\section{Resistência ao cisalhamento}

A resistência ao cisalhamento é calculada de acordo com as normas NBR 8800 (2008) [103] e NBR 6118 (2014) [104]. No dimensionamento da viga mista sem abertura de alma submetida a força cortante, a seguinte condição deve ser atendida:

$$
V_{S d} \leq V_{R d}
$$

em que $V_{S d}$ é a força cortante solicitante de cálculo e $V_{R d}$ é a força cortante resistente de cálculo.

A força cortante resistente de cálculo da viga mista corresponde à soma das resistências ao cisalhamento da laje de concreto, $V_{R d c}$, mais a do perfil, $V_{R d a}$ :

$$
V_{R d}=V_{R d c}+V_{R d a}
$$

\subsection{1}

\section{Resistência ao cisalhamento do perfil}

O elemento resistente à força cortante é a alma do perfil. O cálculo do valor da força cortante resistente de cálculo, $V_{R d a}$, da viga fletida considera os estados-limites últimos de escoamento e flambagem por cisalhamento, de acordo com a NBR 8800 (2008) [103].

$$
\begin{gathered}
\lambda \leq \lambda_{p}: V_{R d a}=\frac{V_{p l}}{\gamma_{a 1}} . \\
\lambda_{p}<\lambda \leq \lambda_{r}: V_{R d a}=\left(\frac{\lambda_{p}}{\lambda}\right)\left(\frac{V_{p l}}{\gamma_{a 1}}\right) . \\
\lambda>\lambda_{r}: V_{R d a}=1,24\left(\frac{\lambda_{p}}{\lambda}\right)^{2}\left(\frac{V_{p l}}{\gamma_{a 1}}\right) .
\end{gathered}
$$

em que $\gamma_{a 1}=1,10, \lambda=\frac{h}{t_{w}}, \lambda_{p}=1,1 \sqrt{\frac{k_{v} E}{f_{y}}}, \lambda_{r}=1,37 \sqrt{\frac{k_{v} E}{f_{y}}}, k_{v}=5$ para almas sem enrijecedores transversais.

A força cortante correspondente à plastificação da alma por cisalhamento é dada por: 
Capítulo 3. Comportamento de vigas mistas com mesa de compressão embutida

$$
V_{p l}=0,6 A_{w} f_{y}
$$

\subsection{2}

\section{Resistência ao cisalhamento da laje de concreto}

A força cortante resistente de cálculo da laje de concreto, $V_{R d c}$, calculada de acordo com a NBR 6118 (2014) [104], é dada por:

$$
V_{R d c}=\left(\tau_{R d} k\left(1,2+40 \rho_{1}\right)+0,15 \sigma_{c p}\right) b_{c} h_{c} .
$$

em que $\tau_{R d}=0,25 f_{c t d} ; f_{c t d}=f_{c t k, i n f} / \gamma_{c} ; f_{c t k, \text { inf }}=0,21 f_{c k}^{\frac{2}{3}} ; \gamma_{c}=1,4$; $\rho_{1}=A_{s 1} / b_{c} h_{c} \leq|0,02| ; \sigma_{c p}=N_{S d} / A_{c} ; k=\left|1,6-h_{c}\right| \geq|1|$ com $h_{c}$ em metros; $\tau_{R d}$ é a tensão resistente de cálculo do concreto ao cisalhamento; $A_{s 1}$ é a área da armadura de tração; $N_{S d}$ é a força longitudinal na seção devido a protensão ou carregamento (considera-se que a compressão tem sinal positivo).

\section{5}

\section{Abertura de alma}

O modelo teórico para avaliar a influência das aberturas de alma no comportamento da viga mista foi baseado no Design guide 31 [105]. Na seção com abertura de alma, deve ser feita a verificação da interação força axial momento fletor e cisalhamento - momento fletor.

\subsection{1}

\section{Interação cisalhamento - momento fletor}

$\mathrm{Na}$ maior parte das vigas, o momento fletor e o cisalhamento ocorrem simultaneamente. Em uma seção com abertura de alma, os dois esforços interagem, produzindo resistências menores do que em regiões submetidas ao cisalhamento ou momento fletor puro. Darwin e Donahey (1988) [106] observaram que a interação entre o momento e o cisalhamento poderia ser convenientemente representada por curva de interação cúbica para relacionar as resistências nominais de flexão e cisalhamento, $M_{n}$ e $V_{n}$, com os esforços máximos de momento fletor e cisalhamento, $M_{m}$ e $V_{m}$.

$$
\left(\frac{M_{n}}{M_{m}}\right)^{3}+\left(\frac{V_{n}}{V m}\right)^{3}=R^{3}, R=1 .
$$

\subsection{2}

Verificação do tê inferior submetido à ação combinada da força axial e do momento fletor

A interação dos esforços de flexão e força axial no tê inferior é limitada à flexão em torno de um eixo geométrico. A interação entre os dois esforços 
pode ser obtida por meio da seguinte inequação:

$$
\left(\frac{T_{s}}{T_{n}}\right)+\left(\frac{M_{v s}}{M n}\right) \leq 1
$$

em que $T_{s}$ é a força de tração solicitante; $T_{n}$ é a força de resistência a tração nominal; $M_{v s}$ é o momento fletor solicitante de Vierendeel e $M_{n}$ é a resistência nominal a flexão.

\subsubsection{1}

\section{Momento fletor solicitante de Vierendeel $\left(M_{v s}\right)$}

A flexão de Vierendeel é causada pela transferência da força de cisalhamento por meio das aberturas de alma, criando um momento fletor localizado no tê inferior. A ruptura por Vierendeel ocorre pela formação de rótulas plásticas nos cantos das aberturas, em regiões de grande cisalhamento. Nas vigas mistas, a força de cisalhamento resistida pela laje de concreto é primeiramente deduzida da força de cisalhamento aplicada, e a força de cisalhamento restante é resistida pelo tê inferior do perfil na região de abertura. Não deve-se presumir que as maiores forças internas ocorrem no meio do vão, e cada abertura ao longo da viga deve ser examinada para a interação cisalhamento e flexão.

A ação mista resulta em forças menores sobre o tê, produzindo uma condição de projeto mais favorável. Entretanto, nas aberturas próximas à extremidade da viga, a ação mista provém menos resistência. Isso ocorre devido à menor quantidade de conectores entre a extremidade e a abertura investigada, resultando em menos força suportada pelo concreto e mais força suportada pelo perfil.

O cálculo do momento fletor de Veriendeel é feito no tê inferior do perfil, na seção com abertura de alma. Em seções mistas, permite-se que a laje de concreto absorva parte da força de cisalhamento solicitante, $V_{s}$, diminuindo o momento fletor sobre o tê.

A força de cisalhamento sobre o tê é de:

$$
V_{s t}=V_{s}-V_{R d c}
$$

O momento fletor solicitante de Vierendeel é determinado de acordo com a Eq. 3-22:

$$
M_{v s}=V_{s t}\left(\frac{a_{1}}{2}\right)
$$

\subsubsection{2}

\section{Força de tração solicitante $\left(T_{s}\right)$}

Considera-se a existência de ação mista suficiente para que o concreto resista a toda força de compressão e o tê inferior, a toda força de tração. 
Capítulo 3. Comportamento de vigas mistas com mesa de compressão embutida

Dessa maneira, como mostrado na Fig. 3.8, $C_{s}=T_{s}$. O binário de forças tração/compressão é produzido pelo momento fletor solicitante, $M_{s}$, e, após essa suposição inicial, é necessário recalcular o $Y_{c}$, que é a espessura de concreto que resistirá ao momento global. Na interação dos cálculos, o termo $Y_{c}$ substitui $t_{c}$ nas equações.

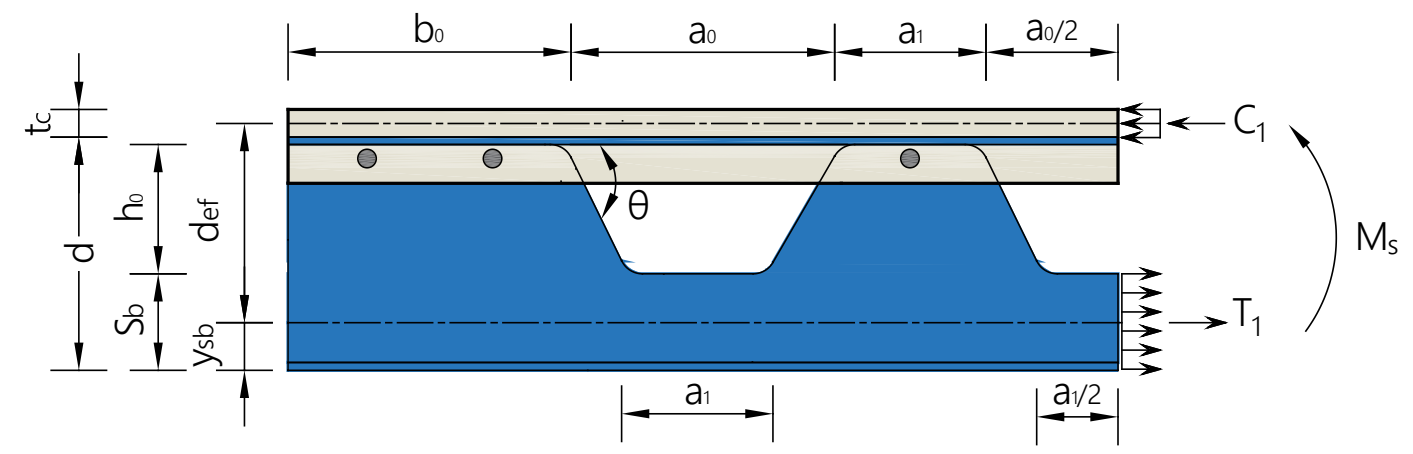

Figura 3.8: Terminologia utilizada para calcular forças axiais em vigas mistas

A altura efetiva da seção mista, $d_{e f}$, é:

$$
d_{e f}=d-y_{s b}+0,5 t_{c} .
$$

Para calcular a força axial no tê inferior, $T_{s}$, e a força axial no concreto, $C_{s}$, presumindo interação completa utiliza-se a seguinte equação:

$$
T_{s}=C_{s}=\frac{M_{s}}{d_{e f}} .
$$

Por outro lado, o cálculo da espessura do bloco de concreto que irá resistir ao momento global, $Y_{c}$, é dado por:

$$
Y_{c}=\frac{T_{s}}{0.85 f_{c k} b_{c}} .
$$

O termo $Y_{c}$ é similar ao "a", que representa a espessura do bloco de tensão no concreto, e é utilizado para substituir o termo $t_{c}$ no cálculo do $d_{e f}$ nas interações subsequentes. Esse processo deve ser refeito até que haja convergência.

\subsubsection{3}

\section{Resistência à força axial $\left(T_{n}\right)$ e ao momento fletor $\left(M_{n}\right)$ no tê inferior}

A resistência nominal do tê inferior deve ser verificada como um elemento submetido à ação combinada da tensão axial mais o momento fletor de Vierendeel. Não é necessário calcular a resistência a compressão do tê inferior, pois todas as aberturas estão em interação total e toda a compressão será resistida 
pela laje de concreto. A força resistente nominal a tração é determinada com base no estado limite de escoamento da seção transversal.

$$
T_{n}=\phi f_{y} A_{s b} .
$$

A resistência a flexão da seção do tê inferior deve ser determinada e comparada com o momento fletor solicitante de Vierendeel. A resistência nominal a flexão, $M_{n}$, é o valor obtido considerando a plastificação da seção transversal, e é determinada da seguinte maneira:

$$
M_{n}=M_{p}=\phi f_{y} Z_{x-t \hat{e}}
$$

em que $Z_{x-t e ̂}$ é o módulo de resistência plástico da seção transversal do tê em relação ao eixo de flexão.

\section{6}

\section{Mecanismo da ligação entre aço e concreto}

A combinação dos elementos de aço e concreto requer o desenvolvimento da ação mista que envolve as superfícies de interface. A principal contribuição para a resistência ao cisalhamento longitudinal é um resultado dos seguintes mecanismos: aderência, travamento mecânico, atrito e armadura transversal.

\subsection{1 \\ Aderência}

A aderência é o primeiro mecanismo a ser mobilizado na interface entre o aço e o concreto, surgindo devido às ligações físico-químicas na interface que são criadas durante as reações de pega do cimento. Ela pode contribuir significativamente para a resistência global, contanto que os efeitos de ligação não sejam reduzidos por contaminantes ao longo da interface. A ligação por aderência tem uma resistência em torno de 0,1 MPa e ocorre sobre a área total entre o perfil de aço e o concreto adjacente [107]. A aderência diminui à medida em que o deslizamento começa e não pode ser restaurada. Devido a essa característica, a teoria da interação completa elástica pode ser usada para realizar estimativas de tensão na interface e verificações, se necessário. A aderência é eficaz apenas em deslizamentos inferiores a 0,05 mm. Alguns dos parâmetros que influenciam a ligação por aderência são:

- preparação (rugosidade, umidade etc.) e limpeza da interface;

- resistência do concreto;

- porosidade e teor de umidade do concreto;

- qualidade e composição do concreto; 
- retração do concreto;

- idade do concreto.

Considerar o efeito da ligação adesiva para a carga máxima implica que o deslizamento relacionado na falha é muito pequeno e, caso contrário, esse efeito entra em colapso.

\subsection{2}

\section{Travamento mecânico}

O travamento de interface é relacionado à restrição passiva local dada por rugosidades e aberturas no perfil de aço. A restrição é fortemente influenciada pela forma, o tamanho e a frequência das aberturas. A resistência desse mecanismo pode variar praticamente de zero para perfis sem rugosidade até 0, 8MPa em perfis com aberturas e nervuras [107].

A resistência é relacionada à área de aço em contato frontal com o concreto (pressão de contato). Além disso, em casos nos quais um material é muito mais fraco que o outro, pode haver tensões de cisalhamento em regiões abaixo da superfície de contato devido a aderência, provocando desgaste do material mais fraco (ver Fig. 3.9).

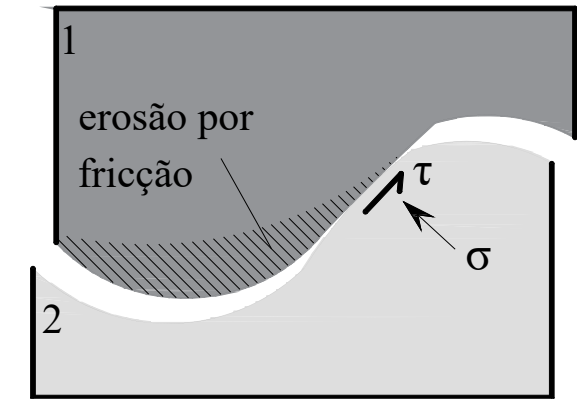

3.9(a): Erosão pro fricção superfície de ruptura na argamassa de cimento

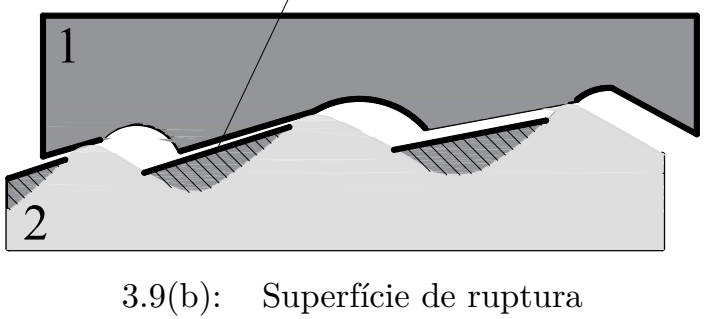

Figura 3.9: Comportamento cinemático na interface aço-concreto

\subsection{3}

\section{Atrito}

Após o rompimento da aderência, a resistência da interface pode ser garantida pelo atrito existente entre as superfícies de contato. $\mathrm{O}$ atrito contribui para a resistência ao cisalhamento longitudinal dependendo das forças normais aplicadas na interface (ex.: cargas externas (q) e tensão de retração do concreto $\left(\sigma_{r c}\right)$ ) e pelos tratamentos de superfície que regem o valor do coeficiente de atrito (ver Fig. 3.10). 


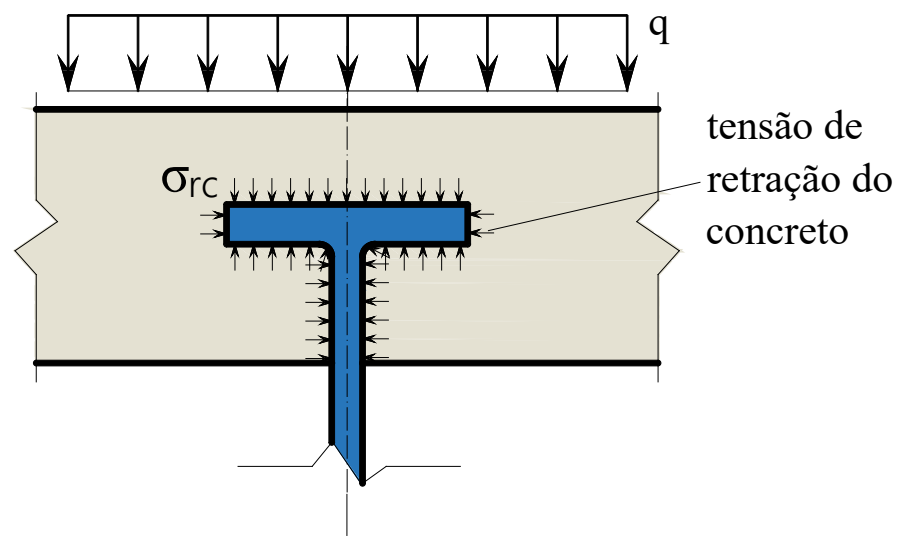

Figura 3.10: Forças normais na interface aço-concreto

A armadura que atravessa a interface também pode levar à ativação de forças de atrito, contanto que a superfície seja suficientemente áspera. De acordo com a norma CEB-FIB (2010) [107], o atrito nas interfaces aço-concreto pode ser explicado por meio da chamada teoria atrito-cisalhamento, proposta em 1966 por Birkeland and Birkeland [108]. De acordo com esse modelo, o cisalhamento longitudinal causa não apenas deslocamentos paralelos, s, mas também deslocamentos perpendiculares à interface de contato, $u_{1}$ e $u_{2}$ (ver Fig. 3.11(a)).

Na Fig. 3.11(b), o descolamento $u_{1}$ é parcialmente impedido pelo confinamento da laje de concreto mais a armadura. As restrições internas associadas a esse deslocamento são as tensões de cisalhamento na interface, $\tau_{i n 1}$ e as tensões de tração na armadura transversal $N$. Por equilíbrio, a tensão de cisalhamento $\tau_{i n 1}$ e a força $N$ induzem tensões compressivas de equalização na interface, $\sigma_{c 1}$. De forma semelhante, como ilustrado na Fig. 3.11(c), a interface na mesa superior do perfil produz um efeito de restrição contra o deslocamento $u_{2}$ (movimento conhecido como uplift). Os esforços de cisalhamento $\tau_{i n 2}$ surgem na interface lateral do perfil e sob a armadura transversal, ao passo que as tensões de compressão, $\sigma_{c 2}$, surgem perpendiculares à mesa.

O coeficiente de atrito entre aço e concreto pode variar de valores muito baixos, de praticamente zero, até 0,6 quando a interface não está engraxada. Comumente, os valores da força de atrito dinâmico são de aproximadamente 0,003MPa, sendo muito menores que os valores fornecidos por aderência e travamento mecânico. No entanto, a sua contribuição geralmente não é negligenciável, uma vez que elas se desenvolvem em toda a superfície da interface. 

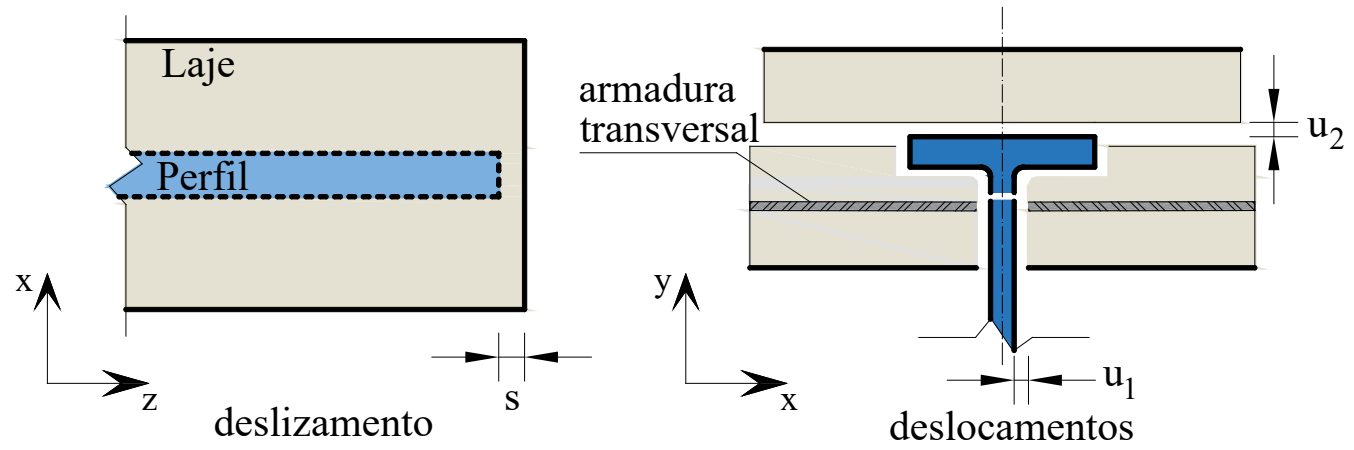

3.11(a): Deslizamento e deslocamentos perpendiculares a interface
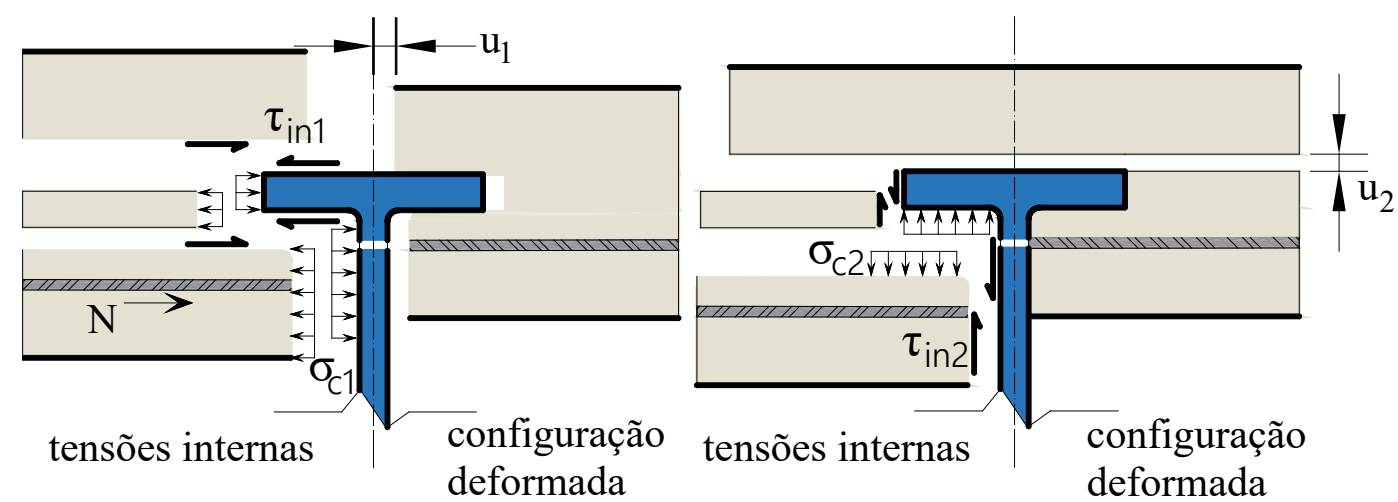

3.11(b): Deslocamento $u_{1}$ e restrições in- 3.11(c): Deslocamento $u_{2}$ e restrições internas ternas associadas associadas

Figura 3.11: Comportamento mecânico da ligação

\subsection{4}

\section{Armadura transversal}

As armaduras transversais são necessárias nas estruturas mistas para transferir o cisalhamento longitudinal produzido na interface aço-concreto e evitar a fissuração do concreto (Fig. 3.12). O concreto, a malha de aço e as armaduras transversais que cruzam cada plano de cisalhamento contribuem para a resistência longitudinal total ao cisalhamento, (Fig. 3.13).

As armaduras transversais funcionam como pontos de ancoragem entre a laje e o perfil. Quando ocorre o deslizamento, a armadura transversal existente na interface contribui para a transferência de tensões de cisalhamento por efeito de pino.

Segundo Braun et al. [11], a armadura pode ser submetida a uma ação combinada de tração, momento fletor e cisalhamento. O surgimento desses esforços depende da razão entre a resistência da armadura transversal e do concreto. Se a resistência ao cisalhamento da armadura for maior que a do concreto, a região de concreto abaixo do vergalhão começa a fissurar, liberando espaço para a armadura se deformar. A armadura fica submetida não somente 
Capítulo 3. Comportamento de vigas mistas com mesa de compressão embutida

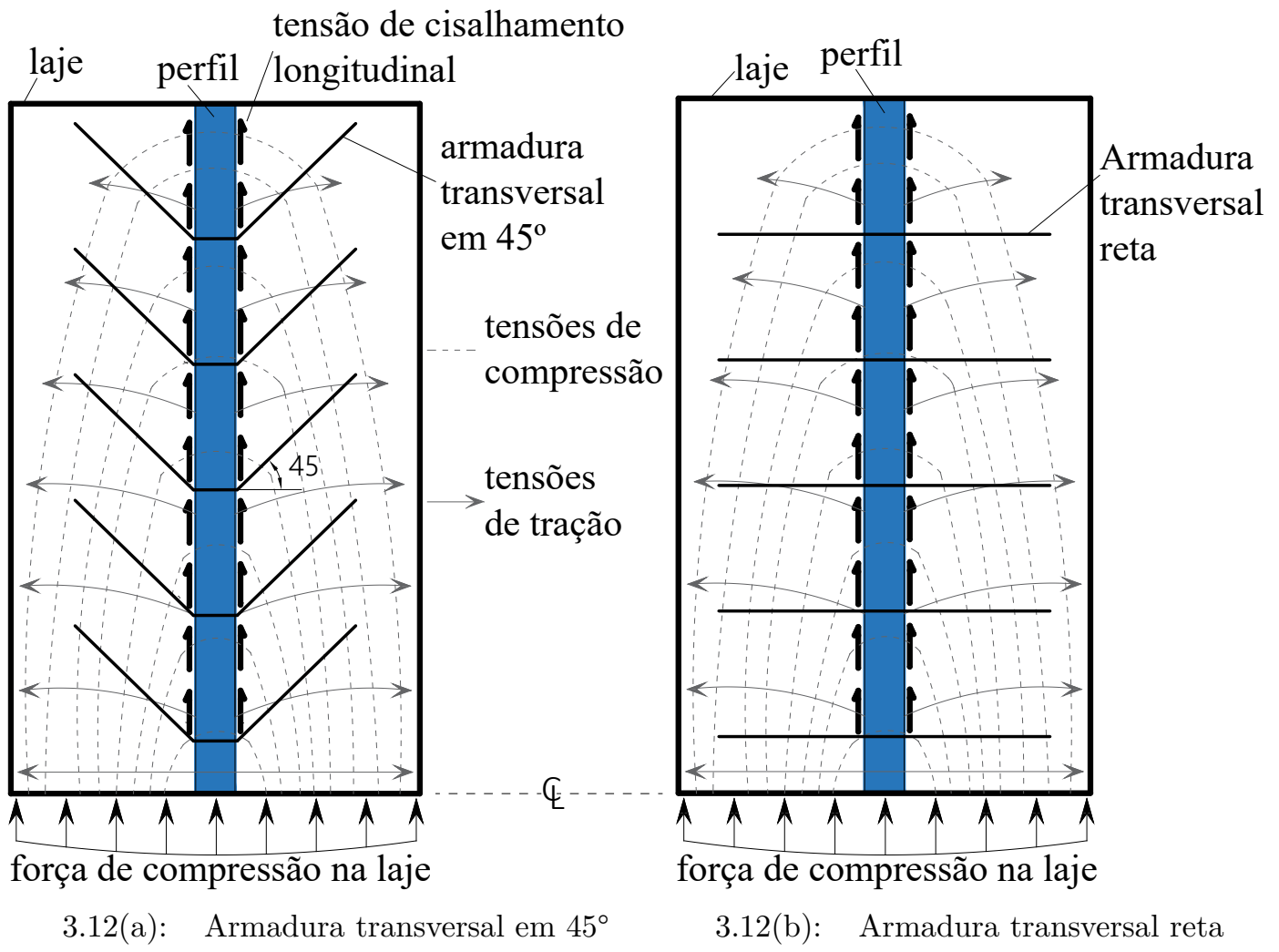

Figura 3.12: Fluxo de tensões em torno da interface aço-concreto planos de cisalhamento
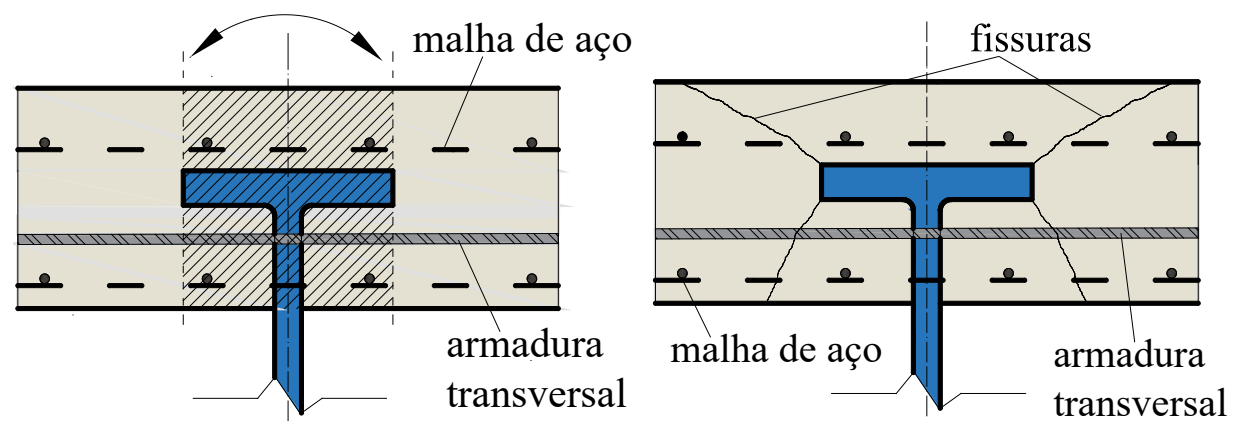

3.13(a): Planos de cisalhamento

3.13(b): Mecanismo de ruptura da laje

Figura 3.13: Idealização do modo de falha sob cisalhamento longitudinal a uma força transversal, como também uma força de tração (ver Fig. 3.14). No caso de o concreto ser mais resistente que a armadura, o vergalhão fica sujeito a um esforço de cisalhamento puro.

De Acordo com Kullmari [109], as vigas com armadura transversal em $45^{\circ}$ apresentam maior resistência ao cisalhamento. Essa configuração das armaduras consegue distribuir a força de cisalhamento longitudinal para uma seção mais larga da laje, diminuindo assim as tensões de compressão sobre a 
Capítulo 3. Comportamento de vigas mistas com mesa de compressão embutida

laje de concreto, e consequentemente retardando a formação de fissuras (ver Fig. 3.14(b)).
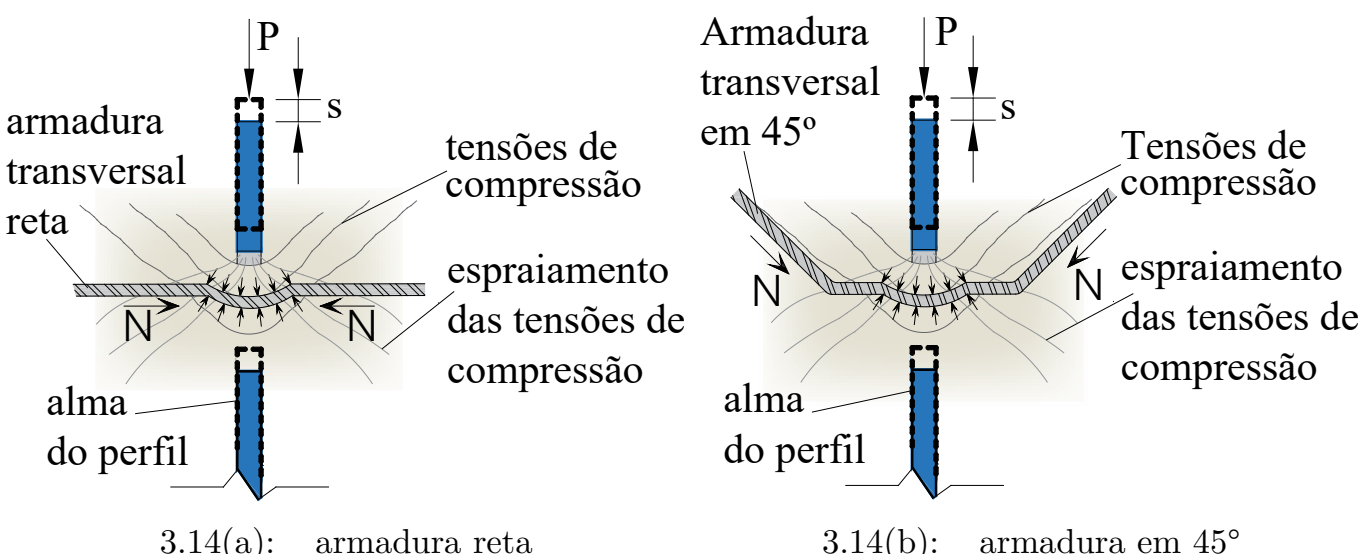

3.14(b): armadura em $45^{\circ}$

Figura 3.14: Influência da armadura transversal na ligação

\subsection{5}

\section{Ação mista}

A ação mista tem a função de evitar deslizamentos na interface açoconcreto, garantindo a realização de análises elásticas e/ou plásticas sob flexão. Dessa forma, a ligação aço-concreto tem forte influência na resposta estrutural global dos elementos, seja nas zonas de introdução de carga, seja nas regiões críticas, onde se desenvolvem fortes forças internas.

Em uma estrutura real sujeita ao carregamento de cisalhamento, os vários mecanismos (e.g. ligação adesiva, travamento mecânico, atrito e armadura transversal) interagem, afetando-se mutuamente em função do deslizamento. Após a ruptura da aderência, com o aumento do deslizamento, os esforços são redistribuídos para o concreto e armaduras transversais enquanto a resistência a fricção diminui. Se não houver nenhum reforço na interface, o comportamento da ligação fica bastante frágil e tipicamente ocorre uma falha com a perda de aderência em deslizamentos abaixo de 0,05 mm. As ligações reforçadas mostram um comportamento mais dúctil dependendo do grau de reforço e de rugosidade na interface, e a ruptura ocorre tipicamente em deslizamentos muito maiores $(0,5-1,5 \mathrm{~mm})$.

\subsection{6}

\section{Modelo para determinação das propriedades mistas}

O fluxo de cisalhamento ao longo da viga é considerado de variação linear em vez de uniforme, como é o caso dos conectores de cisalhamento convencionais. Considera-se que a tensão age em torno do perímetro de contato 
Capítulo 3. Comportamento de vigas mistas com mesa de compressão embutida

do perfil com a laje de concreto (ver a Fig. 3.15(a)). A máxima força de cisalhamento por unidade de comprimento é igual a:

$$
F_{b}=\left(2\left(b_{s}+t_{s}+t_{0}\right)-t_{w}\right) \tau_{d} .
$$

em que $\tau_{d}$ é a tensão de cisalhamento na interface.

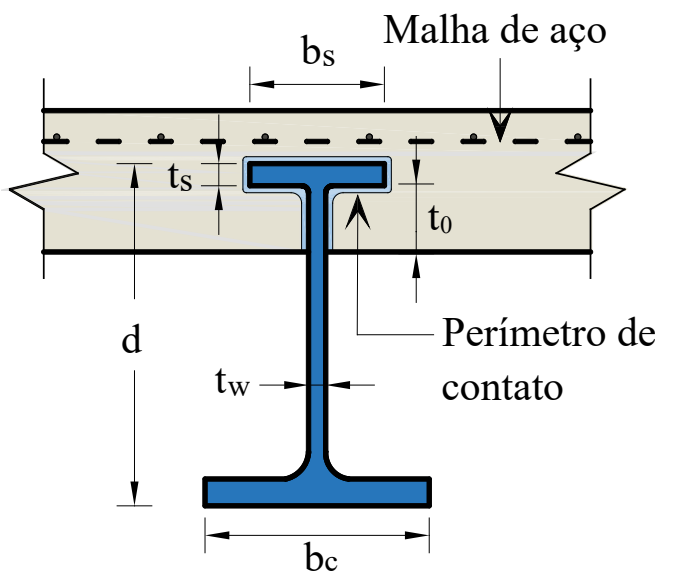

3.15(a): Perímetro de contato em torno da superfície do perfil

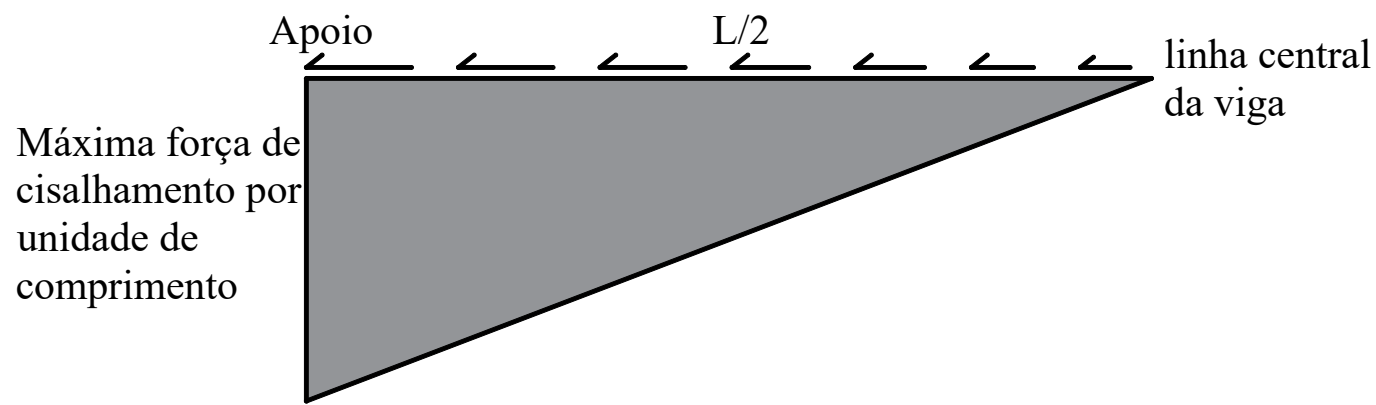

3.15(b): Transferência de cisalhamento ao longo da viga para um carregamento uniformemente distribuído

Figura 3.15: Modelo para determinação das propriedades mistas.

A força total de compressão transferida na interface para um carregamento uniformemente distribuído é igual a:

$$
F_{n}=F_{b} \frac{L}{4} .
$$

\subsection{7}

Recomendações adicionais de projeto para interfaces sujeitas a carregamento cíclico

O carregamento repetido (i.e. fadiga, sismos) gera solicitações de esforço e deslizamento no nível da interface e deve ser considerado com atenção. A principal questão relativa ao comportamento ao cisalhamento longitudinal sob 
Capítulo 3. Comportamento de vigas mistas com mesa de compressão embutida

carregamento dinâmico é se as fissuras ao longo da interface são esperadas ou não.

Assim que aparecem, as fissuras tendem a causar deteriorações mais significativas ao longo da interface. Uma aproximação simples é reduzir a tensão de cisalhamento na interface $\left(\tau_{d}\right)$ para $50 \%$ sob carga de fadiga.

\subsection{8}

\section{Relação tensão-deslizamento na interface}

A relação tensão-deslizamento depende das propriedades das superfícies na interface aço-concreto. Se as endentações e os tratamentos superficiais não estão presentes, o relacionamento constitutivo é muito semelhante a um comportamento rígido plástico (ver Fig. 3.16 Curva A) [107].

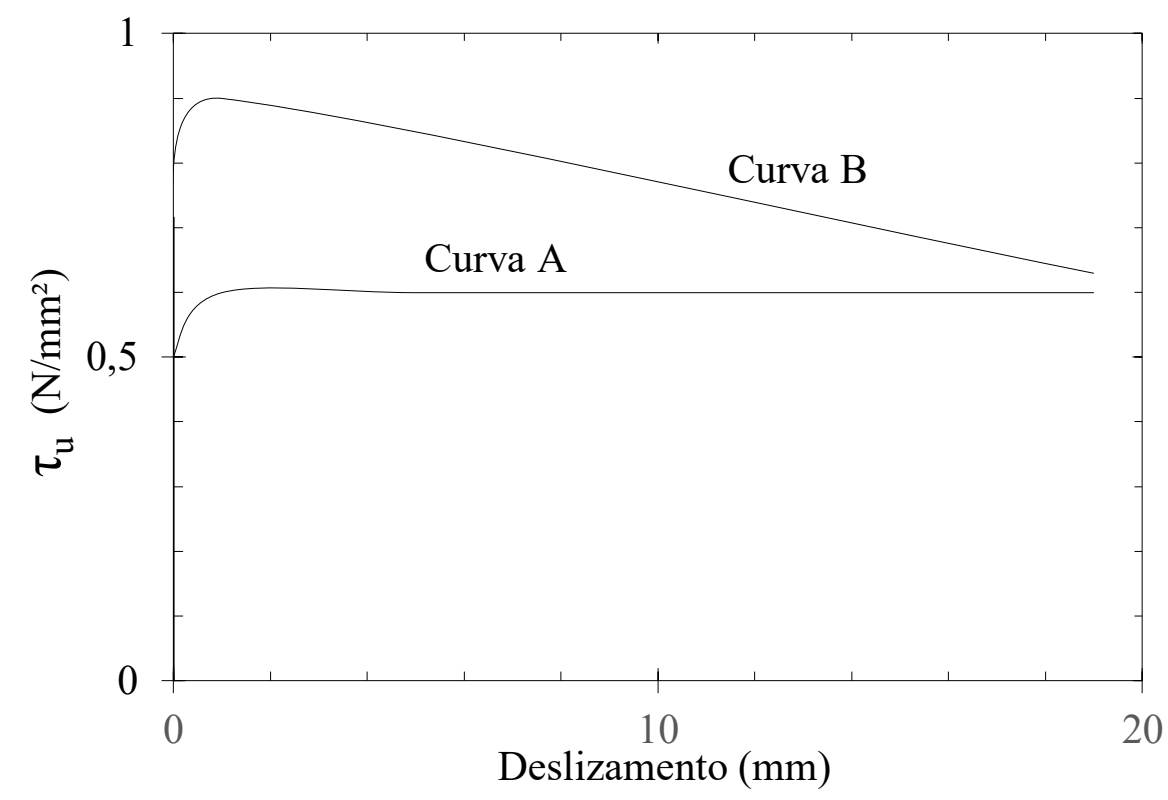

Figura 3.16: Relação tensão-deslizamento para ligação aço-concreto [107]

Assim que a aderência é excedida, dá-se início ao deslizamento com tensão residual relacionada ao desenvolvimento do atrito. Quando as interfaces estão travadas por meio de aberturas no perfil e armaduras transversais, a interação da ligação de cisalhamento exibe um aumento de resistência até atingir valor máximo (pico) e consequente decréscimo até a estabilização devido ao atrito (ver Fig. 3.16 Curva B).

Para fins de projeto, em analogia a fenômenos de interação semelhantes (i.e. aderência de armaduras lisas), as relações teóricas de tensão-deslizamento podem negligenciar os picos de tensão e estabelecer um patamar de deslizamento ao nível da tensão residual. 


\section{4}

\section{Programa Experimental}

Devido aos diversos fatores que podem influenciar o comportamento da ligação não convencional aço-concreto, a descrição analítica se torna complexa. Por tal motivo, é mais fácil descrever o comportamento a partir de resultados experimentais.

Neste capítulo, é apresentado o programa experimental dos ensaios de flexão de vigas mistas e de cisalhamento direto (Push-out). Os ensaios foram realizados no Laboratório de Estruturas e Materiais da Pontifícia Universidade Católica do Rio de Janeiro (LEM/PUC-Rio). Foram confeccionados três protótipos de vigas mistas em escala real e quatro protótipos de cisalhamento direto. Adiante, apresenta-se a configuração dos modelos, o modo de confecção dos protótipos e os procedimentos de ensaio e instrumentação.

\section{1}

\section{Pesquisa anterior}

Em trabalhos de pesquisa anteriores [92], foi estudada uma viga mista semi-castelada, composta por uma seção obtida de um perfil W360x32,9 com aberturas de $300 \mathrm{~mm}$ que recebeu uma barra chata como mesa superior. A ligação de transferência do cisalhamento foi fornecida por três armaduras transversais de $10 \mathrm{~mm}$ de diâmetro localizadas em cada abertura de alma. O vão da viga era de $6180 \mathrm{~mm}$ e a laje de concreto tinha $80 \mathrm{~mm}$ de espessura e 1200 mm de largura, veja a Fig. 4.1.

Neste estudo, os ensaios de cisalhamento direto foram realizados baseados na ligação aço-concreto da viga apresentada em [92]. Para os ensaios de flexão, uma modificação foi feita para investigar a conexão de cisalhamento. As armaduras transversais de $10 \mathrm{~mm}$ foram utilizadas passando por orifícios perfurados de 12,5 mm de diâmetro em substituição das aberturas de alma.

\section{2}

\section{Ensaio de cisalhamento direto - Pushout}

Os ensaios de cisalhamento direto deste trabalho foram desenvolvidos com base nos padrões determinados pelo EUROCODE 4 [36]. Na medida do possível, levou-se em conta as recomendações feitas pela norma acerca da geo- 

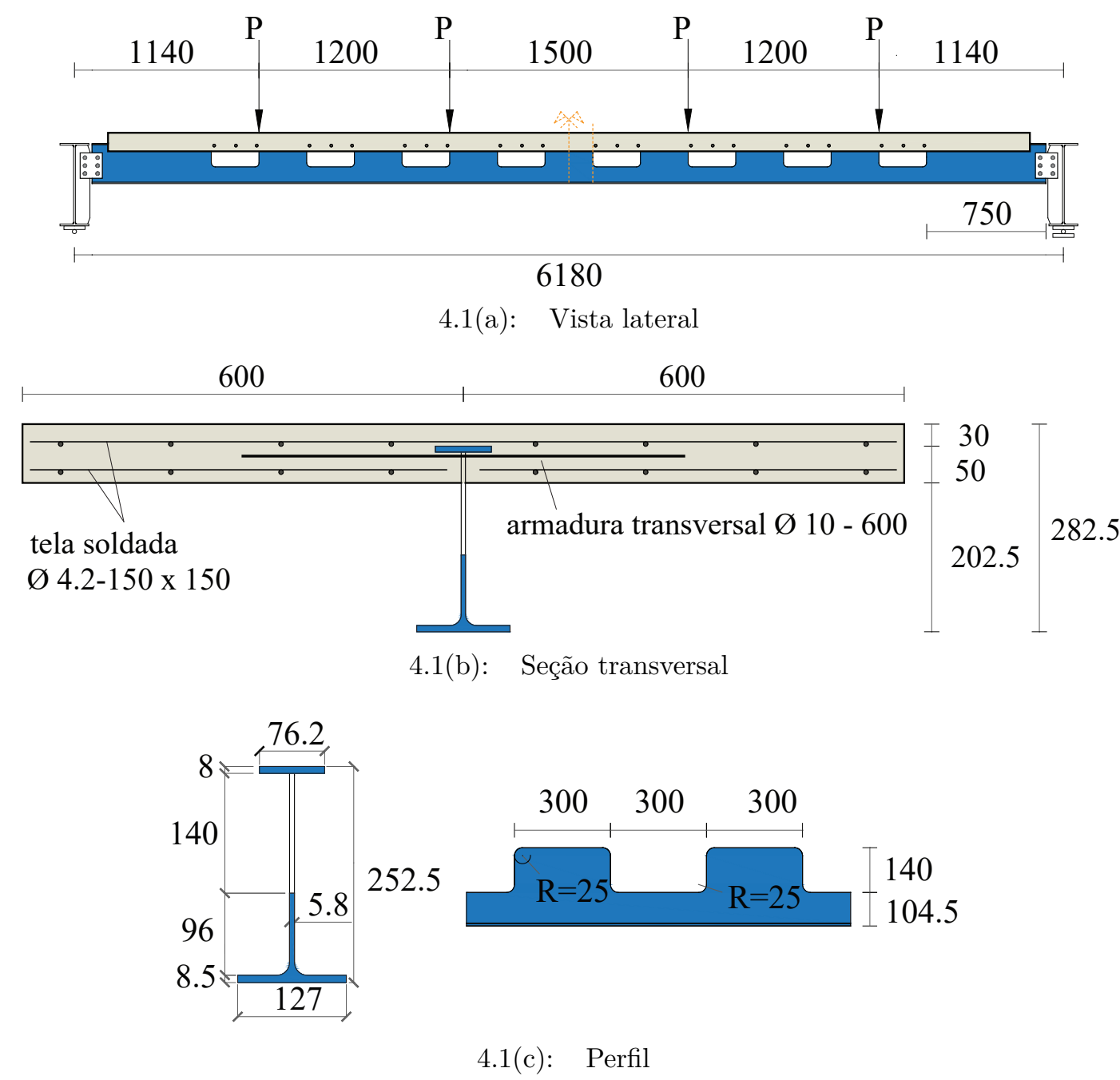

Figura 4.1: Protótipo da viga mista com abertura de alma estudada em [92] $[\mathrm{mm}]$

metria e procedimento de ensaios, mas também foram realizadas modificações para atender ao modelo estudado.

Os ensaios de cisalhamento direto foram realizados para avaliar a resistência ao cisalhamento longitudinal da ligação entre a laje de concreto e a viga metálica. Cada ensaio buscou investigar uma característica particular da ligação. Os detalhes de cada protótipo são apresentados na Tabela 4.1.

Tabela 4.1: Caracteristicas dos protótipos de push-out

\begin{tabular}{llll}
\hline Protótipos & Armadura & $\begin{array}{l}\text { Área de contato } \\
\left(\mathrm{mm}^{2}\right)\end{array}$ & Chapa de alma \\
\hline P1 & $\phi 10.0$ Reta & 176720 & $\mathrm{sem}$ \\
P2 & $\phi 10.0$ Reta & 176720 & $\mathrm{com}$ \\
P3 & $\phi 10.045^{\circ}$ & 176720 & sem \\
P4 & $\phi 10.045^{\circ}$ & 101000 & $\mathrm{sem}$ \\
\hline
\end{tabular}

A geometria do modelo P1 é apresentada na Fig. 4.2(a). O protótipo foi 
armado utilizando malha de aço na face superior e inferior da laje de concreto, com três armaduras transversais retas de $10 \mathrm{~mm}$ de diâmetro transpassando as aberturas de alma. A mesa superior do perfil era embutida na laje de concreto. No protótipo P2, foram mantidas as mesmas características do P1, com a adição de uma chapa de aço à alma do perfil.

Nos ensaios P3 e P4 (Fig. 4.2(b)), optou-se por armaduras tipo espinha de peixe a 45 graus. No protótipo $\mathrm{P} 4$, a área de contato entre o aço e o concreto foi $43 \%$ menor.

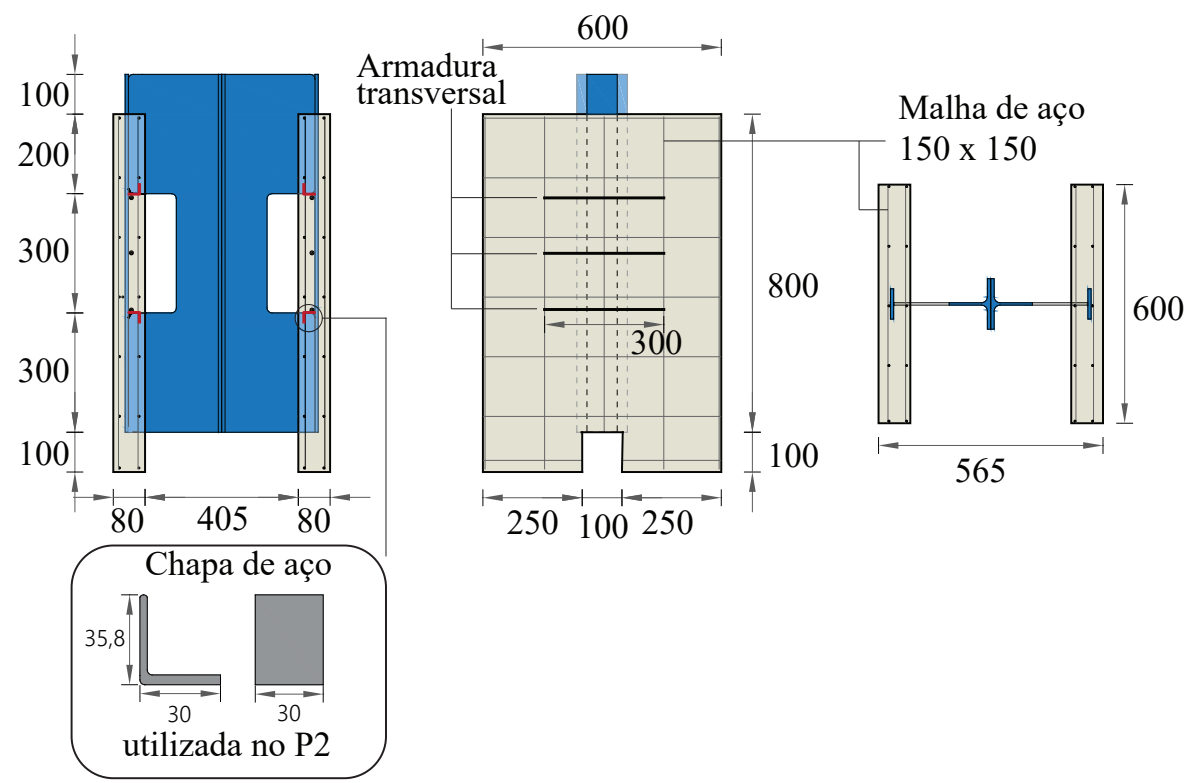

4.2(a): Protótipo P1 e P2

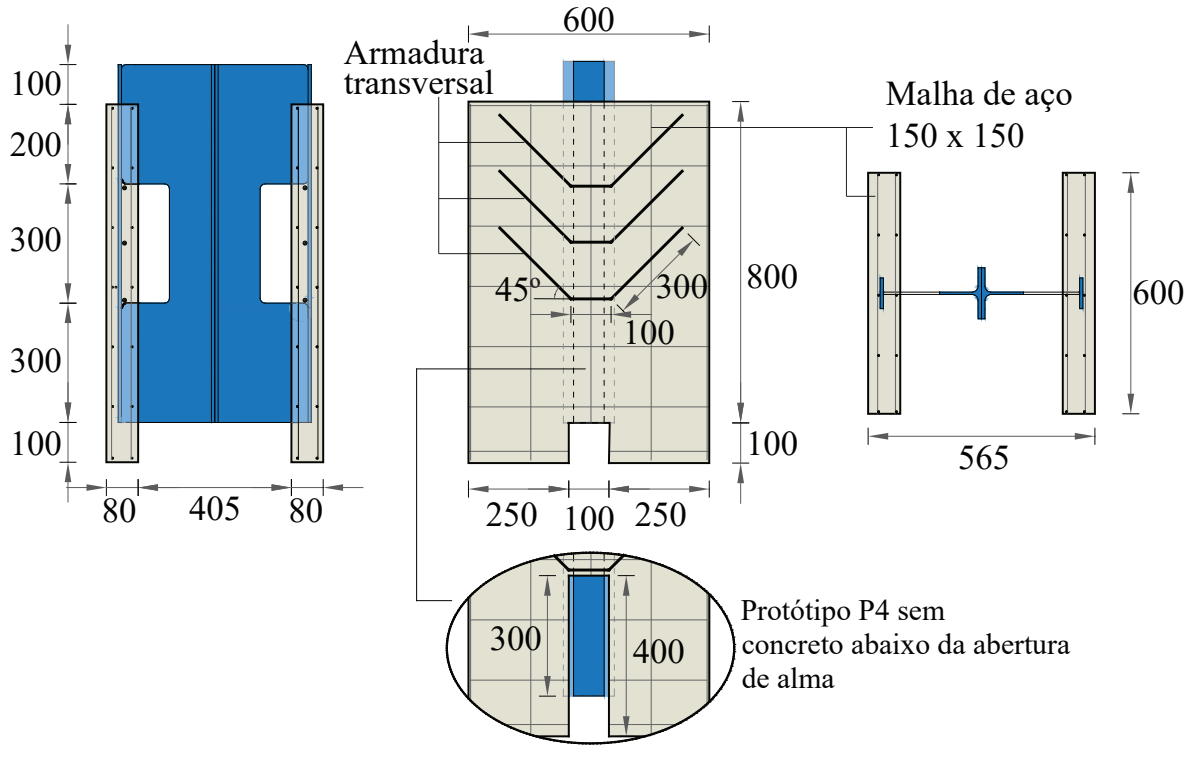

4.2(b): Protótipo P3 e P4

Figura 4.2: Características geométricas dos protótipos de push-out [mm] 


\subsection{1}

\section{Confecção dos protótipos}

A metade de cada protótipo foi confeccionada separadamente e concretada na posição horizontal. A Fig. 4.3(a) mostra a distribuição das armaduras dentro da forma de madeira, ao passo que a Fig. 4.3(b) apresenta a metade de um protótipo concretado. Após a desforma, as metades foram unidas na mesa inferior por meio de solda. A configuração final do protótipo é apresentada na Fig. 4.3(c).

Os protótipos foram modelados utilizando concreto normal e foram curados durante 7 dias. $\mathrm{O}$ concreto foi misturado em betoneira, com o traço de 1:2,45:2,50 e fator água/cimento de 0,45. Corpos de prova (CP's) cilíndricos $(10 \times 20 \mathrm{~cm})$ foram moldados e ensaiados no dia do ensaio de cada viga mista. Os CP's foram moldados e ensaiados de acordo com as normas NBR 5738 [110] e NBR 5739 [111], respectivamente. Os perfis alveolares empregados foram fabricados com aço estrutural ASTM A572 grau 50. As propriedades mecânicas do aço dos perfis foram determinadas por meio de ensaios de tração direta. Seguiu-se as prescrições da norma ASTM E8/E8M [112] para confecção dos CP's e procedimento de ensaio. Três CP's foram retirados da mesa inferior de cada perfil. As propriedades mecânicas do aço e do concreto são apresentadas na Tabela 4.2.

Tabela 4.2: Propriedade do aço e do concreto nos protótipos de push-out

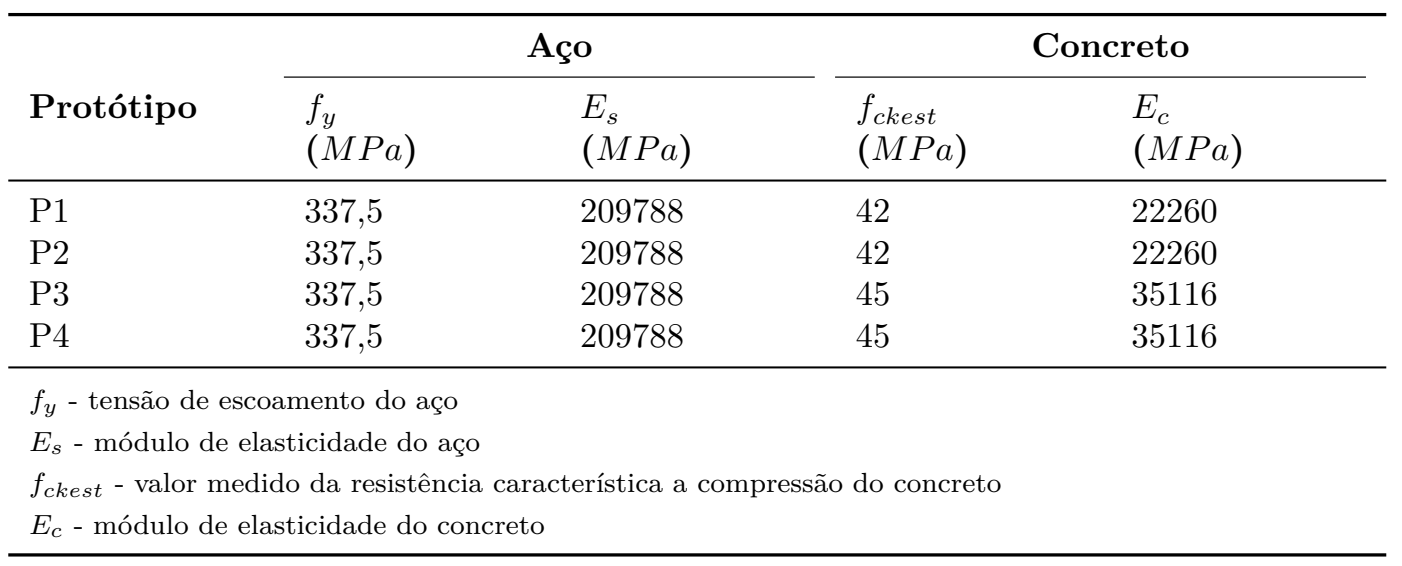

\subsection{2}

\section{Procedimento de ensaio e instrumentação}

A Fig. 4.4 apresenta a configuração de ensaio push-out do protótipo. O sistema era composto por um pórtico de reação e um atuador (MTS) com capacidade de $500 \mathrm{kN}$.

O carregamento foi aplicado em duas etapas. Na primeira etapa, composta pela fase cíclica, a aplicação de carga foi controlada pela força. Foram 


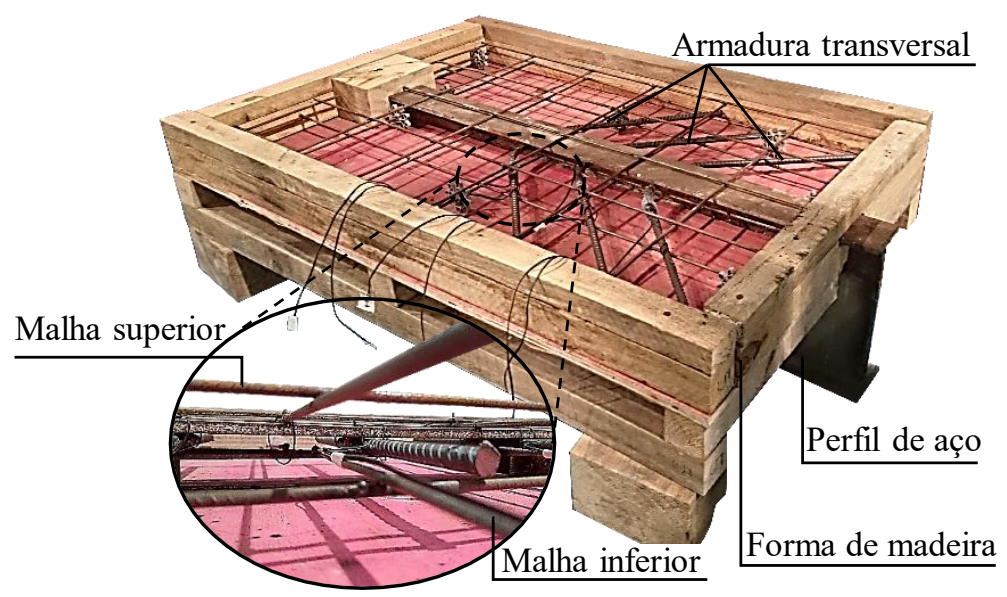

4.3(a): Forma e Armadura

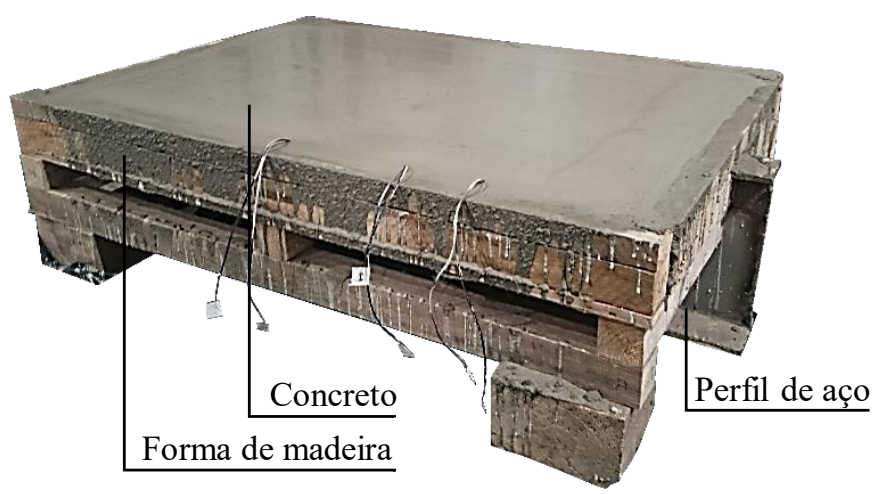

4.3(b): Concreto

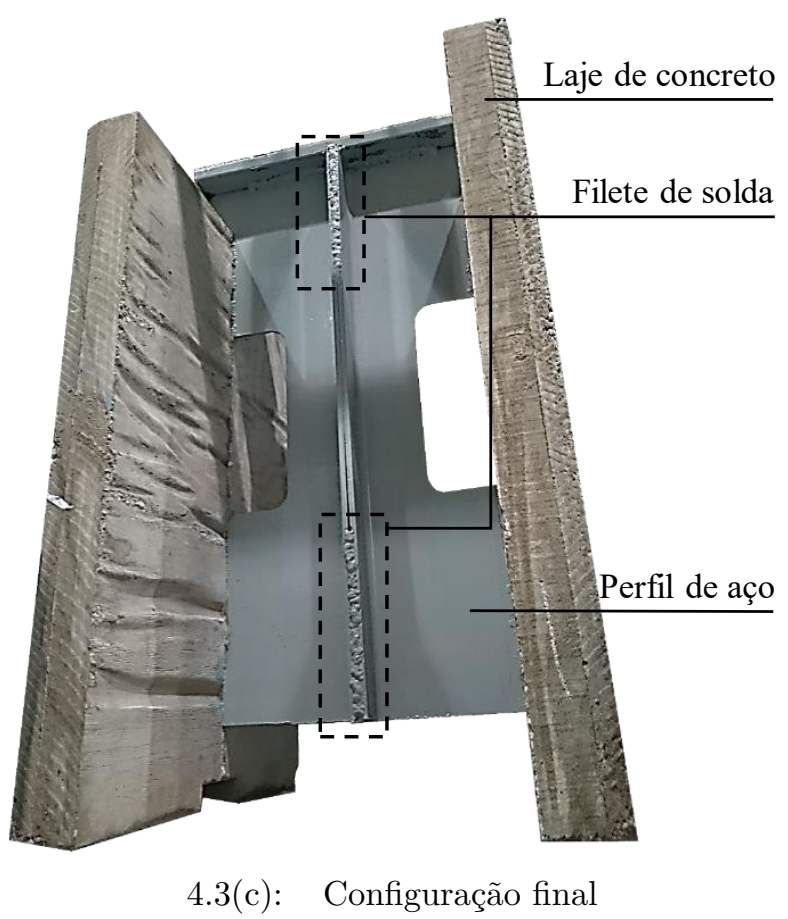

Figura 4.3: Confecção dos protótipos de push-out

aplicados 2000 ciclos de carga e descarga, com frequência de $0,5 \mathrm{~Hz}$ e uma variação de carregamento entre $5 \%$ a $40 \%$ da carga prevista de ruptura. Na 
segunda etapa, o ensaio passou para controle de deslocamento, com velocidade de $0,01 \mathrm{~mm} / \mathrm{s}$ até o colapso.

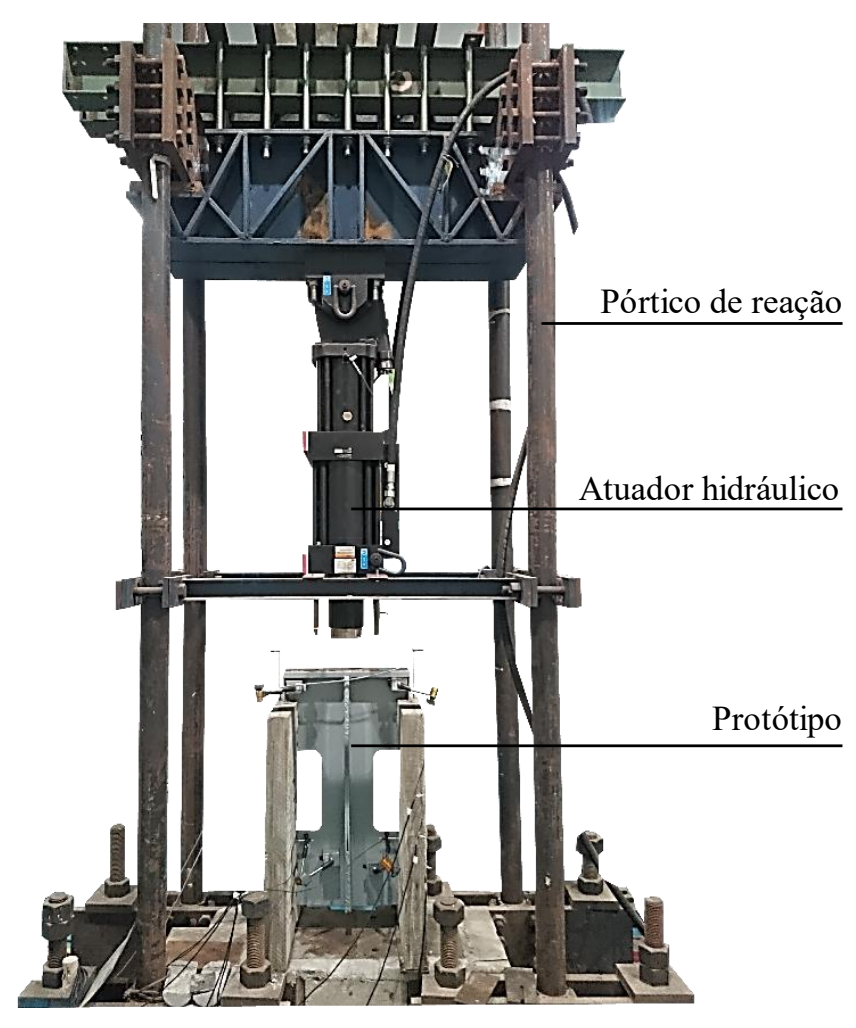

Figura 4.4: Configuração de ensaio de push-out

Para medir o deslizamento, foram utilizados LVDT's (Linear Variable Differential Transformer) com curso de 20 mm (LVDT 1 e 2) (ver Fig. 4.5(a)). A separação entre o perfil e a laje de concreto foi verificada por meio de LVDT's com curso de 10mm (LVDT 3 e 4).

Extensômetros foram utilizados para medir a deformação nas armaduras transversais. Nos ensaios P1 e P2 das barras retas, utilizou-se um extensômetro por barra. Os extensômetros foram numerados de 1 a 3 para a laje- 1 e de 4 a 6 na laje-2. Nos ensaios P3 e P4 das armaduras a $45^{\circ}$, foram utilizados dois extensômetros por barra. Os extensômetros foram numerados de 1 a 6 na laje1 e de 7 a 12 na laje-2. As Fig. 4.5(b) e 4.5(c) apresentam a configuração da instrumentação nas armaduras transversais. 


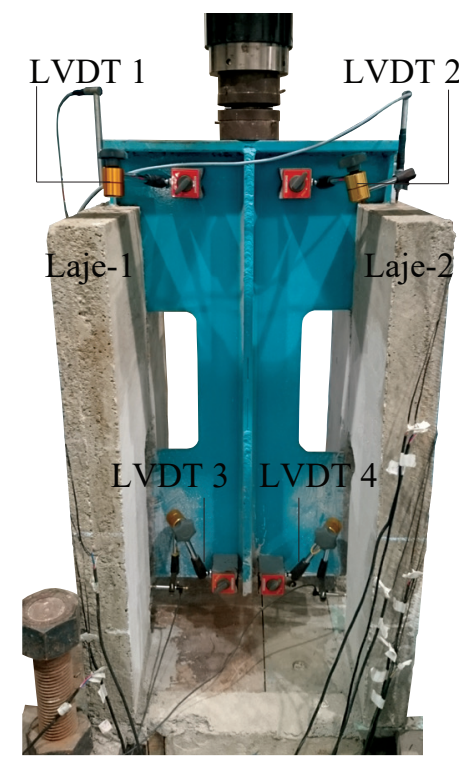

4.5(a): LVDT's

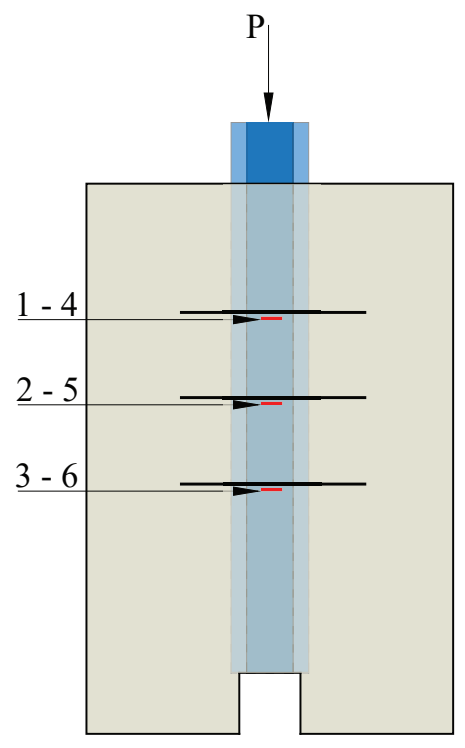

$4.5(\mathrm{~b})$

$\mathrm{P} 2)$

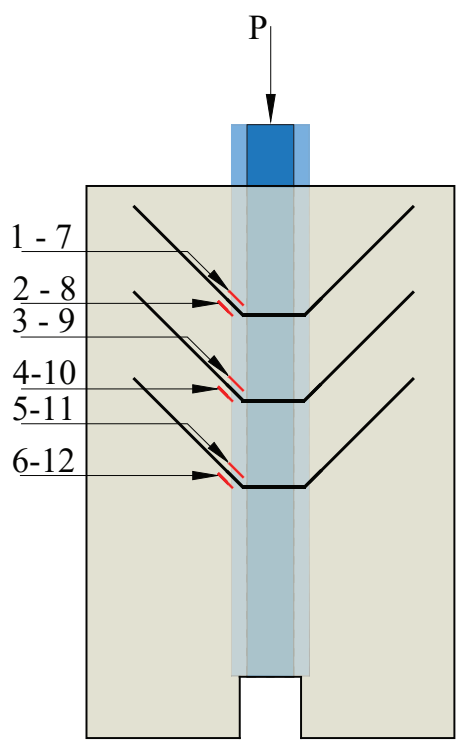

Extensômetros(P3$\mathrm{P} 4)$

Figura 4.5: Configuração da instrumentação dos protótipos de push-out

\section{3}

\section{Ensaio em escala real das vigas mistas}

Foram ensaiadas três configurações de vigas mistas. Os protótipos foram denominados de VMT (viga mista T), VMPI-1 (viga mista PI 1) e VMPI2 (viga mista PI 2). O protótipo VMT tinha formato "T", no qual a mesa superior representa a laje de concreto e a haste representa o perfil $W 250 x 25,3$. Os protótipos VMPI-1 e VMPI-2 eram de formato duplo "T"ou "PI", sendo as nervuras longitudinais constituídas por vigas alveolares assimétricas criadas a partir de um perfil $W 360 x 32,9$.

Para a criação dos novos perfis alveolares, uma viga $W 360 x 32,9$ foi cortada na alma, gerando duas partes com aberturas regularmente espaçadas (Fig. 4.6). Para finalizar, foi adicionada uma barra chata soldada ao topo da alma de cada parte. A configuração final dos novos perfis, V360-01 e V360-02, pode ser vista na Fig. 4.7.

Com o intuito de facilitar a confecção dos protótipos de viga mista, dois perfis V360-01 e dois V360-02 foram ligados entre si, soldando perfis $W 150 x 18,0$ próximo às extremidades (ver Fig. 4.8). 

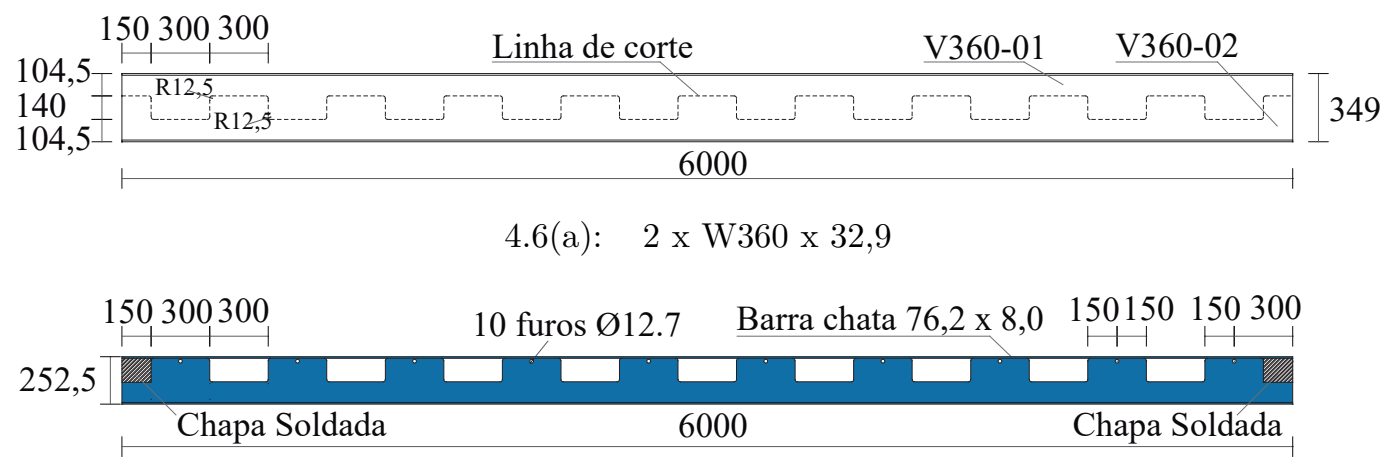

4.6(b): 2 x V360-01

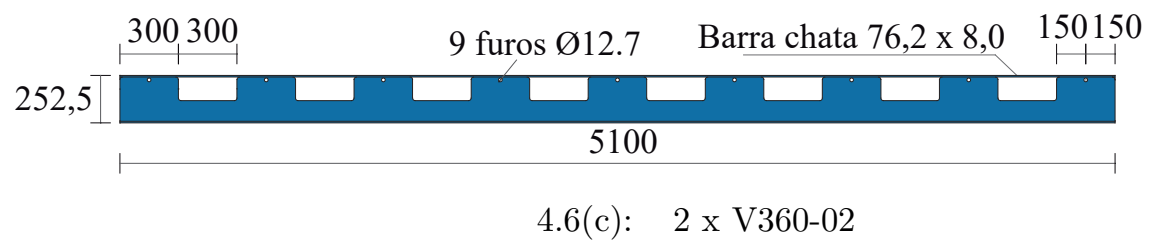

Figura 4.6: Fabricação dos perfis alveolares assimétricos [mm]

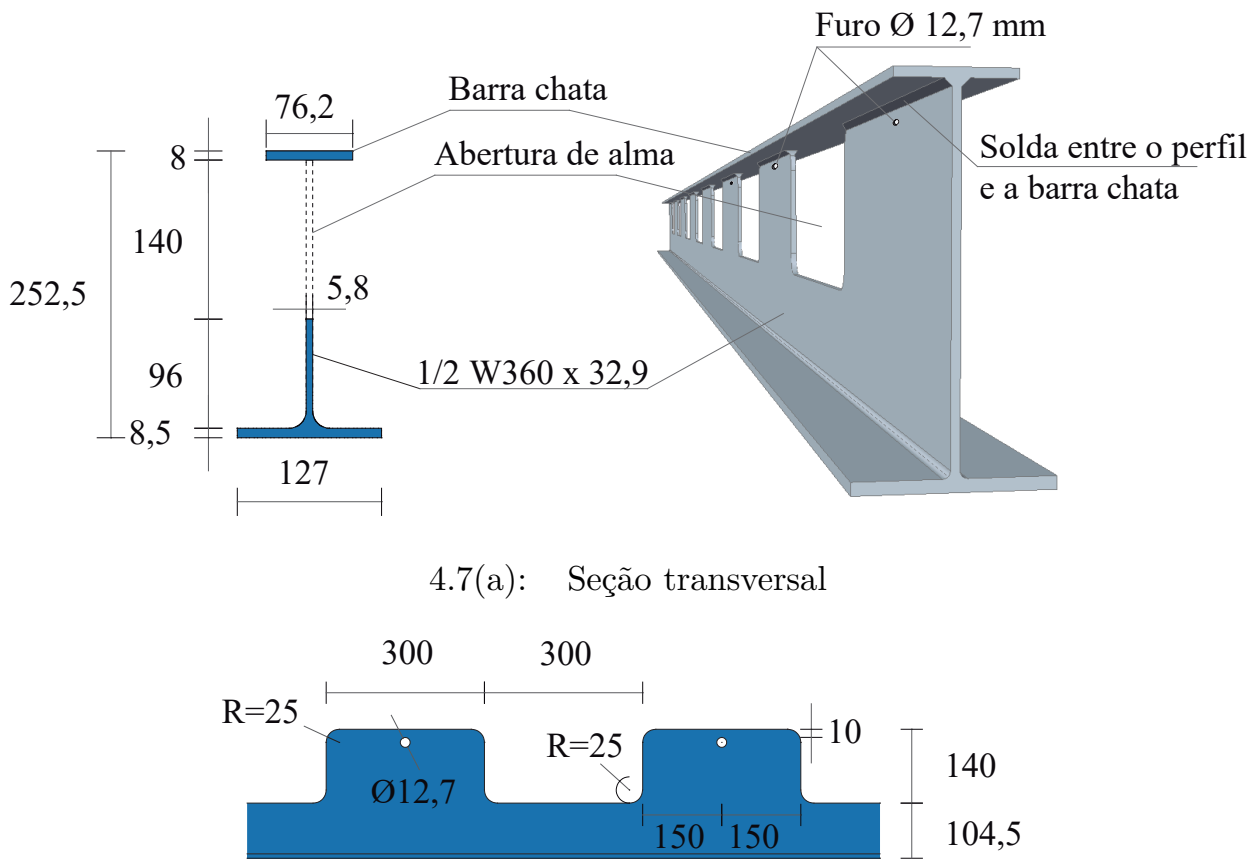

4.7(b): Abertura de alma

Figura 4.7: Detalhe dos perfis V360-01 e V360-02 [mm]

A viga mista VMT era composta por um perfil $W 250 x 25,3$ com a mesa superior embutida na laje de concreto. As dimensões da laje de concreto eram de $80 \mathrm{~mm}$ de espessura, $1200 \mathrm{~mm}$ de largura e $6000 \mathrm{~mm}$ de comprimento. $\mathrm{O}$ protótipo foi armado com telas soldadas de 4,2 $\mathrm{mm}$ de diâmetro e $150 \mathrm{~mm}$ de espaçamento nas duas direções. Foram utilizadas dez armaduras transversais retas com $10 \mathrm{~mm}$ de diâmetro e $600 \mathrm{~mm}$ de comprimento, atravessando os furos 


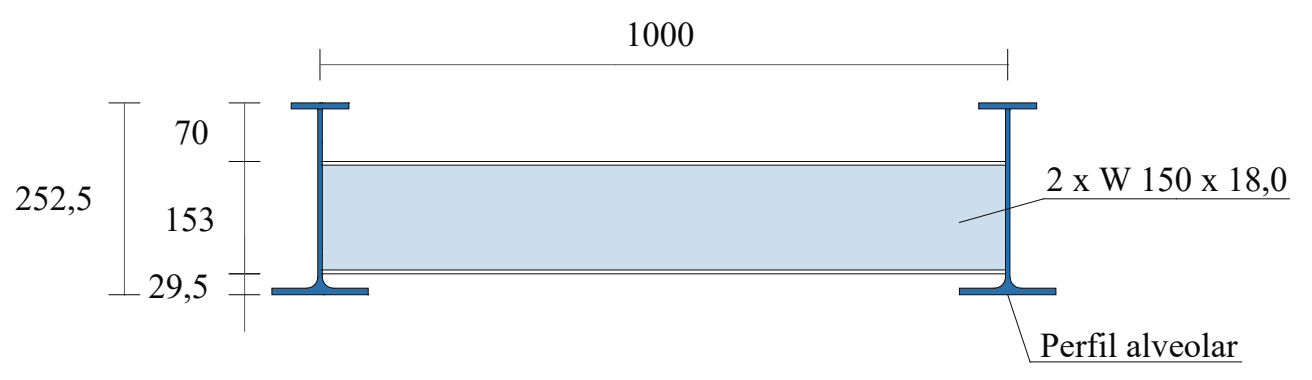

4.8(a): Seção transversal

200

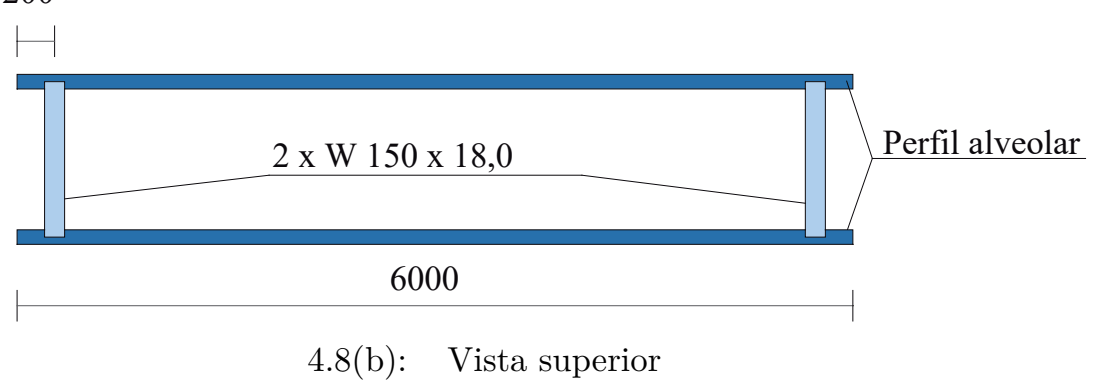

Figura 4.8: Ligação entre perfis alveolares utilizando perfil $W 150 x 18,0$ soldado à alma $[\mathrm{mm}]$

na alma. As armaduras foram espaçadas a cada $600 \mathrm{~mm}$ (ver Fig. 4.9).
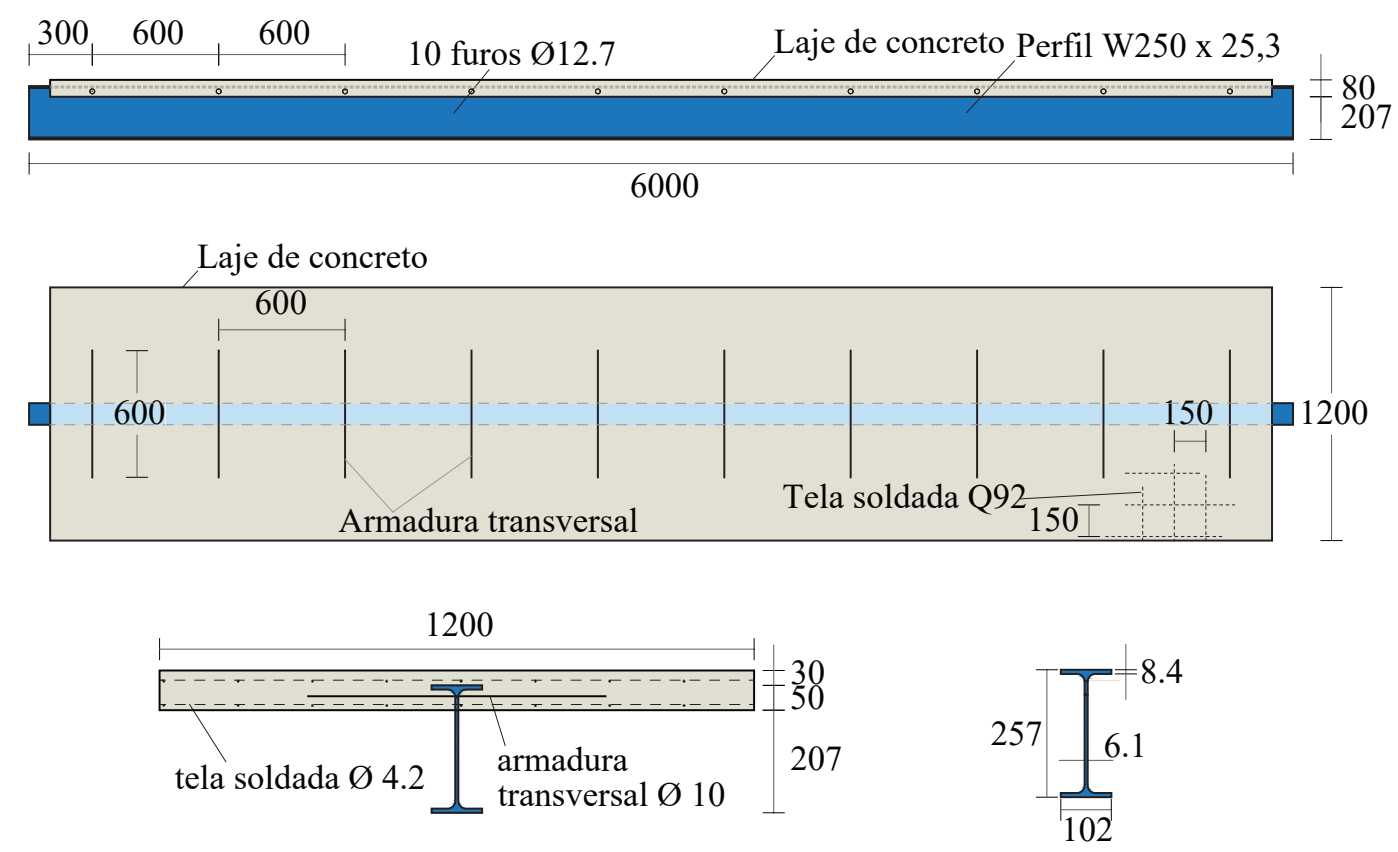

Figura 4.9: Configuração do protótipo VMT [mm]

A viga mista VMPI-1 era composta por dois perfis V360-01 parcialmente embutidos na laje de concreto. A mesa superior do perfil V360-1 foi engraxada. O objetivo do teste VMPI-1, com mesa superior engraxada, foi de eliminação 

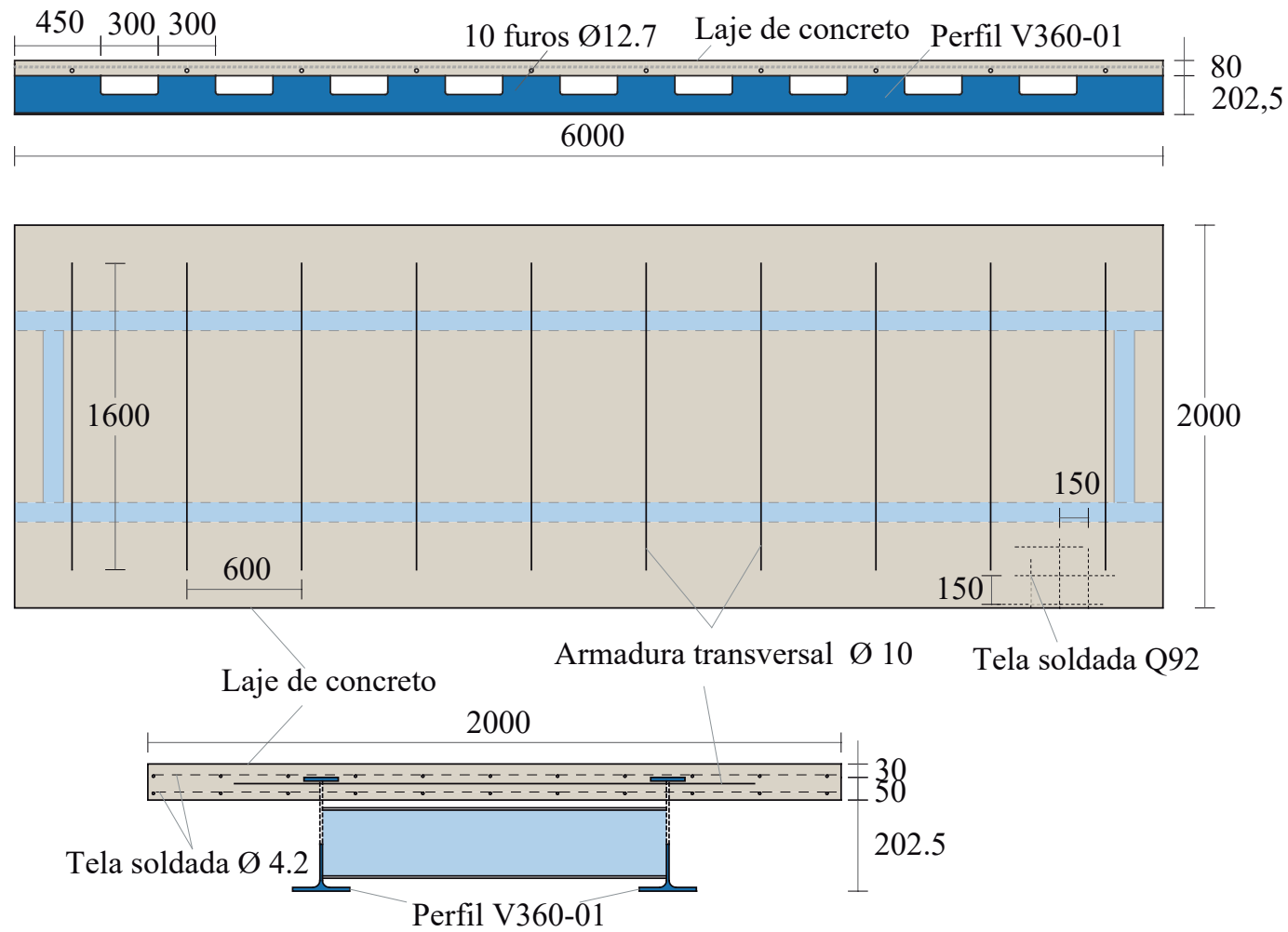

Tela soldada Q92

Figura 4.10: Configuração do protótipo VMPI-1 [mm]

da contribuição da aderência no comportamento global da viga. As dimensões da laje de concreto eram de $80 \mathrm{~mm}$ de espessura, $2000 \mathrm{~mm}$ de largura e $6000 \mathrm{~mm}$ de comprimento. O protótipo foi armado com telas soldadas de $4,2 \mathrm{~mm}$ de diâmetro e $150 \mathrm{~mm}$ de espaçamento nas duas direções. Foram utilizadas dez armaduras transversais retas com $10 \mathrm{~mm}$ de diâmetro e $1600 \mathrm{~mm}$ de comprimento atravessando os furos na alma (ver Fig. 4.10).

A viga mista VMPI-2 era composta por dois perfis V360-02 parcialmente embutidos na laje de concreto, cujas dimensões eram de $80 \mathrm{~mm}$ de espessura, $2000 \mathrm{~mm}$ de largura e $5100 \mathrm{~mm}$ de comprimento. O protótipo foi armado com telas soldadas de $4,2 \mathrm{~mm}$ de diâmetro e $150 \mathrm{~mm}$ de espaçamento nas duas direções. Foram utilizadas nove armaduras transversais retas com $10 \mathrm{~mm}$ de diâmetro e $1600 \mathrm{~mm}$ de comprimento atravessando os furos na alma dos perfis (ver Fig. 4.11). 

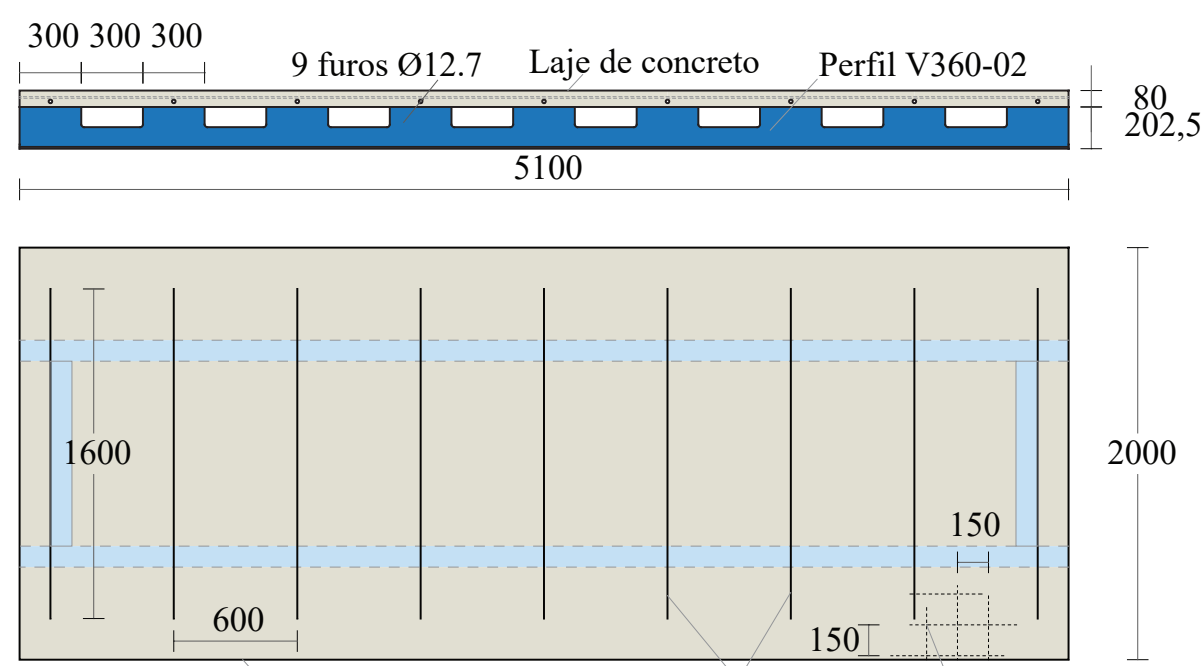

Armadura transversal $\varnothing 10$ tela soldada Q92

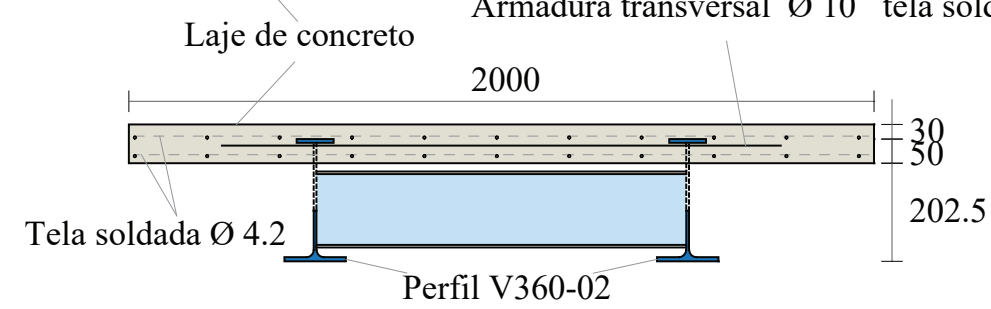

Figura 4.11: Configuração do protótipo VMPI-2 [mm]

\subsection{1}

\section{Confecção dos protótipos}

A concretagem do protótipo VMT foi realizada de forma invertida, com a laje de concreto embaixo e o perfil em cima (ver Fig. 4.12). A forma dos protótipos VMPI-1 e VMPI-2 foi construída com a laje de concreto em cima dos perfis (ver Fig. 4.13).

Em todos os protótipos, a mesa superior e parte da alma do perfil ficaram embutidas na forma de madeira. As telas soldadas foram posicionadas dentro da forma, com cobrimento de $2 \mathrm{~cm}$ das faces superior e inferior da laje de concreto. As armaduras transversais foram centralizadas na laje, transpassando a alma do perfil.

Na VMT, o concreto foi fabricado no laboratório com auxílio da betoneira, com traço de 1:2,7:2,8 e fator água/cimento de 0,55. Nas vigas VMPI-1 e VMPI-2, o concreto foi usinado. Corpos de prova (CP's) cilíndricos (10x20cm) foram moldados e ensaiados no dia do ensaio de cada viga mista. Os CP's foram moldados e ensaiados de acordo com as normas NBR 5738 [110] e NBR 5739 [111], respectivamente. As propriedades mecânicas do concreto são apresentadas na Tabela 4.3.

Os perfis alveolares empregados foram fabricados com aço estrutural 
Tabela 4.3: Propriedade do concreto das vigas mistas

\begin{tabular}{llllll}
\hline Protótipos & No $\mathbf{C P ' s}$ & $\begin{array}{l}f_{c m} \\
(M P a)\end{array}$ & $S_{d}$ & $\begin{array}{l}f_{\text {ckest }} \\
(M P a)\end{array}$ & $\begin{array}{l}E_{c} \\
(M P a)\end{array}$ \\
\hline VMT & 6 & 35,65 & 1,94 & 32,44 & 28327 \\
VMPI-1 & 6 & 37,72 & 1,37 & 35,50 & 27666 \\
VMPI-2 & 6 & 26,5 & 0,8 & 25,20 & 21264 \\
\hline
\end{tabular}

$f_{c m}$ - resistência média dos exemplares

$S_{d}$ - desvio padrão

$f_{\text {ckest }}$ - valor medido da resistência característica a compressão

$E_{c}$ - módulo de elasticidade do concreto

ASTM A572 grau 50. As propriedades mecânicas do aço dos perfis foram determinadas por meio de ensaios de tração direta. Seguiu-se as prescrições da norma ASTM E8/E8M [112] para confecção dos CP's e procedimento de ensaio. Três CP's foram retirados da mesa inferior de cada perfil. A Tabela 4.4 apresenta o resultado dos ensaios.

Tabela 4.4: Propriedade do aço dos perfis

\begin{tabular}{lllll}
\hline Protótipos & No CP's & $\begin{array}{l}f_{y} \\
(M P a)\end{array}$ & $\begin{array}{l}f_{u} \\
(M P a)\end{array}$ & $\begin{array}{l}E_{s} \\
(M P a)\end{array}$ \\
\hline ASTM-A572-G50 & - & 345 mín & 450 mín & 200000 \\
\hline W250 x 25,3 & 3 & 370 & 463 & 193422 \\
V360-01 & 6 & 351 & 466 & 197740 \\
V360-02 & 6 & 361 & 464 & 195016 \\
\hline ASTM-A572-G50 - valores de referência & & & \\
$f_{y}$ - limite de escoamento do aço & & & \\
$f_{u}$ - limite de resistência do aço & & & \\
$E_{s}$ - módulo de elasticidade do aço & & & \\
\hline
\end{tabular}

O aço adotado na confecção da mesa superior do perfil foi o ASTM A36.

Não foram realizados ensaios de caracterização deste material. 


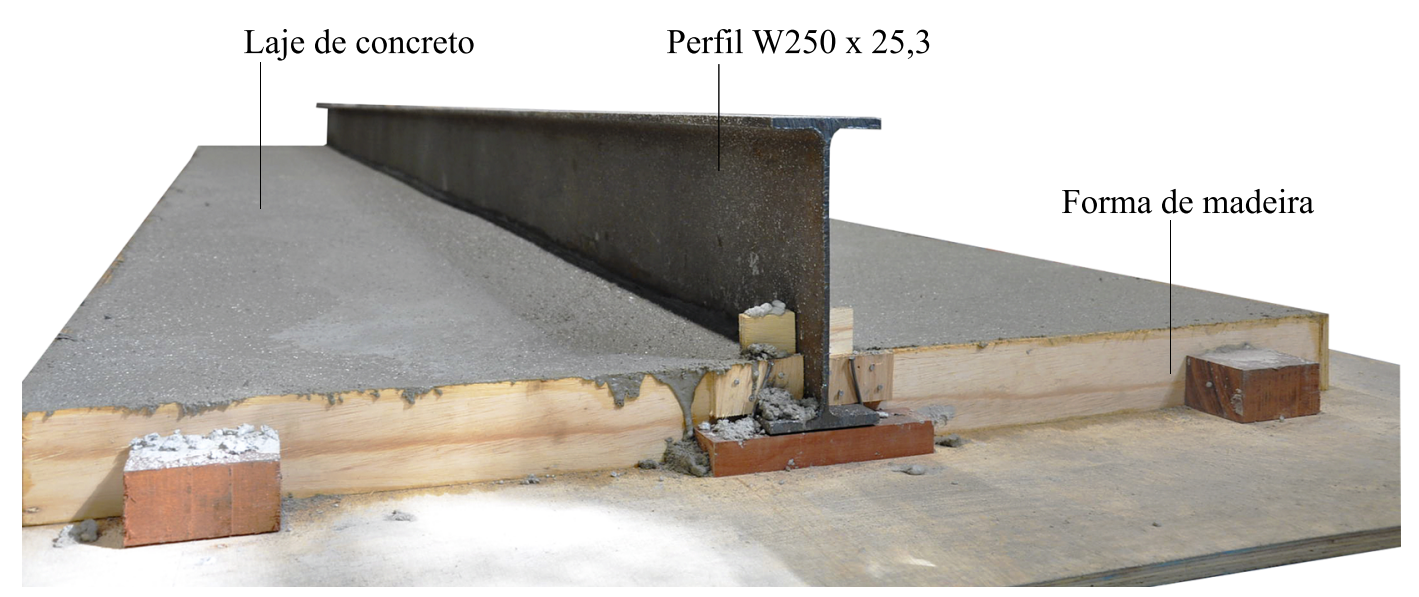

Figura 4.12: Confecção do protótipo VMT

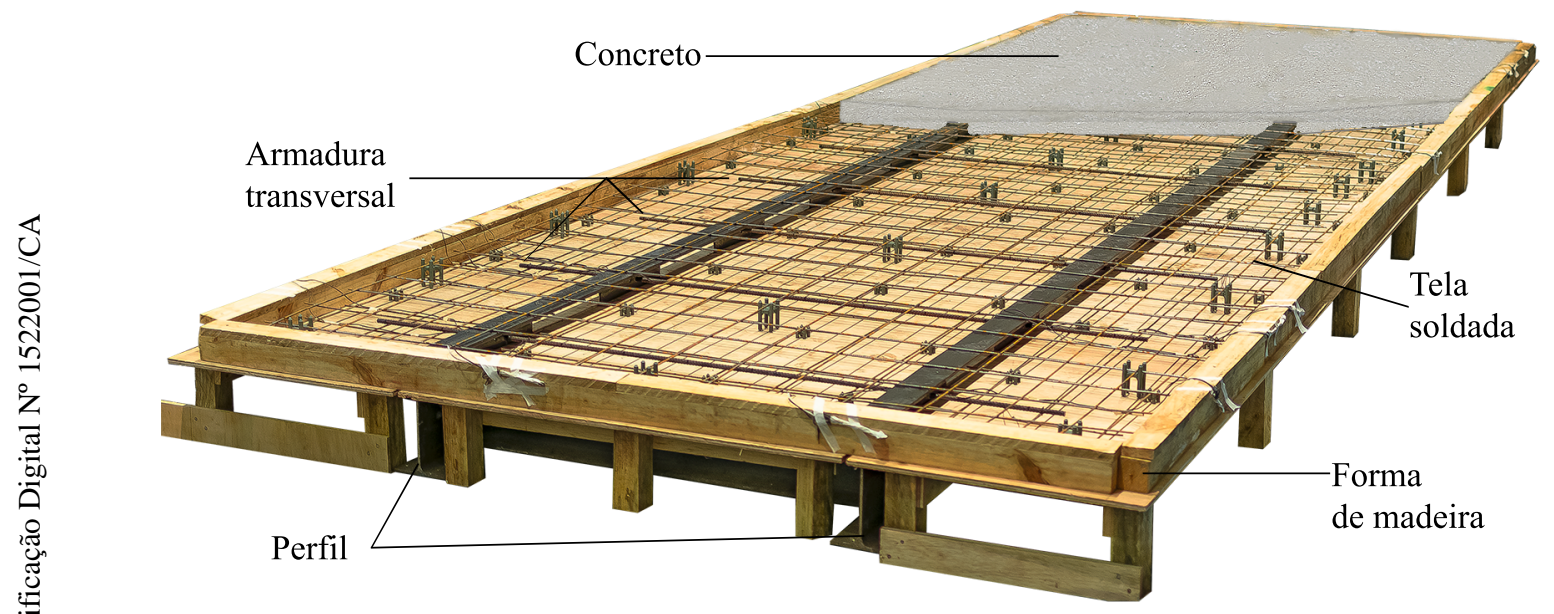

Figura 4.13: Confecção dos protótipos VMPI-1 e VMPI-2

\subsection{2}

\section{Procedimento de ensaio e instrumentação}

A Fig. 4.14 e a Fig. 4.15 mostram as configurações dos ensaios do protótipo VMT e protótipos VMPI-1 e VMPI-2, respectivamente.

Aparelhos de apoio de primeiro e segundo gênero foram utilizados nas extremidades das vigas. O carregamento foi aplicado por um atuador hidráulico (MTS) com capacidade de $500 \mathrm{kN}$. Foi realizado o ensaio a flexão em 6 pontos para a VMT e em 4 pontos para os protótipos VMPI-1 e VMPI-2.

Os ensaios foram divididos em duas etapas, uma cíclica e uma estática. No ensaio cíclico, foram aplicados 5000 ciclos de carga e descarga. O carregamento variou entre $5 \%$ a $60 \%$ da carga prevista de ruptura, e a frequência foi de $0,5 \mathrm{H}_{z}$ para o VMT e $0,45 H_{z}$ para os VMPI-1 e VMPI-2.

No ensaio estático, passou-se para controle de deslocamento. O ensaio 


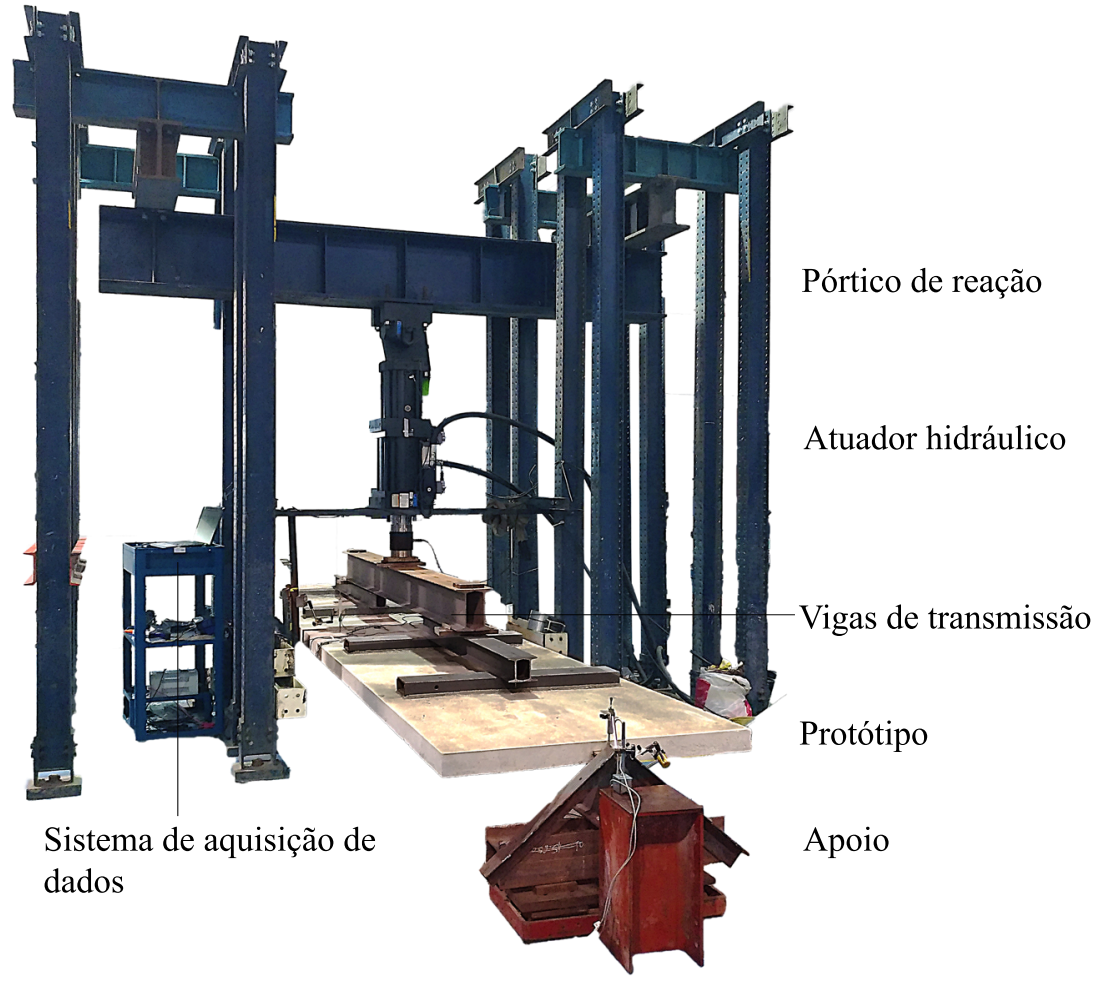

4.14(a): Elementos de ensaio
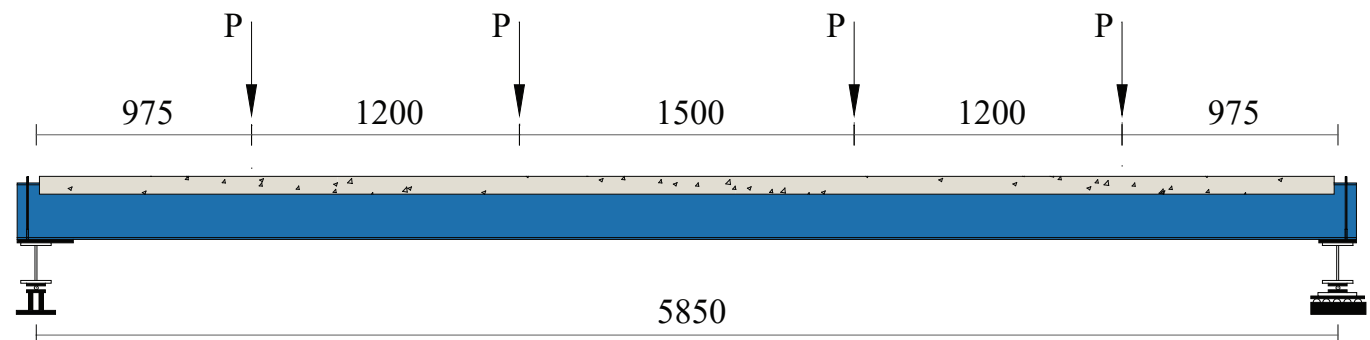

4.14(b): Pontos de aplicação de carga

Figura 4.14: Configuração de ensaio do protótipo VMT [mm]

foi subdividindo em três fases. Na primeira fase, a velocidade de aplicação de carga foi de $1 \mathrm{~mm} / \mathrm{min}$ até atingir o deslocamento de $22 \mathrm{~mm}$. Na segunda fase, diminuiu-se a velocidade para $0,5 \mathrm{~mm} / \mathrm{min}$ até o deslocamento de $40 \mathrm{~mm}$. Por fim, na última fase, a velocidade foi reduzida para $0,3 \mathrm{~mm} / \mathrm{min}$, levando o ensaio à ruptura.

Na Fig. 4.16, é apresentado o posicionamento da instrumentação nas armaduras transversais e na laje de concreto. Dois transdutores de deslocamentos (T1 e T2) foram utilizados para medir a flecha da viga no meio do vão. Os transdutores D1, D2, D3 e D4 mediram o deslizamento relativo entre o perfil e a laje de concreto nas extremidades da viga.

$\mathrm{Na}$ face superior da laje, foram utilizados dois extensômetros (C1 e C2) para medir as deformações do concreto. Nas armaduras transversais, as 


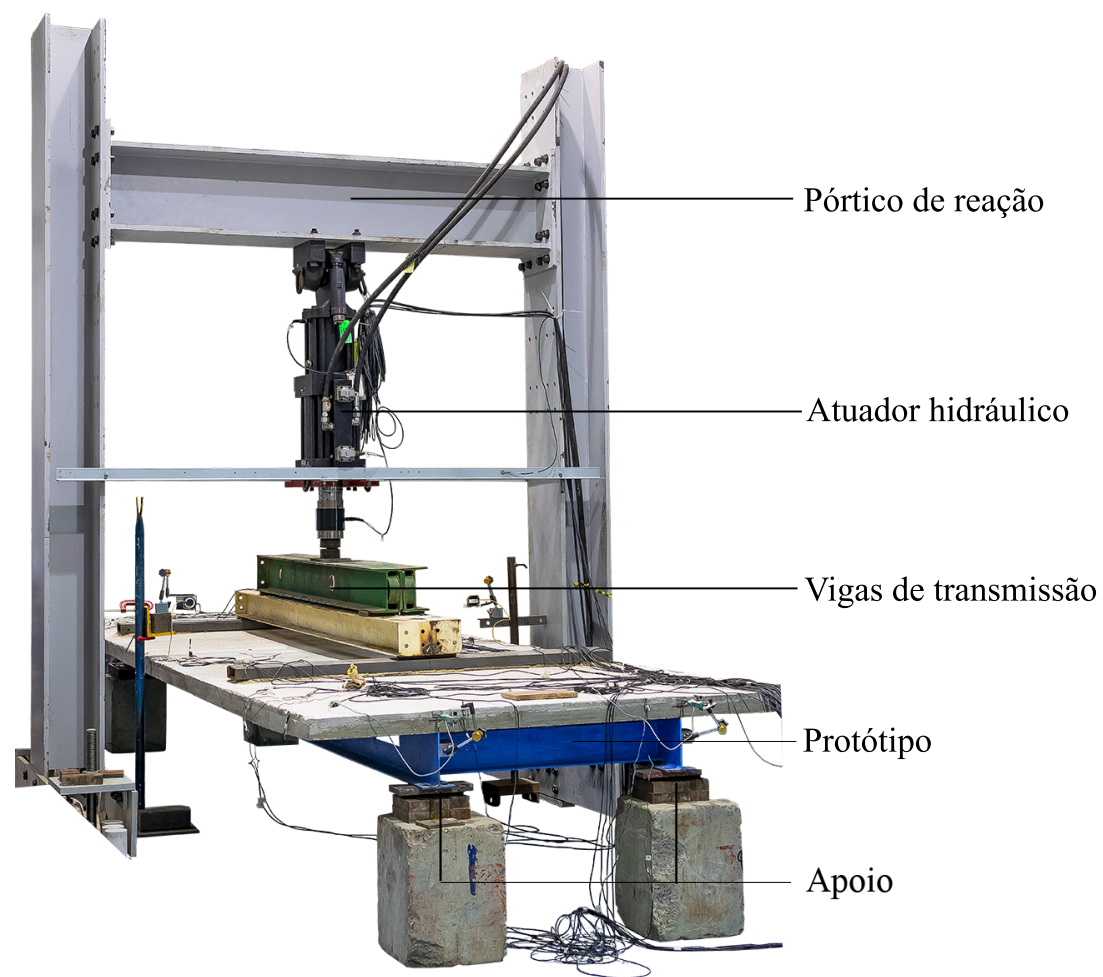

4.15(a): Elementos de ensaio (VMPI-1 e VMPI-2)

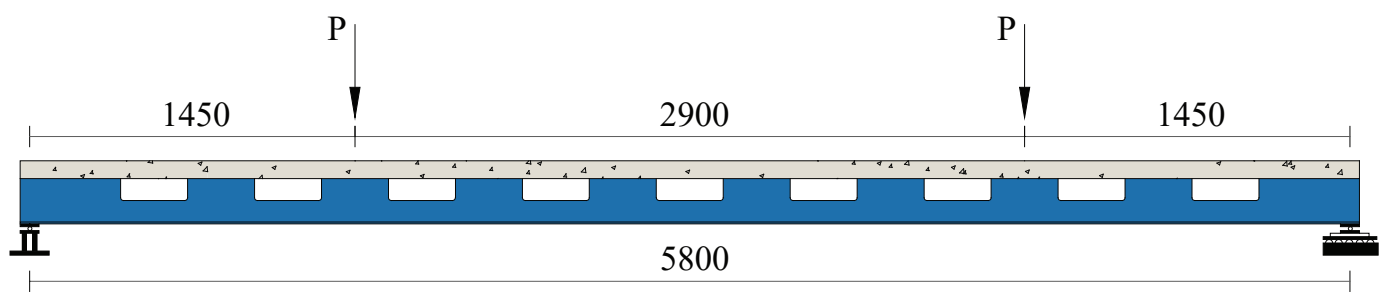

4.15(b): Pontos de aplicação de carga (VMPI-1)

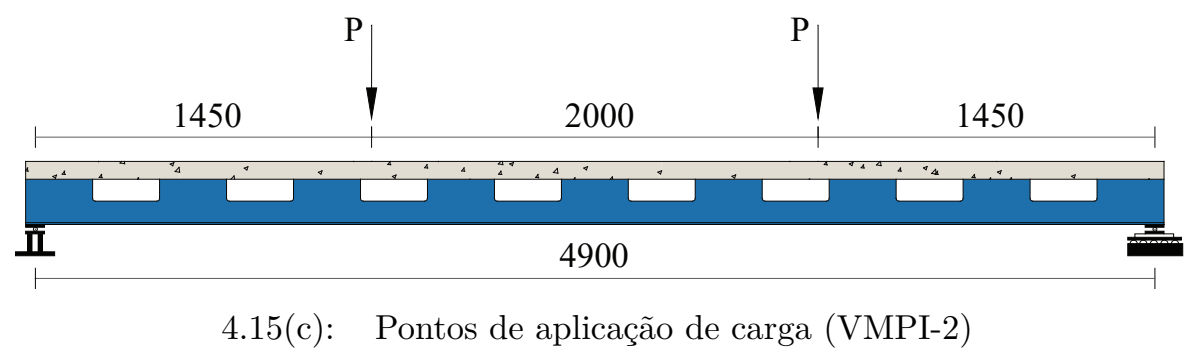

Figura 4.15: Configuração de ensaio dos protótipos VMPI-1 e VMPI-2 [mm]

deformações foram medidas por extensômetros uniaxiais, posicionados perto da alma do perfil.

O perfil de aço foi monitorado por extensômetros na seção do meio do vão. $\mathrm{Na}$ viga mista VMT, dois extensômetros foram fixados na mesa superior (P1 e P2) e dois na mesa inferior (P3 e P4) (ver Fig. 4.17(a)). Nos protótipos VMPI1 E VMPI-2, foram posicionados quatro extensômetros na mesa superior (P1, P2, P3 e P4) e quatro na mesa inferior (P5, P6, P7 e P8) (ver Fig. 4.17(b) e $4.17(\mathrm{c}))$. 


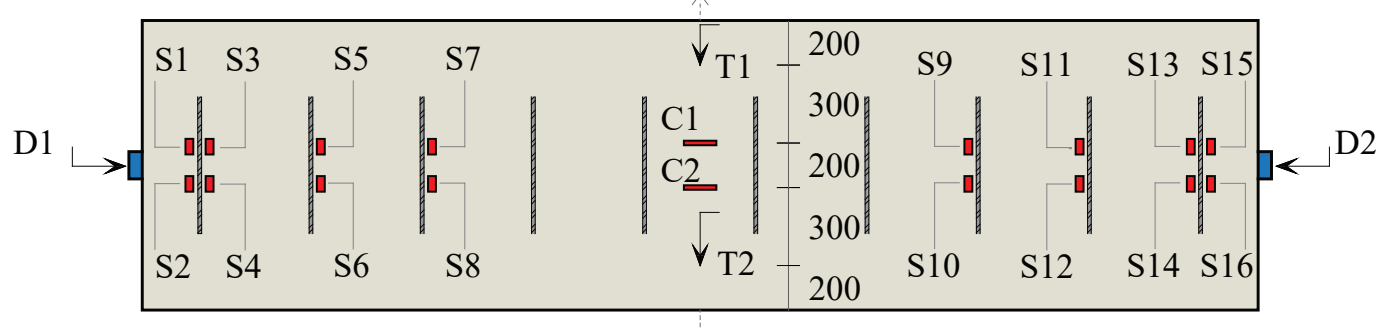

4.16(a): VMT

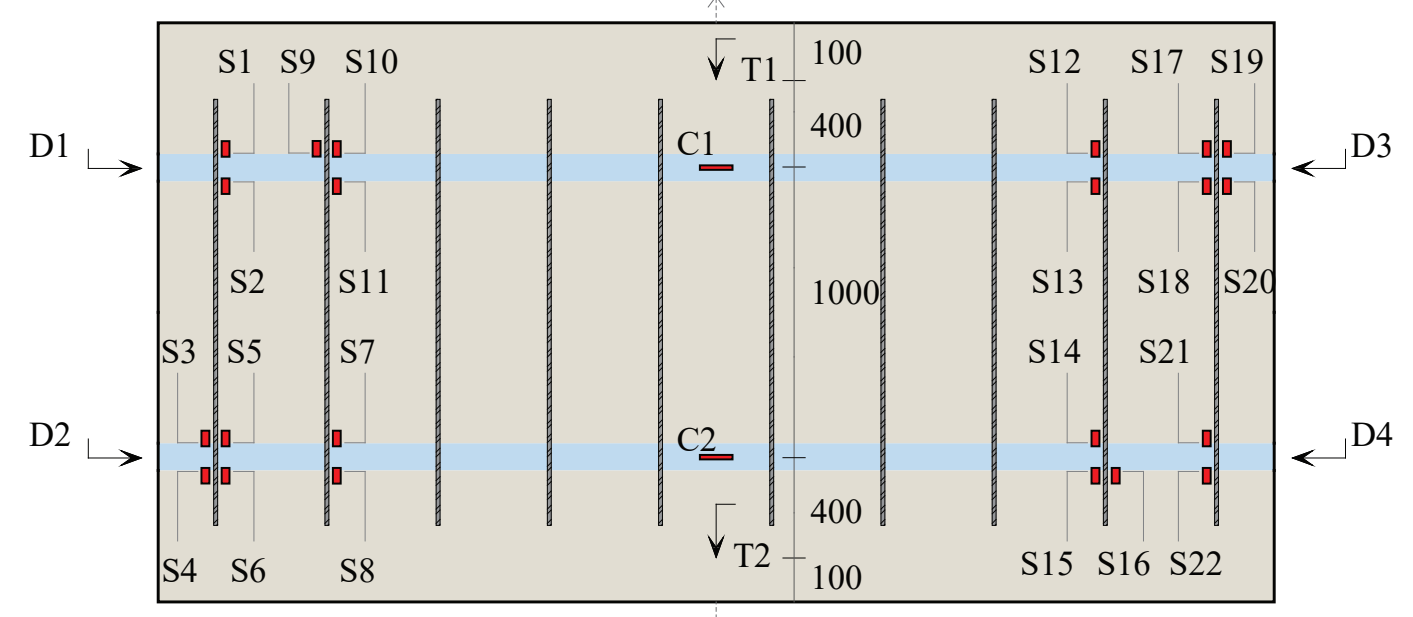

4.16(b): VMPI-1 e VMPI2

Figura 4.16: Instrumentação das armaduras transversais e da laje [mm]

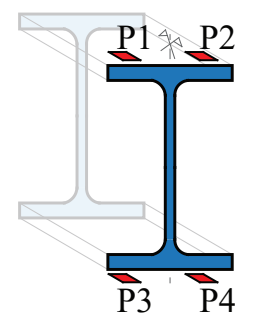

4.17(a): VMT
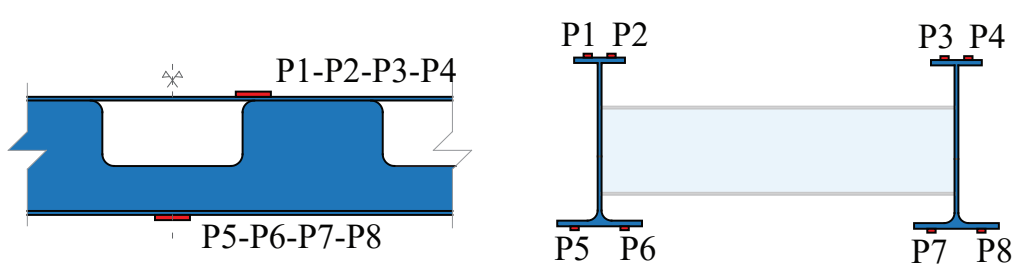

4.17(b): VMPI-1
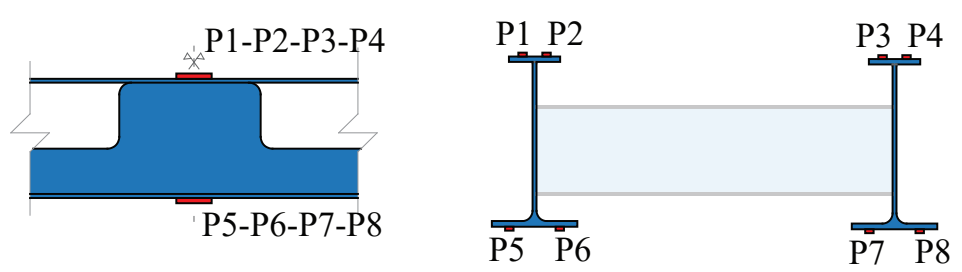

4.17(c): VMPI-2

Figura 4.17: Instrumentação do perfil 


\section{5}

\section{Resultados Experimentais: análise e discussão}

Este capítulo apresenta os resultados experimentais dos protótipos descritos no Capítulo 4 (Programa Experimental). Foram realizados ensaios de cisalhamento direto e de flexão com o objetivo principal de prover informações sobre o comportamento à flexão sob carga cíclica e estática, o mecanismo de ruptura, a resistência ao cisalhamento longitudinal, a influência das armaduras transversais e a contribuição da aderência na ligação mista.

\section{1}

\section{Resultados dos ensaios de cisalhamento direto}

\subsection{1}

\section{Comportamento carga - deslizamento}

A capacidade resistente e a ductilidade são duas características importantes ao avaliar o comportamento de um conector de cisalhamento. Ambas podem ser descritas a partir da relação força de cisalhamento vs. deslizamento relativo entre o aço e o concreto. A curva que representa essa relação foi obtida por meio de ensaios experimentais de cisalhamento direto (push-out) para quatro modelos, conforme apresentado na Fig. 5.1.

A resistência última ao cisalhamento do conector, $P_{u}$, foi obtida dividindo a carga última de ensaio do protótipo pelo número de aberturas (2 aberturas de alma). A capacidade de deslizamento, $\delta_{u}$, corresponde ao deslizamento medido para o nível de carga característico, $P_{R k}$, ou seja, ela corresponde ao deslizamento máximo no qual o conector ainda suporta $90 \%$ de sua resistência característica ao cisalhamento.

A maior parte do cisalhamento longitudinal desenvolveu-se na interface aço-concreto por aderência, cuja ruptura ocorreu já próximo à resistência última, $P_{u}$, iniciando-se o deslizamento na interface aço-concreto. As tensões foram redistribuídas por meio de outros mecanismos da ligação, como as armaduras transversais. A distribuição das tensões de aderência é associada ao início do estado de fissuração da laje de concreto. Os resultados dos ensaios de cisalhamento direto estão resumidos na Tabela 5.1. 

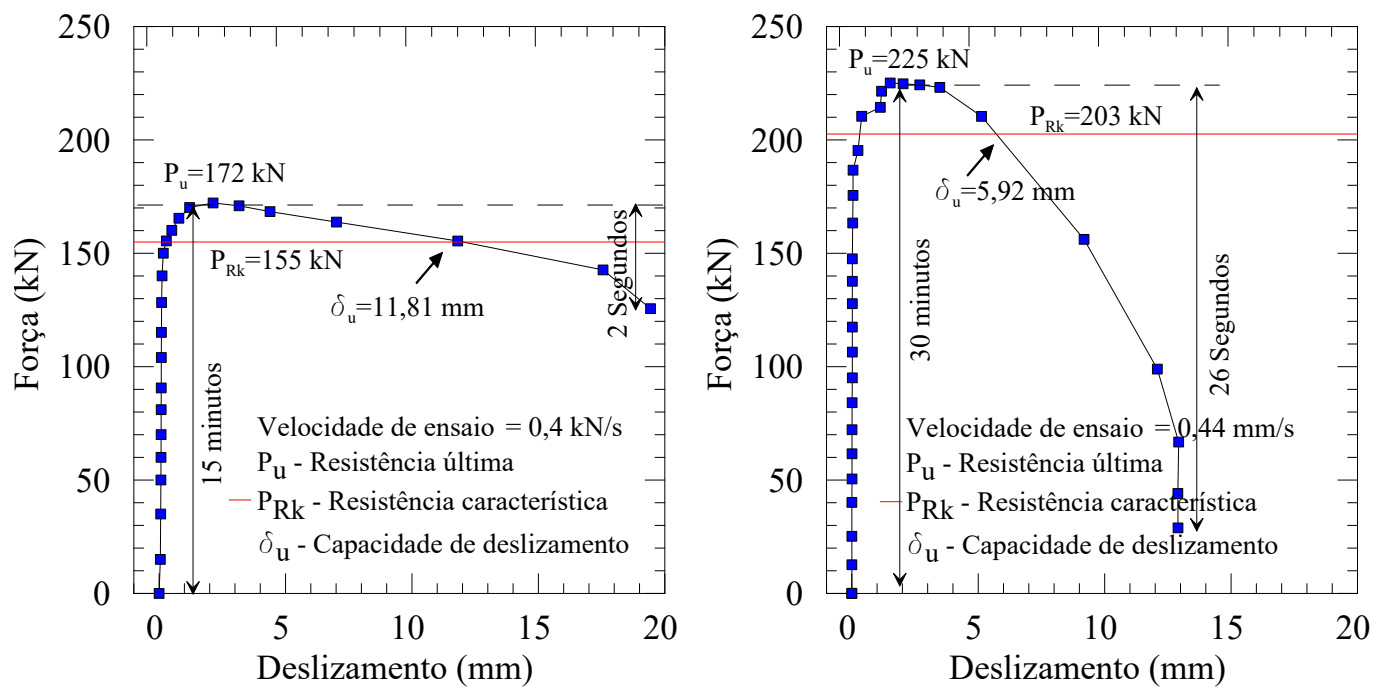

5.1(a): Protótipo P1

5.1(b): Protótipo P2
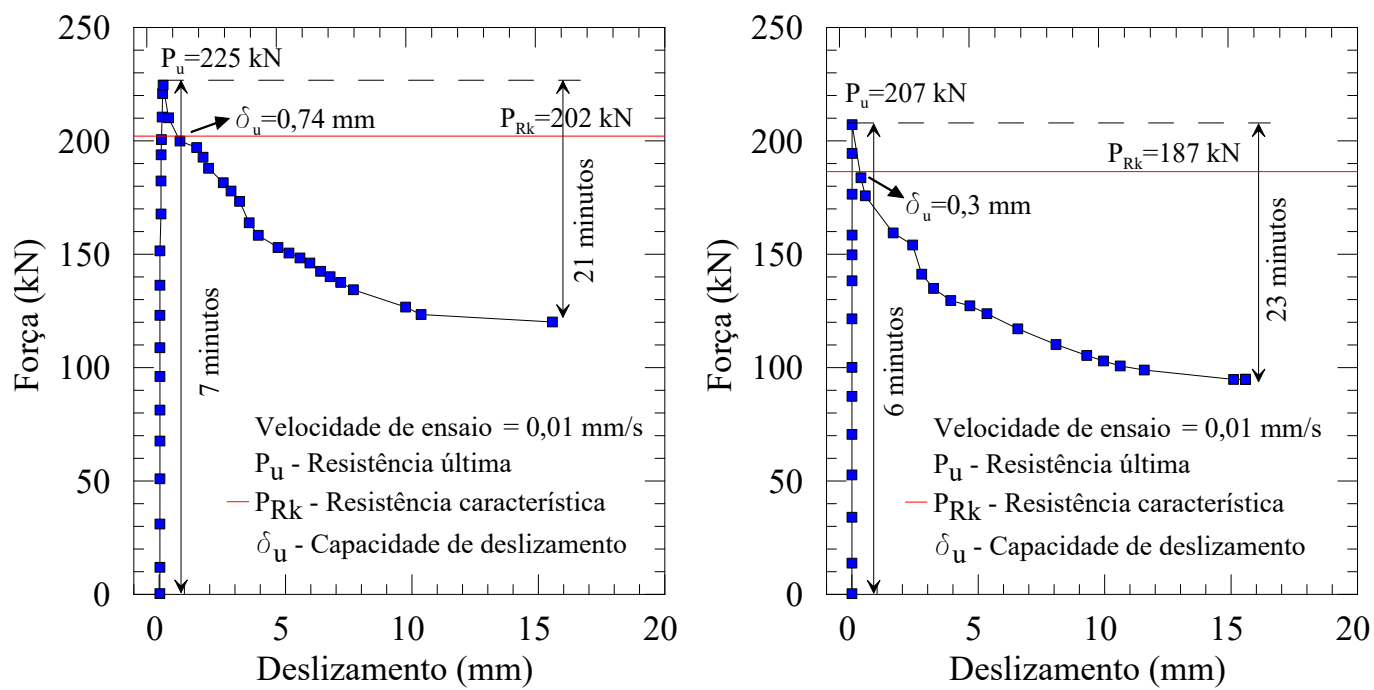

5.1(c): Protótipo P3

5.1(d): Protótipo P4

Figura 5.1: Curva carga vs deslizamento

Tabela 5.1: Resultados dos ensaios de cisalhamento direto

\begin{tabular}{llll}
\hline Protótipo & $\mathbf{P}_{u}$ & $\begin{array}{l}\mathbf{P}_{R k} \\
(k N)\end{array}$ & $\begin{array}{l}\delta_{u} \\
(m m)\end{array}$ \\
\hline P1 & 172.2 & 155.0 & 11.81 \\
P2 & 225.1 & 202.6 & 5.92 \\
P3 & 224.5 & 202.1 & 0.74 \\
P4 & 207.2 & 186.5 & 0.30 \\
\hline
\end{tabular}

$P_{u}$ - Resistência última ao cisalhamento

$P_{R k}$ - Resistência característica ao cisalhamento

$\delta_{u}$ - Capacidade de deslizamento 


\subsection{2 \\ Ductilidade}

Quanto à ductilidade, o conector apresentou comportamento rígido durante a fase cíclica do ensaio e ao longo do carregamento antes de atingir a carga máxima. Nesta fase, nenhum elemento da conexão se deformou.

O comportamento da conexão divergiu entre os ensaios na fase de deslizamento. O ensaio P1 apresentou ductilidade após atingir a carga máxima. A capacidade de deslizamento foi de 11,81 mm, valor superior ao mínimo de $6 \mathrm{~mm}$ para ser classificado como dúctil de acordo com EUROCODE 4 [36]. O ensaio P2 teve capacidade de deslizamento de 5,92 $\mathrm{mm}$, um pouco abaixo do mínimo exigido.

Os ensaios P3 e P4 apresentaram perda imediata da resistência para pequenos deslizamentos. A capacidade de deslizamento foi de $0,74 \mathrm{~mm}$ e 0,30 mm para os protótipos P3 e P4, respectivamente, caracterizando a ligação como rígida.

\subsection{3 \\ Influência da armadura transversal na capacidade do conector}

As armaduras trabalham controlando a abertura das fissuras e, consequentemente, contribuem para a resistência ao cisalhamento do concreto no pós-fissuração. Na Fig. 5.2, são apresentadas as curvas força vs. deformação para as armaduras transversais referentes aos protótipos P1, P2, P3 e P4, respectivamente.

As deformações nas armaduras foram observadas após a ruptura da aderência entre a laje e o perfil, quando ocorreu a redistribuição das tensões pela laje de concreto e o aparecimento de fissuras longitudinais. Nesta fase do ensaio, as armaduras apresentaram aumento das deformações com diminuição da força aplicada, demonstrando que não foram capazes de manter a capacidade de carga dos protótipos.

Em todos os ensaios, as três barras de aço dentro de cada abertura não foram solicitadas da mesma maneira, com as barras mais próximas da alma contribuindo com a maior parte da resistência e atingindo a ruptura. Comparando os resultados dos protótipos P1 e P3, a mudança da armadura reta para $45^{\circ}$ aumentou a resistência última em $30 \%$, ao passo que nos ensaios com viga mista realizadas por Kullmari [109], o aumento foi de $15 \%$. 


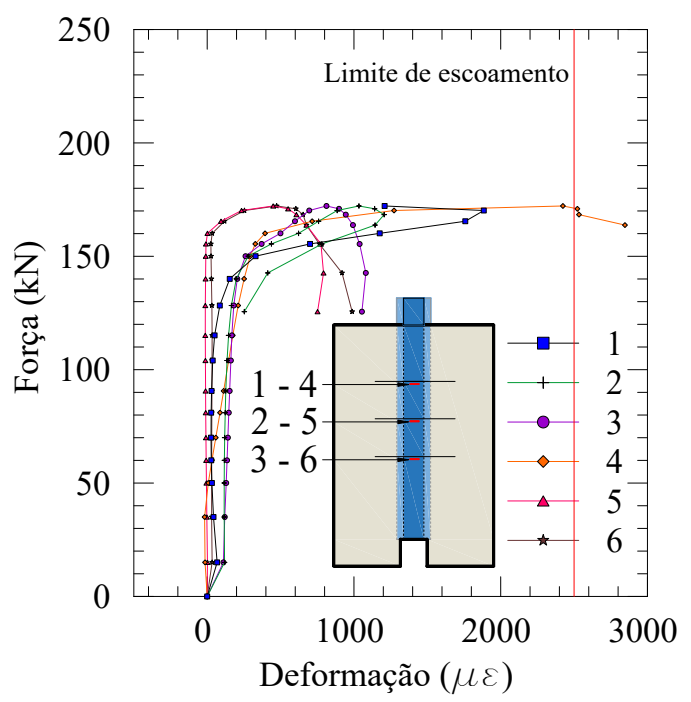

5.2(a): Protótipo P1

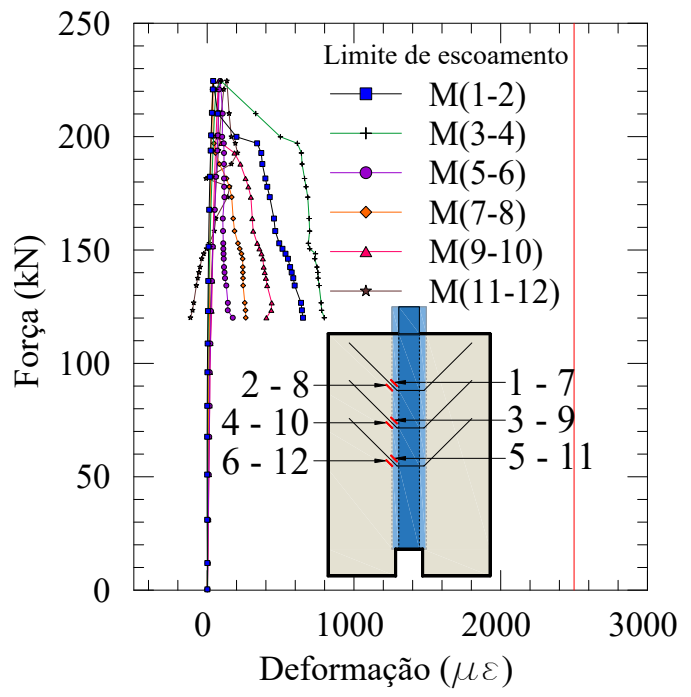

5.2(c): Protótipo P3

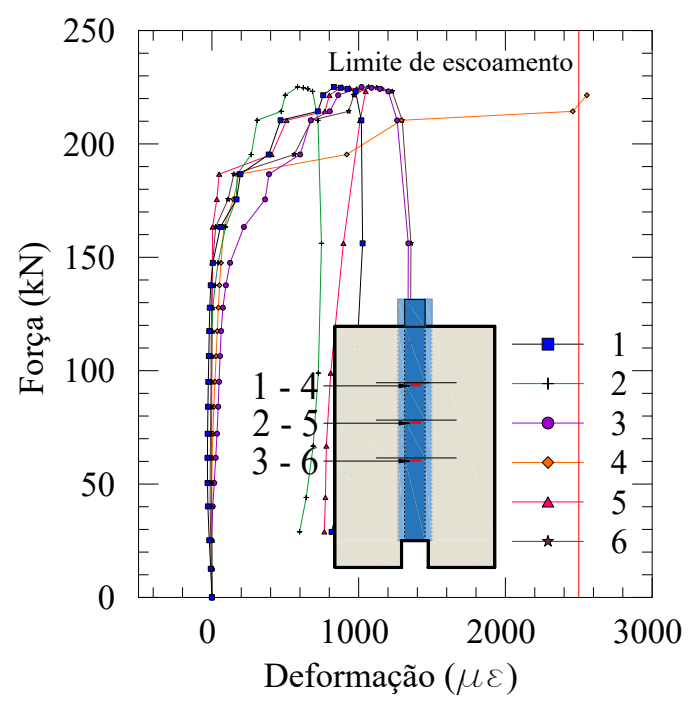

5.2(b): Protótipo P2

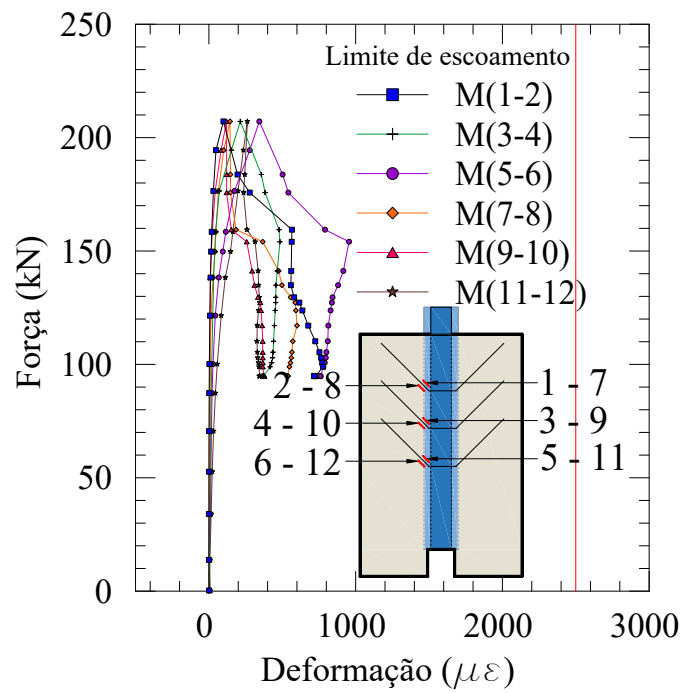

5.2(d): Protótipo P4

Figura 5.2: Curva carga vs deformação da armadura transversal

\subsection{4}

\section{Influência da chapa de alma}

Nos modelos sem chapa de alma (P1, P3 e P4), a alma do perfil na região de abertura encontrava-se em contato direto com o concreto (ver Fig. 5.3(a)). Dessa forma, a região em compressão no concreto ficou reduzida, produzindo tensões de tração consideráveis que originou fissuras de separação no plano da abertura.

Para o protótipo $\mathrm{P} 2$, foi adicionado uma chapa soldada à alma do perfil em cada extremidade da abertura. O aumento da região sob compressão permitiu que as forças se distribuíssem melhor no concreto confinado, da mesma forma que o conector T-Perfobond [16]. Nesse caso, o concreto atingiu 
o limite de resistência ao cisalhamento nos dois planos de corte coincidentes com as faces laterais da chapa, conforme ilustrado na Fig. 5.3(b).

O modelo com chapa (P2) obteve um aumento de 30\% na resistência última em comparação com o protótipo equivalente sem chapa (P1).

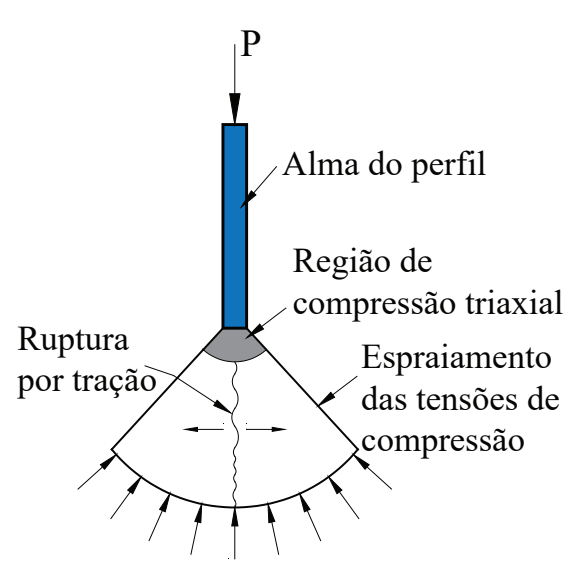

5.3(a): Protótipo P1, P3 e P4

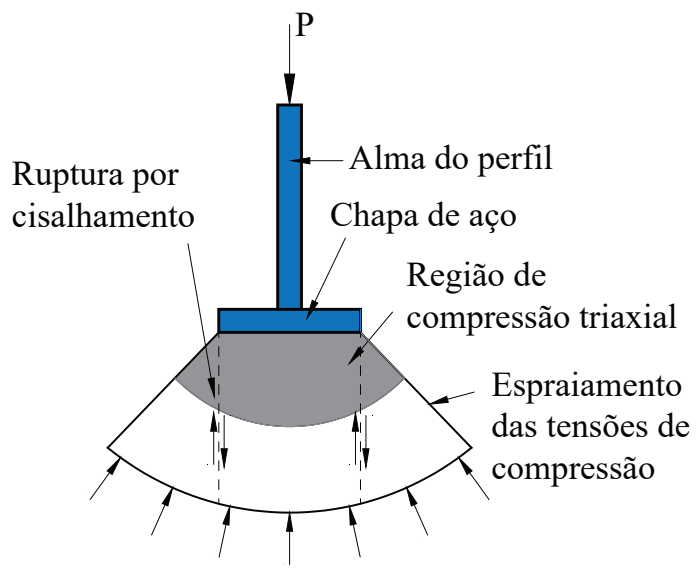

5.3(b): Protótipo P2

Figura 5.3: Influência da chapa de alma na ligação aço-concreto

\section{2}

\section{Configuração das fissuras}

A transferência pontual dos esforços do perfil para a laje introduz no concreto tensões inclinadas de compressão e, consequentemente, esforços transversais de tração. O comportamento do concreto, tanto sob compressão quanto sob tração, está intimamente ligado à formação e à propagação de fissuras. A Fig. 5.4 apresenta a configuração das fissuras nos protótipos.

Os ensaios apresentaram um padrão de fissuração. Na face externa da laje, as fissuras surgiram próximo à mesa embutida no concreto e seguiram até a abertura na base dos protótipos. Na face interna, além de fissuras, ocorreu a desagregação do concreto.

O protótipo P1 foi o ensaio que apresentou maior dano ao concreto (ver Fig. 5.5). As armaduras em $45^{\circ}$ demonstraram melhor controle da abertura e propagação das fissuras. A Fig. 5.6 apresenta o estado final da armadura transversal no protótipo P2, enquanto as Fig. 5.7 e 5.8 apresentam a configuração final dos protótipos P3 e P4. 


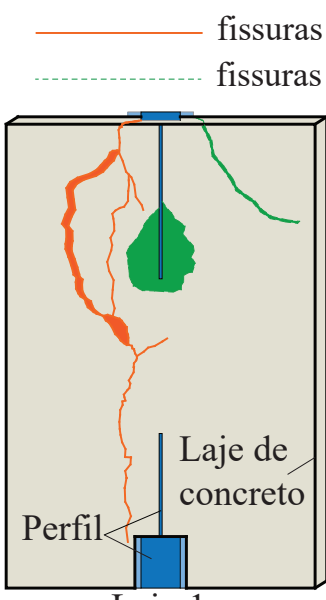

Laje-1

Laje-1 5.4(c): Protótipo P3 5.4(a): Protótipo P1

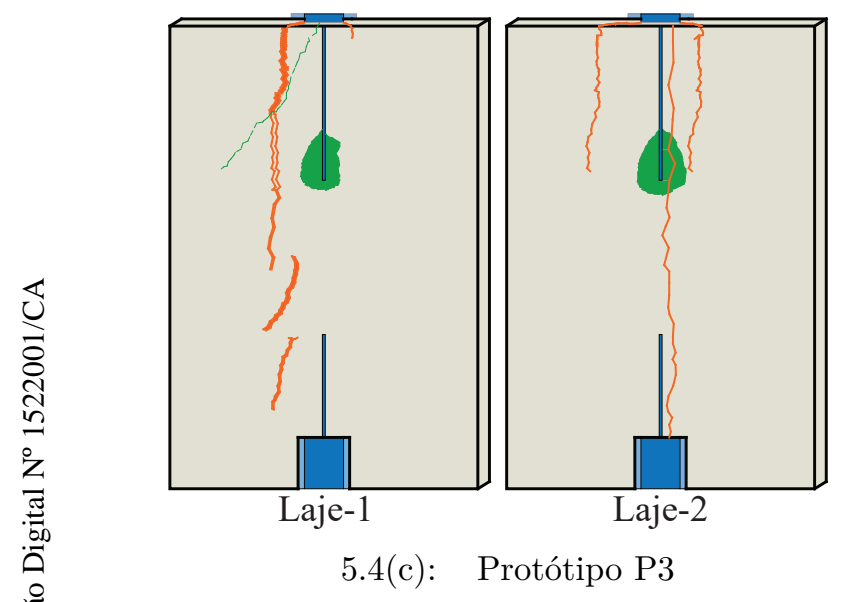

Laje-2
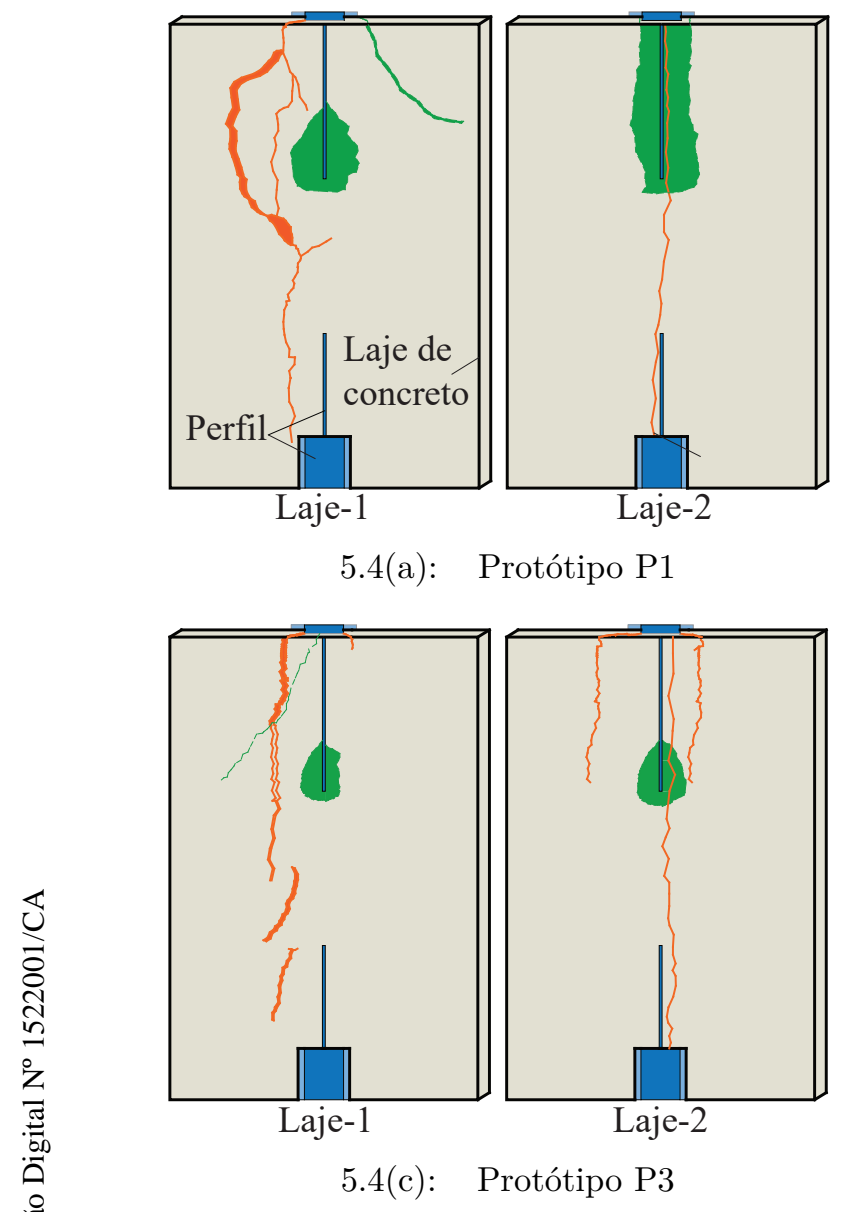

Laje-2 desagregação na face superior da laje desagregação na face inferior da laje
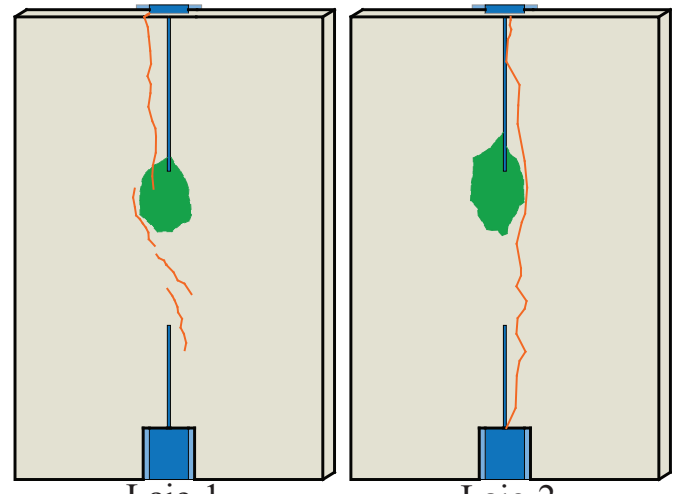

Laje-2

5.4(b): Protótipo P2

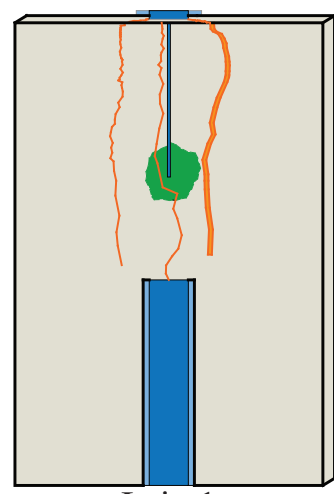

Laje-1

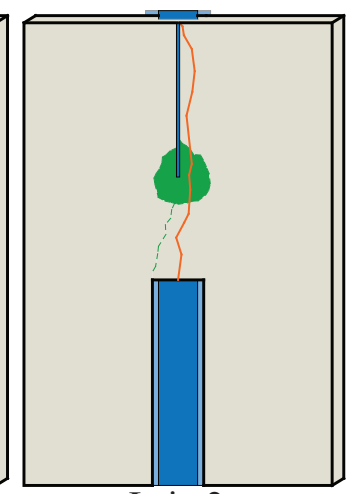

Laje-2

5.4(d): Protótipo P4

Figura 5.4: Curva carga vs deformação da armadura transversal

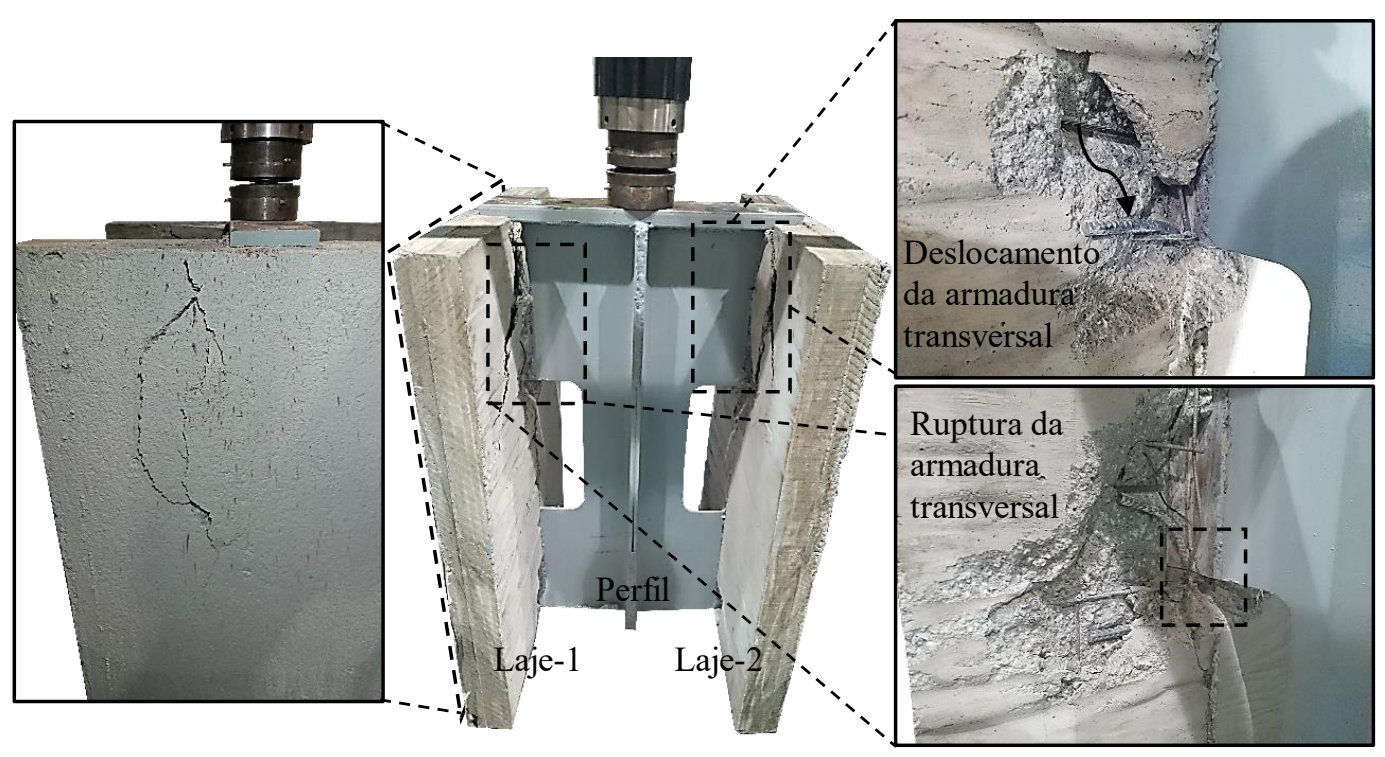

Figura 5.5: Configuração final do protótipo P1 


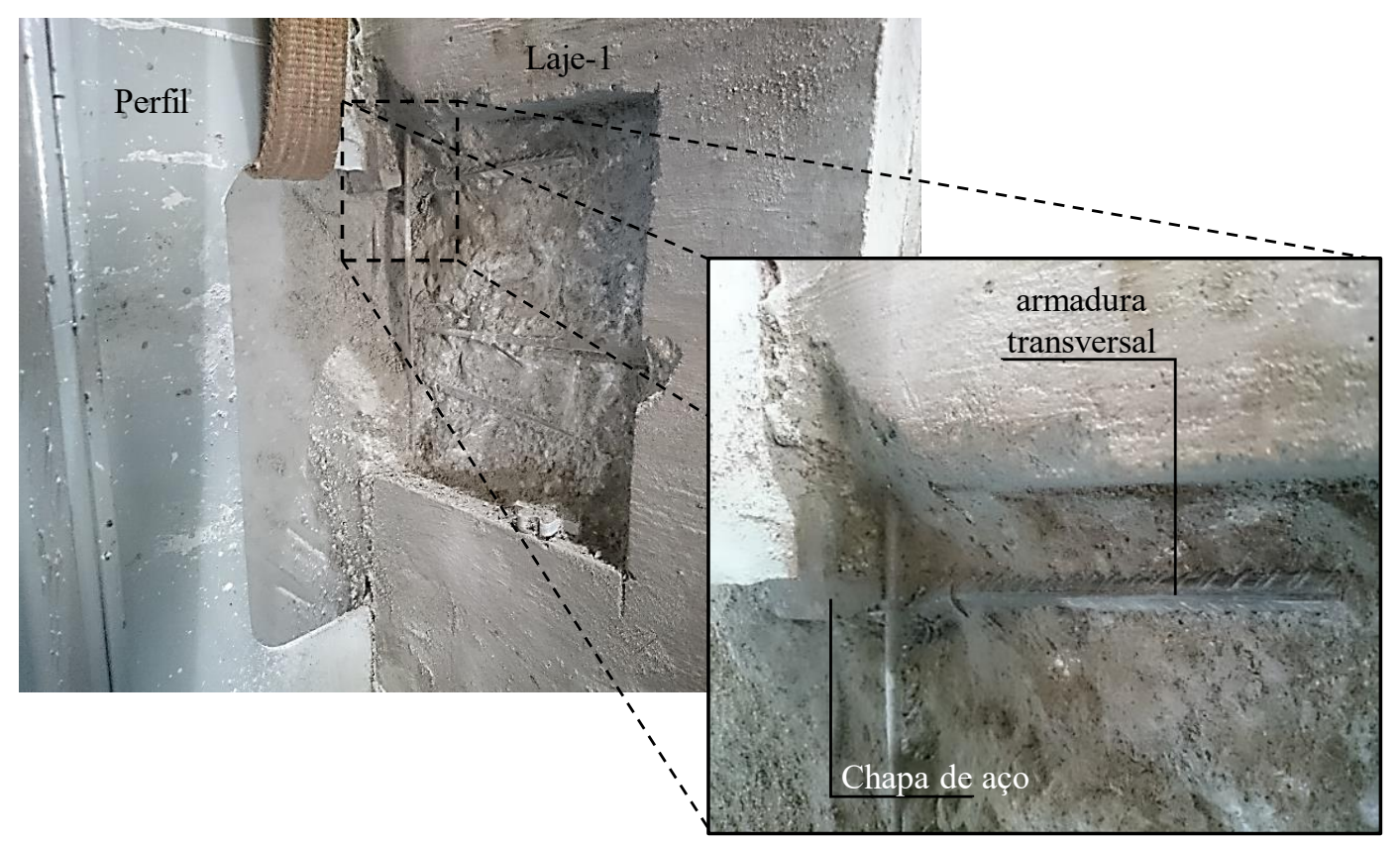

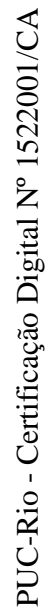

Figura 5.6: Flexão da armadura transversal no protótipo P2

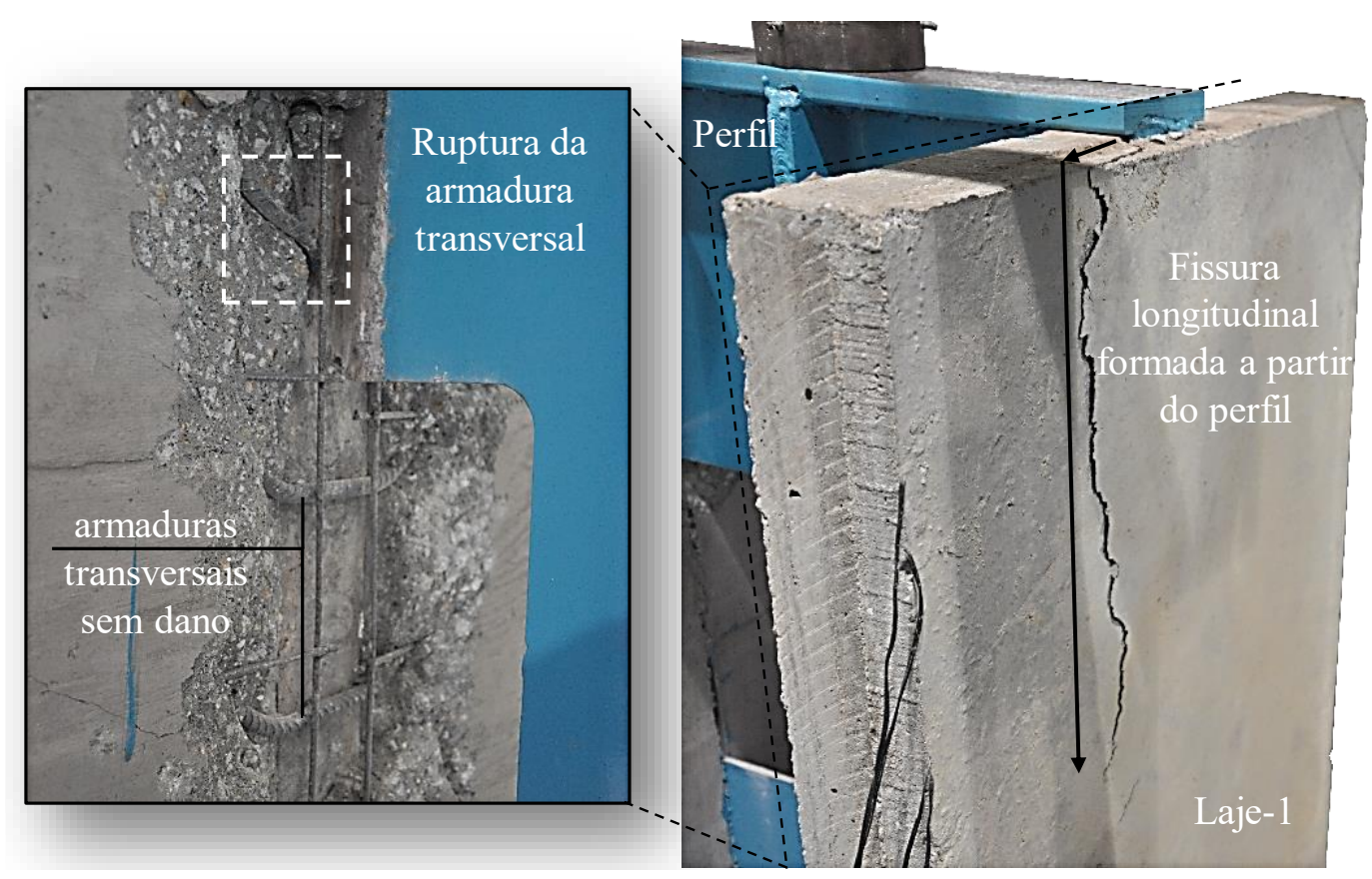

Figura 5.7: Configuração final do protótipo P3 

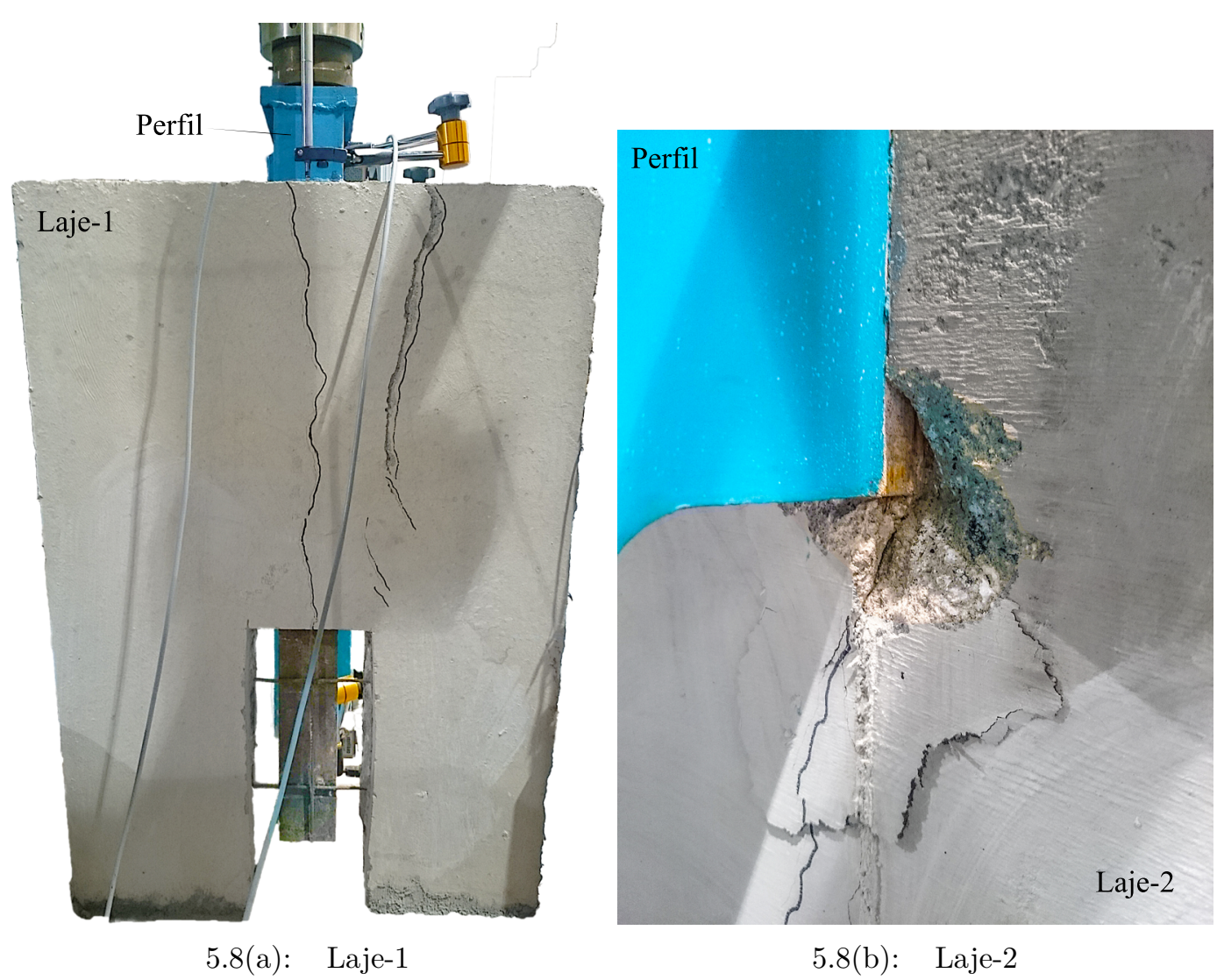

Figura 5.8: Configuração final do protótipo P4

\section{3}

\section{Resultados dos ensaios de flexão das Vigas Mistas}

\subsection{1}

\section{Ensaio cíclico}

O ensaio cíclico foi realizado aplicando um carregamento cíclico vertical com amplitude constante. O deslizamento residual na interface aço-concreto foi monitorado ao final dos 5000 ciclos. Além disso, foi observada a variação de tensão na seção do meio do vão no concreto da laje e no aço do perfil.

As Figuras 5.9 a 5.11 apresentam os gráficos dos resultados obtidos no ensaio cíclico. A Tabela 5.2 apresenta um resumo dos valores máximos e mínimos de tensão no aço e concreto, o momento fletor, a flecha e o deslizamento residual. 
Tabela 5.2: Resultados medidos do ensaio cíclico

\begin{tabular}{lllllll}
\hline Protótipo & $\begin{array}{l}\sigma_{s} \\
(M P a)\end{array}$ & $\begin{array}{l}\sigma_{c} \\
(M P a)\end{array}$ & $\begin{array}{l}M F \\
(k N . m)\end{array}$ & $\begin{array}{l}\text { Flecha } \\
(m m)\end{array}$ & $\begin{array}{l}\text { Deslizamento } \\
(m m)\end{array}$ & $\begin{array}{l}\text { Frequência } \\
(H z)\end{array}$ \\
\hline VMT & {$[32-179]$} & {$[1-7]$} & {$[8-74]$} & {$[2-17]$} & 0 & 0,50 \\
VMPI-1 & {$[52-104]$} & {$[3-5]$} & {$[37-78]$} & {$[7-14]$} & 2,85 & 0,45 \\
VMPI-2 & {$[57-159]$} & {$[2-6]$} & {$[40-120]$} & {$[5-13]$} & 0,22 & 0,45 \\
\hline
\end{tabular}

[Mín - Máx] - resultado mínimo e máximo do ensaio cíclico

$\sigma_{s}$ - tensão do aço na mesa inferior do perfil

$\sigma_{c}$ - tensão do concreto na laje

$M F$ - momento fletor no meio do vão

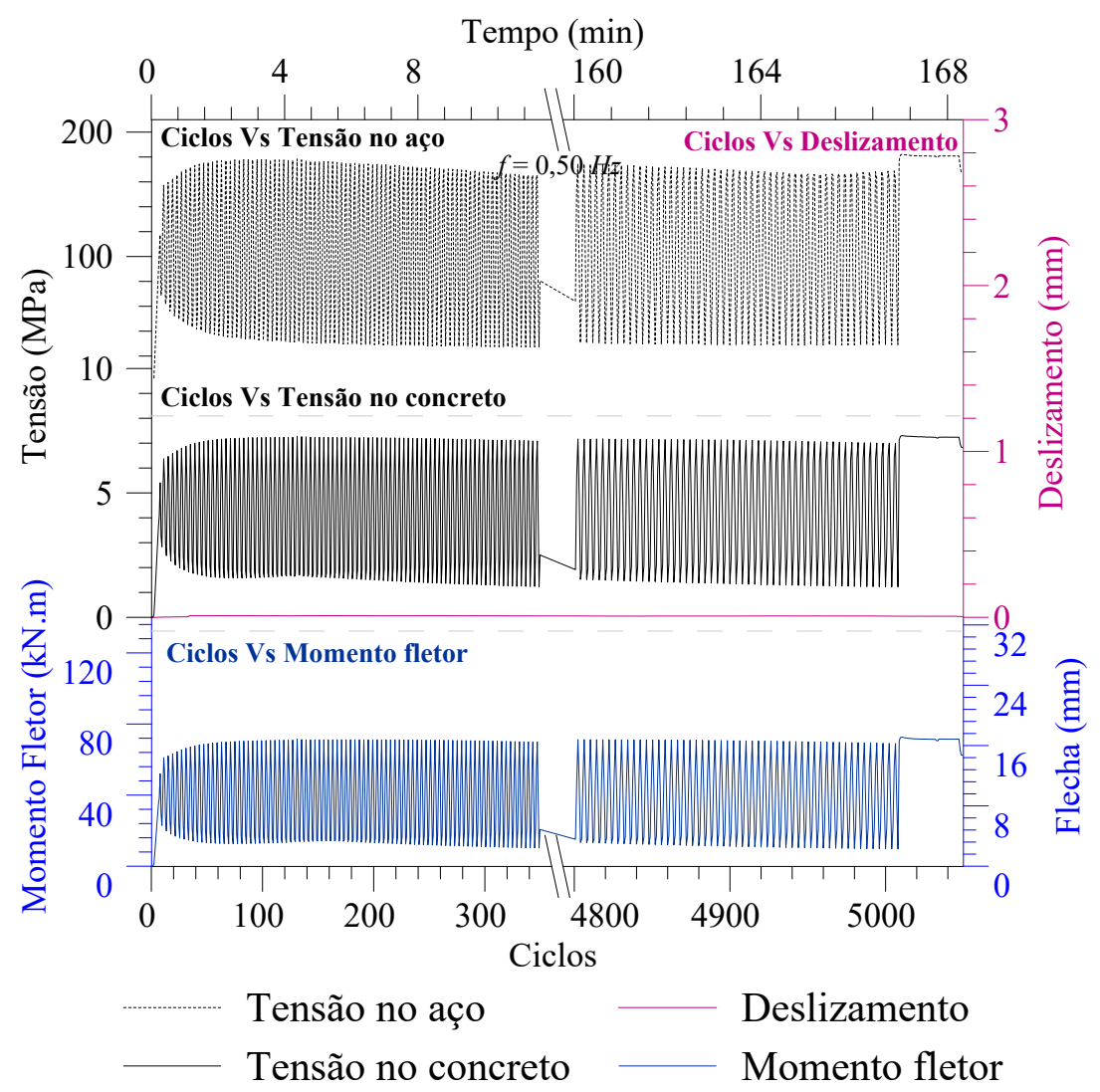

Figura 5.9: Resultado do ensaio cíclico - VMT

Nessa fase cíclica, como esperado, os materiais (aço e concreto) não tiveram dano e nem mesmo entraram em escoamento. O protótipo VMT atingiu $48 \%$ do valor da tensão de escoamento do aço e $21 \%$ da resistência a compressão do concreto. Os protótipos VMPI-1 e VMPI-2, por sua vez, atingiram $30 \%$ e $44 \%$ da tensão de escoamento do aço e $14 \%$ e $23 \%$ da resistência a compressão do concreto, respectivamente. Não foi identificado deslizamento relativo na interface aço-concreto do protótipo VMT, ao passo que o protótipo VMPI-1 (engraxado na superfície de contato aço-concreto) 


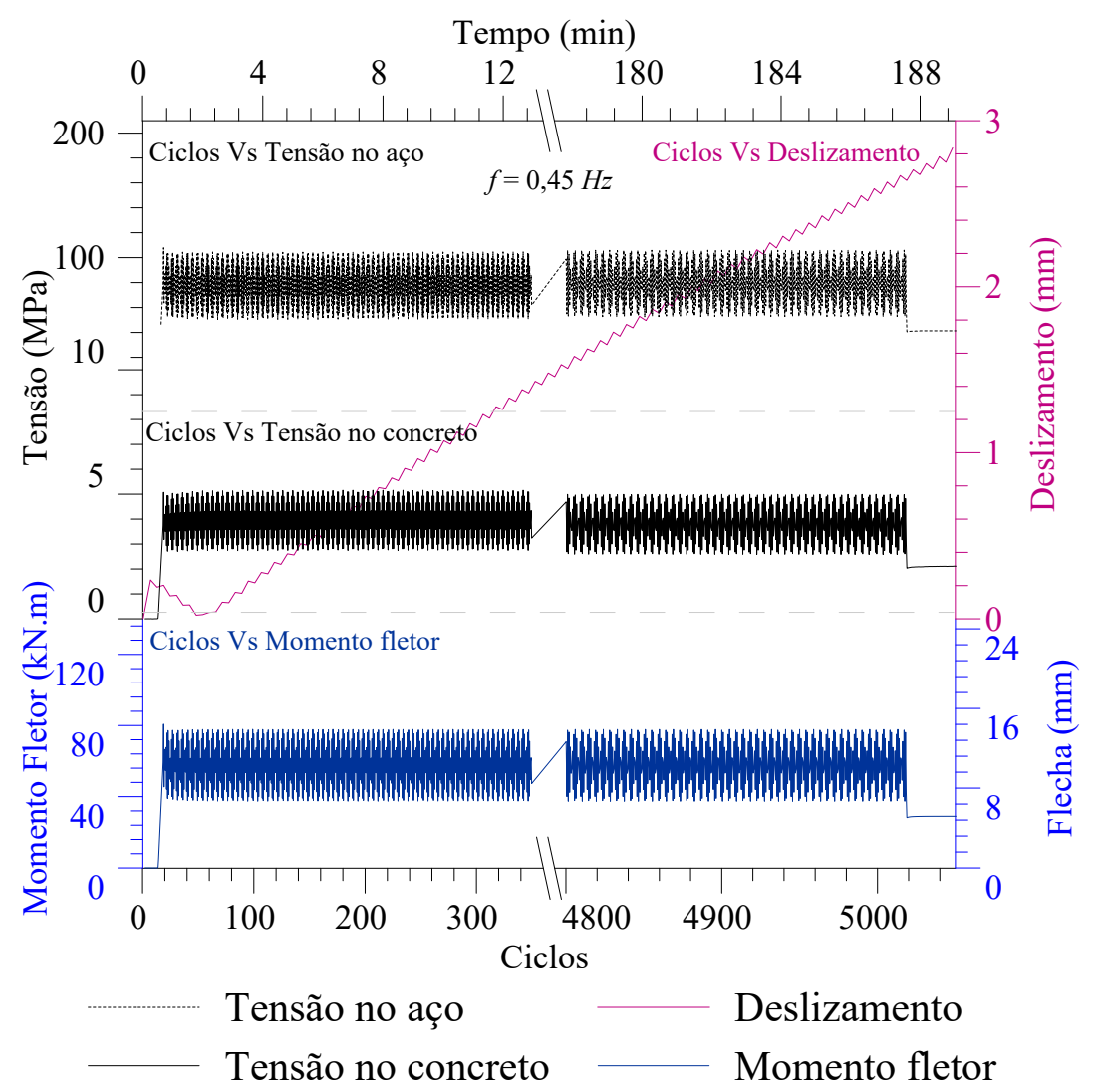

Figura 5.10: Resultado do ensaio cíclico - VMPI-1

atingiu um deslizamento de 2,85mm e o VMPI-2 teve deslizamento de 0,22mm.

\subsection{2}

\section{Ensaio Estático}

\subsubsection{1}

\section{Comportamento momento fletor vs. deflexão}

A Fig. 5.12 apresenta os resultados do comportamento momento fletor vs. deflexão dos protótipos de vigas mistas. As curvas são caracterizadas por três comportamentos: uma fase elástica seguida por uma fase plástica e, por último, a perda de resistência. A Tabela 5.3 apresenta os valores do momento fletor de início da plastificação $\left(M_{y}\right)$, o momento fletor máximo $\left(M_{u}\right)$ e os deslocamentos máximos $\left(d_{m a ́ x}\right)$.

\subsubsection{2}

\section{Deslizamento na interface aço-concreto}

O comportamento do deslizamento pode ser influenciado por muitos fatores: rugosidade da interface aço-concreto, excentricidades (inclinação da 


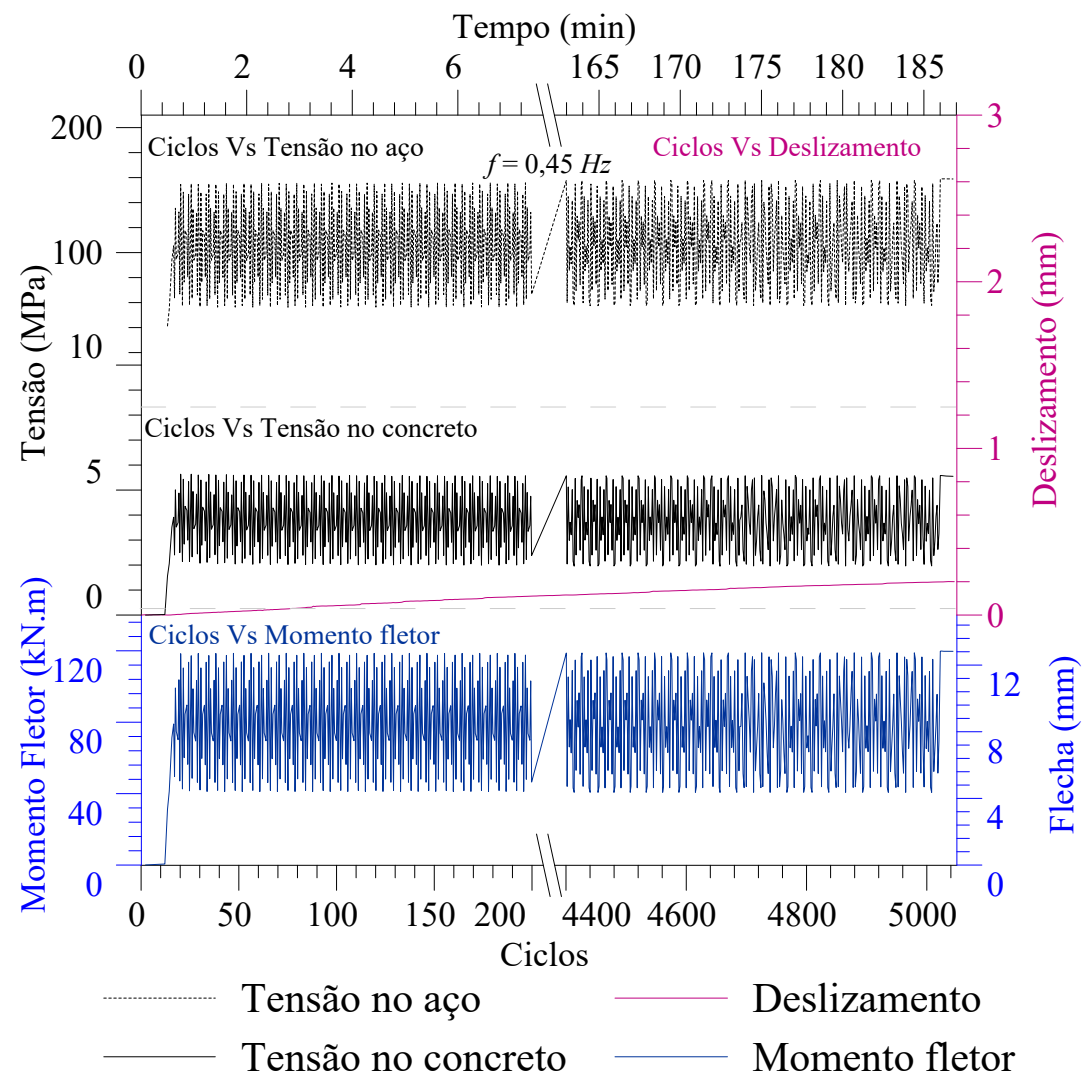

Figura 5.11: Resultado do ensaio cíclico - VMPI-2

Tabela 5.3: Resultados medidos do ensaio estático

\begin{tabular}{llllll}
\hline Protótipo & $\begin{array}{l}M_{y} \\
(k N . m)\end{array}$ & $\begin{array}{l}M_{u} \\
(k N . m)\end{array}$ & $\begin{array}{l}d_{m a ́ x} \\
(m m)\end{array}$ & $\begin{array}{l}\text { Laje } \\
(m m)\end{array}$ & $\begin{array}{l}\text { Vão } \\
(m m)\end{array}$ \\
\hline VMT & 95 & 158 & 148 & 1200 & 5850 \\
VMPI-1 & 140 & 200 & 102 & 1000 & 5800 \\
VMPI-2 & 160 & 238 & 86 & 1000 & 4900 \\
\hline
\end{tabular}

força de cisalhamento), taxa de armadura atravessando a da interface, presença de aberturas de alma e características do concreto.

No protótipo VMPI-1, foi utilizado um lubrificante pastoso na superfície de contato entre o perfil e a laje, contribuindo para a diminuição da aderência e do atrito entre os materiais. Por outro lado, os protótipos VMT e VMPI-2 mantiveram a área de contato sem tratamento superficial.

A taxa de armadura atravessando a interface manteve-se igual para todos os protótipos. Nos protótipos VMPI-1 e VMPI-2, as aberturas de alma preenchidas com concreto contribuíram para o travamento mecânico. Por outro lado, no protótipo VMT sem abertura de alma, a área de contato entre o aço e o concreto foi $29 \%$ e $40 \%$ maior que nos protótipos VMPI-1 e VMPI-2, respectivamente. Isso contribuiu para o aumento da resistência por aderência 


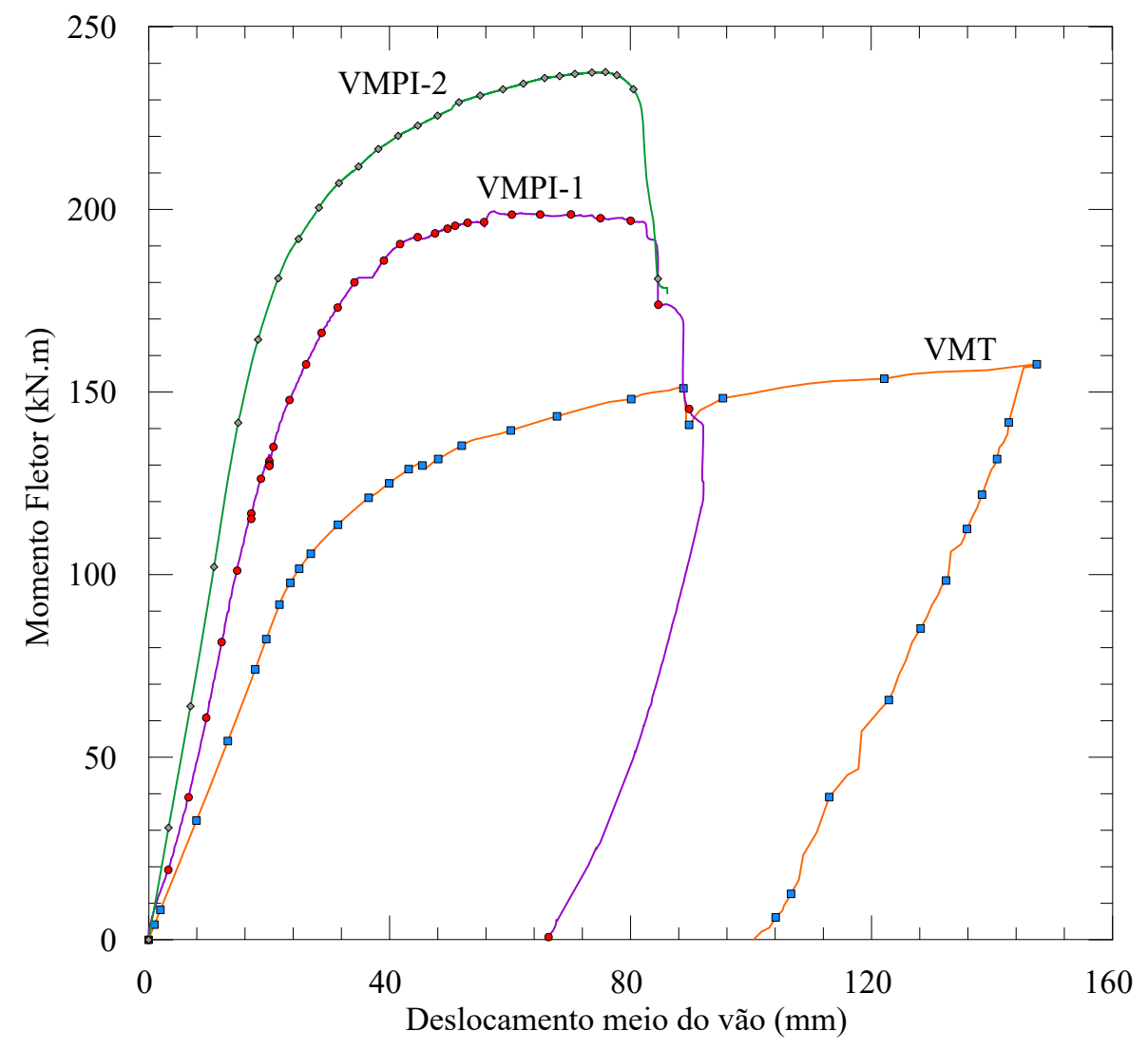

Figura 5.12: Comportamento momento fletor vs. deflexão

e atrito.

Os ensaios estáticos começaram com um valor residual de deslizamento devido ao ensaio cíclico. A Fig. 5.13 apresenta o comportamento da curva momento fletor vs. deslizamento. As curvas são caracterizadas por uma fase inicial de aderência, sem deslizamento e, após a ruptura do atrito estático, inicia-se a fase de deslizamento seguida pela perda de resistência.

A maior parte dos ensaios ocorreu sob interação total, com o deslizamento iniciando-se próximo da resistência última. No protótipo VMT, o deslizamento iniciou-se com $82 \%$ do momento máximo, ao passo que, nos protótipos VMPI1 e VMPI-2, o deslizamento iniciou-se com $75 \%$ e $71 \%$ da resistência última, respectivamente.

Na Tabela 5.4, são apresentados os valores de deslizamentos sob solicitação máxima e residual para cada protótipo.

\subsubsection{3}

\section{Deformação específica medida nos perfis}

Os valores médios de deformação medidos nas mesas superior e inferior do perfil são apresentados na Fig. 5.14, bem como o valor limite para o escoamento 

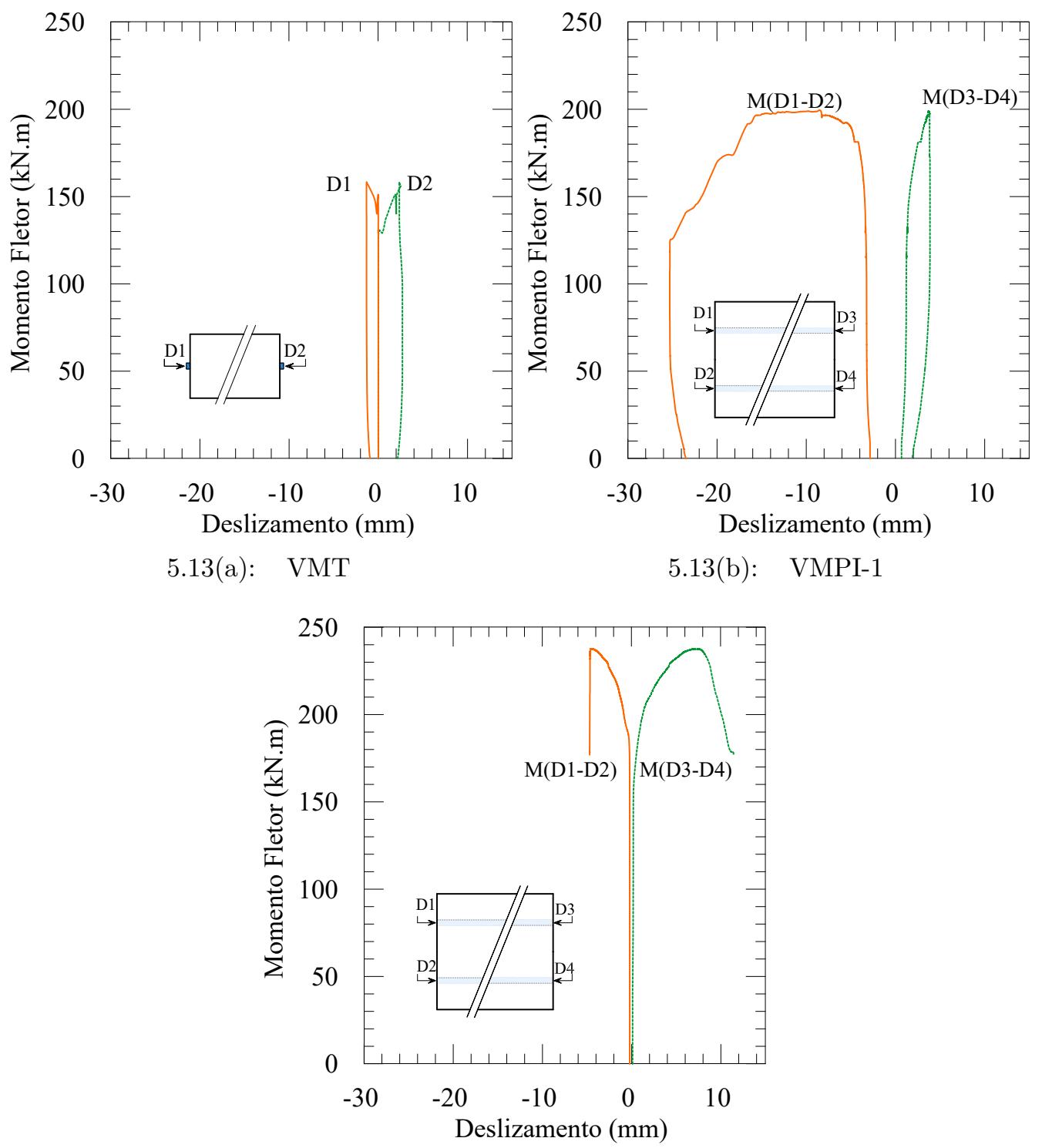

5.13(c): VMPI-2

Figura 5.13: Deslizamento na interface aço-concreto

Tabela 5.4: Resultado do deslizamento aço-concreto

\begin{tabular}{llllll}
\hline \multirow{2}{*}{ Protótipo } & \multicolumn{3}{c}{ deslizamento máximo } & & \multicolumn{2}{c}{ deslizamento residual } \\
\cline { 2 - 3 } \cline { 6 - 6 } & $\begin{array}{l}\mathrm{D} 1 \mid \mathrm{M}(\mathrm{D} 1-\mathrm{D} 2) \\
(\mathrm{mm})\end{array}$ & $\begin{array}{l}\mathrm{D} 2 \mid \mathrm{M}(\mathrm{D} 3-\mathrm{D} 4) \\
(\mathrm{mm})\end{array}$ & & $\begin{array}{l}\mathrm{D} 1 \mid \mathrm{M}(\mathrm{D} 1-\mathrm{D} 2) \\
(\mathrm{mm})\end{array}$ & $\begin{array}{l}\mathrm{D} 2 \mid \mathrm{M}(\mathrm{D} 3-\mathrm{D} 4) \\
(\mathrm{mm})\end{array}$ \\
\hline VMT & 1,31 & 2,36 & & 0,93 & 2,17 \\
VMPI-1 & 8,52 & 3,68 & & 23,47 & 1,86 \\
VMPI-2 & 4,54 & 7,42 & & 4,71 & 11,44 \\
\hline
\end{tabular}

do aço, obtido por meio de ensaios de tração direta.

As deformações da mesa inferior do protótipo VMT apresentaram comportamento linear até atingir $60 \%$ do momento máximo, com deformação equivalente a $1235 \mu \varepsilon$, que é $35 \%$ menor que o valor previsto no ensaio de tra- 
ção direta. A mesa superior exibiu um estado mais moderado de deformações compressivas. Os protótipos VMPI-1 e VMPI-2, por sua vez, apresentaram comportamento predominantemente elástico, atingindo o limite de escoamento próximo do momento máximo.

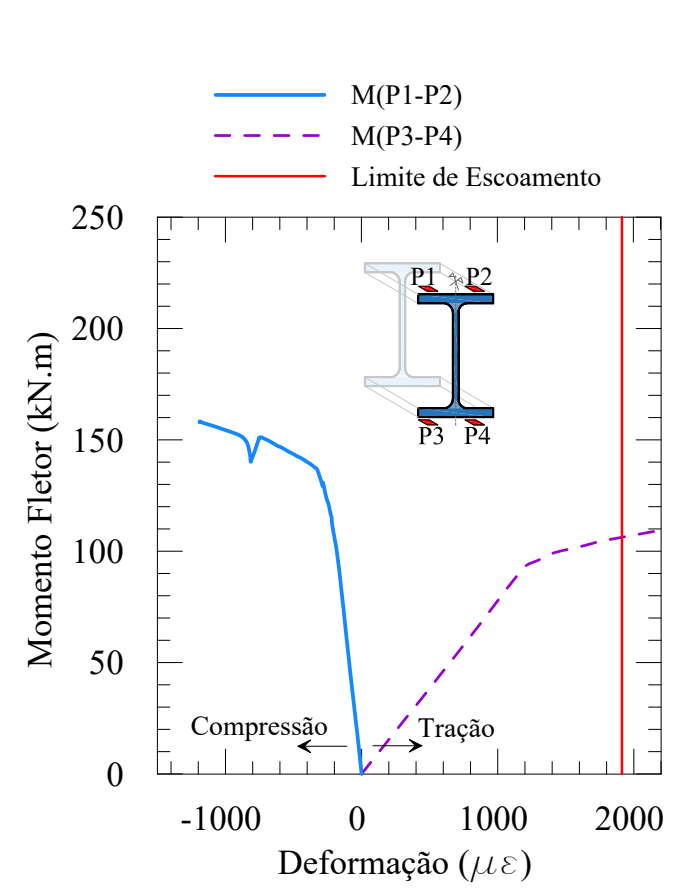

5.14(a): VMT

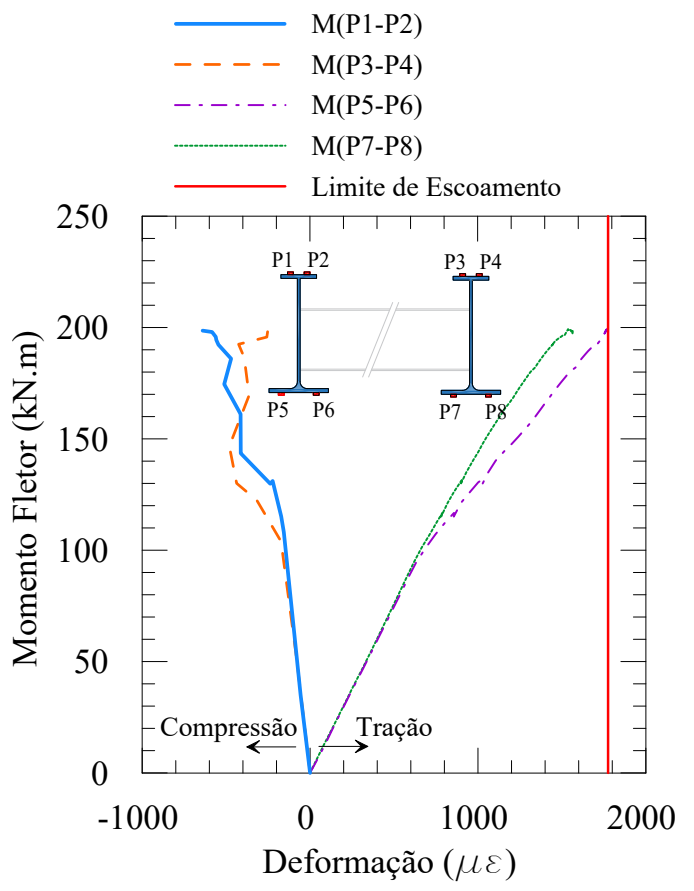

5.14(b): VMPI-1

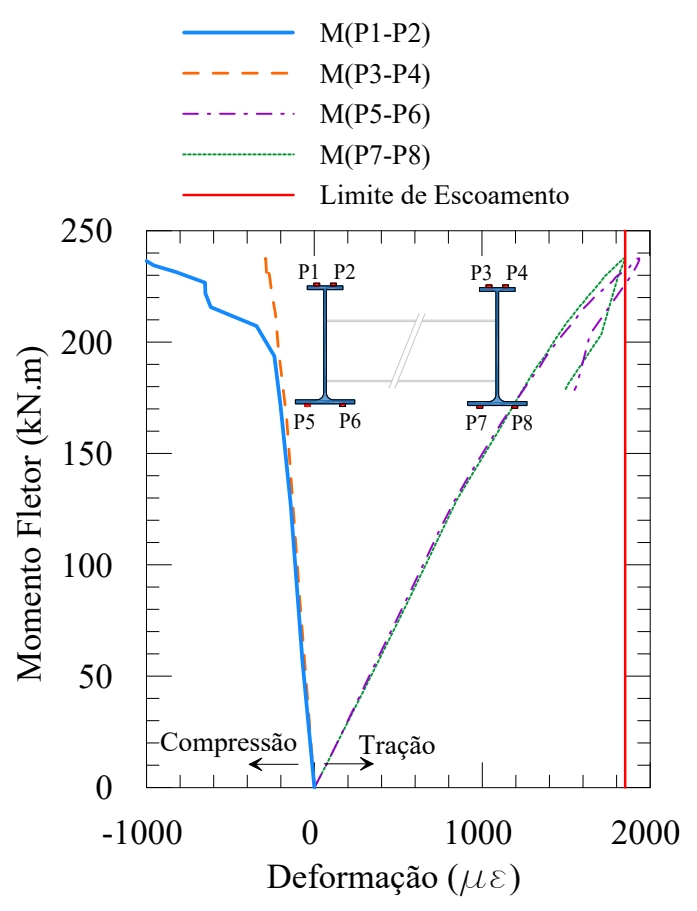

5.14(c): VMPI-2

Figura 5.14: Deformação no perfil 


\subsubsection{4}

\section{Deformação específica medida na laje de concreto}

Os valores de deformação do concreto medidos na face superior da laje são apresentados na Fig. 5.15. No protótipo VMT, o concreto comportou-se linearmente até atingir $60 \%$ do momento máximo. Os protótipos VMPI-1 e VMPI-2 exibiram comportamento predominantemente linear até a ruptura.

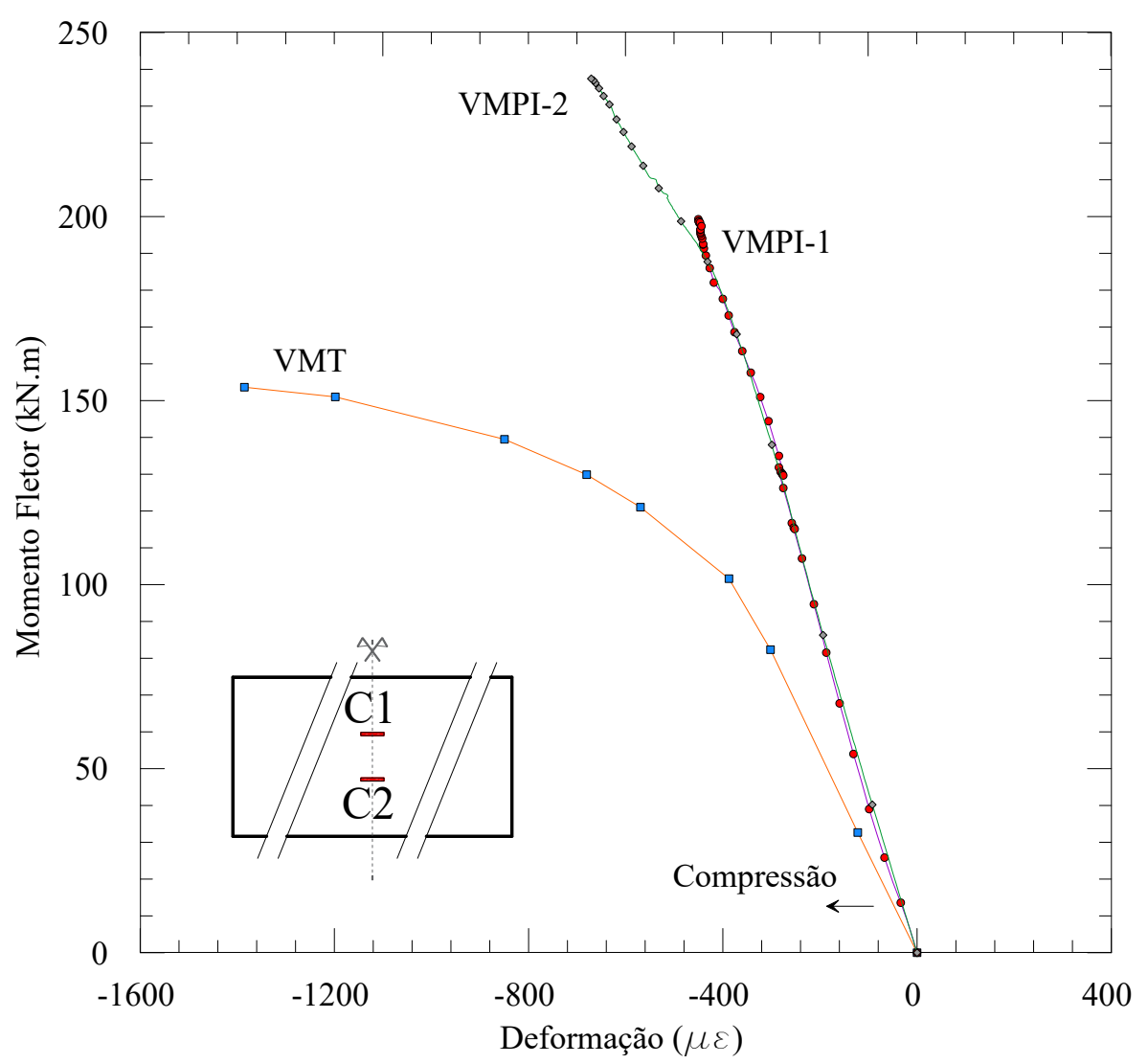

Figura 5.15: Curvas força vs. deformação na face superior da laje de concreto

\subsubsection{5}

\section{Deformação específica medida na armadura transversal}

As Fig. 5.16, 5.17 e 5.18 descrevem as deformações médias mensuradas nas armaduras transversais. Nos protótipos VMT e VMPI-2, as armaduras não apresentaram deformações antes do início do deslizamento. Já no protótipo VMPI-1, com lubrificante na interface de contato aço-concreto, verificou-se deformações mesmo sem ocorrer deslizamento. De modo geral, as deformações nas armaduras localizadas próximas às extremidades das vigas apresentaram os maiores valores, e as barras próximas à seção de um quarto do vão exibiram valores de deformação insignificantes. 

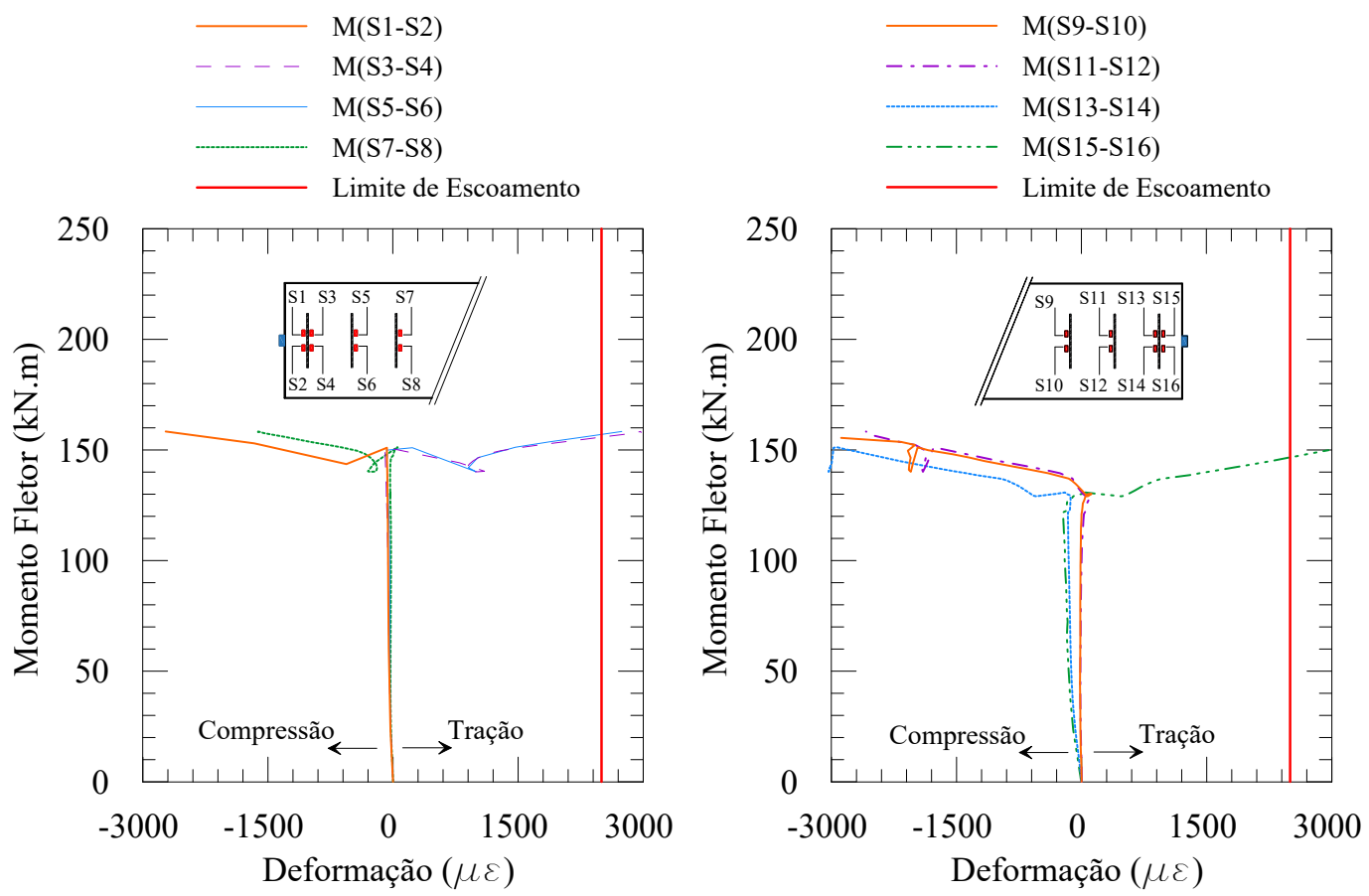

5.16(a): Armaduras extremidade esquerda

5.16(b): Armaduras extremidade direita

Figura 5.16: Deformação na armadura transversal do protótipo VMT
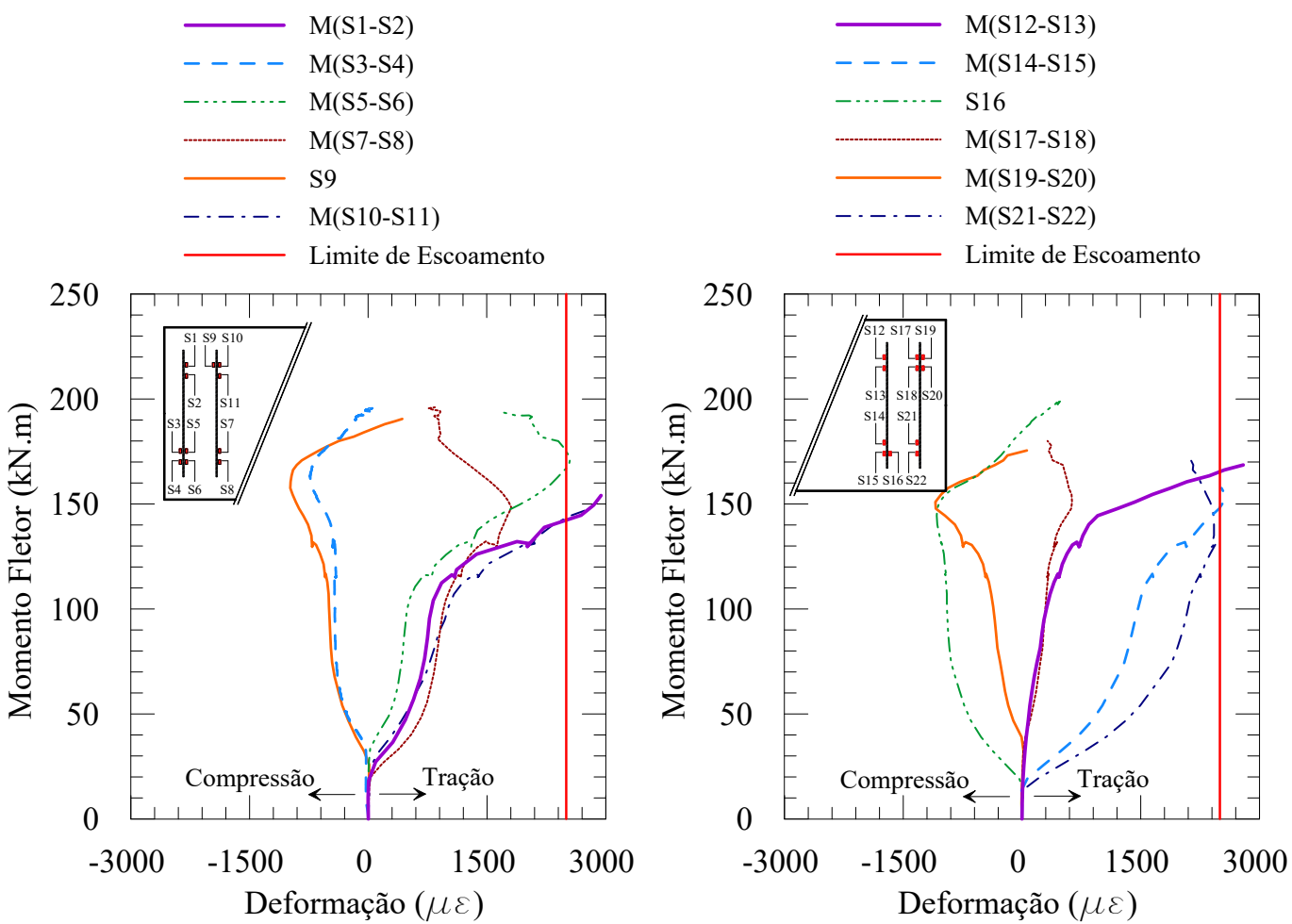

5.17(a): Armaduras extremidade esquerda

5.17(b): Armaduras extremidade direita

Figura 5.17: Deformação na armadura transversal do protótipo VMPI-1 

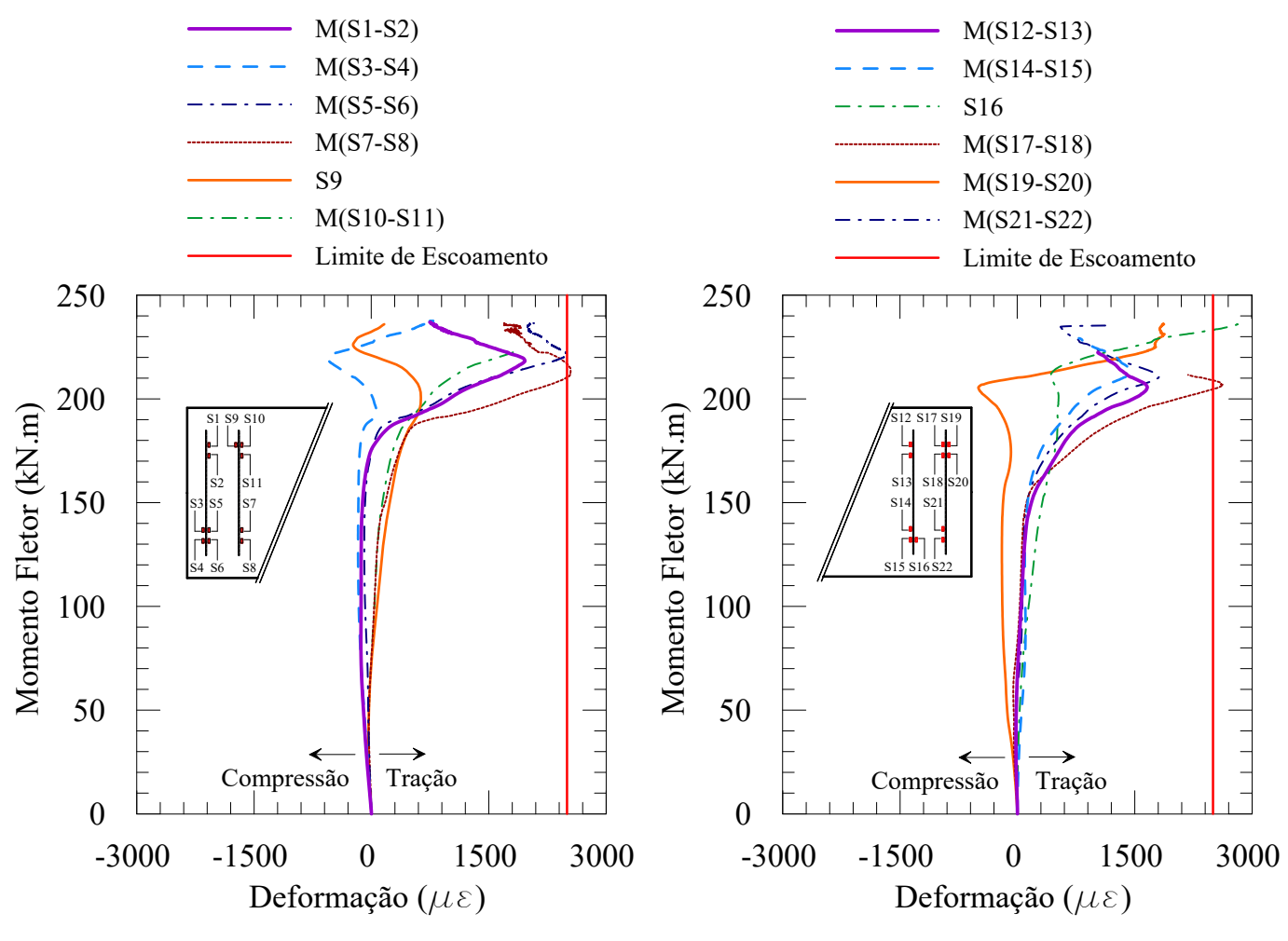

5.18(a): Armaduras extremidade esquerda

5.18(b): Armaduras extremidade direita

Figura 5.18: Deformação na armadura transversal do protótipo VMPI-2

\subsubsection{6}

\section{Configuração da fissuração e modo de ruptura}

As Fig. 5.19 a 5.21 ilustram a configuração final das fissuras no concreto observadas ao longo dos ensaios. A Fig. 5.22 apresenta a configuração das fissuras ao longo da altura da laje nas extremidades das vigas VMPI-1 e VMPI-

2. Em ambos os protótipos, observa-se um padrão de fissuras originadas nos cantos da mesa superior, que se propagaram na diagonal até as faces superior e inferior da laje.

$\mathrm{Na}$ viga VMT, a primeira fissura surgiu quando o momento fletor solicitante atingiu 130 kN.m (82\% do momento máximo). A fissura na direção longitudinal começou nas extremidades, propagando-se em direção ao meio do vão. Ao atingir 150 kN.m, surgiram fissuras de flexão na face inferior da laje, próximas ao meio do vão. A viga mista não apresentou falhas na conexão aço-concreto, e o ensaio foi interrompido quando a configuração da viga estava altamente deformada (ver Fig. 5.23(a)).

$\mathrm{Na}$ viga mista VMPI-1, as primeiras fissuras surgiram na face inferior da laje, próximo aos pontos de aplicação de carga. A fissuração iniciou-se sob um momento fletor solicitante de $87 \mathrm{kN} . \mathrm{m}$, representando $43 \%$ da resistência máxima. A viga mista também apresentou duas fissuras longitudinais na face 


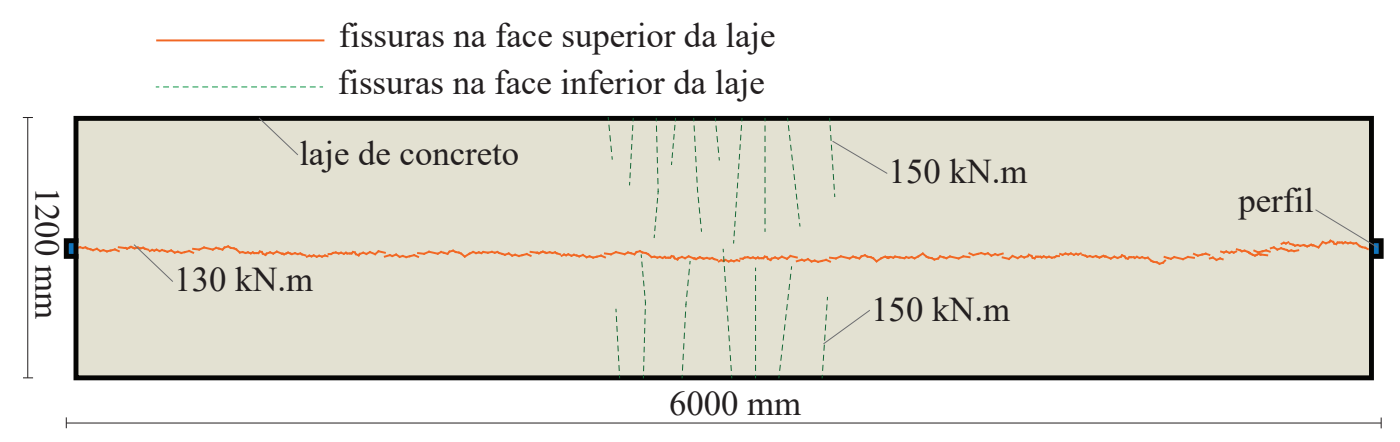

Figura 5.19: Configuração das fissuras na laje do protótipo VMT

superior da laje, distribuídas ao longo do comprimento do perfil. A Fig. 5.24(a) mostra a configuração deformada da viga mista submetida ao carregamento máximo, e a Fig. 5.24(b) exibe o aspecto final de uma armadura transversal posicionada próximo à extremidade da viga.

fissuras na face superior da laje fissuras na face inferior da laje desagregação do concreto na face superior da laje desagregação do concreto na face inferior da laje

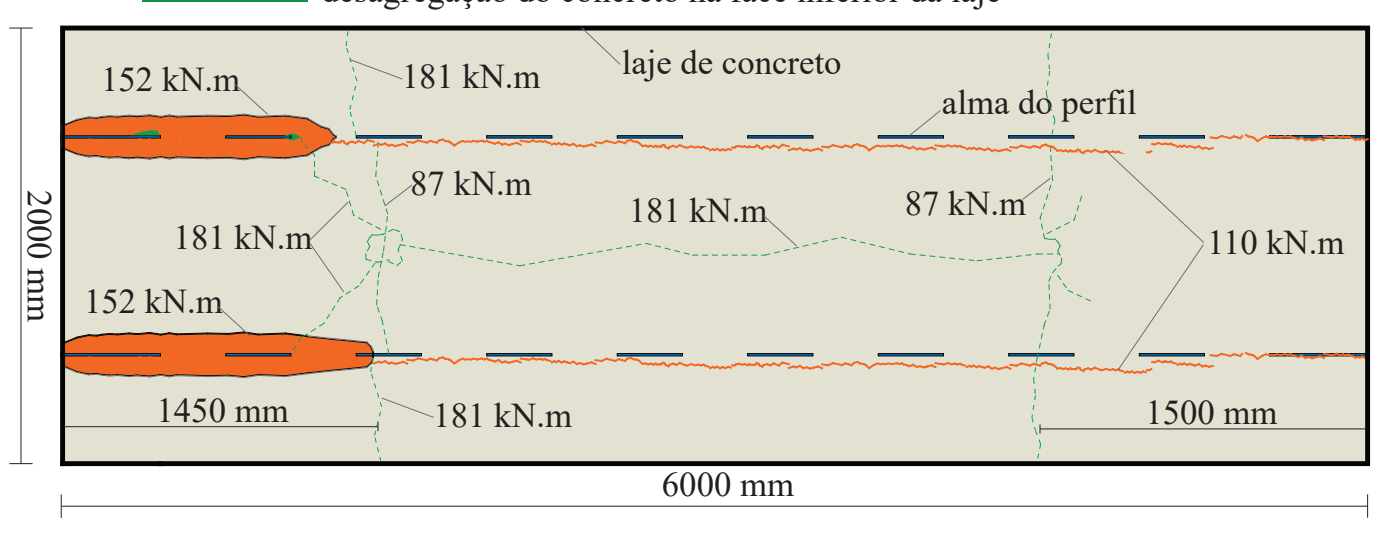

Figura 5.20: Configuração das fissuras na laje do protótipo VMPI-1

A ruína do protótipo VMPI-1 ocorreu devido à ruptura da ligação açoconcreto. Com o espraiamento das tensões de compressão na laje, surgiram tensões de tração acima da resistência do concreto, levando à desagregação do concreto superficial (Fig. 5.25(a)) e, consequentemente, à perda da aderência entre os dois materiais. Sem a capa de concreto, a mesa superior do perfil ficou exposta, contribuindo para a instabilidade local do perfil na região de abertura de alma (ver Fig. 5.25(c)).

No protótipo VMPI-2 (Fig. 5.26), a configuração das fissuras ocorreu de maneira semelhante ao protótipo VMPI-1, entretanto, as primeiras fissuras surgiram sob momento fletor de 197 kN.m (83\% da resistência última). A ruína ocorreu devido à desagregação do concreto na face inferior da laje, na região de 
abertura de alma (ver Fig. 5.27(a)). A mesa superior do perfil também sofreu instabilidade local (ver Fig. 5.27(c)).

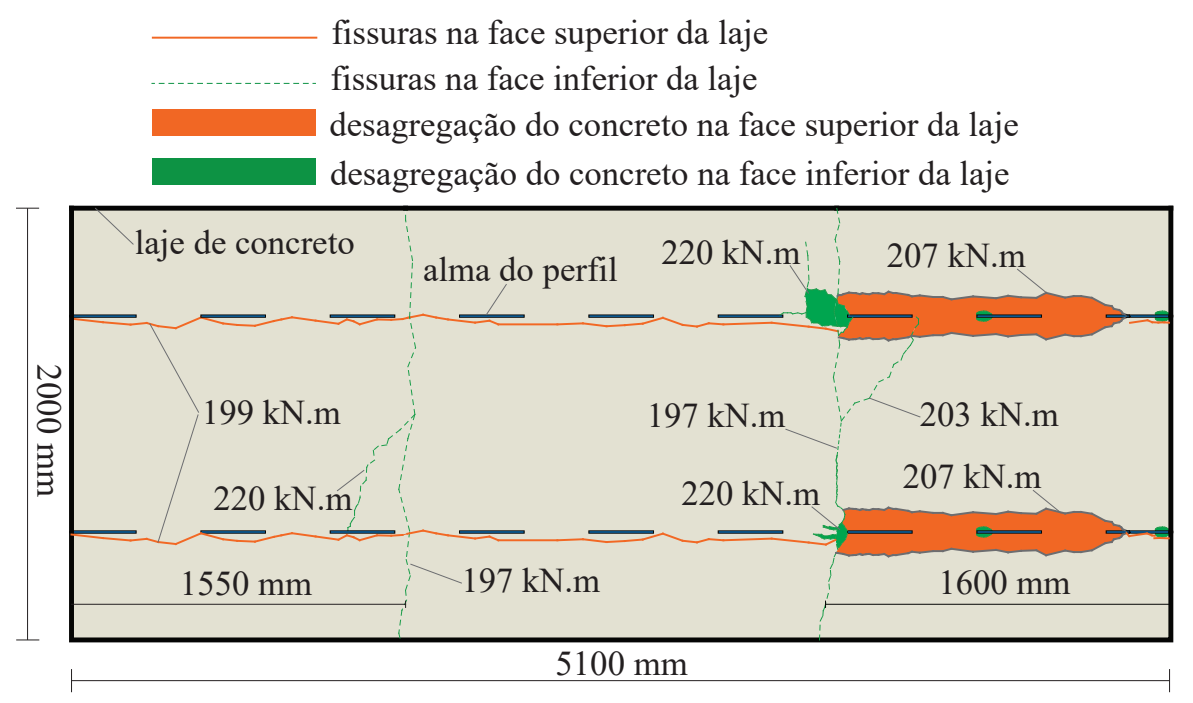

Figura 5.21: Configuração das fissuras na laje do protótipo VMPI-2
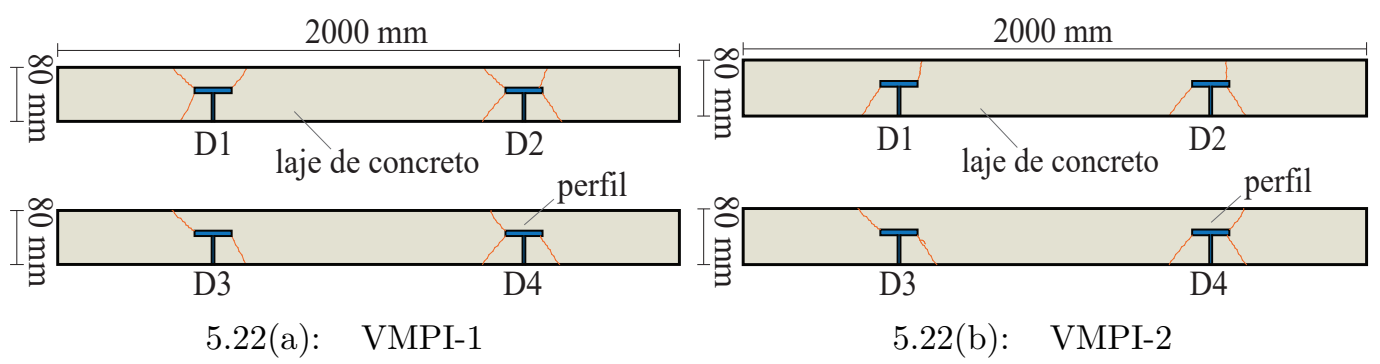

Figura 5.22: Configuração das fissuras nas extremidades das vigas

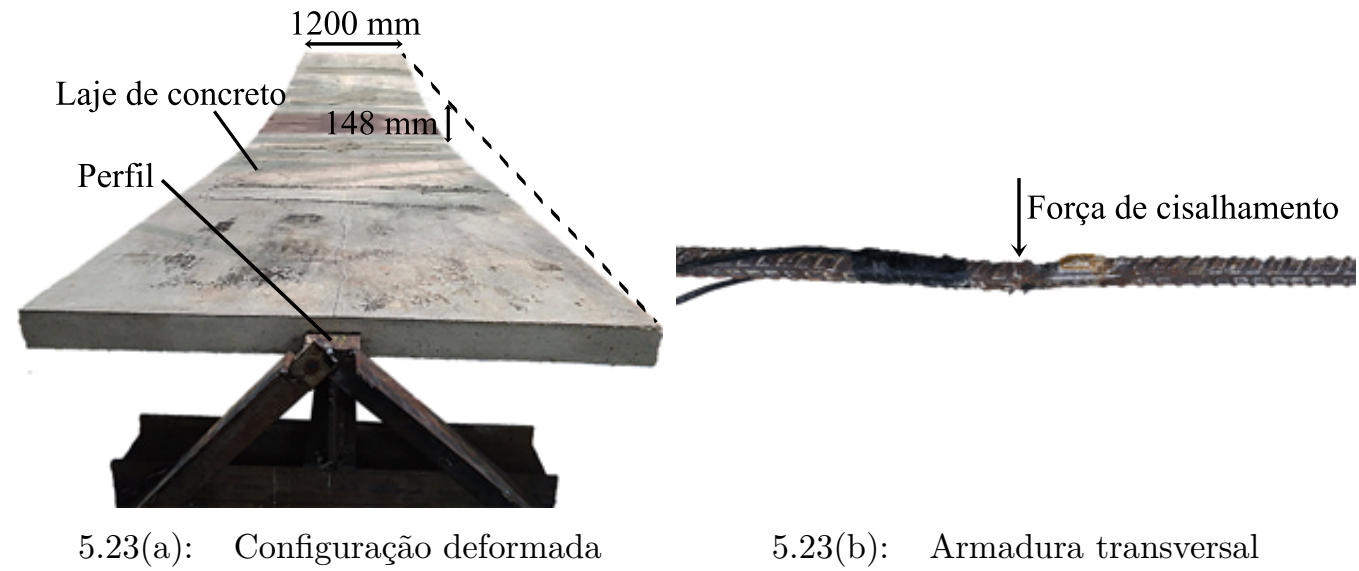

Figura 5.23: Configuração final do protótipo VMT 


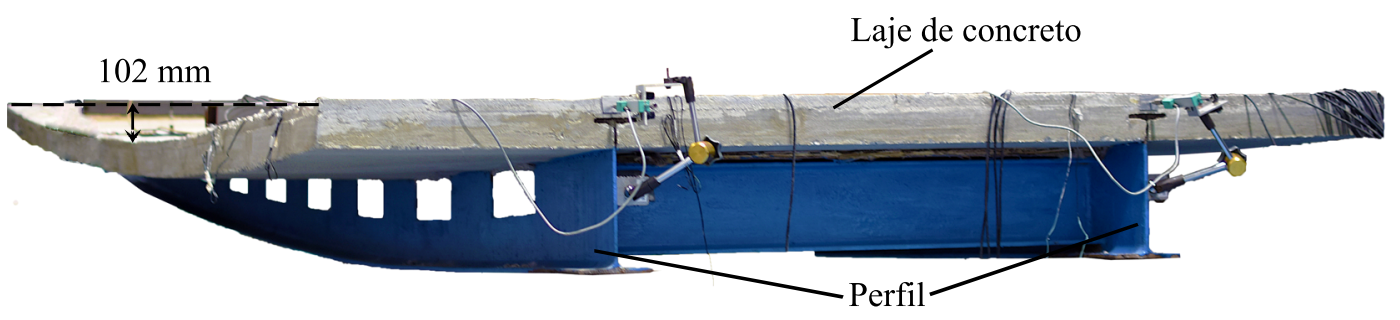

5.24(a): Configuração deformada

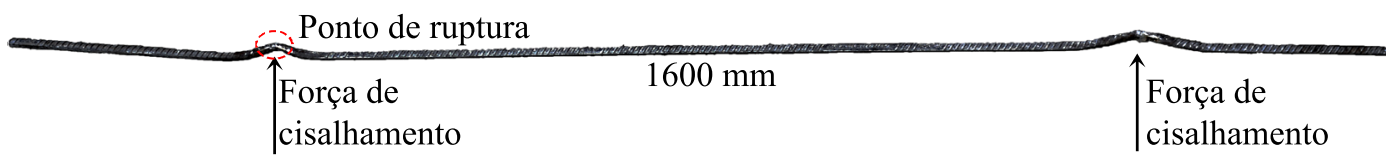

5.24(b): Armadura transversal

Figura 5.24: Configuração final do protótipo VMPI-1

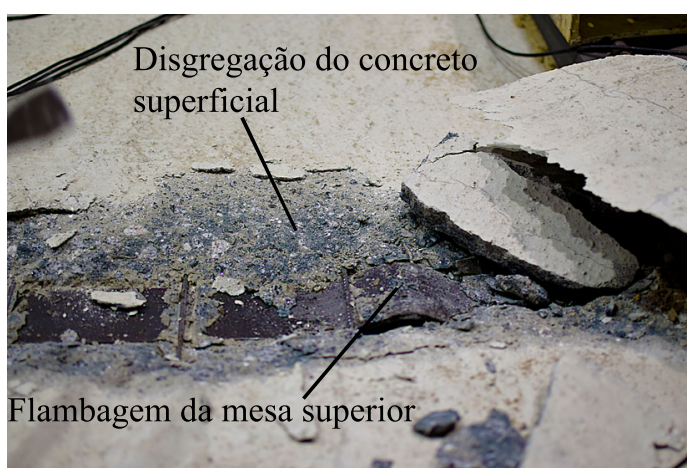

5.25(a): Desagregação do concreto

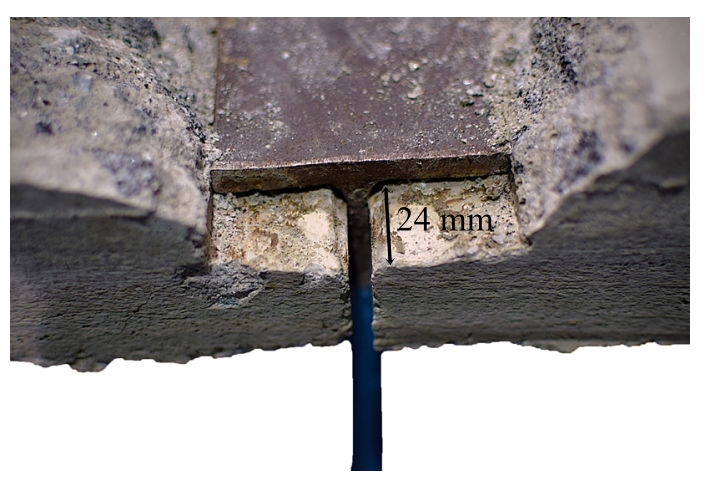

5.25(b): Deslizamento aço-concreto (D1)

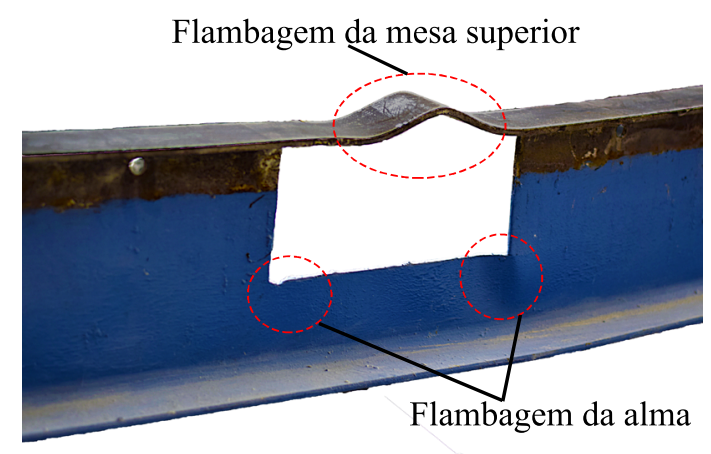

5.25(c): Flambagem do perfil

Figura 5.25: Modo de falha no protótipo VMPI-1 


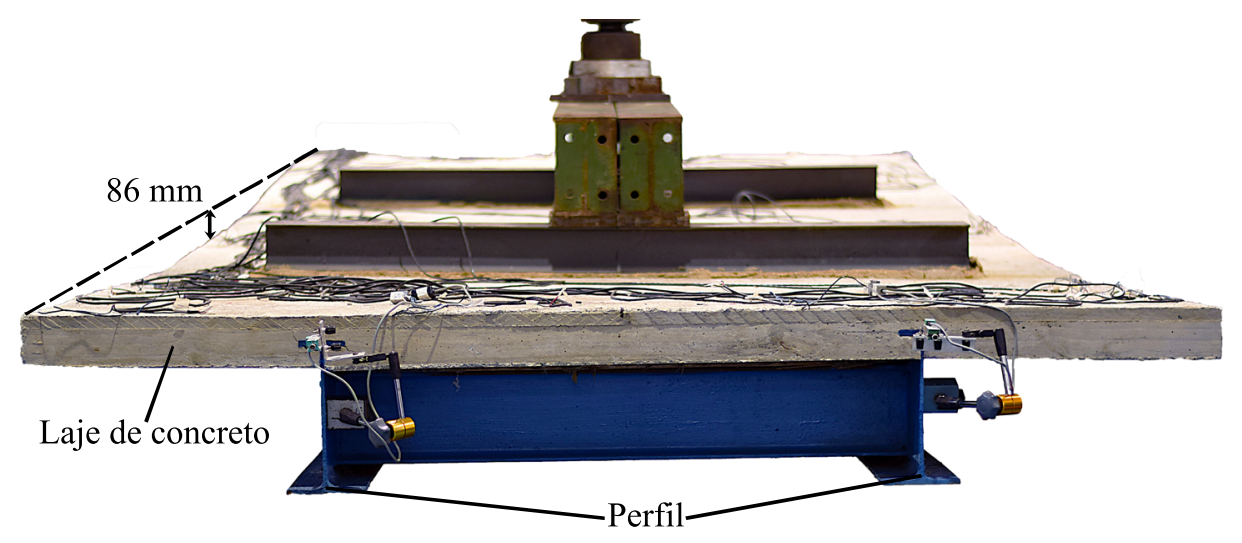

Figura 5.26: Configuração final do protótipo VMPI-2

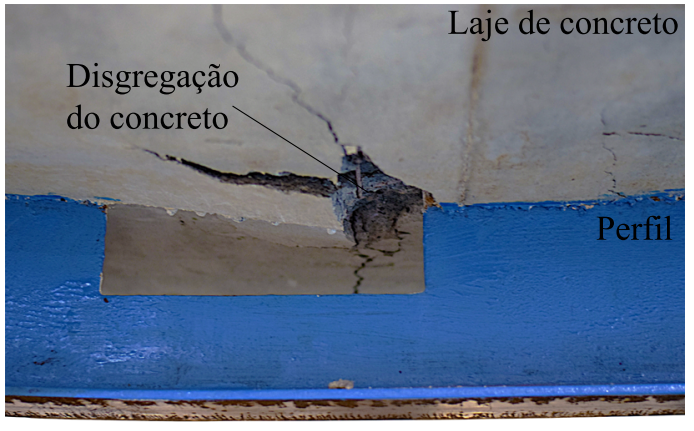

5.27(a): Desagregação do concreto

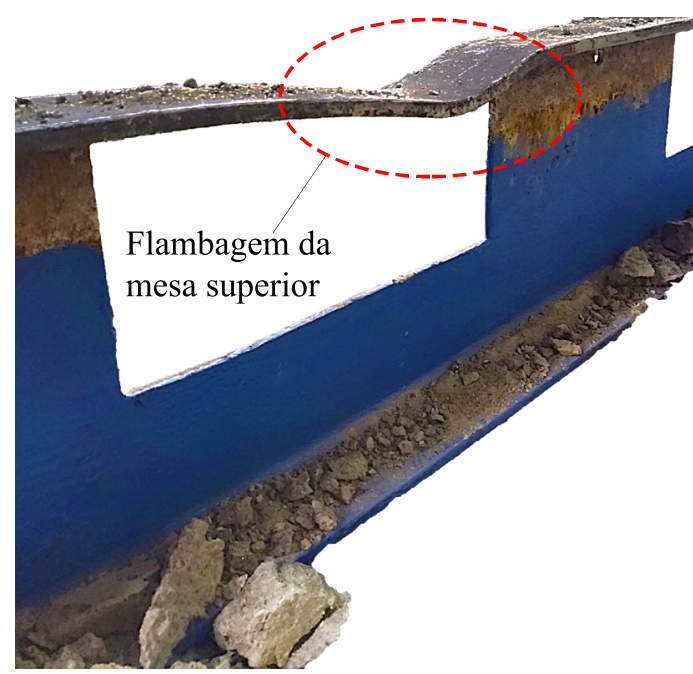

5.27(c): Flambagem do perfil

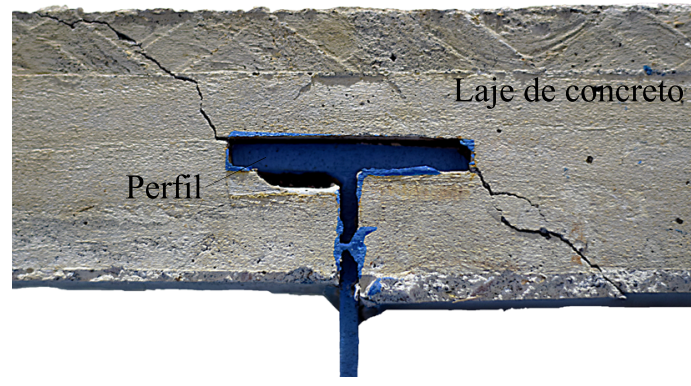

5.27(b): Fissuras na borda (D3)

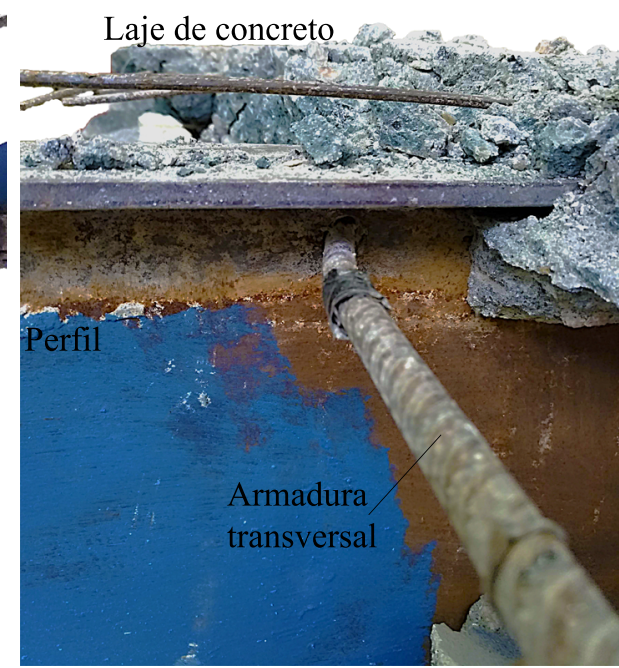

5.27(d): Armadura transversal

Figura 5.27: Modo de falha no protótipo VMPI-2 


\section{6}

\section{Modelagem em Elementos Finitos}

Além dos ensaios experimentais, uma análise não-linear em Elementos Finitos (EF) foi realizada com o software de simulação ABAQUS [113]. O objetivo dessas simulações numéricas era recalcular os resultados dos ensaios com precisão suficiente, usando um conjunto de parâmetros consistente. O modelo de análise quasi-static explicit que foi utilizado para a simulação é recomendado para cálculos altamente não-lineares e dinâmicos com muitos graus de liberdade. Em contraste com os métodos numéricos implícitos (e.g. Newton-Raphson), esse cálculo explícito é baseado no equilíbrio dinâmico.

A modelagem em EF pode fornecer uma boa visão sobre o comportamento de vigas mistas de aço-concreto com perfil parcialmente embutido. No entanto, é bastante complicado desenvolver um modelo em Elementos Finitos que seja preciso e eficiente e que aborde todos os modos de falha. Os modos de falha da viga mista são, principalmente, o esmagamento do concreto, a falha por tração no concreto, o escoamento da viga de aço e a ruptura da conexão na interface aço-concreto.

\section{1}

\section{Propriedades geométricas e condições de contorno do modelo}

O modelo numérico proposto foi construído em concordância com a geometria (Fig. 4.9 a 4.11) e condições de contorno (Fig. 4.14 e 4.15) apresentadas pelos modelos experimentais (VMT, VMPI-1 e VMPI-2). Os modelos em EF foram apoiados a $100 \mathrm{~mm}$ de cada extremidade, com as condições de contorno dos apoios modeladas na mesa inferior da viga de aço. As translações do apoio fixo (esquerdo) foram restringidas nas 3 (três) direções globais (X, Y e Z) e, para o apoio móvel (direito), foram impedidas as translações vertical e transversal ( $\mathrm{Y}$ e X), deixando livre a translação na direção axial.

O controle de deslocamento foi adotado na solução da análise por EF. O deslocamento foi aplicado no topo da laje de concreto, nos pontos correspondentes às vigas de transmissão utilizadas nos ensaios experimentais. 


\section{2}

\section{Elementos finitos adotados e malha}

Há uma grande variedade de Elementos Finitos disponível no programa ABAQUS [113]. Para elaboração do modelo, foram utilizados os seguintes elementos:

- C3D8R: este é um elemento sólido ou contínuo (C), tridimensional (3D), com oito (8) nós e integração reduzida (R). O elemento C3D8R também tem uma formulação com interpolação de primeira ordem ou linear. Cada nó tem 3 graus de liberdade, referentes às translações nas direções $\mathrm{X}, \mathrm{Y}$ e Z. Esse elemento foi utilizado para discretizar o perfil metálico e a laje de concreto;

- T3D2: este é um elemento de treliça (T), unidimensional no espaço tridimensional (3D) e com dois nós (2). Cada nó possuí 3 graus de liberdade, referentes às translações nas direções X, Y e Z. Esse elemento transmite apenas forças de tração e compressão e não possui resistência a flexão. É um tipo de elemento utilizado para modelar telas soldadas;

- B31: este é um elemento de viga (B), unidimensional no espaço tridimensional (3) e interpolação linear (1). Possui rigidez associada à deformação no eixo da viga, que consiste em alongamento axial, mudança de curvatura (flexão), torção e deformação devido ao cisalhamento transversal. Esse elemento foi utilizado para discretizar a armadura transversal.

A malha do modelo é gerada automaticamente. Devido à geometria regular da laje e do perfil, essas partes do modelo foram discretizadas com uma malha estruturada. Nesse caso, os elementos da malha apresentaram grande uniformidade, mantendo sua forma constante ao longo da malha (ver Fig. 6.1 e 6.2). A Tabela 6.1 apresenta a descrição do tipo de elemento finito utilizado e a quantidade usada para cada parte da estrutura.

Tabela 6.1: Quantidade de elementos finitos

\begin{tabular}{lllll}
\hline Viga Mista & Perfil & Laje & Tela Soldada & $\begin{array}{l}\text { Armadura } \\
\text { Transversal } \\
\mathbf{( B 3 1 )}\end{array}$ \\
& $\mathbf{( C 3 D 8 R )}$ & $\mathbf{( C 3 D 8 R )}$ & $\mathbf{( T 3 D 2 )}$ & 300 \\
\hline VMT & 34629 & 86688 & 9854 & 800 \\
VMPI-1 & 32444 & 148632 & 17114 & 720 \\
VMPI-2 & 39068 & 268880 & 14525 & \\
\hline
\end{tabular}




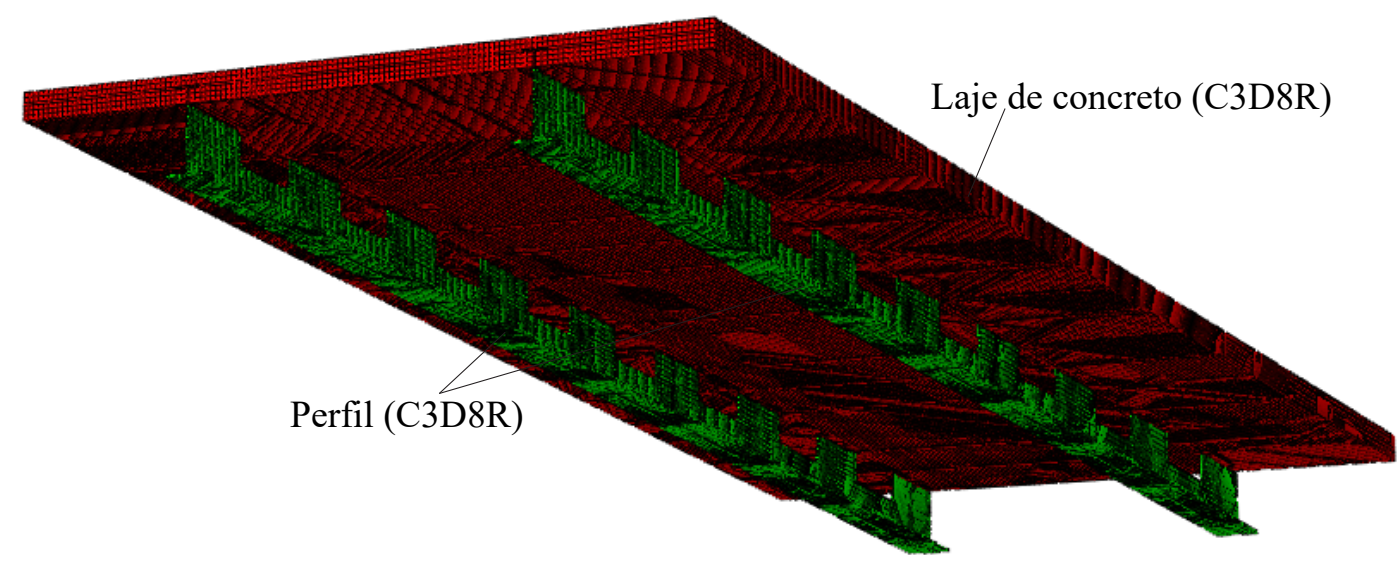

Figura 6.1: Discretização da malha da viga mista em Elementos Finitos

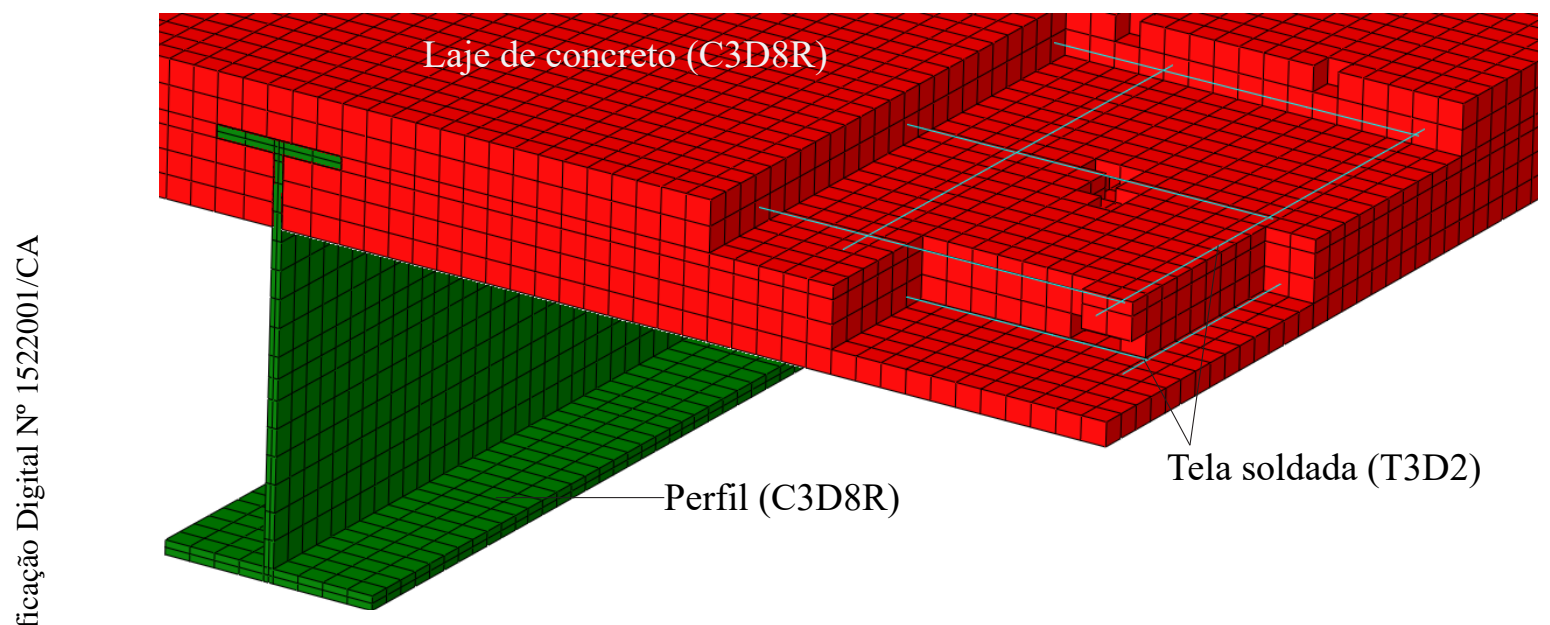

Figura 6.2: Detalhe da tela soldada no modelo em Elementos Finitos

\section{3}

\section{Restrições e interações de contato}

As armaduras (tela soldada) foram implementadas na laje de concreto usando a função Embedded, na qual os graus de liberdade translacionais dos vergalhões são restringidos cinematicamente aos nós adjacentes do concreto. Nesta interação, qualquer possível deslizamento entre concreto e armadura é negligenciado nos cálculos.

$\mathrm{Na}$ ligação mista (perfil-laje de concreto) e na ligação armadura transversal-laje de concreto, utilizou-se simulação de contato baseada em superfície (general contact). A função general contact automaticamente atribui funções mestre-escrava puras para a maioria das interações de contato.

As propriedades de contato foram adicionadas utilizando o modelo de atrito isotrópico de Coulomb. As interações na direção ortogonal à superfície 


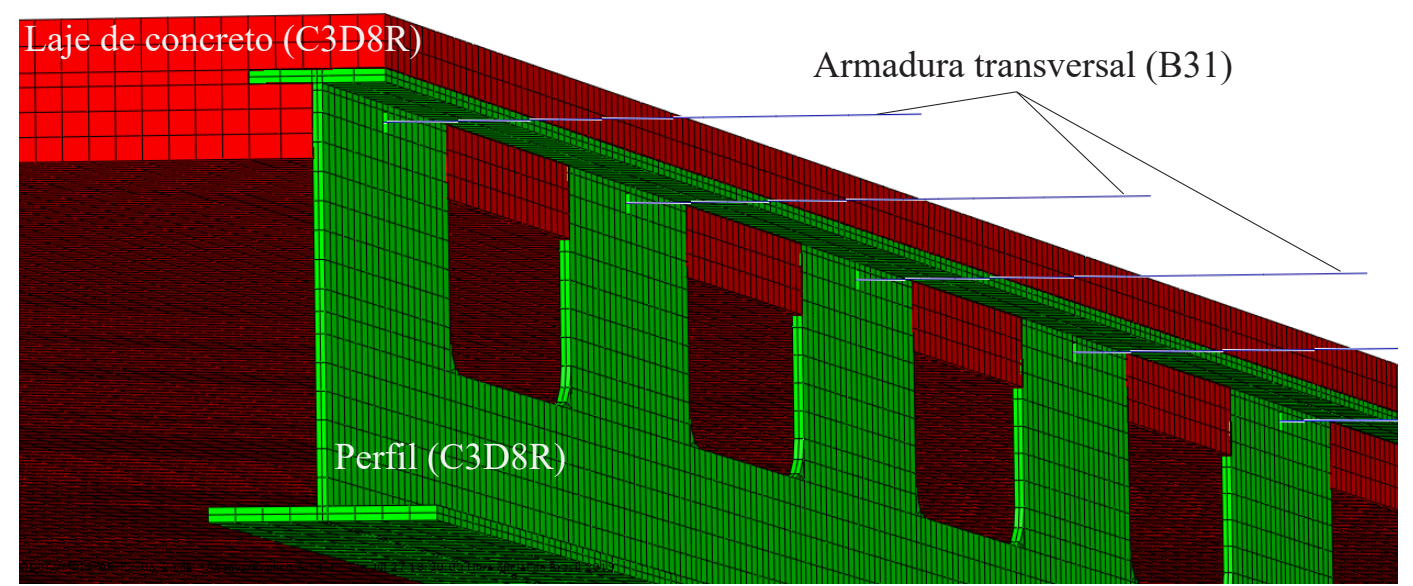

Figura 6.3: Detalhe das armaduras transversais no modelo em Elementos Finitos

(Direção Normal) impediram a penetração da viga de aço e da laje de concreto (Hard Contact). Já na direção tangencial, o coeficiente de atrito foi definido como uma função da taxa de escorregamento equivalente e da pressão de contato.

Na viga VMPI-1, engraxada na superfície de contato, não foi considerado atrito (função frictionless) entre as superfícies de contato do perfil e da laje. No entanto, no contato entre a armadura transversal e a laje, foi considerado um coeficiente de atrito $\mu=0,6$ [107].

Nas vigas VMT e VMPI-2, o contato friccional entre as superfícies do concreto e do aço (perfil-laje e armadura transversal-laje) foi definido com um coeficiente de atrito $\mu=0,6$ [107].

\section{4}

\section{Relações constitutivas para os materiais}

\subsection{1}

\section{Modelo do material para o aço}

Para o aço da armadura, foi adotada uma relação constitutiva (diagrama $\sigma \mathrm{x} \epsilon$ ) do tipo elastoplástico com endurecimento linear. Esse modelo é associado ao critério de von Mises, com base na relação entre as tensões uniaxiais e suas respectivas deformações plásticas equivalentes. Usando o diagrama tensão x deformação fornecido pelo EUROCODE 2 [114], o comportamento adotado está representado na curva "A"da Fig. 6.4.

A relação constitutiva descrita para a viga de aço é do tipo elastoplástico, obtida por meio de ensaios de tração. A fase plástica é constituída pelo 


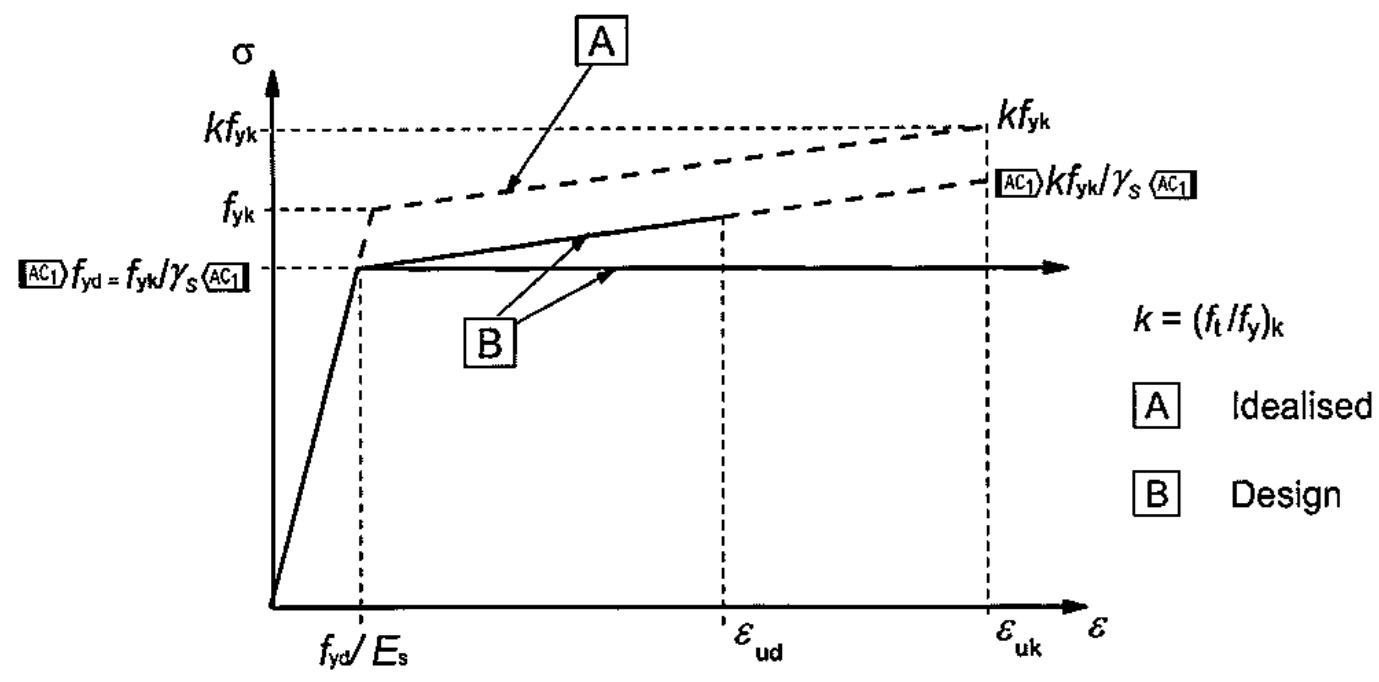

Figura 6.4: Modelo constitutivo do aço [114]

escoamento do aço acompanhado por um endurecimento. Os resultados experimentais da fase plástica foram ajustados considerando a perda de rigidez do material (ver Fig. 6.5(a)), tornando necessária a conversão dos dados nominais para uma tensão "verdadeira" (tensão de Cauchy), $\sigma_{\text {true }}$, e deformação logarítmica, $\epsilon_{l n}^{p l}$, de acordo com as eq. (6-1) e (6-2).

$$
\begin{gathered}
\sigma_{\text {true }}=\sigma_{\text {nom }}\left(1+\epsilon_{\text {nom }}\right) \\
\epsilon_{l n}^{p l}=\ln \left(1+\epsilon_{\text {nom }}\right)-\frac{\sigma_{\text {true }}}{E}
\end{gathered}
$$

\section{4 .2}

\section{Modelo do material para o concreto}

Para a modelagem do concreto, foi utilizado o modelo constitutivo Concrete Damaged Plasticity (CDP). O Modelo de Dano CDP permite a análise de estruturas de concreto sob cargas cíclicas e/ou dinâmicas. Os principais mecanismos de falha desse modelo são baseados na ruptura por fissuração na tração e no esmagamento por compressão.

O modelo CDP é representado por meio do módulo de elasticidade, do coeficiente de Poisson, das curvas do concreto submetido a compressão e a tração e dos parâmetros de plasticidade aplicados juntamente com o modelo de dano com plasticidade. Todos os parâmetros $\left(K_{c}=0.667\right.$, ex $=0.1, \psi=38$, 
$f b 0 / f c 0=1.16)$ utilizados nos cálculos foram escolhidos de acordo com os valores recomendados em [113].

A curva do concreto submetido a compressão foi definida de acordo com o EUROCODE 2 [114], por meio da relação de tensão de compressão, $\sigma_{c}$, e deformação, $\epsilon_{c}$, no concreto, conforme a eq. (6-3):

$$
\frac{\sigma_{c}}{f_{c m}}=-\left(\frac{k \eta-\eta^{2}}{1+(k-2) \eta}\right)
$$

Sendo: $\eta=\epsilon_{c} / \epsilon_{c 1} ; \epsilon_{c 1}=0,7 \cdot f_{c m}^{0,31} \leq 2,8 ; k=1,05 \cdot E_{c m} \cdot \epsilon_{c 1} / f_{c m} ;$ $f_{c m}=$ valor médio da resistência a compressão do corpo de prova do concreto obtido experimentalmente; $f_{c k}=$ resistência característica a compressão do concreto obtida experimentalmente; $E_{c m}=$ módulo de elasticidade do concreto obtido experimentalmente; O coeficiente de Poisson do concreto, $\nu_{c}$, é considerado num valor de 0,2 .

O comportamento do concreto na tração, por sua vez, é definido pelo ABAQUS [113] por meio da curva tension stiffening. Esse efeito representa a capacidade que o concreto intacto entre fissuras vizinhas possui de resistir a uma certa quantidade de forças de tração. A razão para esse efeito é a aderência entre o concreto e a armadura. Em modelos numéricos, a consideração do efeito de tension stiffening é interessante para modelos com pouca ou nenhuma armadura, pois melhora a convergência dos modelos e a precisão dos resultados.

O comportamento do concreto à tração após a fissuração pode ser representado por relações da tensão em função da abertura de fissura ou da deformação do material. Quando a relação tensão x deformação é utilizada, os resultados são sensíveis ao tamanho da malha, uma vez que a deformação depende do tamanho do elemento.

Alternativamente, a relação tensão x abertura de fissura depende da distância entre os pontos de integração do elemento, reduzindo, em parte, a sensibilidade à malha. Para a estimativa da resistência a tração média, $f_{c t m}$, o EUROCODE 2 [114] prescreve a eq. (6-4):

$$
f_{c t m}=0,3 \cdot\left(f_{c k}\right)^{\frac{2}{3}}
$$

A deformação correspondente à tensão de tração é calculada por meio da eq. $(6-5)$ : 


$$
\epsilon_{c t m}=10 \cdot\left(\frac{f_{c t m}}{E_{c m}}\right)
$$

A curva tensão-deformação uniaxial para as vigas mistas é mostrada na Fig. 6.5.

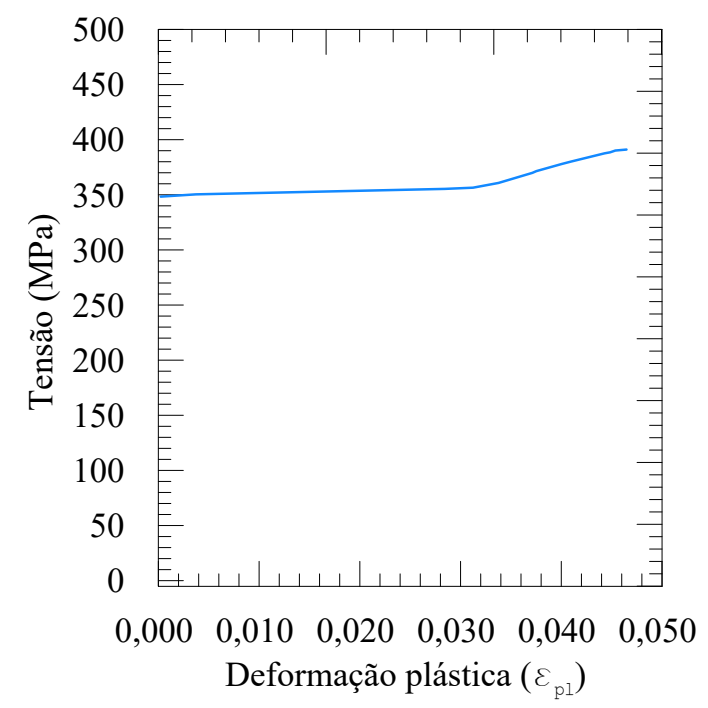

6.5(a): Aço

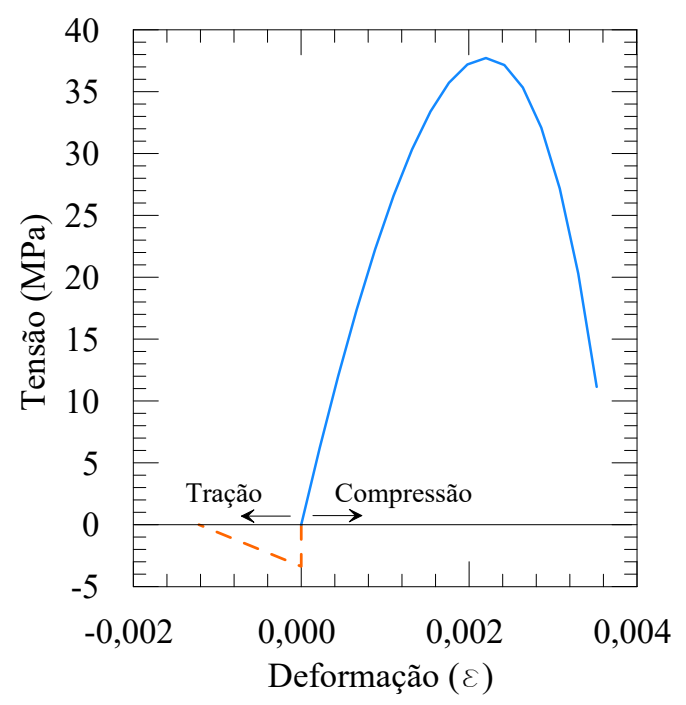

6.5(b): Concreto

Figura 6.5: Curva tensão-deformação para o concreto da laje e para o aço do perfil

\section{5 \\ Procedimento de análise}

Para o modelo em Elementos Finitos, foi realizada uma análise quase estática utilizando o método de solução explícita. O procedimento explícito é utilizado em análises dinâmicas e foi originalmente desenvolvido para modelar eventos de impacto de alta velocidade nos quais a inércia desempenha um papel dominante na solução. Entretanto, o Abaqus/Explicit também resolve certos tipos de problemas estáticos.

Uma vantagem do procedimento explícito em relação ao procedimento implícito (Abaqus/Standard) é a maior facilidade com a qual ele resolve problemas de contato. Além disso, à medida em que os modelos tornam-se muito grandes, o procedimento explícito requer menos recursos do sistema do que o procedimento implícito.

A aplicação do procedimento dinâmico explícito em problemas quase estáticos requer algumas considerações especiais. Visto que, por definição, uma solução estática é uma solução a longo prazo, muitas vezes, é computacionalmente impraticável simular um evento em sua escala de tempo natural, pois 
isso exigiria um número excessivo de pequenos incrementos de tempo. Para obter uma solução econômica, o evento deve ser acelerado de alguma forma, mas o problema é que, à medida em que isso é feito, o estado de equilíbrio estático evolui para um estado de equilíbrio dinâmico no qual as forças inerciais tornam-se mais dominantes. Sendo assim, o objetivo é modelar o processo no menor período de tempo em que as forças inerciais permanecem insignificantes.

Para precisão e eficiência, análises quase estáticas requerem a aplicação de uma carga que seja o mais suave possível. Movimentos bruscos e repentinos provocam ondas de tensão que podem induzir soluções ruidosas ou imprecisas. Aplicar a carga da maneira mais suave possível exige que a aceleração mude apenas um pouco de um incremento para o outro. Se a aceleração é suave, as mudanças na velocidade e no deslocamento também o são.

Para determinar a taxa de carregamento adequada, deve-se conhecer a frequência e, correspondentemente, o período do modo de vibração mais baixo da estrutura. Dessa forma, é possível estimar o tempo necessário para obter a resposta estática adequada.

O primeiro modo de vibração e sua frequência natural foram obtidos por meio de uma análise de autovalores e autovetores. Com esse valor, calcula-se o período/tempo necessário para a análise quase-estática (ver Tabela 6.2).

Tabela 6.2: Resultados da análise modal

\begin{tabular}{lll}
\hline Viga Mista & $\begin{array}{l}\text { Frequência } \\
(\mathbf{H z})\end{array}$ & $\begin{array}{l}\text { Tempo } \\
(\mathbf{s})\end{array}$ \\
\hline VMT & 2,82 & 0,35 \\
VMPI-1 & 0,18 & 5,45 \\
VMPI-2 & 5,2 & 0,19 \\
\hline
\end{tabular}

\section{6}

\section{Confiabilidade do modelo numérico}

O meio mais geral de avaliar se uma simulação está ou não produzindo uma resposta quase estática apropriada envolve o estudo das energias do modelo. Como uma regra geral, a energia cinética do material não deve exceder uma pequena fração (tipicamente de $5 \%$ a 10\%) da energia interna durante a maior parte do processo [113]. A Fig. 6.6 faz uma comparação entre a energia interna e cinética dos modelos estudados. Com os resultados, justifica-se a suposição de um comportamento quase estático.

O modelo de Elementos Finitos desenvolvido neste estudo foi verificado com os resultados experimentais apresentados no capítulo 5. As Fig. 6.7(a), 


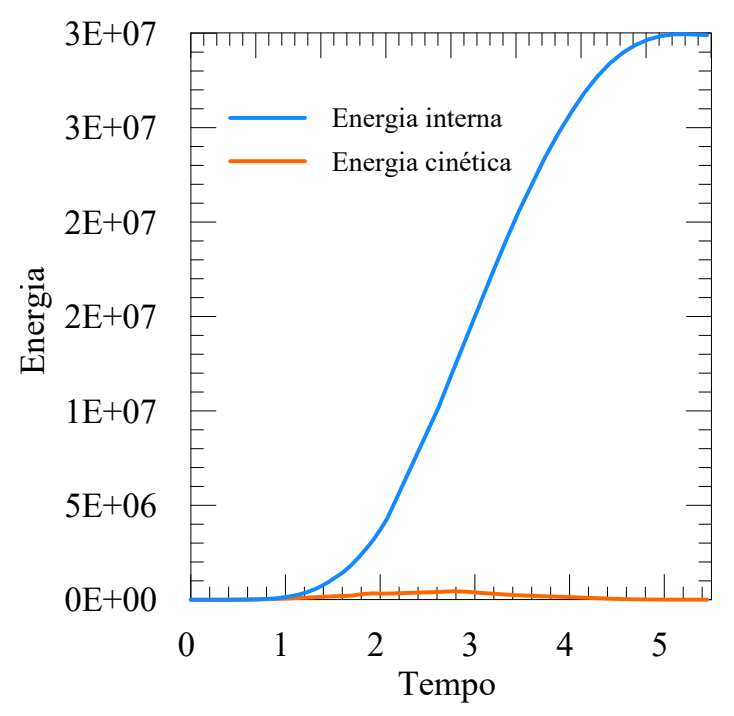

Figura 6.6: Energia vs. tempo

6.8(a) e 6.9(a) ilustram a comparação entre valores numérico e experimental obtidos da relação entre o momento fletor solicitante e os deslocamentos verticais que ocorrem no meio do vão da viga mista. O modelo numérico apresentou uma convergência satisfatória em comparação aos resultados experimentais para os três protótipos. Em todas as vigas, os valores de momento fletor máximo dos modelos em EF atingiram 101\% do resultado experimental.

$\mathrm{Na}$ viga VMPI-1, engraxada na interface de contato aço-concreto, presumiu-se não haver atrito entre os materiais na modelagem em EF. Os resultados dos deslizamentos, apresentados na Fig. 6.8(b), mostram que o modelo experimental apresentou maior deslizamento do que o modelo numérico para uma das extremidades (D1-D2) e menor deslizamento para a outra (D3D4).

Nas análises em EF das vigas VMT e VMPI-2, foi utilizado um coeficiente de atrito de 0,6. Os resultados de momento fletor vs. deslizamento se mostraram coerentes comparados aos resultados experimentais (Fig. 6.7(b) e 6.9(b)).

As Fig. 6.7(c),6.8(c) e 6.9(c) apresentam as curvas de deformação no perfil e as Fig. 6.7(d),6.8(d) e 6.9(d) mostram as deformações no concreto. Os dados experimentais foram obtidos por meio de strain gages posicionados nas mesas superior e inferior do perfil e na face superior da laje, na seção central do vão. Para esses mesmos pontos, foi traçada a curva dos resultados numéricos, gerando uma comparação entre os dois modelos que revela compatibilidade de resultados tanto para o concreto da laje como para a mesa inferior do perfil. $\mathrm{Na}$ mesa superior, os resultados experimentais destoaram dos resultados numéricos devido aos diferentes tipos de aço utilizados no modelo experimental (ASTM A36) e na modelagem (ASTM A572). 

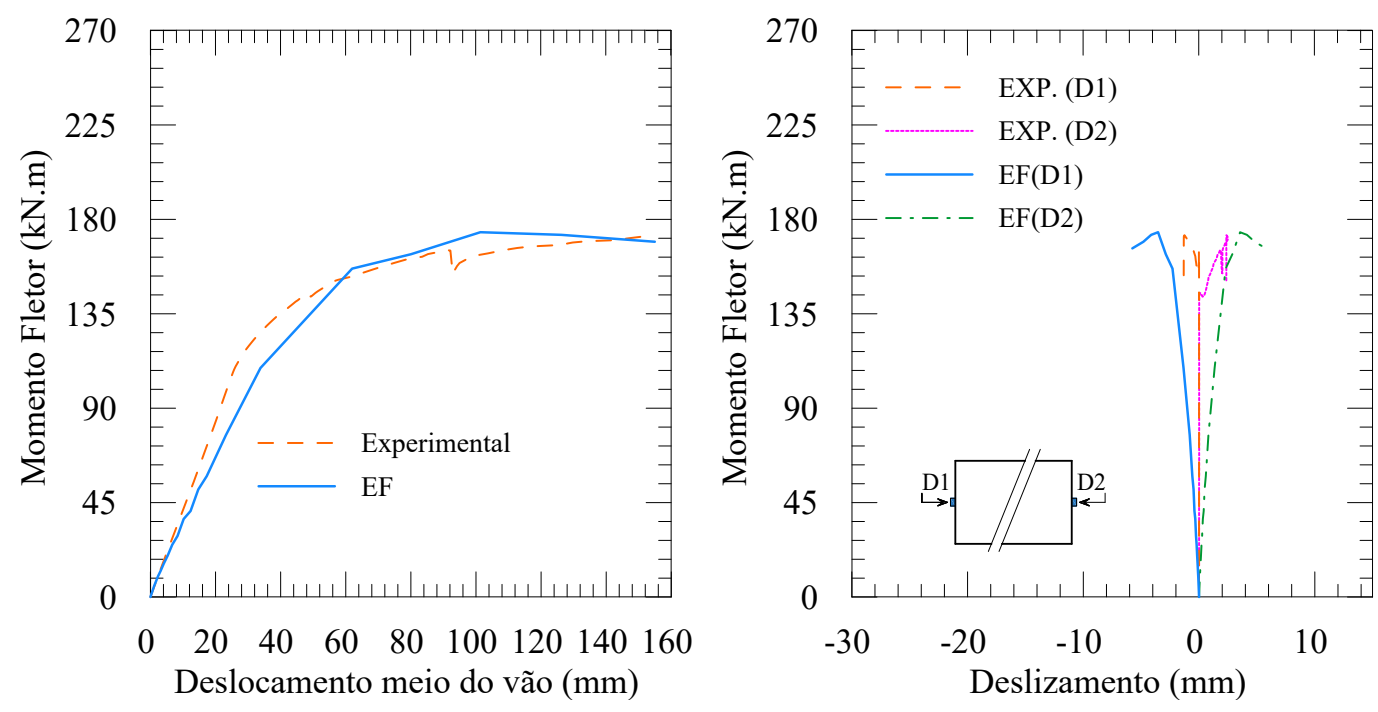

6.7(a): Momento fletor vs. deflexão

6.7(b): Momento fletor vs. deslizamento
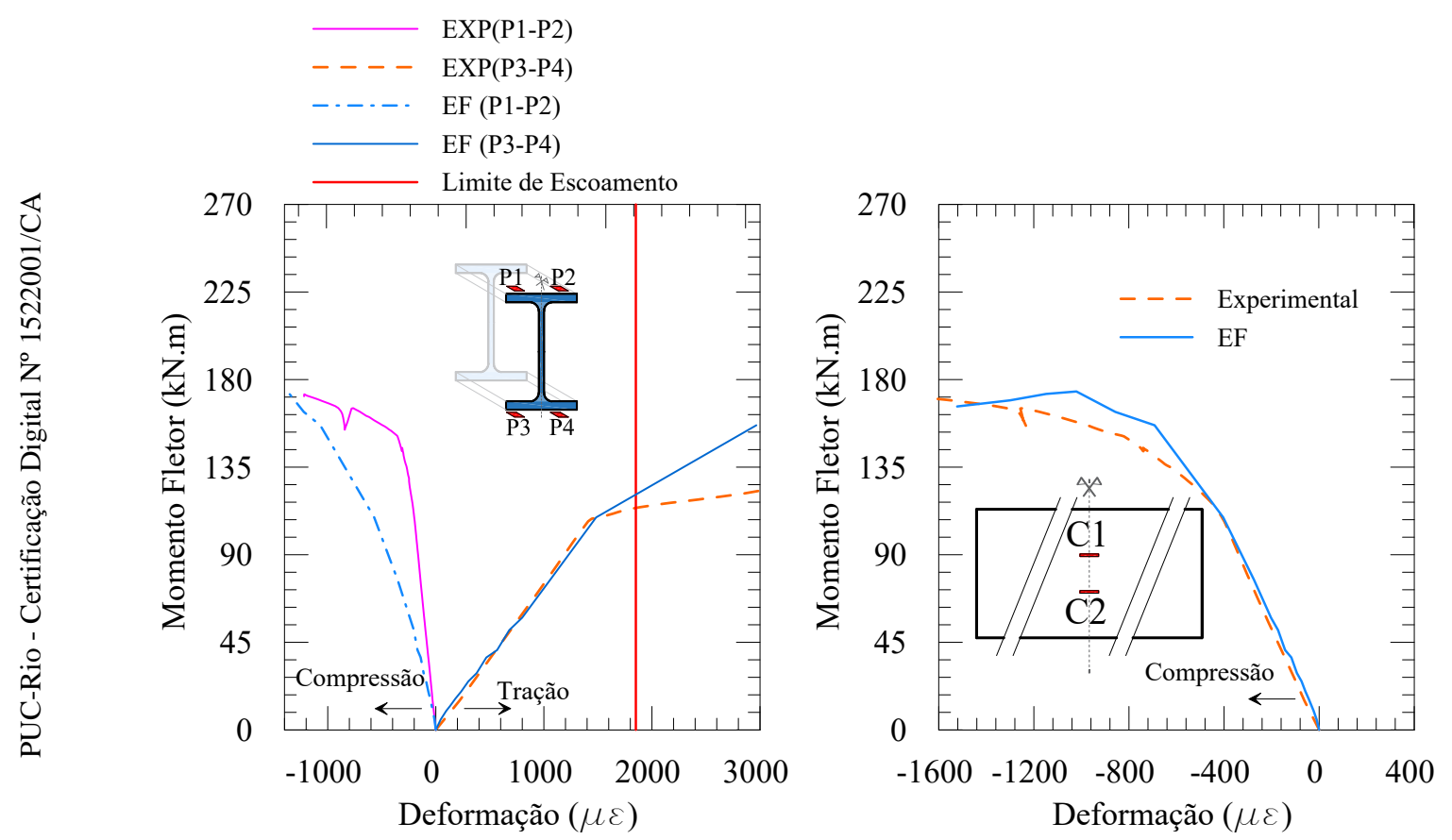

6.7(c): Momento fletor vs. deformação no 6.7(d): Momento fletor vs. deformação no perfil concreto

Figura 6.7: Comparação entre resultados experimentais e modelo em EF VMT

Além disso, foram investigados os modos de falha dos modelos. Nos ensaios, a viga VMT não apresentou um modo de falha específico, considerando que os deslocamentos foram excessivos (vão/50). Nas vigas VMPI-1 e VMPI-2, a ruptura ocorreu na ligação entre o perfil e a laje de concreto. Os mesmos modos de falha foram observados nos modelos numéricos.

As Fig. 6.10(a), 6.11(a) e 6.12(a) apresentam a distribuição das tensões de von Mises nos perfis para o carregamento último. Os pontos com tensão acima 

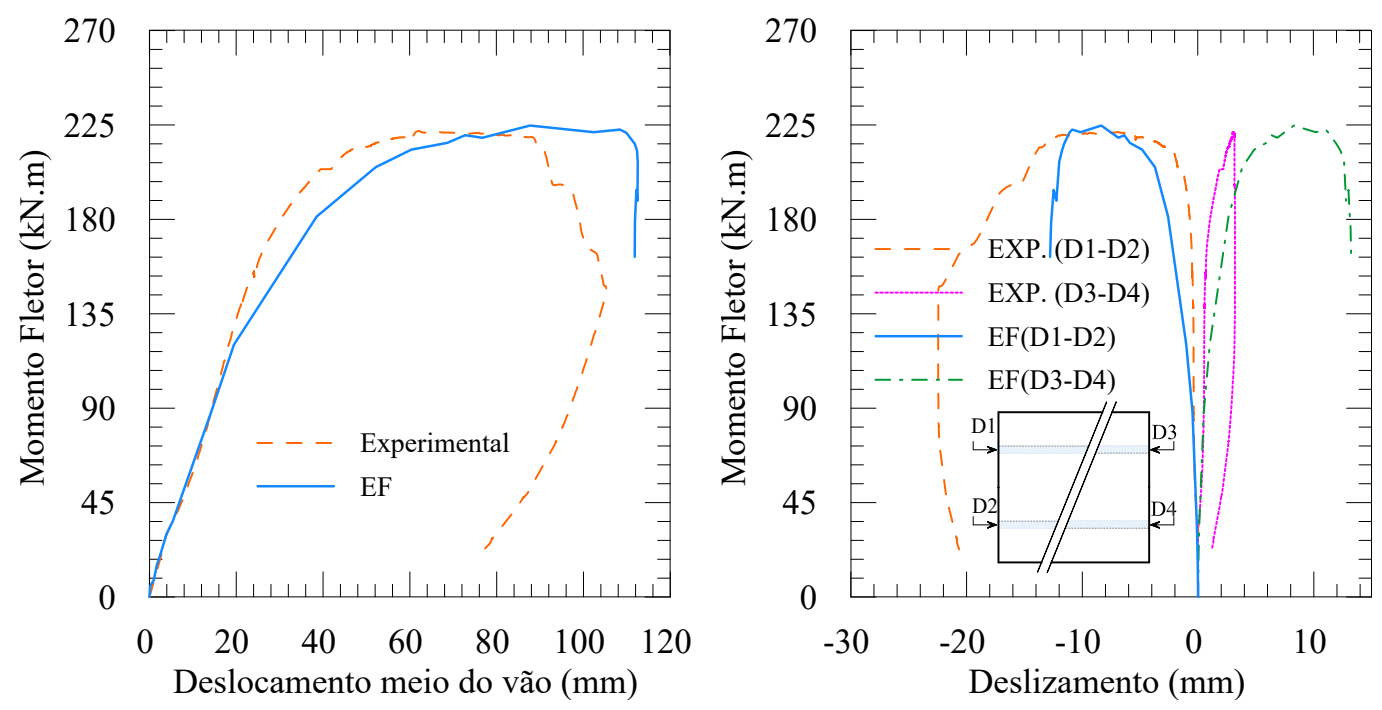

6.8(a): Momento fletor vs. deflexão

6.8(b): Momento fletor vs. deslizamento
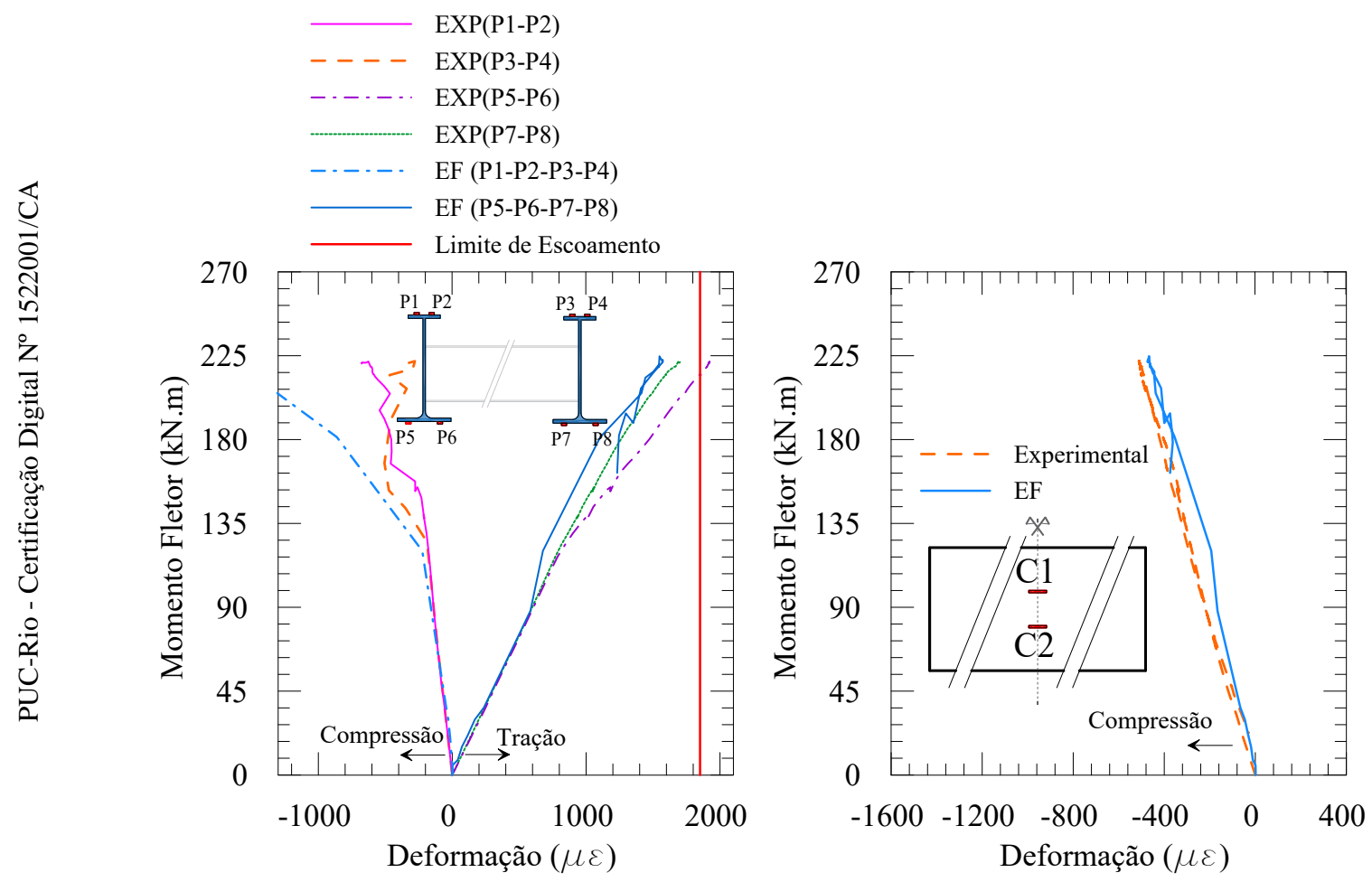

6.8(c): Momento fletor vs. deformação no 6.8(d): Momento fletor vs. deformação no perfil concreto

Figura 6.8: Comparação entre resultados experimentais e modelo em EF VMPI-1

do valor de escoamento do material, determinado em ensaio de tração direta, foram destacados na cor cinza. As aberturas mais próximas das extremidades foram as mais solicitadas, com destaque para a instabilidade local da mesa superior no modelo VMPI-2, da mesma forma em que foi observado durante os ensaios (ver Fig. 5.27(c)).

As Fig. 6.10, 6.11 e 6.12 apresentam o padrão de fissuras nas lajes de 

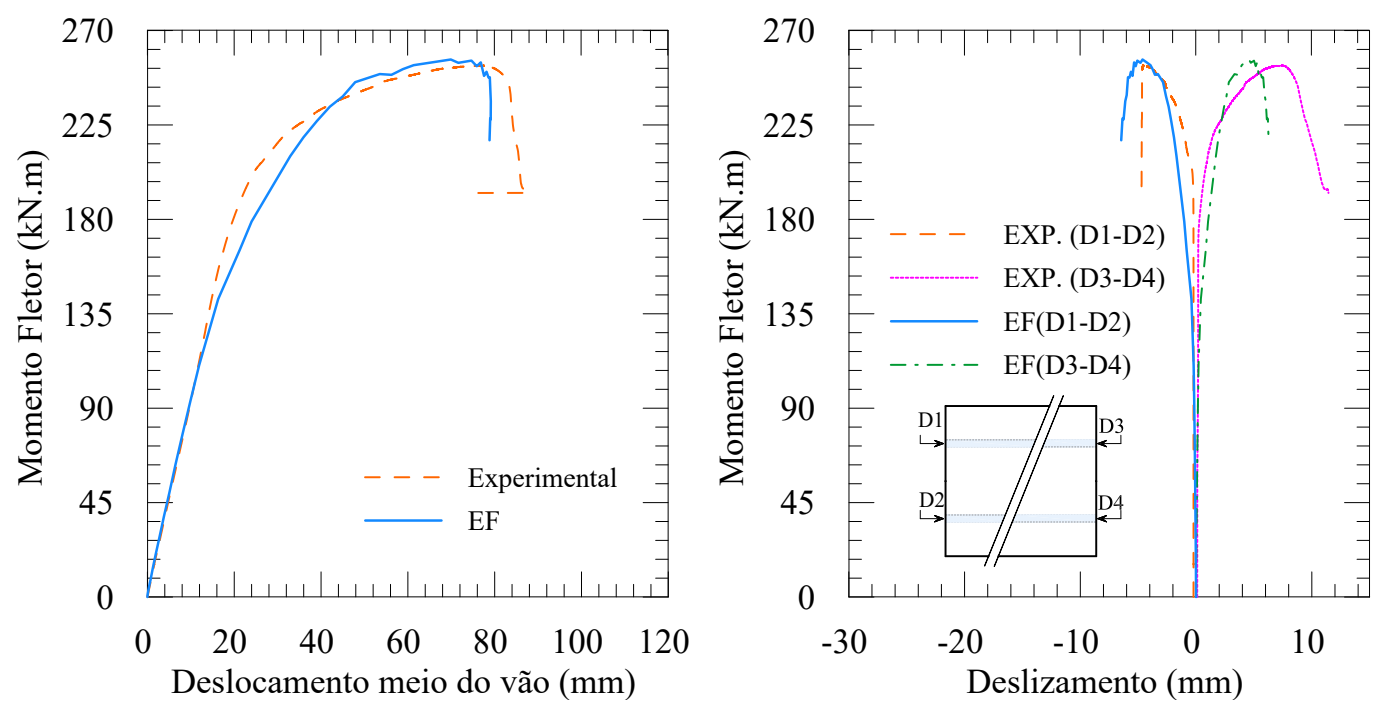

6.9(a): Momento fletor vs. deflexão

6.9(b): Momento fletor vs. deslizamento
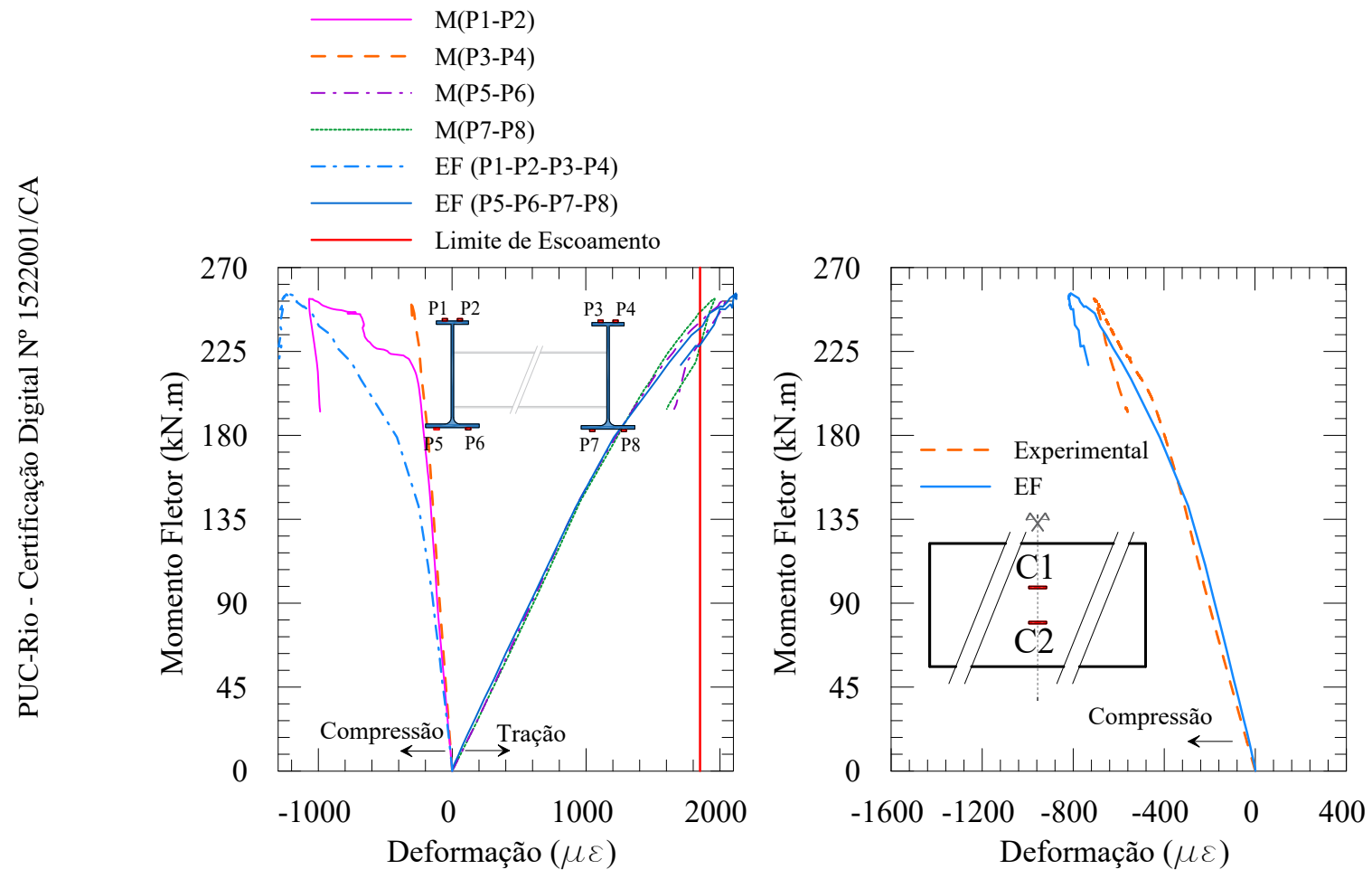

6.9(c): Momento fletor vs. deformação no 6.9(d): Momento fletor vs. deformação no perfil concreto

Figura 6.9: Comparação entre resultados experimentais e modelo em EF VMPI-2

concreto dos protótipos. A variável de dano é associada à falha por tração do material, com as regiões em vermelho representando trincamento por tração. As fissuras no modelo em Elementos Finitos foram equivalentes àquelas observadas no ensaio (ver Fig. 5.19, 5.20 e 5.21). Da mesma forma como foi observado em ensaio, a face superior da laje apresentou desagregação de cones de concreto nas extremidades das vigas. Na face inferior da laje, observou-se 
a ruptura do concreto dentro das aberturas de alma e a formação de fissuras transversais nos pontos de aplicação de carga.

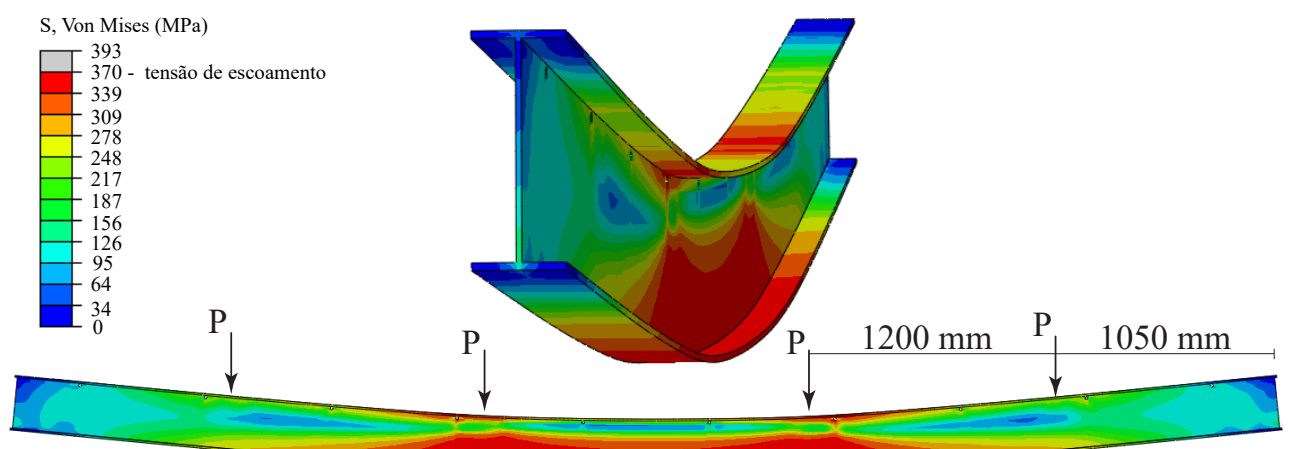

$6000 \mathrm{~mm}$

6.10(a): Distribuição das tensões no perfil W250X25,3

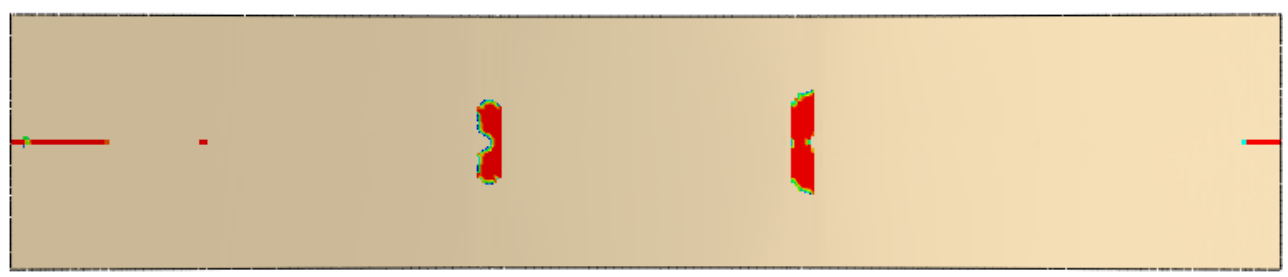

6.10(b): Dano do concreto por tração na face superior da laje

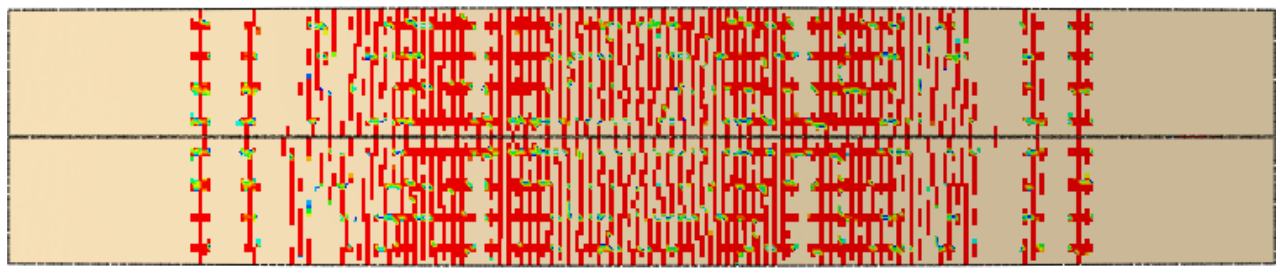

6.10(c): Dano do concreto por tração na face inferior da laje

Figura 6.10: Modelo em EF do protótipo VMT 


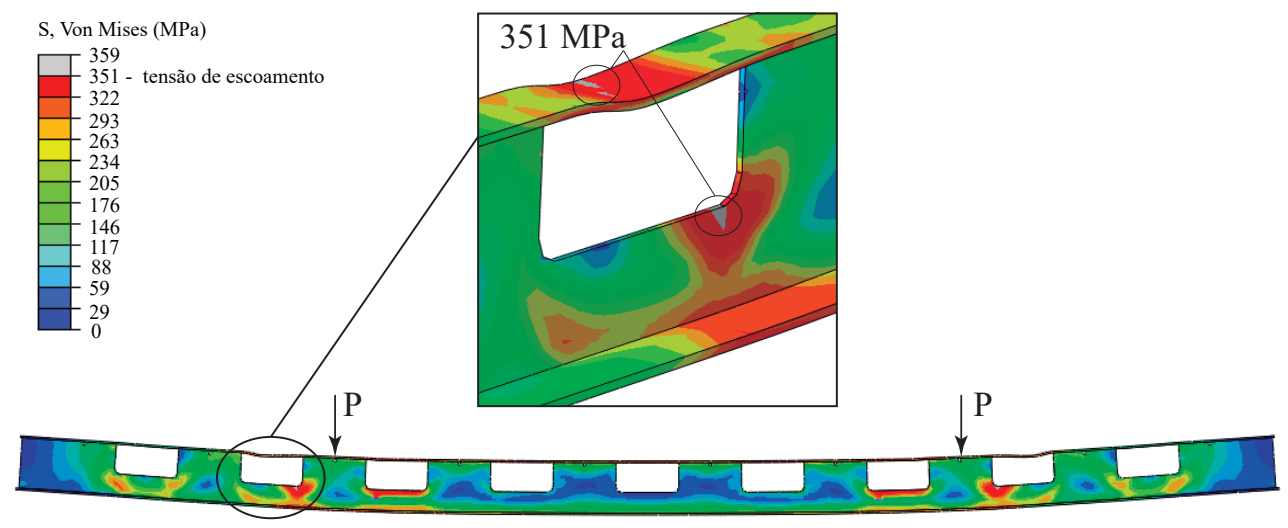

6.11(a): Distribuição das tensões no perfil V360-01

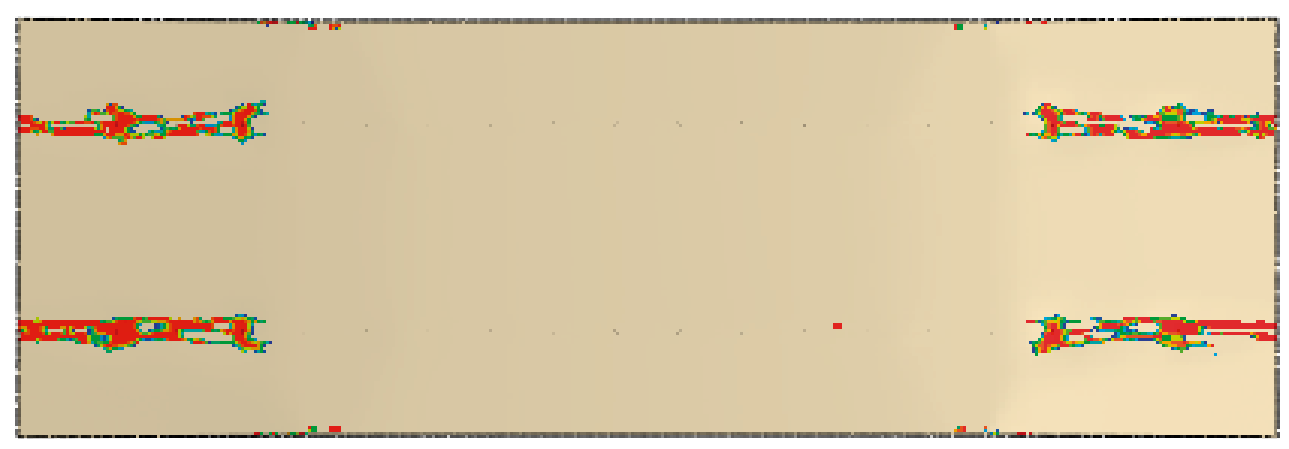

6.11(b): Dano no concreto por tração na face superior da laje

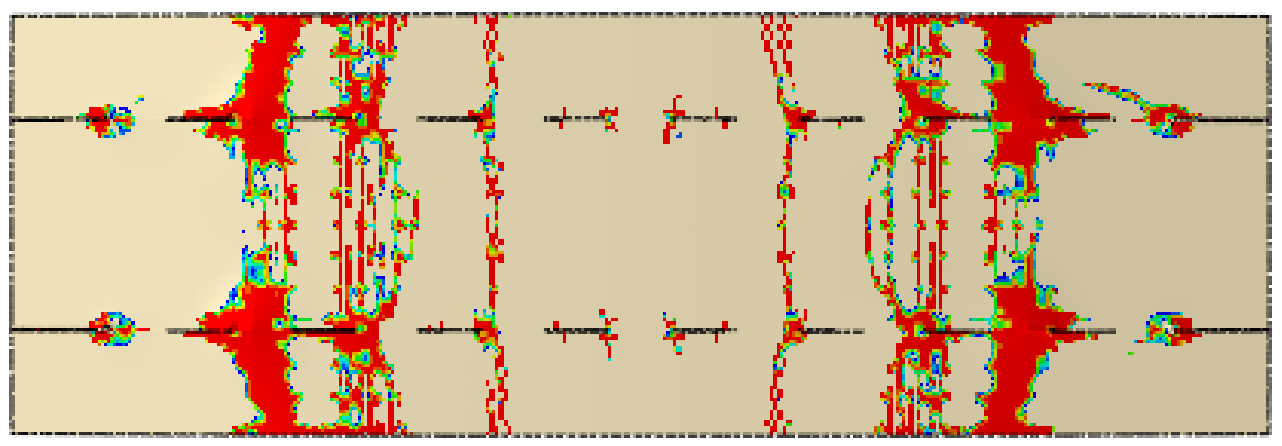

6.11(c): Dano no concreto por tração na face inferior da laje

Figura 6.11: Modelo em EF do protótipo VMPI-1 


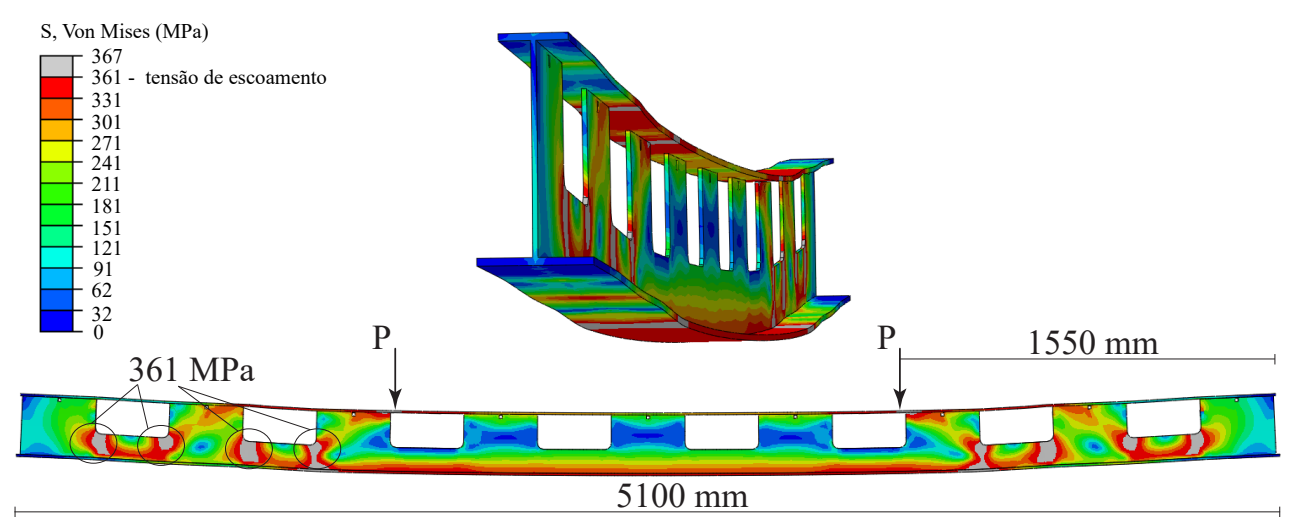

6.12(a): Distribuição das tensões no perfil V360-02

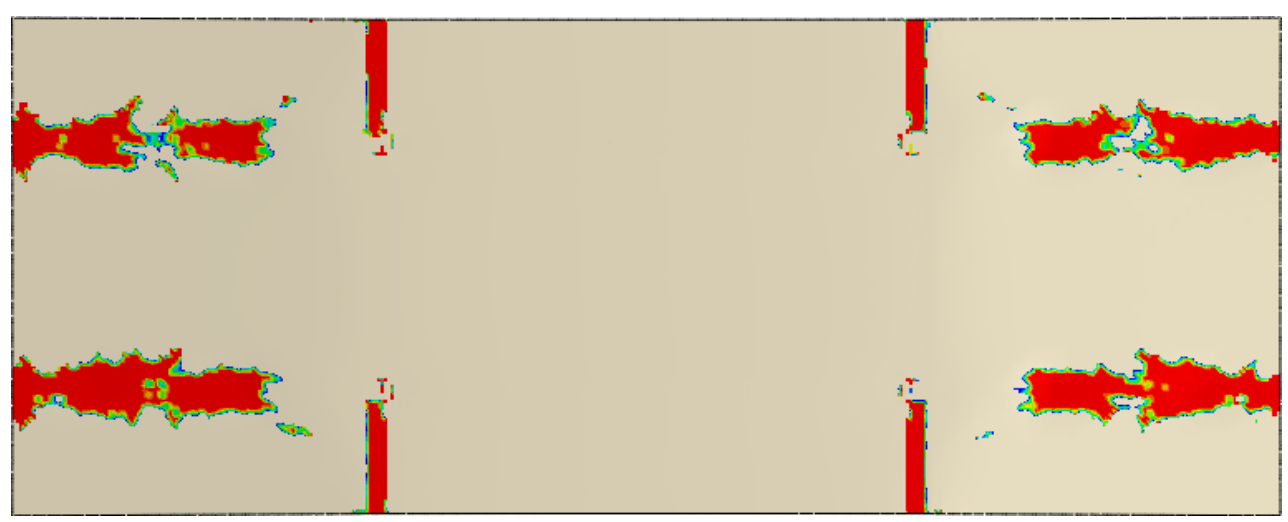

6.12(b): Dano no concreto por tração na face superior da laje

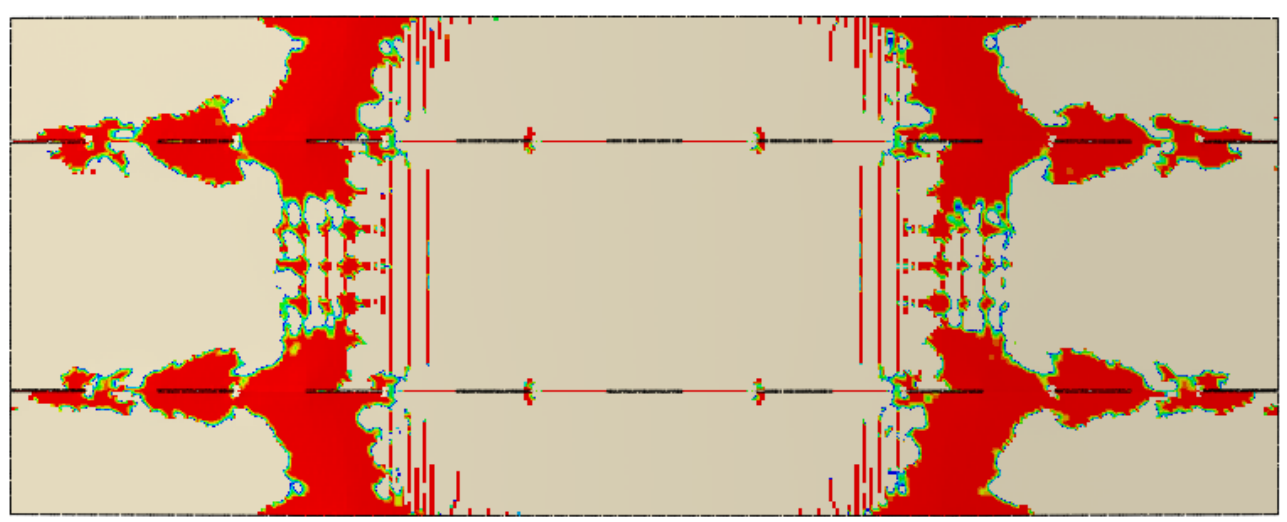

6.12(c): Dano no concreto por tração na face inferior da laje

Figura 6.12: Modelo em EF do protótipo VMPI-2 


\section{7}

\section{Comparação entre resultados previstos e experimentais}

A Fig. 7.1 mostra o momento fletor previsto vs. deflexão e os valores experimentais das vigas mistas. Ambos os resultados mostraram uma boa concordância no domínio elástico, porém o comportamento não-linear dos materiais e o início do deslizamento entre o aço e concreto fez com que as curvas se distanciassem. Próximo ao momento último, a curva experimental dos protótipos VMT e VMPI-1 tendeu a se aproximar dos valores previstos, com os resultados medidos atingindo 99\% (VMT), 100\% (VMPI-1) e 113\% (VMPI-2) dos resultados previstos.

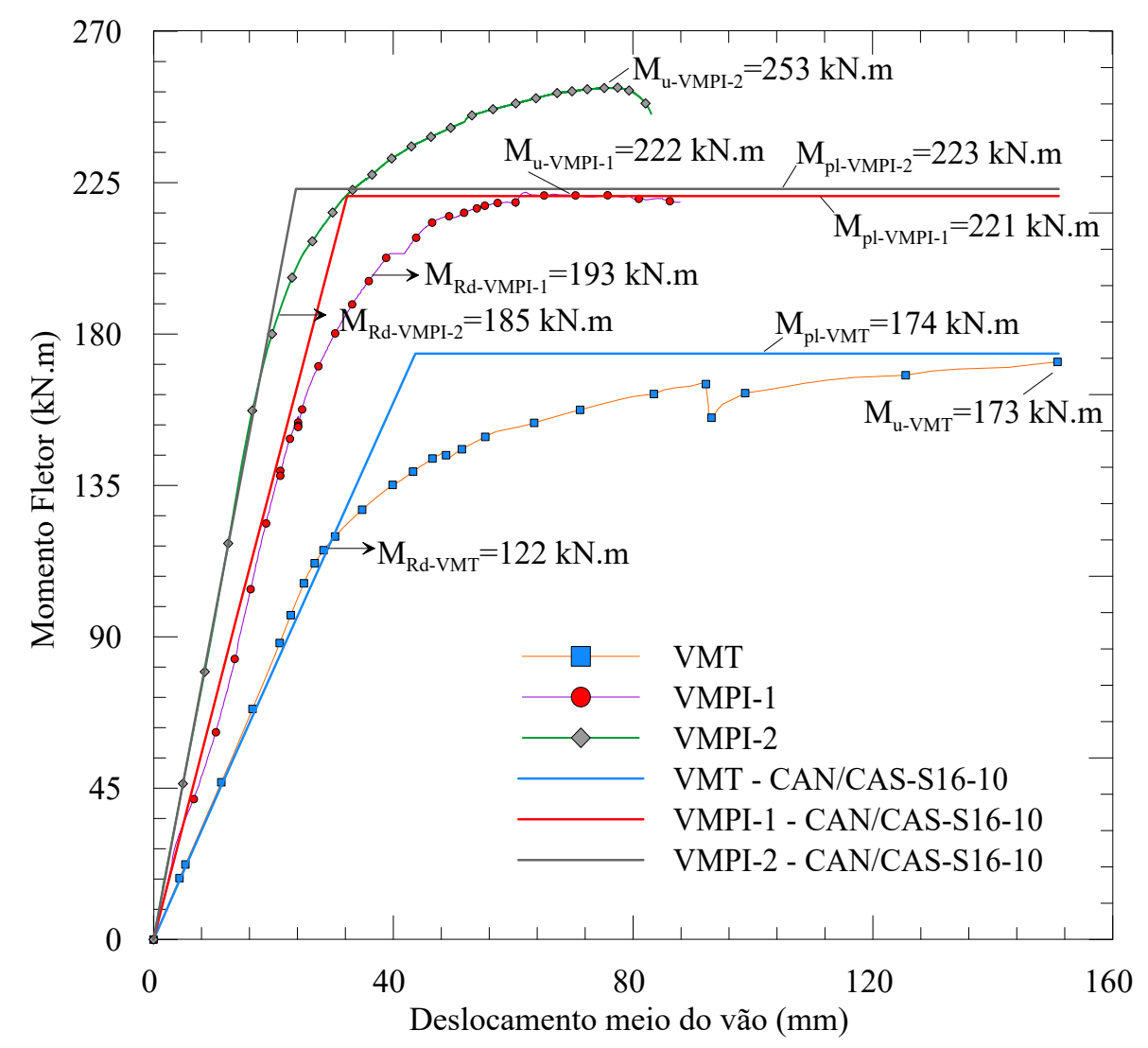

Figura 7.1: Momento fletor vs. deslocamento no meio do vão

A resistência de projeto $\left(M_{R d}\right)$ das vigas mistas foi avaliada de acordo com as recomendações da norma CAN/CAS-S16-10 [102]. O valor de projeto representou $68 \%$ (VMT), $87 \%$ (VMPI-1) e $73 \%$ (VMPI-2) do valor experimen- 
tal $\left(M_{u}\right)$. Esses resultados indicam que a conexão de cisalhamento proposta é eficiente para transmitir as forças da laje para a seção da viga.

A Tabela 7.1 apresenta os valores de momento fletor máximo obtidos experimentalmente $\left(M_{u}\right)$, bem como os valores obtidos pela análise por Elementos Finitos $\left(M_{E F}\right)$, o momento fletor devido à plastificação da seção mista $\left(M_{p l}\right)$ e a resistência de projeto $\left(M_{R d}\right)$ para cada protótipo.

Tabela 7.1: Momentos fletores obtidos para cada viga

\begin{tabular}{|c|c|c|c|c|c|c|c|}
\hline \multirow{2}{*}{ Protótipo } & \multirow{2}{*}{$\begin{array}{c}M_{u} \\
(\mathrm{MPa})\end{array}$} & \multicolumn{2}{|c|}{$M_{E F}$} & \multicolumn{2}{|c|}{$M_{p l}$} & \multicolumn{2}{|c|}{$M_{R d}$} \\
\hline & & (MPa) & $\% M_{u}$ & (MPa) & $\% M_{u}$ & (MPa) & $\% M_{u}$ \\
\hline VMT & 173 & 174 & 101 & 174 & 101 & 122 & 70 \\
\hline VMPI-1 & 222 & 225 & 101 & 221 & 100 & 193 & 87 \\
\hline VMPI-2 & 253 & 256 & 101 & 223 & 88 & 185 & 73 \\
\hline
\end{tabular}

A Fig. 7.2 apresenta uma comparação entre o comportamento momento fletor medido vs. deflexão para a viga de pesquisa anterior [92], com formato "T"e aberturas de alma de $300 \mathrm{~mm}$, além dos resultados medidos atuais. Para fins de comparação, os resultados foram exibidos como uma função dos respectivos momentos de plastificação da viga.

O mesmo foi feito para o comportamento momento fletor vs. deslizamento, conforme mostrado na Fig. 7.3. Embora o ensaio da viga VMPI-1 tenha apresentado maior deslizamento na interface aço-concreto do que o ensaio anterior [92], pode-se observar que o comportamento $M / M_{p l}$ vs. deflexão foi bastante semelhante. Por outro lado, as armaduras passando por furos na alma (VMT, VMPI-1 e VMPI-2) foram mais eficientes do que as armaduras passando pelas aberturas de alma, como apresentado nos ensaios de cisalhamento direto e nos ensaios das vigas mistas em [92].

Os ensaios de cisalhamento direto apresentaram um comportamento rígido com ruptura frágil da ligação aço-concreto, parecido com a Curva $\mathrm{B}$ da Fig. 3.16 (Capítulo 3). Assim que a aderência é excedida, dá-se início ao deslizamento com tensão residual relacionada ao desenvolvimento do atrito, travamento mecânico e efeito pino nas armaduras transversais. Entretanto, nos ensaios das vigas mistas observou-se um comportamento mais dúctil após a ruptura da aderência. A diferença entre os resultados demonstra que os ensaios de cisalhamento direto não foram capazes de descrever adequadamente o comportamento da ligação mista. Por outro lado, os ensaios de cisalhamento direto contribuíram para a análise individualizada da conexão composta por uma abertura de alma e armaduras transversais. No geral, as vigas mistas apresentaram um comportamento dúctil e satisfatório para fins de projeto. 


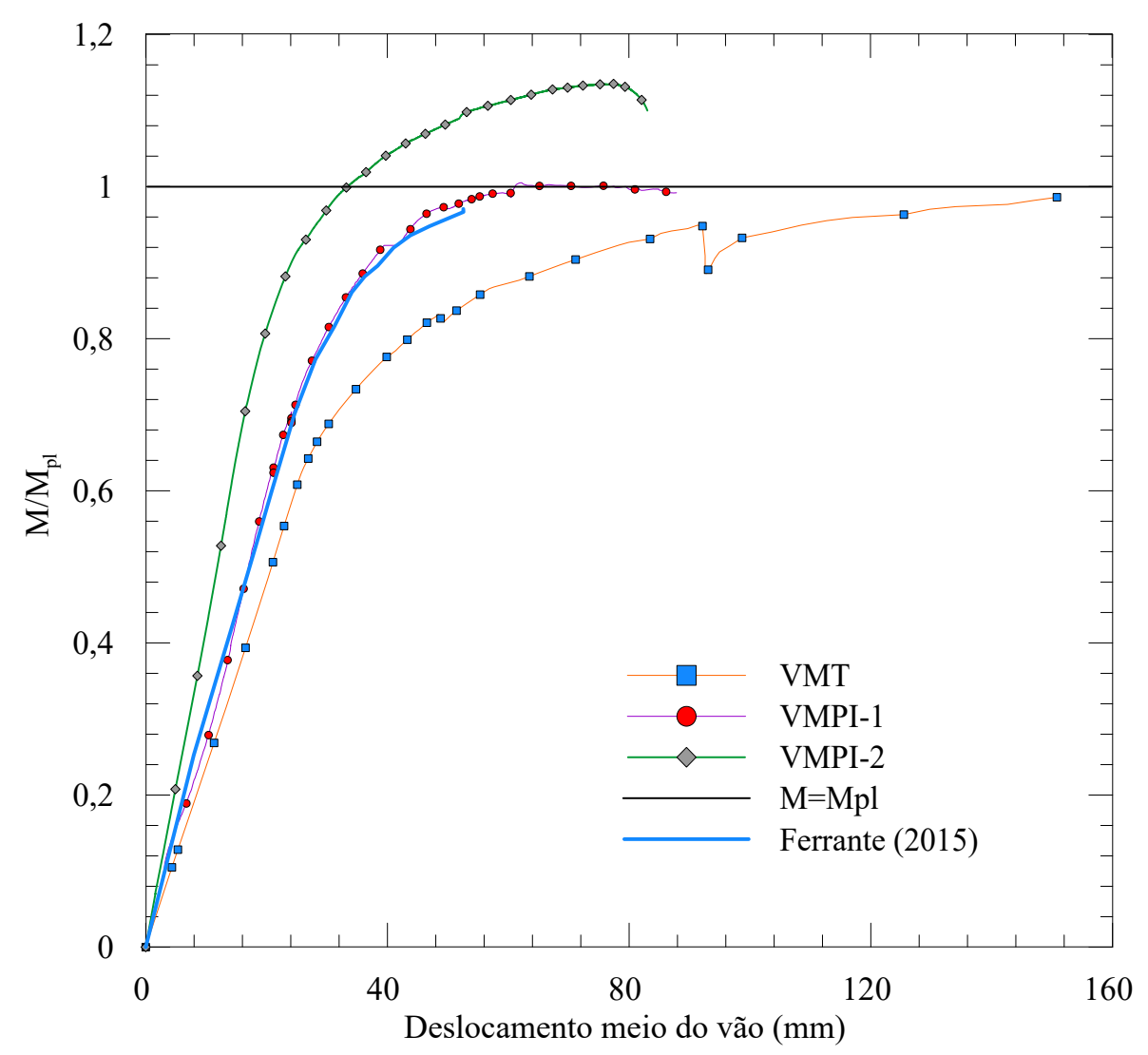

Figura 7.2: Momento fletor vs. deslocamento

O cisalhamento vertical não foi determinante no comportamento das vigas mistas. Os ensaios das vigas mistas VMT, VMPI-1 e VMPI-2 atingiram $13 \%, 30 \%$ e $40 \%$ do valor previsto, respectivamente, com a laje de concreto contribuindo com boa parte da resistência ao cortante. Os valores previstos, considerando interação total, mostraram que o concreto e o perfil suportam, respectivamente, $60 \%$ e $40 \%$ do cisalhamento para o modelo VMT e $70 \%$ e $30 \%$ para as vigas VMPI-1 e VMPI-2.

A maior influência ocorreu nas vigas com aberturas de alma. O ensaio VMPI-1 apresentou instabilidades nos cantos da alma da segunda abertura (ver Fig. 5.25(c)), que foi submetida aos maiores esforços combinados de cisalhamento vertical e momento fletor (ver Fig. 4.15(b)). Entretanto, as instabilidades locais só foram observadas após a ruptura da laje, o que causou a transferência do cisalhamento vertical para a alma do perfil. 


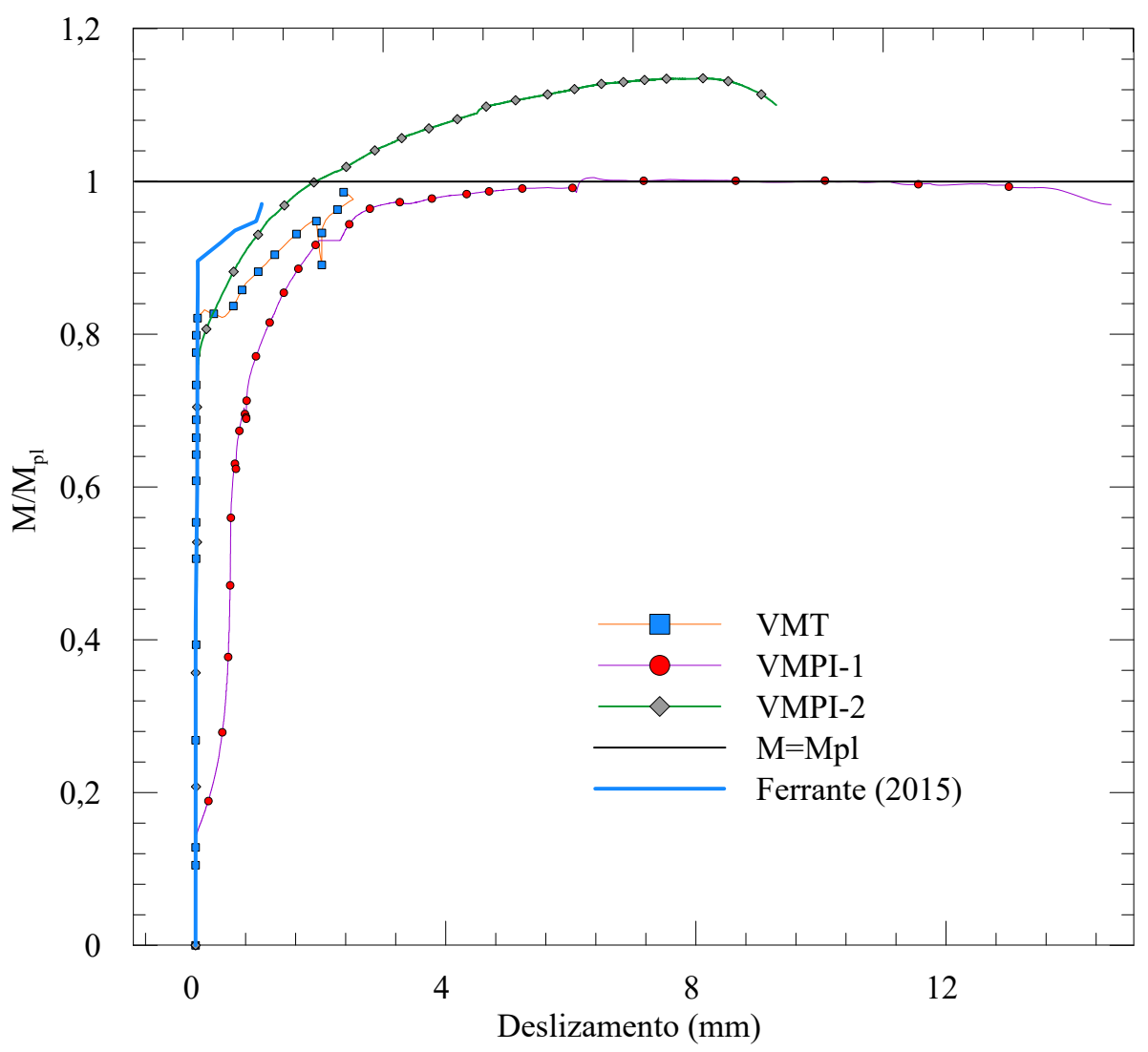

Figura 7.3: Momento fletor vs. deslizamento 


\section{8 \\ Considerações finais}

A contribuição efetiva deste trabalho está em apresentar uma alternativa de piso misto como uma solução eficiente, econômica e construtiva para a construção de edifícios comerciais. Este estudo fornece uma melhor compreensão sobre o comportamento da ligação mista não convencional utilizada em pisos mistos de pequena altura. Também destaca-se a inovação apresentada na configuração do ensaio de cisalhamento direto adaptado das recomendações feitas pela norma Eurocode 4 [36].

No decorrer da pesquisa, buscou-se caracterizar o comportamento misto aço-concreto e quantificar a capacidade resistente a flexão de uma nova proposta de sistema de piso, usando uma abordagem teórica e experimental.

O sistema proposto é constituído por perfil alveolar assimétrico com mesa de compressão embutida na laje de concreto. O mecanismo de transferência de cisalhamento foi estabelecido por meio de uma inovadora conexão por aderência, atrito e efeito pino (por armaduras transversais passando por furos na alma).

Para a pesquisa experimental, foram realizados 3 ensaios de vigamentos mistos aço-concreto em escala real com vãos de $5,85 \mathrm{~m} ; 5,8 \mathrm{~m}$ e $4,9 \mathrm{~m}$ além de 4 ensaios de cisalhamento direto. Também foram realizadas simulações numéricas para recalcular os resultados dos ensaios das vigas mistas.

Após a execução da análise parcial teórico-experimental das vigas mistas e dos ensaios de cisalhamento direto, concluiu-se que o modelo proposto é teoricamente viável. Os resultados previstos e os resultados medidos apresentaram boa correlação. Também pode-se concluir que:

1. Os ensaios de cisalhamento direto ajudaram a explicar as conexões de alta resistência por aderência, e a ligação entre o concreto e o aço apresentou um comportamento rígido. A capacidade de deslizamento dos protótipos P1, P2, P3 e P4 foi de 11,81 mm, 5,92 mm, 0,74 mm e 0,30 mm, respectivamente;

2. Após a carga máxima, a ruptura da aderência entre os materiais fez com que o deslizamento aumentasse rapidamente, passando a acionar outros mecanismos, como as armaduras transversais. A carga última para os 
modelos P1, P2, P3 e P4 foi de $172,2 \mathrm{kN}, 225,1 \mathrm{kN}, 224,5 \mathrm{kN}$ e $207,2 \mathrm{kN}$, respectivamente;

3. Devido à presença da chapa de alma, o modelo P2 apresentou um aumento de cerca de $30 \%$ da capacidade resistente em relação ao modelo $\mathrm{P} 1$;

4. As armaduras tipo espinha de peixe utilizadas nos modelos P3 e P4 contribuíram para o aumento da capacidade resistente em 30\% em relação aos modelos com armadura reta;

5. A resistência de projeto $\left(M_{R d}\right)$ das vigas mistas foi avaliada de acordo com as recomendações da norma CAN/CAS-S16-10 [102]. O valor de projeto representou 68\% (VMT), 87\% (VMPI-1) e 73\% (VMPI-2) do valor experimental $\left(M_{u}\right)$. Esses resultados indicam que a conexão de cisalhamento proposta é eficiente para transmitir as forças da laje para a seção da viga;

6. O modelo teórico foi capaz de prever adequadamente o comportamento experimental das vigas mistas. A resistência medida atingiu 99\% (VMT), 100\% (VMPI-1) e 113\% (VMPI-2) da resistência a flexão prevista;

7. No ensaio cíclico das vigas mistas, os materiais (aço e concreto) não apresentaram dano nem entraram em escoamento. O protótipo VMT atingiu $48 \%$ do valor da tensão de escoamento do aço e $21 \%$ da resistência a compressão do concreto. Os protótipos VMPI-1 e VMPI-2, por sua vez, atingiram $30 \%$ e $44 \%$ da tensão de escoamento do aço e $14 \%$ e $23 \%$ da resistência a compressão do concreto, respectivamente;

8. No protótipo VMPI-1, foi utilizado lubrificante pastoso na superfície de contato entre o perfil e a laje, ao passo que os protótipos VMT e VMPI2 permaneceram com a área de contato sem tratamento superficial. No protótipo VMT, o deslizamento começou com $82 \%$ do momento máximo, enquanto, nos protótipos VMPI-1 e VMPI-2, o deslizamento iniciou-se com $75 \%$ e $71 \%$ da resistência última, respectivamente;

9. As armaduras passando por furos na alma (VMT, VMPI-1 e VMPI-2) foram mais eficientes do que as armaduras passando pelas aberturas de alma, conforme apresentado nos ensaios de cisalhamento direto. No geral, as vigas mistas apresentaram um comportamento dúctil e satisfatório para fins de projeto; 
10. O cisalhamento vertical não foi determinante no comportamento das vigas mistas. Os ensaios das vigas mistas VMT, VMPI-1 e VMPI-2 atingiram $13 \%, 30 \%$ e $40 \%$ do valor previsto, respectivamente;

11. A viga mista VMT não apresentou um modo de ruína, e seu ensaio foi interrompido quando a configuração da viga estava altamente deformada. A ruína dos protótipos VMPI-1 e VMPI-2 ocorreram devido à ruptura da ligação aço-concreto. Com o espraiamento das tensões de compressão na laje, surgiram tensões de tração acima da resistência do concreto, levando à desagregação do concreto superficial e à consequente perda da aderência entre os dois materiais;

12. O modelo numérico desenvolvido foi capaz de representar adequadamente o comportamento das vigas mistas. Os resultados obtidos apresentaram boa correlação com os resultados experimentais, tanto na resistência última como na curva.

\section{1 \\ Recomendações para trabalhos futuros}

Visando continuidade aos estudos na mesma linha de pesquisa, sugere-se:

1. Realizar ensaios de cisalhamento direto (push-out) utilizando as armaduras transversais passando por furos na alma do perfil e parametrizar os ensaios variando a quantidade e o diâmetro das armaduras;

2. Executar avaliação numérica, via método dos Elementos Finitos, para os modelos de push-out e desenvolver um estudo paramétrico para as vigas mistas;

3. Avaliar comparativamente os custos de fabricação do sistema proposto e o custo de sistemas de vigamentos de piso alternativos. 


\section{Referências bibliográficas}

[1] AHMED, I. M.; TSAVDARIDIS, K. D. The evolution of composite flooring systems: applications, testing, modelling and eurocode design approaches. Journal of Constructional Steel Research, 155:286300, 2019.

[2] LU, X.; MÄKELÄINEN, P. Slim floor developments in sweden and finland. Structural Engineering International, 6:127-129, 1996.

[3] LAWSON, R. M.; BEGUIN, P.; OBIALA, R.; BRAUN, M.. Slim-floor construction using hollow-core and composite decking systems. Steel Construction, 8:85-89, 2015.

[4] LAM, D.; DAI, X.; KUHLMANN, U.; RAICHLE, J.; BRAUN, M. Slim-floor construction-design for ultimate limit state. Steel Construction, 8:79-84, 2015.

[5] MENSINGER, M.; FONTANA, M.; FRANGI, A. Entwicklung eines multifunktionalen deckensystems mit erhöhter ressourceneffizienz. Stahlbau, 79:282-297, 2010.

[6] JU, Y. K.; CHUN, S.; KIM, S.-D. Flexural test of a composite beam using asymmetric steel section with web opennings. Journal of Structural Engineering, 135:448-458, 2009.

[7] JU, Y. K.; KIM, S.-D. Behaviour of rc column to itech composite beam joint. In: PROCEEDINGS OF THE INSTITUTION OF CIVIL ENGINEERS - STRUCTURES AND BUILDINGS, p. 97-107, 2004.

[8] NARDIN, S.; EL DEBS, A. L. H. C. Study of partially encased composite beams with innovative position of stud bolts. Journal of constructional steel research, 65:342-350, 2009.

[9] NARDIN, S.; EL DEBS, A. L. H. C. Composite connections in slimfloor system: An experimental study. Journal of constructional steel research, 68:78-88, 2012. 
[10] LAWSON, R. M.; DEREK, L. M.; RACKHAM, J. W. Design of Asymmetric Slimflor Beams Using Deep Composite Decking. Steel Construction Institute, Ascot, 1nd edition, 1997.

[11] BRAUN, M.; HECHLER, O.; OBIALA, R. Untersuchungen zur verbundwirkung von betondübeln. Stahlbau, 83:302-308, 2014.

[12] QURESHI, J.; LAM, D.; YE, J. The influence of profiled sheeting thickness and shear connector's position on strength and ductility of headed shear connector. Engineering Structures, 33:1643-1656, 2011.

[13] ARAúJO, D. L.; SAleS, M. W. R.; PAUlO, S. M.; El DeBS, A. L. H. C. Headed steel stud connectors for composite steel beams with precast hollow-core slabs with structural topping. Engineering Structures, 107:135-150, 2016.

[14] BONILLA, J.; BEZERRA, L. M.; MIRAMBELL, E. Resistance of stud shear connectors in composite beams using profiled steel sheeting. Engineering Structures, 187:478-489, 2019.

[15] RODRIgueS, M. C.; ANDRADE, S. A. L.; LIMA, L. R. O.; VELLASCO, P. C. G. S.; RAMIRES, F. B. Experimental assessment of the composite joints shear connector component. Journal of Constructional Steel Research, 132:203-216, 2017.

[16] VIANNA, J. C.; COSTA-NEVES, L. F.; VELLASCO, P. C. G. S.; ANDRADE, S. A. L. Structural behaviour of t-perfobond shear connectors in composite girders: An experimental approach. Engineering Structures, 30:2381-2391, 2008.

[17] CÂNDIDO-MARTINS, J. P. S.; COSTA-NEVES, L. F.; VELLASCO, P. C. G. S. Experimental evaluation of the structural response of perfobond shear connectors. Engineering Structures, 32:1976-1985, 2010.

[18] COSTA-NeVES, L. F.; Figueiredo, J. P.; VEllasCo, P. C. G. S.; VIANNA, J. C. Perforated shear connectors on composite girders under monotonic loading: An experimental approach. Engineering Structures, 56:721-737, 2013.

[19] AlLAHYARIA, H.; NIKBIN, I. M.; RAHIMI, S. R.; HEIDARPOUR, A. A new approach to determine strength of perfobond rib shear 
connector in steel-concrete composite structures by employing neural network. Engineering Structures, 157:235-249, 2018.

[20] ZHAO, C.; LI, Z.; DENG, K.; WANG, W. Experimental investigation on the bearing mechanism of perfobond rib shear connectors. Engineering Structures, 159:172-184, 2018.

[21] VIANNA, J. C.; ANDRADE, S. A. L.; VellaSCO, P. C. G. S.; COSTANEVES, L. F. Experimental study of perfobond shear connectors in composite construction. Journal of Constructional Steel Research, 81:62-75, 2013.

[22] KIM, S.-H.; KIM, K.-S.; PARK, S.; AHN, J.-H.; LEE, M.-K. Y-type perfobond rib shear connectors subjected to fatigue loading on highway bridges. Journal of Constructional Steel Research, 122:445-454, 2016.

[23] KIM, S.-H.; HAN, O.; KIM, K.-S.; PARK, J.-S. Experimental behavior of double-row y-type perfobond rib shear connectors. Journal of Constructional Steel Research, 150:221-229, 2018.

[24] GU, J.-C.; LIU, D.; DENG, W.-Q.; ZHANG, J.-D. Experimental study on the shear resistance of a comb-type perfobond rib shear connector. Journal of Constructional Steel Research, 158:279-289, 2019.

[25] HENDERSON, I. E. J.; ZHU, X. Q.; UY, B.; MIRZA, O. Dynamic behaviour of steel-concrete composite beams with different types of shear connectors. part i: Experimental study. Engineering Structures, 103:298-307, 2015.

[26] HENDERSON, I. E. J.; ZHU, X. Q.; UY, B.; MIRZA, O. Dynamic behaviour of steel-concrete composite beams retrofitted with various bolted shear connectors. Engineering Structures, 131:115135, 2017.

[27] ZHANG, J.-L.; LIU, B.-D.; ZHANG, P.-Y.; WANG, Z.-H. Small-scale test and analysis of corrugated-steel-plate--concrete composite member adopting novel shear connectors. Engineering Structures, 184:369-383, 2019.

[28] SENCU, R. M.; WANG, Y. C.; YANG, J.; LAM, D. Performance evaluation of demountable shear connectors with collar step at ambient and elevated temperatures. Engineering Structures, 194:94105, 2019. 
[29] REHMAN, N.; LAM, D.; DAI, X.; ASHOUR, A. F. Experimental study on demountable shear connectors in composite slabs with profiled decking. Journal of Constructional Steel Research, 122:178-189, 2016.

[30] BARAN, E.; TOPKAYA, C. An experimental study on channel type shear connectors. Journal of Constructional Steel Research, 74:108-117, 2012.

[31] KEO, P.; LEPOURRY, C.; SOMJA, H.; PALAS, F. Behavior of a new shear connector for $\mathrm{u}$-shaped steel-concrete hybrid beams. Journal of Constructional Steel Research, 145:153-166, 2018.

[32] LIU, Y.; GUO, L.; QU, B.; ZHANG, S. Experimental investigation on the flexural behavior of steel-concrete composite beams with ushaped steel girders and angle connectors. Engineering Structures, 131:492-502, 2017.

[33] BeZERRA, L. M.; CAVALCANTE, O. O.; CHATER, L.; BONILLA, J. $\mathrm{V}$-shaped shear connector for composite steel-concrete beam. Journal of Constructional Steel Research, 150:162-174, 2018.

[34] HOSSEINPOUR, E.; BAHAROM, S.; BADARUZZAMAN, W. H. W.; ZAND, A. W. A. Push-out test on the web opening shear connector for a slim-floor steel beam: Experimental and analytical study. Engineering Structures, 163:137-152, 2018.

[35] FERRANTE, C. A. O. Estudo teórico-experimental do comportamento à flexão de vigas mistas com perfil assimétrico parcialmente embutido. Dissertação de mestrado, Pontifícia Universidade Católica do Rio de Janeiro, Rio de Janeiro, 2015.

[36] EUROPEAN COMMITTEE FOR STANDARDIZATION. Eurocode 4 : Design of composite steel and concrete structures part 1-1 : General rules and rules for buildings. Technical report, Brussels, 2004.

[37] LAWSON, R. M. Slimflor and slimdek construction: European developments. The Structural Engineer, 77:22-30, 1999.

[38] RACKHAM, J. W.; HICKS, S. J.; PROPOSEDMAN, G. M. Design of Asymmetric Slimflor Beams with Precast Concrete Slabs. The Steel Construction Institute, Ascot, 1nd edition, 2006. 
[39] JU, Y. K.; KIM, D. H.; KIM, S. D. Experimental assessment of the shear strength of an asymmetric steel composite beam with web openings. Canadian Journal of Civil Engineering, 32:314-328, 2005.

[40] MULLETT, D. L. Composite floor system. Blackwell Science Ltd, 1998.

[41] WANG, Y.; YANG, L.; SHI, Y.; ZHANG, R. Loading capacity of composite slim frame beams. Journal of constructional steel research, 65:650-661, 2009.

[42] HECHLER, O.; BRAUN, M. O. R. K. U. E. F. H. G.. Cosfb-composite slim-floor beam: experimental test campaign and evaluation. In: COMPOSITE CONSTRUCTION IN STEEL AND CONCRETE VII, p. 158-172, 2013.

[43] BRAUN, M.; OBIALA, R.; ODENBREIT, C. Analyses of the loadbearing behaviour of deepembedded concrete dowels, cosfb. Steel Construction, 8:167-173, 2015.

[44] BRAUN, M.; OBIALA, R.; ODENBREIT, C. Numerical simulation of the load bearing behaviour of concrete dowels in slim-floor construction-cosfb. ce/papers, 1:1831-1840, 2017.

[45] KLAIBER, F.W.; WIPF, T.J. An alternate shear connector for composite action. In: MID-CONTINENT TRANSPORTATION SYMPOSIUM PROCEEDINGS, p. 115-120, 2000.

[46] HE, S.; FANG, Z.; FANG, Y.; LIU, M.; LIU, L.; MOSALLAM, A. S. Experimental study on perfobond strip connector in steel-concrete joints of hybrid bridges. Journal of Constructional Steel Research, 118:169-179, 2016.

[47] PEIKKO. Deltabeam slim floor structure technical manual, 2019. Acesso em: Janeiro de 2019.

[48] PELTONEN, S.; LESKELÄ, M. V. Connection behaviour of a concrete dowel in a circular web hole of a steel beam. In: INTERNATIONAL CONFERENCE ON COMPOSITE CONSTRUCTION IN STEEL AND CONCRETE V - ASCE, p. 544-552, South Africa, 2006.

[49] LESKEL, M. V.; PELTONEN, S.; ILIOPOULOS, A.; KIRIAKOPOULOS, $P$. Numerical and experimental investigations on the vertical 
shear resistance of boxed steel cross-sections with concrete infill (deltabeams). In: EUROSTEEL 2014, p. 6, Naples, Italy, 2014.

[50] MARAVEAS, C.; TSAVDARIDIS, K. D.; NADJAI, A. Fire resistance of unprotected ultra shallowfloor beams (usfb): a numerical investigation. Fire Technology, 53:609-627, 2017.

[51] MARAVEAS, C. Fire resistance of delta composite beams: A numerical investigation. Journal of Structural Fire Engineering, 8, 2017.

[52] HICKS, S.; PELTONEN, S. Vibration performance of composite floors using slim floor beams. In: INTERNATIONAL CONFERENCE ON COMPOSITE CONSTRUCTION IN STEEL AND CONCRETE VII ASCE, p. 185-198, North Queensland, Australia, 2013.

[53] JU, Y. K.; CHUN, S. C.; KIM, D. Y.; KIM, D. H.; KIM, S. D.; CHUNG, K.R. Structural performance of i-tech composite beam steel with web openings. In: THE CIB-CTBUH INTERNATIONAL CONFERENCE ON TALL BUILDINGS, p. 411-418, Kuala Lumpur, Malaysia, 2003.

[54] JU, Y. K.; KANG, S. W.; CHUN, S. C.; LEE, Y. K.; KIM, S. D.; KIM, D. H.; CHUNG, K. R.; YOON, S. W. Experimental assessment of floor vibration using itech composite beam. In: THE CIB-CTBUH INTERNATIONAL CONFERENCE ON TALL BUILDINGS, p. 488-495, Seoul, Coreia, 2004.

[55] HUO, B. Y. Experimental and Analytical Study of the Shear Transfer in Composite Shallow Cellular Floor Beams. Tese de doutorado, City University London, London, 2012.

[56] HUO, B. Y.; D'MELLO, C.. Shear transferring mechanisms in a composite shallow cellular floor beam with web openings. Structures, 9:134-146, 2017.

[57] TSAVDARIDIS, K. D. Structural Performance of Perforated Steel Beams with Novel Web Openings and With Partial Concrete Encasement. Tese de doutorado, City University London, London, 2010.

[58] TSAVDARIDIS, K. D.; D'MELLO, C.; HUO, B. Y. Computational study modelling the experimental work conducted on the shear capacity of perforated concrete-steel ultra shallow floor beams (usfb). In: 6TH NATIONAL CONCRETE CONFERENCE, p. 1-12, Paphos, Cyprus, 2009. 
[59] TSAVDARIDIS, K. D.; D'MELLO, C.; HAWES, M. Experimental study of ultra-shallow floor beams (usfb) with perforated steel sections. In: NORDIC STEEL CONSTRUCTION CONFERENCE, Malmö, Sweden, 2009.

[60] HUO, B. Y.; D'MELLO, C.. Push-out tests and analytical study of shear transfer mechanisms in composite shallow cellular floor beams. Journal of Constructional Steel Research, 88:191-205, 2013.

[61] HUO, B. Y.; D'MELLO, C.; TSAVDARIDIS, K. D. Experimental and analytical study of push-out shear tests in ultra shallow floor beams. In: IABSE SYMPOSIUM REPORT 97, p. 31-38, Veneza, Itália, 2010.

[62] AGHAEE, K.; YAZDI, M. A.; TSAVDARIDIS, K. D. Mechanical properties of structural lightweight concrete reinforced with waste steel wires. Magazine of Concrete Research, 66:1-9, 2014.

[63] CHEN, S.; LIMAZIE, T.; TAN, J. Flexural behavior of shallow cellular composite floor beams with innovative shear connections. Journal of constructional steel research, 106):329-346, 2015.

[64] LIMAZIE, T.; CHEN, S. Effective shear connection for shallow cellular composite floor beams. Journal of Constructional Steel Research, 128:772-788, 2017.

[65] KANSINALLY, R.; TSAVDARIDIS, K. D. Vibration response of usfb composite floors. In: NORDIC STEEL CONSTRUCTION CONFERENCE, p. 22-25, Leeds, Inglaterra, 2015.

[66] TSAVDARIDIS, K. D.; GIARALIS, A. Derivation of dynamic properties of steel perforated ultra shallow floor beams (usfb) via finite element modal analysis and experimental verification. In: 7TH NATIONAL CONFERENCE ON STEEL STRUCTURES, p. 321-329, Tehran, Iran, 2011.

[67] TSAVDARIDIS, K. D.; GALIATSATOS, G. Assessment of cellular beams with transverse stiffeners and closely spaced web openings. Thin-Walled Structures, 94:636-650, 2015.

[68] VERÍSSIMO, G. S. Desenvolvimento de um conector de cisalhamento em chapa dentada para estruturas mistas de aço e concreto e estudo do seu comportamento. Tese de doutorado, Universidade Federal de Minas Gerais, Minas Gerais, 2004. 
[69] LEONHARDT, F.; ANDRÄ, W.; ANDRÄ, H. P.; HARRE, W. Neues vorteilhaftes verbundmittel für stahlverbund-tragwerk mit höher dauerfestigkeit. Beton-und Stahlbetonbau, 12:325-331, 1987.

[70] KRAUS, D.; WURZER, O. Nonlinear finite-element analysis of concrete dowels. Computers and Structures, 64:1271-1279, 1997.

[71] LECHNER, T.; GEHRLEIN, S.; FISCHER, O. Structural behaviour of composite dowels in thin uhpc elements. Steel Construction, 9:132137, 2016.

[72] HARNATKIEWICZ, P.; KOPCZYNSKI, A.; KOZUCH, M.; LORENC, W.; ROWINSKI, S. Research on fatigue cracks in composite dowel shear connection. Engineering Failure Analysis, 18:1279-1294, 2011.

[73] LI, G. Q.; LI, X.; LI, L. Experimental study on the bend and shear behaviors of steel-concrete composite beams with notched web of inverted t-shaped steel section. International Journal of Steel Structures, 12:391-401, 2012.

[74] LORENC, W.; KOŻUCH, M.; ROWIŃSKI, S. The behaviour of puzzleshaped composite dowels - part i: Experimental study. Journal of Constructional Steel Research, 101:482-499, 2014.

[75] LORENC, W.; KOŻUCH, M.; ROWIŃSKI, S. The behaviour of puzzleshaped composite dowels - part ii: Theoretical investigations. Journal of Constructional Steel Research, 101:500-518, 2014.

[76] CLASSEN, M.; HERBRAND, M. Shear behaviour of composite dowels in transversely cracked concrete. Structural Concrete, 2:195206, 2015.

[77] CLASSEN, M.; GALLWOSZUS, J. Concrete fatigue in composite dowels. Structural Concrete, 17:63-73, 2016.

[78] CLASSEN, M.; HEGGER, J. Anchorage of composite dowels. Steel Construction, 9:138-150, 2016.

[79] JURKIEWIEZ, B.; HOTTIER, J. M. Static behaviour of a steelconcrete composite beam with an innovative horizontal connection. Journal of Constructional Steel Research, 61:1286-1300, 2005.

[80] DAUNER, H. G. Techniken zum bau der fahrbahnplatte bei verbundbrücken. Journal of Constructional Steel Research, 81:62-75, 2013. 
[81] THOMANN, M. Connexions par adhérence pour les ponts mixtes acier-béton. Tese de doutorado, École Polytechnique Fédérale de Lausanne, Lausanne, 2005.

[82] PAPASTERGIOU, D.; LEBET, J. P. Design and experimental verification of an innovative steel-concrete composite beam. Journal of Constructional Steel Research, 93:9-19, 2014.

[83] DIOGENES, H. J. F. Análise numérica e experimental de ligações por aderência aço-concreto aplicada em estruturas mistas. Tese de doutorado, Universidade de São Paulo, São Carlos, 2013.

[84] ANDRADE, S. A. L.; SANTOS, A. C. L. Sistemas de vigamentos de piso em treliça mista primeira parte. A Construção São Paulo, 2221:19-22, 1990.

[85] MEllO, A. V. A.; SILVA, J. G. S.; VEllasCO, P. C. G. S.; ANDRADE, S. A. L.; LIMA, L. R. O. Modal analysis of orthotropic composite floors slabs with profiled steel decks. Latin American Journal of Solids and Structures, 5:47-73, 2008.

[86] MEllo, A. V. A.; SilVA, J. G. S.; VELlasCO, P. C. G. S.; ANDRADE, S. A. L.; LIMA, L. R. O. An evaluation of the steel-concrete interaction over the composite floors dynamic response. In: 4TH INTERNATIONAL CONFERENCE ON STEEL AND COMPOSITE STRUCTURES (ICSCS'10), p. 251-256, Sydney, Australia, 2010.

[87] MEllO, A. V. A.; SILVA, J. G. S.; VELLASCO, P. C. G. S.; ANDRADE, S. A. L.; LIMA, L. R. O. Dynamic analysis of building composite floors submiteed to human walking. In: TENTH INTERNATIONAL CONFERENCE ON COMPUTATIONAL STRUCTURES TECHNOLOGY, p. 1-11, Edimburgo, Escócia, 2010.

[88] SPERANDIO, M. J. Comportamento e projeto de sistemas de vigamento de piso tipo stub-girder. Dissertação de mestrado, Pontifícia Universidade Católica do Rio de Janeiro, Rio de Janeiro, 1992.

[89] HEITOR, A. C. J. Estudo de um sistema de vigamento de piso tipo "stub-girder"modificado. Dissertação de mestrado, Pontifícia Universidade Católica do Rio de Janeiro, Rio de Janeiro, 2017.

[90] LOPES, E. D. C.; SILVA, J. G. S.; ANDRADE, S. A. L. Vibration analysis of steel-concrete composite floors when submitted to 
human rhythmic activities. In: 4TH INTERNATIONAL CONFERENCE ON COMPUTATIONAL METHODS IN STRUCTURAL DYNAMICS AND EARTHQUAKE ENGINEERING, p. 1-13, ILHA DE KÓS, GRECIA, 2013.

[91] SILVA, J. G. S.; ANDRADE, S. A. L.; LOPES, E. D. C. Parametric modelling of the dynamic behaviour os a steel-concrete composite floor. Engineering Structures, 75:327-339, 2014.

[92] Ferrante, C. A. O.; Andrade, S. A. L.; Silva, R. A. C. Comportamento estático de vigas mistas de aço-concreto utilizando perfil celular assimétrico. In: XXXVI IBERO-LATIN AMERICAN CONGRESS ON COMPUTATIONAL METHODS IN ENGINEERING, p. 1-20, RIO DE JANEIRO, Brasil, 2015.

[93] VIANNA, J. C.; NEVES, L. F. C.; VELLASCO, P. C. G. S.; ANDRADE, S. A. L. Experimental assessment of perfobond and t-perfobond shear connectors structural response. Journal of Constructional Steel Research, 65:408-421, 2009.

[94] VELLASCO, P. C. G. S.; ANDRADE, S. A. L.; FERREIRA, L. T. S.; LIMA, L. R. O. Semi-rigid composite frames with perfobond and t-rib connectors - part 1: Full scale tests. Journal of Constructional Steel Research, 63:263-279, 2006.

[95] ANDRADE, S. A. L.; VELLASCO, P. C. G. S.; FERREIRA, L. T. S.; LIMA, L. R. O. Semi-rigid composite frames with perfobond and trib connectors part 2: Design models assessment. Journal of Constructional Steel Research, 63:280-292, 2007.

[96] FERREIRA, L. T. S.; ANDRADE, S. A. L.; VELLASCO, P. C. G. S. Connections - a design model for bolted composite semi-rigid connections. Stability and Ductility of Steel Structures, 1:293-306, 1998.

[97] RAMIRES, F. B.; ANDRADE, S. A. L.; VELLASCO, P. C. G. S.; LIMA, L. R. O. Composite semi-rigid joints optimization with genetic algorithms. In: THE THIRTEENTH INT. CONFERENCE ON CIVIL, STRUCTURAL AND ENVIRONMENT ENGINEERING COMPUTING, p. 1-20, Chania, Creta, 2011.

[98] RAMIRES, F. B.; ANDRADE, S. A. L.; VEllaSCO, P. C. G. S. Experimental analysis of composite semi-rigid beam to colum joints. In: FIFTH EUROPEAN CONFERENCE ON STEEL AND COMPOSITE STRUCTURES, p. 471-476, 2008. 
[99] SILVA, R. A. C.; ANDRADE, S. A. L.; FERRANTE, C. A. O. Estudo teÓrico-experimental de uma ligaÇÃo semirrÍgida mista com conectores do tipo perfobond nas vigas. In: XXXVI IBERO-LATIN AMERICAN CONGRESS ON COMPUTATIONAL METHODS IN ENGINEERING, p. 1-20, RIO DE JANEIRO, Brasil, 2015.

[100] RODRIGUES, M. C.; ANDRADE, S. A. L.; LIMA, L. R. O.; VELLASCO, P. C. G. S. Estudo experimental das ligações mistas semirrígidas em regiões de momento negativo - componente conectores de cisalhamento. In: CONSTRUMETAL, p. 1-20, São Paulo, Brasil, 2016.

[101] KERDAL, D.; NETHERCOT, D. A. Failure modes for castellated beams. Journal of Constructional Steel Research, 4:295-315, 1984.

[102] ASSOCIATION CANADIAN STANDARDS. CAN/CAS-S16-10: Limit states design of steel structures. Ontario, 2010.

[103] ASSOCIAÇÃO BRASILEIRA DE NORMAS TÉCNICAS. NBR 8800: Projeto de estruturas de aço e de estruturas mistas de aço e concreto de edifícios. Rio de Janeiro, 2008.

[104] ASSOCIAÇÃO BRASILEIRA DE NORMAS TÉCNICAS. NBR 6118: Projeto de estruturas de concreto - Procedimento. Rio de Janeiro, 2014.

[105] AMERICAN INSTITUTE OF STEEL CONSTRUCTION. AISC DESIGN GUIDE 31: Castellated and Cellular Beam Design. 2016.

[106] DARWIN, D.; DONAHEY, R. C. Lrfb for composite beams with unreinforced web openings. Journal of Structural Engineering, 114:535552, 1988.

[107] FÉdÉRATION INTERNATIONALE DU BÉTON. Bulletin 55: Model Code 2010, First complete draft, volumen 1. Lausanne, Switzerland, 2010.

[108] BIRKELAND, P. W.; BIRKELAND, H. W. Connections in precast concrete construction. Journal of the American Concrete Institute, 63:345-367, 1966.

[109] KULLMARI, R. B.; HOSAIN, M. U. Shear capacity of stub-girders: full scale tests. Journal of Structural Engineering, 111:56-75, 1985. 
[110] TÉCNICAS, A. B. D. N.. NBR 5738: Moldagem e cura de corposde-prova cilíndricos ou prismáticos de concreto. Rio de Janeiro, 2003.

[111] TÉCNICAS, A. B. D. N.. NBR 5739: Concreto - ensaio de compressão de corpos-de-prova cilíndricos. Rio de Janeiro, 2007.

[112] TESTING, A. S. F.; MATERIALS. E8/E8M: Standard Test Methods for Tension Testing of Metallic Materials. West Conshohocken, 2013.

[113] ABAQUS. Abaqus theory manual. MANUAL 6.14, 1146p., SIMULIA, 2014.

[114] STANDARDIZATION, E. C. F.. Eurocode 2: Design of concrete structures - Part 1: General rules and rules for buildings. Brussels, 2004. 